\title{
CORRELATION OF FIRE LOAD SURVEY METHODOLOGIES TOWARDS DESIGN FIRES FOR OFFICE BUILDINGS
}

\author{
A thesis submitted to \\ the Faculty of Graduate and Postdoctoral Affairs \\ in Partial Fulfillment of the requirements for the degree \\ Master of Applied Science in Civil Engineering \\ by \\ JAMES EDUFUL \\ B.Sc. Architecture, Master of Architecture \\ Department of Civil and Environmental Engineering \\ Carleton University \\ Ottawa-Carleton Institute of Civil and Environmental Engineering
}

March 2012

C2012, James Eduful 
Library and Archives

Canada

Published Heritage

Branch

395 Wellington Street

Ottawa ON K1A ON4

Canada
Bibliothèque et

Archives Canada

Direction du

Patrimoine de l'édition

395 , rue Wellington

Ottawa ON K1A ON4

Canada
Your file Votre référence

ISBN: 978-0-494-91571-4

Our file Notre référence

ISBN: 978-0-494-91571-4
NOTICE:

The author has granted a nonexclusive license allowing Library and Archives Canada to reproduce, publish, archive, preserve, conserve, communicate to the public by telecommunication or on the Internet, loan, distrbute and sell theses worldwide, for commercial or noncommercial purposes, in microform, paper, electronic and/or any other formats.

The author retains copyright ownership and moral rights in this thesis. Neither the thesis nor substantial extracts from it may be printed or otherwise reproduced without the author's permission.
AVIS:

L'auteur a accordé une licence non exclusive permettant à la Bibliothèque et Archives Canada de reproduire, publier, archiver, sauvegarder, conserver, transmettre au public par télécommunication ou par l'Internet, prêter, distribuer et vendre des thèses partout dans le monde, à des fins commerciales ou autres, sur support microforme, papier, électronique et/ou autres formats.

L'auteur conserve la propriété du droit d'auteur et des droits moraux qui protege cette thèse. $\mathrm{Ni}$ la thèse ni des extraits substantiels de celle-ci ne doivent être imprimés ou autrement reproduits sans son autorisation.
In compliance with the Canadian Privacy Act some supporting forms may have been removed from this thesis.

While these forms may be included in the document page count, their removal does not represent any loss of content from the thesis.
Conformément à la loi canadienne sur la protection de la vie privée, quelques formulaires secondaires ont été enlevés de cette thèse.

Bien que ces formulaires aient inclus dans la pagination, il n'y aura aucun contenu manquant. 


\section{Dedication}

This thesis is dedicated to the Eduful family 


\begin{abstract}
Performance-based fire protection design provides several advantages over prescriptivebased designs. However, development of design fires has always been a difficult task as a result of several uncertainties in inputs used for fire tests and computer simulations. Those inputs include: fire load and its pertinent characteristics. The survey methodology used to obtain fire load has been recognized to have a significant impact on survey results; however, this impact has not been explicitly quantified. This thesis seeks to correlate various fire load survey methodologies and to enhance and develop guidance on the means to conduct fire load surveys to reduce the level of uncertainty in results. In addition, the study seeks to recommend design fire curves that are representative of typical office occupancies using Computational Fluid Dynamics (CFD) modelling. A total floor area of $935 \mathrm{~m}^{2}$ in five office buildings was surveyed. Percentage differences and comparison of fire load density among different methodologies have been presented. Discussions based on design fire curves presented in this study offers valuable insights in the development of design fires for office occupancies in a performance based fire design.
\end{abstract}




\section{Acknowledgement}

We are like clay jars in which this treasure is stored. The real power comes from God and not from us - 2 Corinthians 4:7(CEV)

I thank Dr. Ehab Zalok (Thesis Supervisor) for his time, patience, useful suggestions and guidance. His invaluable support has made this thesis a success. To all the professors of the department of civil engineering who have contributed to my life and this project in particular, I say thank you.

I appreciate all the offices that gave me permission and access to survey their premises for this project. This project wouldn't have been possible without their support. I also appreciate Miss Naki Ocran, M.A.Sc Civil Engineering candidate, who helped with the surveys.

I am very grateful to the Fire Protection Research Foundation of the National Fire Protection Association (NFPA) for funding this project and the opportunity to present findings of the fire load survey results at the 2011 NFPA Conference and Expo, Boston, USA.

I appreciate the prayer, financial and moral support of my family. Mr. Peter F.K. Eduful, your support as a father and concern for your children has brought me this far. Mrs. Akosua Eduful, your love and encouragement carried me through this thesis. I say, Ayekoo!!!

Last but not the least, to all my friends and classmates, most especially the fire group, (Lindsay and Glen) who contributed one way or the other to this project, I say thank you. 


\section{Table of Contents}

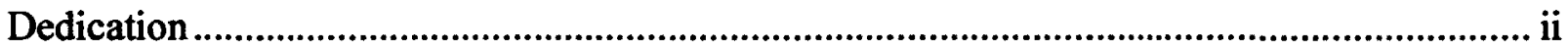

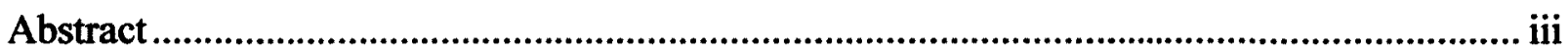

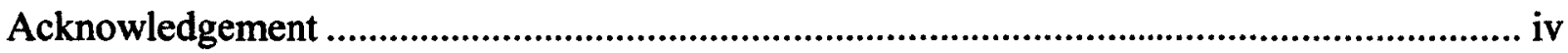

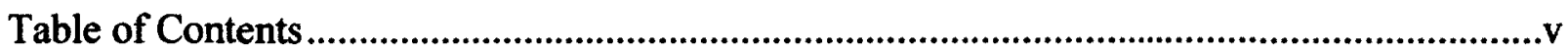

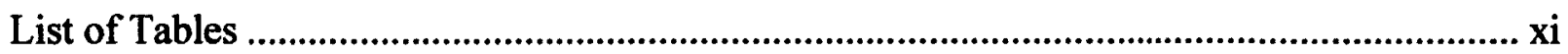

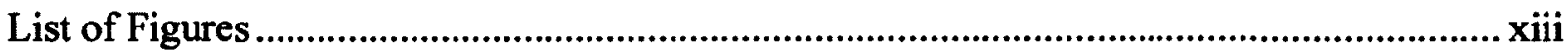

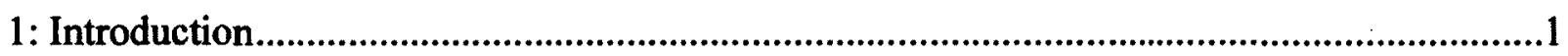

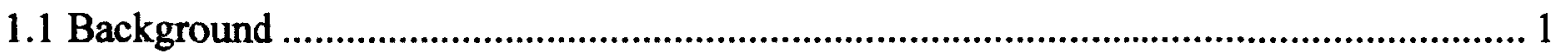

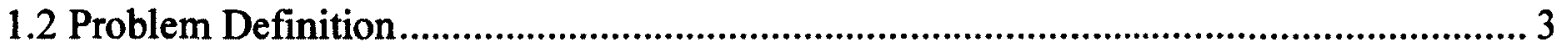

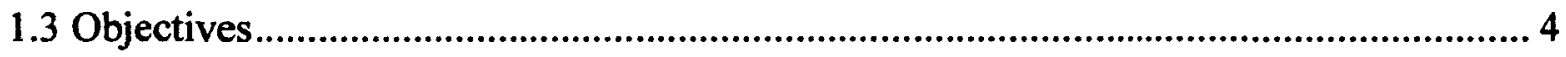

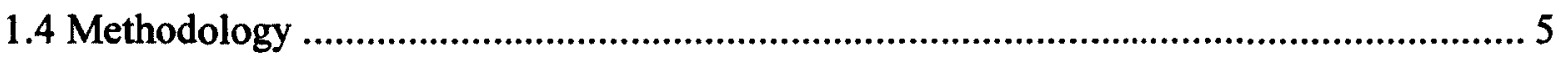

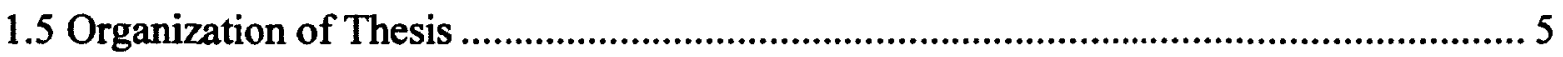

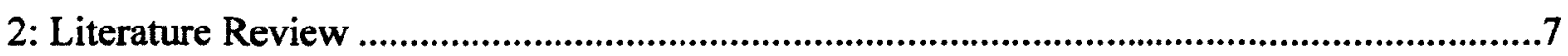

2.1 Prescriptive-based and Performance-based Codes.............................................................. 7

2.1.1 Prescriptive-based Codes....................................................................................... 7

2.1.2 Performance-based or Objective-based Codes ..................................................... 8

2.2 Fire Code Review of Group D-type Buildings................................................................ 9

2.3 Fire Protection Engineering Design ............................................................................. 13

2.3.1 Fire Protection Engineering Design Process (Performance-based)......................... 13

2.4 Fire Scenarios and Design Fire Scenarios........................................................................... 16

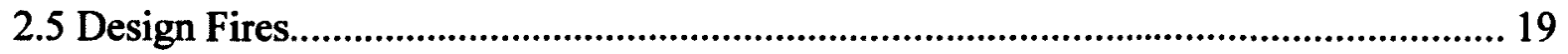

2.5.1 Selection of Design Fires.................................................................................. 20 


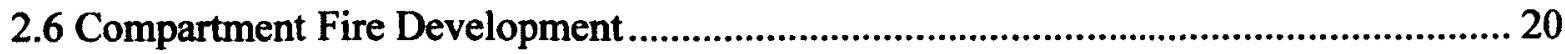

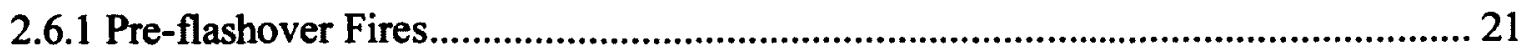

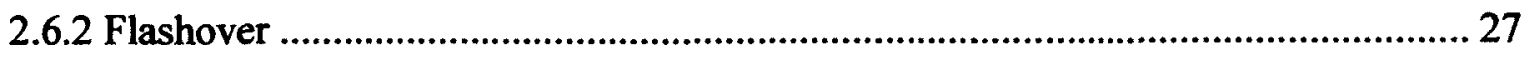

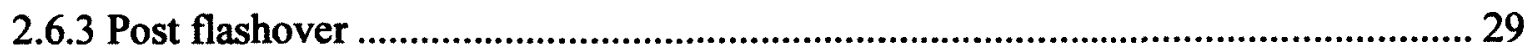

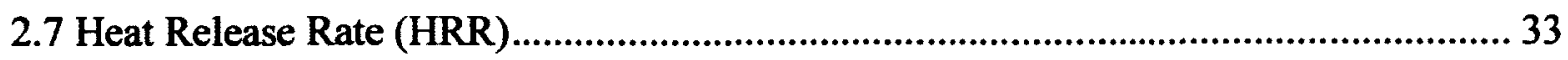

2.7.1 Development of Heat Release Rate ....................................................................... 35

2.7.1.1 Analysis and Synthesis of Experimental Data..................................................... 35

2.7.1.2 Computer Modelling and Fire Simulation....................................................... 36

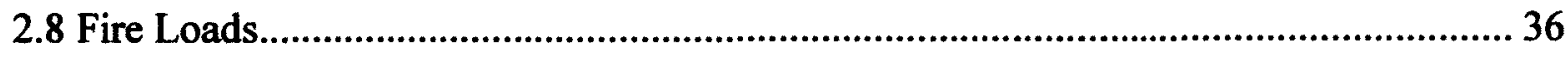

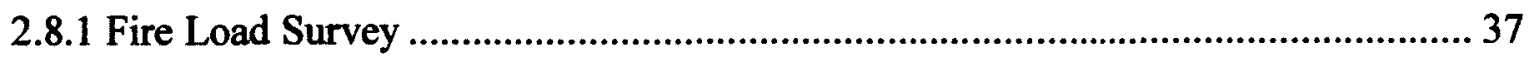

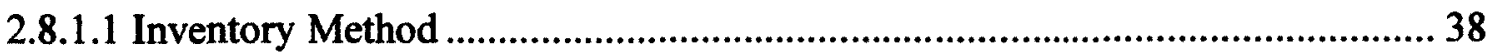

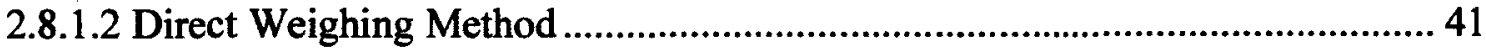

2.8.1.3 Combination of Direct Weighing and Inventory Method .................................. 44

2.8.1.4 The Questionnaire Method ................................................................................... 48

2.8.1.5 Real Estate Website Review............................................................................ 50

2.8.2 Evaluation of Fire Load Survey Methodologies....................................................... 51

2.8.3 Review of Fire Load Survey Results in Office Buildings ..................................... 53

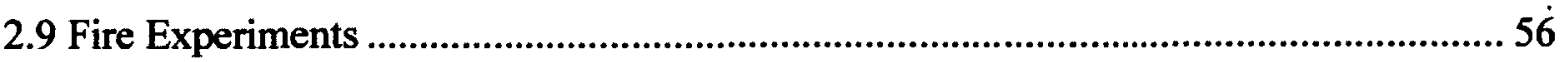

2.9.1 Fire Experiments in Office Buildings.................................................................. 56

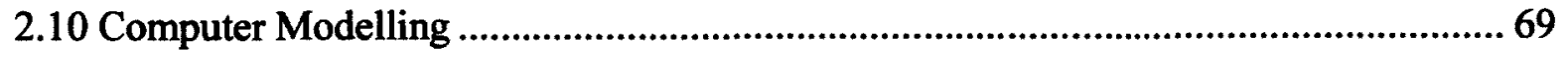

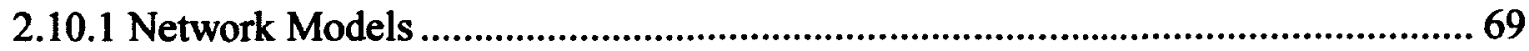

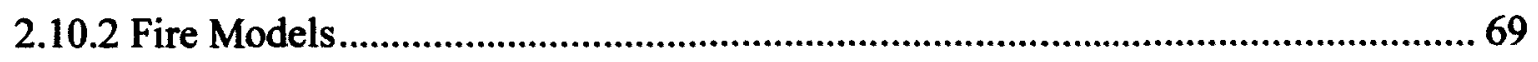

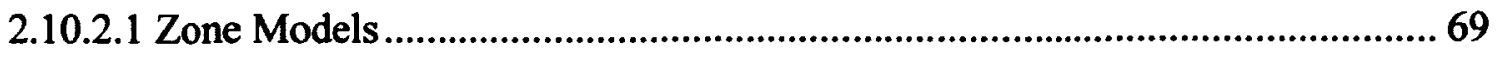

2.10.2.2 Field Model (Computational Fluid Dynamics) .............................................. 70

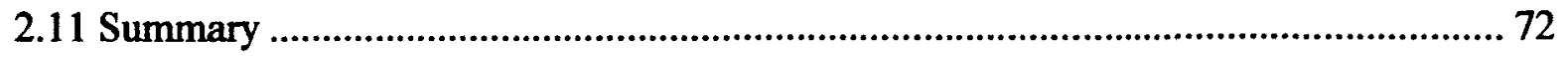

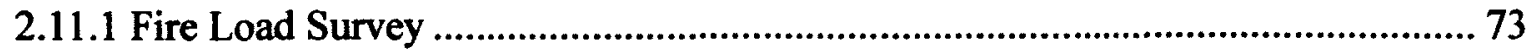

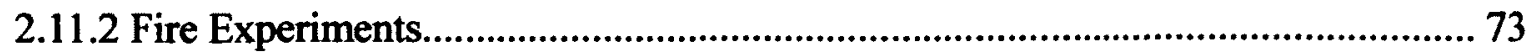




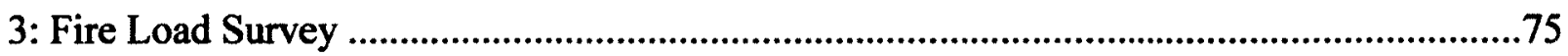

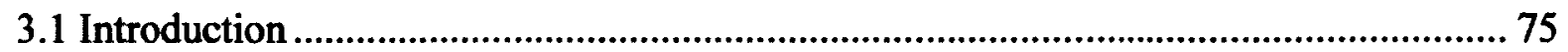

3.2 Surveyed Buildings .......................................................................................................... 75

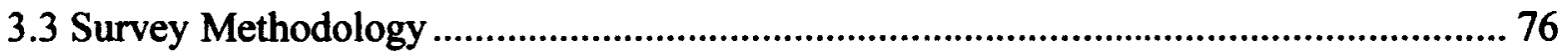

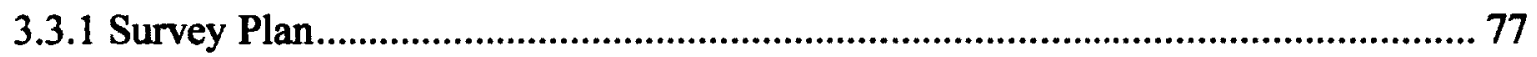

3.3.2 Data Collection and Fire Load Calculations......................................................... 78

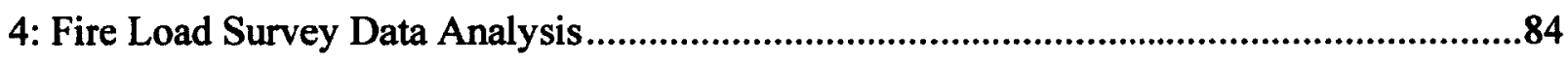

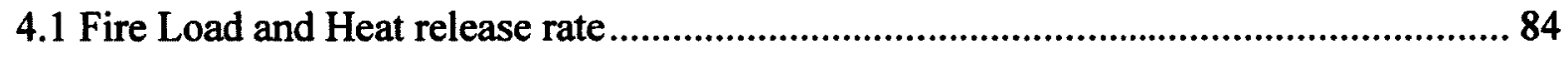

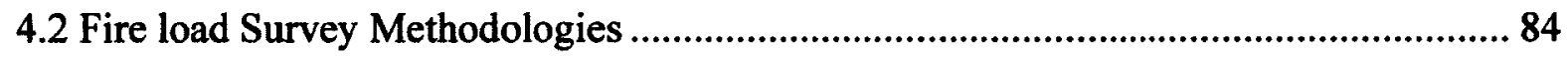

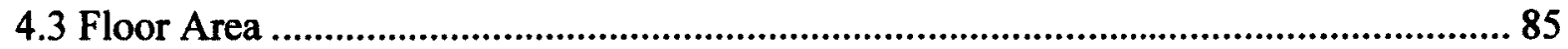

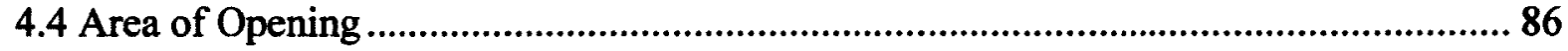

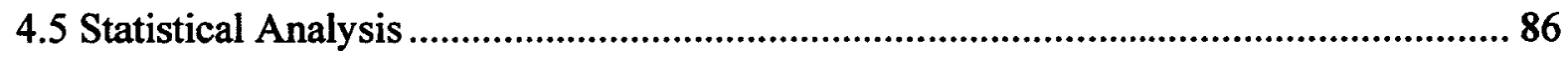

4.6 Fire Load Data among Various Methodologies ................................................................. 88

4.7 Contribution of Different Materials to the Total Combustible Content......................... 90

4.7.1 Percentage Contribution of Different Materials to the Fire Load Density ............. 90

4.7.2 Percentage Contribution of Fixed and Content Combustibles ................................ 91

4.8 Comparison of Fire Load Density Based on Inventory, Weighing and Combination

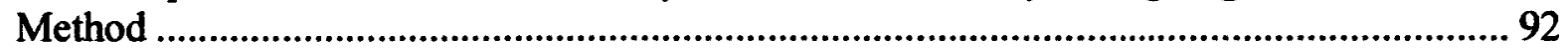

4.8.1 Mean, 95 ${ }^{\text {th }}$ Percentile, and Standard Deviation ..................................................... 92

4.8.2 Percentage Difference between Inventory and Weighing Method.......................... 94

4.8.3 Percentage Difference between Inventory and Combination Method..................... 95

4.8.4 Percentage Difference between Combination and Weighing Method .................... 97

4.9 Comparison of Fire Load Density Among Three Different Survey Methodologies..... 98

4.10 Questionnaire Method ..................................................................................................... 100 


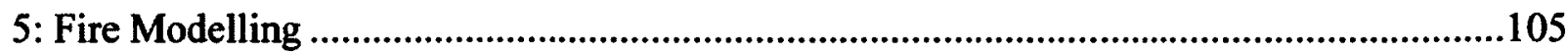

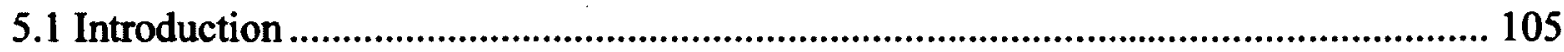

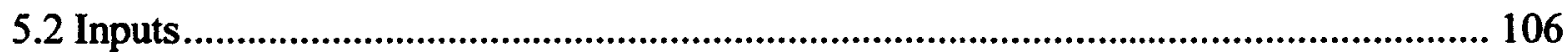

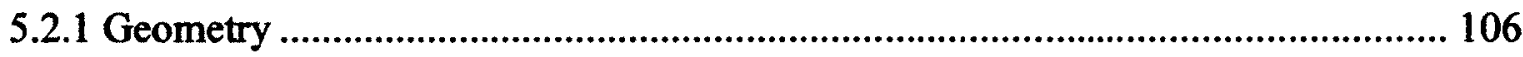

5.2.2 Description of the Typical Office Floor Layout .................................................... 108

5.2.3 Computational Grid Size ..................................................................................... 108

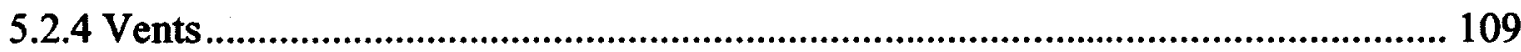

5.2.5 Boundary Conditions and Materials Properties........................................................ 111

5.2.6 Ignition sources and Fire Size ......................................................................... 113

5.3 Tenability Criteria ..................................................................................................... 113

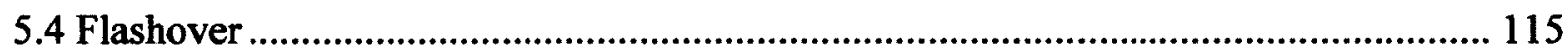

5.5 Fire Detection and Suppression System Activation...................................................... 116

5.5.1 Heat Detectors and Smoke Detectors ................................................................... 116

5.5.2 Sprinklers........................................................................................................... 117

5.6 FDS Model Uncertainity ............................................................................................ 117

6 Modelling Results and Discussion......................................................................................118

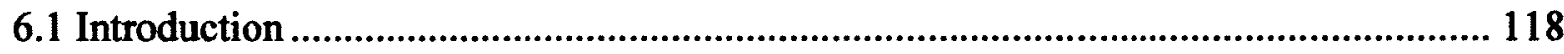

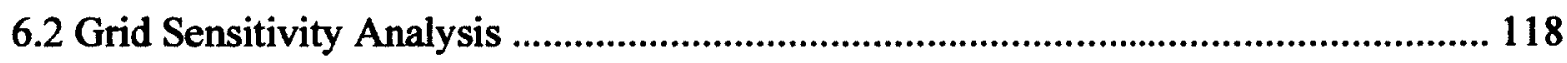

6.3 Simulation 1: Typical Enclosed Office .......................................................................... 120

6.4 Comparison of Model Results to Theoretical Equations ............................................. 122

6.5 Effects of Window Configuration on HRR and Gas Temperature .............................. 123

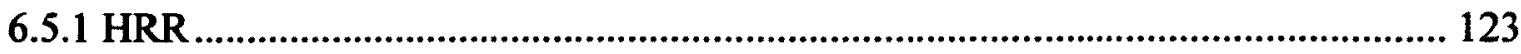

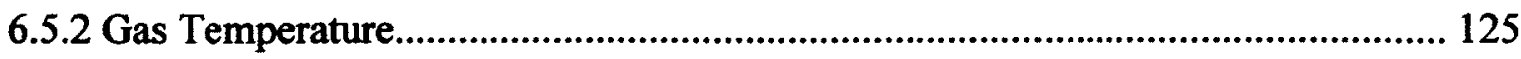

6.6 Simulation 2: Typical Office Floor (Non Sprinklered) ............................................... 127 


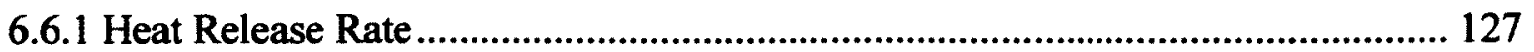

6.6.2 Fire Detection System Activation........................................................................... 130

6.6.3 Temperature Profiles of the Cubicle Office Fire Scenario ..................................... 131

6.6.3.1 Gas Temperature Measurements at Cubicle \& Circulation Location............. 132

6.6.3.2 Gas Temperature Measurements within Enclosed Offices............................. 133

6.6.4 Flashover .......................................................................................................... 135

6.6.5 Toxicity and Gas Concentration ............................................................................ 136

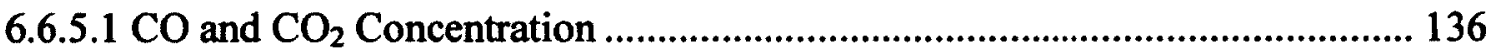

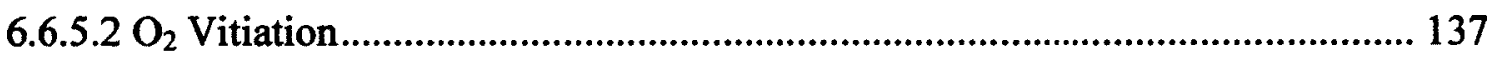

6.6.5.4 Hazard and Time to Untenable Conditions ................................................ 139

6.7 Simulation 3: Typical Office Floor (Sprinklered) ...................................................... 140

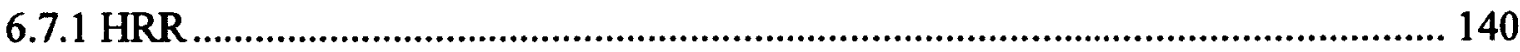

6.7.2 Gas Temperature................................................................................................. 141

6.7.3 Toxicity and gas concentration............................................................................ 142

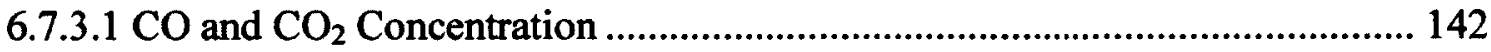

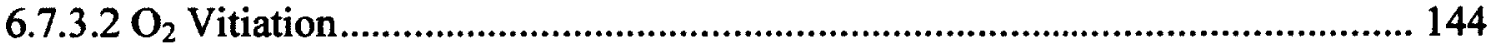

6.7.3.3 Optical Density (OD) .................................................................................... 145

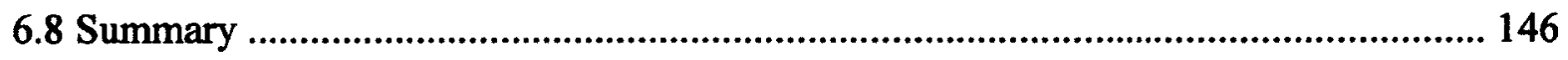

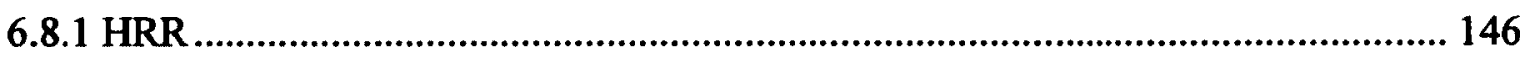

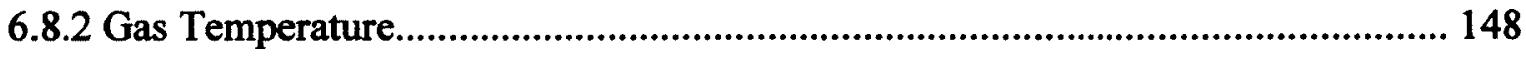

6.8.3 Tenability .............................................................................................................. 149

6.2.4 Fire Detection and Suppression System Activation ................................................ 151

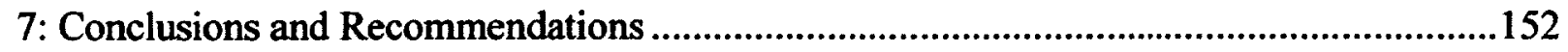

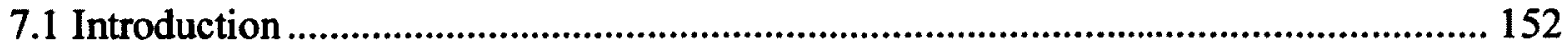

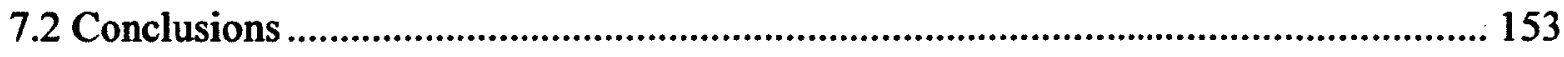

7.2.1 Fire Load Survey …............................................................................................. 153 
7.3 Contribution

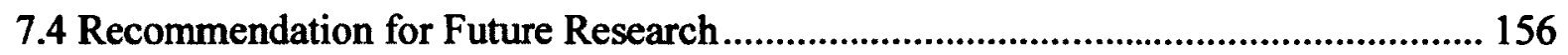

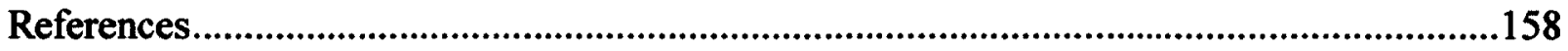

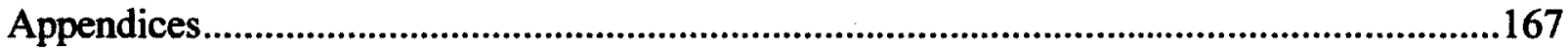

Appendix A: Review of Fire Load Survey Results in Residential Buildings .................... 167

Appendix B: Review of Fire Load Survey Results in Other Occupancies ....................... 168

Appendix C: Calorific value of Wood/ Cellulosic Material ............................................... 169

Appendix D: Calorific Value of Different Products and Composites............................... 170

Appendix E Calorific Values of Different Plastics ........................................................... 171

Appendix F: Fire Load Survey Forms............................................................................ 173

Appendix G: Sample FDS Input File (Single Enclosed Office) ....................................... 180

Appendix H: Tenability Criteria for FED …................................................................... 184 


\section{List of Tables}

Table 2-1 Advantages and Disadvantages of Prescriptive-based and Performance-based Codes [3] ........................................................................................................................... 9

Table 2-2 Acceptable Criteria [7] ...................................................................................... 10

Table 2-3 Permissible Building Area for up to 3 Storey Non-sprinklered Building [7]......... 11

Table 2-4 Comparison of Definitions [8]............................................................................. 17

Table 2-5 The Growth Constant with Typical Combustibles [2] ........................................... 23

Table 2-6 Effects of Oxygen concentration limits [15] .......................................................... 24

Table 2-7 Comparison of Different Methods for Predicting Heat Release Rate ...................... 28

Table 2-8 Summary Table ................................................................................................. 52

Table 2-9 Fire Load Survey Results from Different Researchers........................................... 55

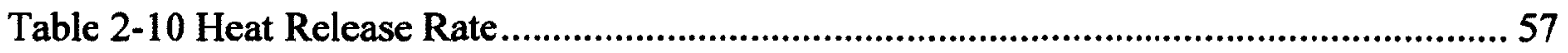

Table 2-11 Mass of Workstation Material by Type, [48] ....................................................... 64

Table 2-12 The Mass Loss Rate during the Rapid and Slow Burning Periods, [48]............. 64

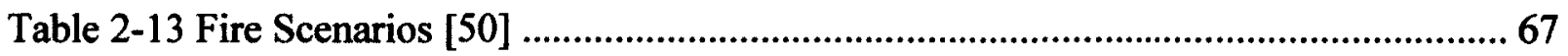

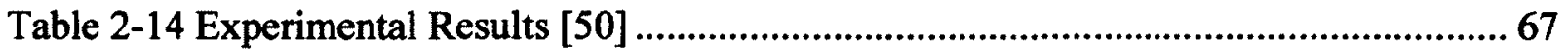

Table 3-1 Sample size of Rooms surveyed...............................................................................75

Table 3-2 Heat Release (MJ/kg) of Different Materials .......................................................... 79

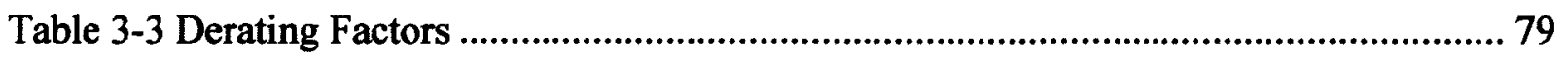

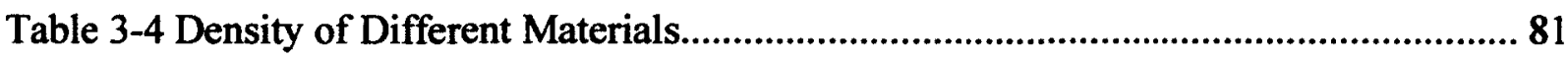

Table 4-1 Comparison of Fire Load Density ............................................................................89

Table 4-2 Contribution of Different Materials to the Total Fire Load ...................................... 90

Table 4-3 Mean, $95^{\text {th }}$ centile and Standard Deviation Fire Load Densities $\left(\mathrm{MJ} / \mathrm{m}^{2}\right)$............. 93

Table 4-4 Mean, 95 ${ }^{\text {th }}$ centile and Standard Deviation Fire Load (MJ) ................................... 94

Table 4-5 $95^{\text {th }}$ centile Fire Load Density of Inventory and Weighing Method ....................... 94 
Table 4-6 $95^{\text {th }}$ centile Fire Load Density of the Combination and Inventory Method ........... 96

Table 4-7 95 $5^{\text {th }}$ centile Fire Load Density of Combination and Weighing Method .................. 97

Table 4-8 Fire Load Density (Questionnaire Method versus Other Methods) ...................... 100

Table 4-9 Comparison of Fire Load Density Results Between the Questionnaire Method and the Combination of Weighing and Inventory Method........................................................... 101

Table 4-10 Comparison of Floor Area (Estimated by Occupant and Measured by Surveyor)

Table 5-1 Floor Areas and Fire Load...................................................................................108

Table 5-2 Boundary Condition ............................................................................................. 112

Table 5-3 Material Properties [39]................................................................................... 112

Table 5-4 Modified Material Properties [39] .................................................................... 112

Table 5-5 Tenability Criteria ................................................................................................ 114

Table 6-1 Grid Sizes Impact on Peak HRR, Time to Peak and Computational Time Requirement.................................................................................................................120

Table 6-2 Comparison of Model Results and Theoretical Calculations............................... 123

Table 6-3 Opening Characteristics..................................................................................... 123

Table 6-4 Height of Opening and Theoretical Peak HRR .................................................... 125

Table 6-5 Device Activation and Radial Distance................................................................. 130

Table 6-6 Hazard and Time to Reach Untenable Conditions ............................................... 139 


\section{List of Figures}

Figure 2-1 Performance-based FSE Design Process (modified from [2]) ............................ 15

Figure 2-2 Fire Growth Curve (modified from [11]) ............................................. 21

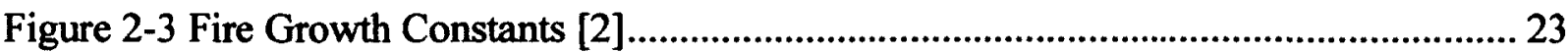

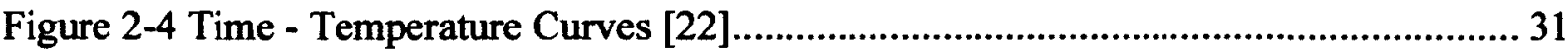

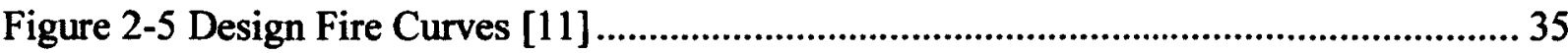

Figure 2-6 Schematic Plan and Elevation View of the Workstation [47] ........................... 58

Figure 2-7 Heat Release Rate and Heat Flux Measurements [47] ................................... 59

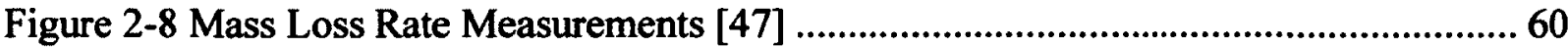

Figure 2-9 Schematic Layout of the Test Compartment, [47] ............................................ 61

Figure 2-10 Heat Release Rate Measurements [47] .................................................. 62

Figure 2-11 Gas Temperature Measurements within the Compartment (A), [47] .............. 62

Figure 2-12 Gas Temperature Measurements within the Compartment (B), [47].............. 63

Figure 2-13 The Heat Release Rate as a Function of Time, [48] ................................... 65

Figure 2-14 Bare Bead Thermocouple Measurements as a Function of Time at Different Locations. 65

Figure 2-15 The Volume Fraction of $\mathrm{O}_{2}, \mathrm{CO}, \mathrm{CO}_{2}$ on a Dry Basis as a Function of Time, [48] 66

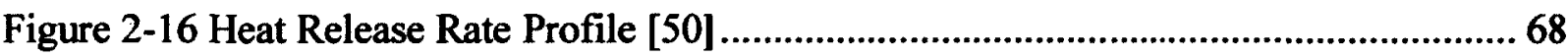

Figure 4-1 Floor Area of Enclosed and Cubicle Offices................................................85

Figure 4-2 Cumulative Fire Load Density and Three Best Fit Curves ............................... 88

Figure 4-3 Correlation of Fire Load Density among Different Methods............................. 89

Figure 4-4 Contribution of Fixed and Content Combustibles to the Total Fire Load ........... 91

Figure 4-5 Conversion of Fire Load Density among Three Different Survey Methodologies99 
Figure 6-1 Grid Size Impact on HRR ...................................................................... 119

Figure 6-2 Grid Sizes Impact on Gas Temperature …........................................................ 120

Figure 6-3 HRR of a Typical Enclosed Office …………................................................. 121

Figure 6-4 Gas Temperature Measurements of a Typical Enclosed Office........................... 122

Figure 6-5 Impact of Opening Sizes on HRR ..................................................................... 124

Figure 6-6 Upper Layer Gas Temperature among Three Different Opening Sizes............... 126

Figure 6-7 Lower Layer Gas Temperature among Three Different Opening Sizes .............. 126

Figure 6-8 Heat Release Rate of the Entire Office Floor (Two Scenarios) ............................ 128

Figure 6-9 Heat Release Rate of the Entire Office Floor (Cubicle Fire Scenario) ............... 129

Figure 6-10 Peak and Average Gas Temperature (Entire Floor)............................................ 132

Figure 6-11 Average Gas Temperature Profile (Cubicle Offices).......................................... 133

Figure 6-12 Average Gas Temperature Profile (Enclosed Offices)....................................... 134

Figure 6-13 CO Concentration......................................................................................... 136

Figure 6-14 $\mathrm{CO}_{2}$ Concentration ........................................................................................ 137

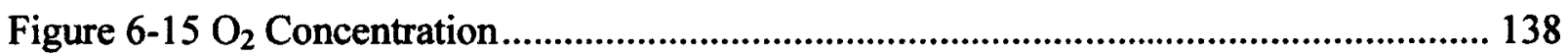

Figure 6-16 Tenability Limit of Optical Density .................................................................... 139

Figure 6-17 Heat Release Rate of Sprinklered Office Floor................................................... 140

Figure 6-18 Gas Temperature of Sprinklered Office Floor (Cubicle Offices) ...................... 141

Figure 6-19 Gas Temperature of Sprinklered Office Floor (Enclosed Offices) .................... 142

Figure 6-20 $\mathrm{CO}_{2}$ Concentration ................................................................................... 143

Figure 6-21 CO Concentration............................................................................................... 144

Figure 6-22 $\mathrm{O}_{2}$ Concentration ............................................................................................ 145

Figure 6-23 Tenability Limit of Optical Density .................................................................... 146

Figure 6-24 HRR of Sprinklered and Non-sprinklered Office Floor..................................... 147

Figure 6-25 Peak Gas Temperature of Sprinklered and Non-sprinklered Floor.................... 148 
Figure 6-26 CO Concentration of Sprinklered and Non-sprinklered Floor ........................... 149

Figure 6-27 $\mathrm{CO}_{2}$ Concentration of Sprinklered and Non-sprinklered Floor......................... 150

Figure 6-28 $\mathrm{O}_{2}$ Concentration of Sprinklered and Non-sprinklered Floor ........................... 150

Figure 6-29 Optical Density of Sprinklered and Non-sprinklered Floor................................ 151 


\section{1: Introduction}

\subsection{Background}

The use of performance-based fire protection designs for buildings is becoming more acceptable in many countries with the introduction of performance-based codes. Performance-based designs consider how the building and its fire protection systems perform in the event of a fire. Building performance is evaluated following a fire hazard analysis procedure, which requires the identification of possible fire scenarios that may occur in the building. Fires that are representative of those expected in buildings are used to evaluate building performance. These fires are known as design fires. These designs are done using engineering calculations based on fire experiments and computer models to demonstrate acceptable performance.

The increasing use of performance based designs has resulted in the need to identify and characterize design fires for various buildings. The burning characteristics of design fires depend on the type, amount, and arrangement of combustible materials (fire load), geometry and available ventilation in the room of fire origin, and the ignition source. The type and arrangement of combustibles affect the growth characteristics, while the total amount of fuel and ventilation characteristics in the compartment of fire origin govern the intensity and duration of the fire. The key parameters that define design fires include heat release rate (HRR), room temperature, and production rates of toxic gases. The complete specification of design fires requires knowledge of all stages of the fire; ignition, growth, steady burning (fully developed), and decay. There are specific fire protection concerns at each stage of the fire development. The growth characteristics of the design fire influence the time of detection 
and activation of fire suppresion systems, as well as the time when conditions in the compartment of fire origin become untenable. As a result of rising temperatures and production of harmful gases, the major concern of fire protection at the initial stage of the fire development is life safety. After flashover, during the fully developed stage, the major concern shifts from life safety to structural safety, and safety of fire fighters. The fire may begin to spread beyond the compartment of fire origin, if the fire continues without intervention. Fire spread may be aided by structural failure, integrity failure (cracks through walls and floors), insulation failure (increased temperature at the unexposed side of the fire compartment) and spread through openings (e.g. windows and doors). If the fire protection objective is for structural resistance, the expected duration of the fire needs to be considered. To determine this value, it is necessary to determine or estimate the fire load for design purposes.

The total combustible content, known as fire load (MJ), is a very important input parameter in design fires. Fire load is often determined by conducting surveys. NFPA Standard 557 recommends that fire load surveys are conducted by using the weighing method or the inventory method. The total fire load is the total heat energy (MJ) that can be released through complete combustion of all available combustibles. It is often expressed as energy density per unit floor area, $Q^{\prime \prime}\left(\mathrm{MJ} / \mathrm{m}^{2}\right)$. It must be noted that, in some surveys, the fire load is expressed in terms of fire load per unit area of the internal bounding surface of a compartment. The fire load is determined by surveying a representative sample of the buildings of interest and listing the compartments' dimensions, fixed and content (movable) combustibles and their pertinent characteristics. Several fire load surveys in the past have 
used different survey methodologies, including: the inventory, weighing, a combination of inventory and weighing, use of questionnaires and web based photographs of real estate sites. The design fire is often needed to evaluate building performance in a performance-based fire protection engineering design. The design fire is a quantitative description of assumed fire characteristics based on appropriate fire scenarios. A combination of hazard analysis and risk analysis may be used to develop design fire scenarios. Variables used in the description of a design fire include: HRR, fire size (including flame length), quantity of fire effluent, temperatures of hot gases, and time to key events such as flashover. However, design fires are most often expressed as the heat release rate. Characterization of the behavior of the HRR is often based on experimental data or computer modelling and fire simulations. Fire tests are most often very expensive to conduct, especially in full scale tests. As a result of the high cost of conducting fire tests, computer modelling and simulation provide better alternatives. Computational Fluid Dynamics (CFD) modelling is the most widely used in fire protection. The use of CFD models has allowed simulation in complex geometries, and the incorporation of a wide variety of physical phenomena. Most CFD models require the input of several parameters. These include geometry, computational grid size, vents (location and opening of vent to the outside), ignition sources (location and energy release rate), boundary conditions, and amount, size and thermal properties of materials.

\subsection{Problem Definition}

Fire load is a very important input parameter in the development of design fires, often determined by conducting surveys. The method of data collection has been recognized to have a significant impact on survey results; however, this impact has not been explicitly 
quantified. Several fire load surveys for office buildings have been conducted and reported in the past by different researchers using different survey methodologies. There is a wide variation in the survey results. Lack of an indepth understanding of the impact of the survey methodology on the fire load results makes it difficult to compare two survey results of the same building occupancy. As a resut, using a particular fire load data over another becomes highly questionable. Furthermore, as a result of the difficulties associated with the development of design fires, few attempts have been made to develop and recommend design fires that are representive of typical fire scenarios in office occupancies.

\subsection{Objectives}

This study seeks to correlate different fire load survey methodologies and to enhance and develop guidance on means to conduct fire load surveys to reduce the level of uncertainty in the results. In addition, the study seeks to recommend design fire curves that are representative of office occupancies and to provide valuable insights into the development of those design fires using CFD modelling. The objectives of this research can be crystalised under the following headings:

(i) Determination of fire loads representative of office occupancies,

(ii) Sensitivity analysis of fire load values obtained from different survey methods to,

- establish a structured approach to validate different fire load survey methodologies

- develop guidelines on how to correlate the fire load density values obtained from the various methodologies. 
(iii) Recommendations for design fire (growth profiles) characteristics for typical office occupancies.

\subsection{Methodology}

As mentioned above, the focus of the research has been divided into: development and correlation of fire loads using different survey methodologies, and development of design fires using CFD modelling.

Fire load density values were obtained by conducting surveys in office buildings within the Ottawa and Gatineau areas from November 2010 to March 2011. A total of 103 office rooms were surveyed for the study. The survey methodologies used include: weighing, inventory, combination of weighing and inventory, and questionnaire method.

The design fire curves in this research have been developed using the Fire Dynamic Simulator (FDS) 5 computer program, developed at the National Institute of Standards and Technology (NIST). The amount and arrangement of combustibles in FDS were obtained from the fire load surveys conducted for this study. Inputs for material characteristics in FDS were based on a series of small scale and full scale tests presented in the literature.

\subsection{Organization of Thesis}

The thesis is organized into seven chapters.

- Chapter 1 gives a general background and objective of the study.

- Chapter 2 presents a literature review on prescriptive and performance based codes. The chapter discusses fire load, fire scenarios and design fires. It further evaluates 
different fire load survey methodologies and finally presents a discussion on fire experiments and fire modelling.

- Chapter 3 describes the current fire load survey plan and the data collection process.

- Chapter 4 presents an analysis of the fire load data collected during the survey and compares the results of fire load and fire load densities of different survey methods.

- Chapter 5 presents a discussion on the CFD fire modelling and simulations using the fire dynamic simulation (FDS).

- Chapter 6 discusses the CFD modelling results.

- Chapter 7 presents conclusions and recommendations made from the study. 


\section{2: Literature Review}

This section presents discussions on literature gathered for this study. It begins with a discussion on prescriptive and performance based codes. It continues with a discussion on design fires and fire loads. Fire load survey methodologies have been compared and evaluated. Finally, discussions on fire experiments and fire simulations are presented.

\subsection{Prescriptive-based and Performance-based Codes}

Over the past 25-30 years, there has been increased interest towards the adoption of performance-based codes. This has led to a gradual shift from prescriptive-based codes into objective or performance-based codes in several countries. These countries include Great Britain, New Zealand, Australia, Japan, Finland, Netherlands, Norway, Poland, Spain, Sweden, United States, and Canada.

\subsubsection{Prescriptive-based Codes}

Prescriptive codes usually specify requirements for broad classifications of buildings in terms of fixed values. These requirements are often given without stating the intent of the requirement. For example, in fire safety engineering (FSE), prescriptive-based codes will specify requirements such as minimum spacing of fire suppression and detection system, minimum fire resistance rating (FRR), water supply requirement and etc. However, the degree of damage cannot be explicitly quantified. For example, the loss before sprinklers activate or the amount of harmful gases before complete evacuation is not defined in prescriptive-based codes. According to Meacham and Custer [1], prescriptive codes may 
provide the designer with sufficient guidance for buildings that are 'typical' in size, shape and use. However, this may not be the case for more complex buildings or where the fire safety objective is to protect a property where there can be high property or life loss. For example, a small fire can be very devastating in occupancies such as telecommunication and power generation facilities. In such occupancies, simple application of prescriptive codes may not produce sufficient protection. It must however be noted that, in most codes, an alternative method or equivalency clause appears. This provides an opportunity for an engineering-based design approach through a standardized methodology [2].

\subsubsection{Performance-based or Objective-based Codes}

Performance-based codes provide safety goals or objectives, often expressed qualitatively, which the design must meet. Examples of the objectives are: 'safeguard people from injury', 'give adequate time to reach a safe place'. Performance-based codes reference acceptable methods that can be used to demonstrate compliance with their requirements. The codes allow the use of any solution that can demonstrate compliance to the specified requirements. The historic development of performance based codes has been well documented in the literature [1,3]. Hadjisophocleous et al [3], presented a summary of advantages and disadvantages of prescriptive-based and performance-based regulations, as summarized in Table 2-1.

Performance-based codes offer several advantages over prescriptive codes. This includes flexibility, globalization aspect, cost effective fire protection, and measurable consistent levels of safety [3-5]. The major set-backs of the performance based codes are: the difficulty to prove compliance with the objectives and the definition of acceptable level of safety. 
Table 2-1 Advantages and Disadvantages of Prescriptive-based and Performance-based Codes [3]

\begin{tabular}{|c|c|c|}
\hline Code & Advantages & Disadvantages \\
\hline $\begin{array}{l}\text { Prescriptive } \\
\text { Codes }\end{array}$ & $\begin{array}{l}\text { Straight forward evaluation of } \\
\text { compliance with established } \\
\text { requirements } \\
\text { - No requirements for high level of } \\
\text { engineering expertise }\end{array}$ & $\begin{array}{l}\text { - Requirements specified } \\
\text { without statement of } \\
\text { objective } \\
\text { - Complexity of Structure of } \\
\text { codes } \\
\text { - No promotion of cost- } \\
\text { effective designs } \\
\text { - Very little flexibility for } \\
\text { innovation } \\
\text { - Presumption that there is only } \\
\text { one way of providing the } \\
\text { level of safety }\end{array}$ \\
\hline $\begin{array}{l}\text { Performance } \\
\text { Codes }\end{array}$ & $\begin{array}{l}\text { - Establishment of clear safety goals } \\
\text { and leaving the means of achieving } \\
\text { those goals to the designer } \\
\text { - Permit innovative design solutions that } \\
\text { meet the performance requirements } \\
\text { - Eliminate technical barriers to trade } \\
\text { for a smooth flow of products } \\
\text { - Facilitate use of new knowledge when } \\
\text { available } \\
\text { - Allow for cost-effectiveness and } \\
\text { flexibility in design } \\
\text { - Non Complex documents } \\
\text { - Permit the prompt introduction of new } \\
\text { technologies into the market }\end{array}$ & $\begin{array}{l}\text { - Difficult to define } \\
\text { quantitative levels of safety } \\
\text { (performance criteria) } \\
\text { - Need for education because } \\
\text { of lack of understanding } \\
\text { especially during first stages } \\
\text { of application } \\
\text { - Difficult to evaluate } \\
\text { compliance with established } \\
\text { requirements } \\
\text { - Need of computer models for } \\
\text { evaluating performance }\end{array}$ \\
\hline
\end{tabular}

\subsection{Fire Code Review of Group D-type Buildings}

This section provides a review of various provisions for Group D type buildings in the 2010 Canadian National Building Code. Information gathered in the review aided in material selection and specification during the fire modelling phase of this project. 
The major objectives of fire protection engineering are to protect life and property. To achieve those objectives, Division A of the 2010 Canadian National Building Code [6] provides functional requirements to which a building or facility or its element must satisfy to meet the acceptable criteria. Those functions include: minimizing accidental ignition; limit fire severity and fire spread beyond the compartment of fire origin; retard failure or collapse; facilitate safe evacuation; and minimize injury to persons (as a result of falling, contact with hot surfaces or gases, or inhalation of harmful gases). Division B of the code provides acceptable solutions. The code further states that if a design meets the acceptable solution in the Division B, it is implied that the objectives and functional statements of Division A has been met.

Similar to the National Building Code, the 2006 Ontario Building Code [7] permits both noncombustible and combustible construction for Group D buildings (including office). Table 2-2 gives the acceptable criteria for combustible and noncombustible construction.

Table 2-2 Acceptable Criteria [7]

\begin{tabular}{|c|c|}
\hline Noncombustible Construction & Combustible Construction \\
\hline $\begin{array}{l}\text { - Sprinklered if high-rise with a major office } \\
\text { occupancy } \\
\text { The floor assemblies must have a fire resistant } \\
\text { rating (FRR) of not less than } 2 \text { hours. } \\
\text { - However, if the building is not more than 6- } \\
\text { storey in building height, the minimum } \\
\text { permissible FRR for floor assemblies and } \\
\text { structure is } 45 \text { minutes. } \\
\text { - If the building is not sprinklered, then the roof } \\
\text { must be fire rated except for single storey } \\
\text { building height. }\end{array}$ & $\begin{array}{l}\text { - It must: not be more than } 4 \\
\text { storey in building height } \\
\text { - Sprinklered } \\
\text { - The building area must be } \\
\text { less than } 3600 \mathrm{~m}^{2} \\
\text { - } \text { and the floor assembly must } \\
\text { have a fire resistant rating of } \\
\text { not more than } 1 \text { hour }\end{array}$ \\
\hline
\end{tabular}

It must be noted that, if the building is of combustible construction but not sprinklered, it must; not be more than 3-storeys in building height, the floor assembly and the structure is 
permitted to have a fire resistant rating of 45 minutes, and the building area must not be more than the provisions set out in Table 2-3 below

Table 2-3 Permissible Building Area for up to 3 Storey Non-sprinklered Building [7]

\begin{tabular}{cccc}
\hline \multirow{2}{*}{ No. of Storeys } & \multicolumn{3}{c}{ Maximum Area, $\mathrm{m}^{2}$} \\
\cline { 2 - 4 } & Facing 1 Street & Facing 2 Street & Facing 3 Street \\
\hline 1 & 4800 & 6000 & 7200 \\
\hline 2 & 2400 & 3000 & 3600 \\
\hline 3 & 1600 & 2000 & 2400 \\
\hline
\end{tabular}

Requirements differ if the building is up to 2 storeys. However, the minimum requirement fire resistant rating for floor assemblies and the structure is $45 \mathrm{~min}$. There are also different requirement if the building is made of heavy timber construction.

Building content provisions in the code has been reviewed to understand the type of materials and finishes that is permitted in Group $\mathrm{D}$ buildings. The information presented in this section aided in material specification during the fire modeling stage of this research. The National Building Code [6] defines interior finish material to include any material that forms part of the interior surface of a floor, wall, partition or ceiling (including, interior cladding); doors, windows and trim; lighting elements and lenses forming part of the finished surface of the ceiling; and carpet material. Combustible finished flooring is permitted in a building required to be of noncombustible construction. Combustible interior ceiling finishes, other than foamed plastics, are permitted in a building required to be of noncombustible construction provided they: are not more than $25 \mathrm{~mm}$ thick, except for exposed fire-retardant treated wood battens, and have a flame-spread rating not more than 25 on any exposed surface, or on any surface that would be exposed by cutting through the material in any direction, or are of fireretardant treated wood. In addition, $10 \%$ of the ceiling area within each fire compartment may have a flame-spread rating up to 150 . The code permit combustible interior wall 
finishes, other than foamed plastics, in a building required to be of noncombustible construction. However, the material must not be more than $25 \mathrm{~mm}$ thick, and must have a flame-spread rating not more than 150 on any exposed surface, or any surface that would be exposed by cutting through the material in any direction. According to the National Building Code [6], gypsum board with a tightly adhering paper covering not more than $1 \mathrm{~mm}$ thick is permitted in a building required to be of noncombustible construction provided the flamespread rating of the surface is not more than 25 . The building code provides limits for flame spread of all interior finishes. The flame-spread rating of interior wall and ceiling finishes, including glazing and skylights, shall not be more than 150 .

In addition to the building content and finishes review, fire alarm systems provisions in the code have been reviewed. This was done to understand the requirements for fire detection systems in office buildings. This information was vital during the modeling phase of this thesis. According to the Building Code [6], Fire Alarm and Detection Systems, a fire alarm system shall be installed in a building with: a contained use area, an impeded egress zone, more than 3 storeys, including storeys below the first storey, a total occupant load more than 300 , an occupant load more than 150 above or below the first store, and an interconnected floor space. The requirement for heat and smoke detectors in office buildings is based on the requirement for fire alarm systems described above. According to section 3.2.4.11, if a fire alarm system is required, smoke detectors shall be installed in: each room in a contained use area and corridors serving those rooms, and each exit stair shaft. It further recommends at least one smoke alarm must be provided on each floor or mezzanine.

It must be noted that, interior walls/partitions are considered in the code as walls that provide full compartmentation. For example, partitions often used in open/cubicle offices are not 
classified as interior walls or partitions. As a result of this classification, those partitions have no limitations to their use in terms of material composition and flame spread. Partitions may be a significant source of fire load and may contribute immensely to fire spread within an open office set-up.

\subsection{Fire Protection Engineering Design}

Fire protection engineering involves the application of science and engineering principles to protect people and their environment from destructive fire, which includes: fire hazard analysis; mitigation of fire damage by proper design, construction, arrangement, and use of buildings; materials, structures, industrial processes, and transportation systems; the design, installation and maintenance of fire detection and suppression and communication systems; and post fire investigation and analysis.

\subsubsection{Fire Protection Engineering Design Process (Performance-based)}

For the purpose of this study, performance-based fire protection engineering (FSE) design has been defined as 'an engineering approach based on (i) established fire safety goals and objectives; (ii) deterministic and probabilistic analysis of fire scenarios; and (iii) quantitative assessment of design alternatives against the fire safety goals and objectives using accepted engineering tools, methodologies, and performance criteria' [2]. Performance-based FSE provides a rational approach to fire safety assessment. According to the SFPE [2], Performance-based engineering assessment may provide a more effective fire protection that addresses a specific need and also, improved knowledge of loss potential. Tools often employed in Performance-based FSE design includes: deterministic analysis techniques, 
probabilistic analysis techniques, application of the theory of fire dynamics, application of deterministic, probabilistic fire effects modelling, application of human behavior, and toxic effects modelling. Figure 2-1 shows the processes involved in performance-based FSE design. The process starts with developing a fire protection engineering brief. This involves defining the project scope and goals. The design objectives of the stakeholder are defined and performance criteria developed. Several design fire scenarios are developed and a trial design selected. According to the SFPE [2], guidance on performance-based fire protection engineering, the selection of design fire scenario or design fire represent an important process in performance-based FSE design. The selection of appropriate design fire scenario depends on knowledge of the available combustible contents and their arrangement, material characteristics, and possible ignition sources. The design process concludes with evaluation of the trial design against the performance criteria. If the trial design meets the performance criteria, the final design is selected and design documentation is then prepared. On the other hand if it does not meet the performance criteria, the design or objectives are modified. Trial designs are developed and evaluated until the performance criteria are met (see Figure 2-1). 


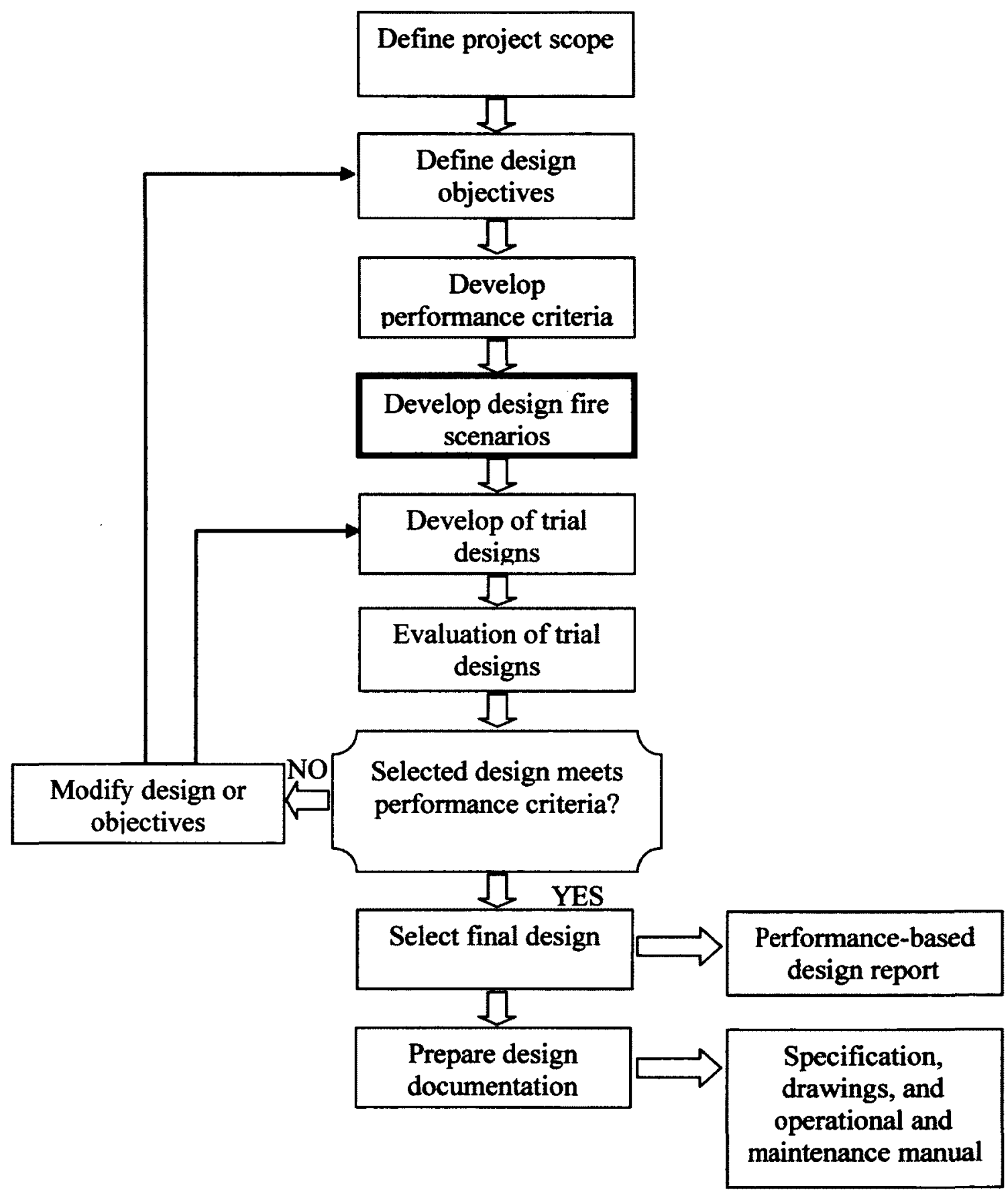

Figure 2-1 Performance-based FSE Design Process (modified from [2]) 
In addition to the performance-based FSE design process, ISO/TS 16733 [8] presented a summary of the fire safety engineering assessment process in four broad headings. The process begins with a qualitative review; which involves: fire safety objectives and acceptance criteria, review of prescribed design, characterization of the building and its occupants, identification of potential fire hazards, selection of fire scenarios, establishment of trial fire safety solutions, and indication of appropriate methods of analysis. The next step after the review is the quantitative analysis which involves the selected design fire and analysis through the use of mathematical models. The third step is the assessment of the outcome of the analysis against safety criteria (The process is repeated if the acceptance criteria are not satisfied). The final stage is reporting and presentation of acceptable results. Similar to the SFPE performance-based FSE design process, an essential component of the assessment process is the selection of the design fire against which the performance of the building component is assessed.

\subsection{Fire Scenarios and Design Fire Scenarios}

The selection of the design fire scenarios or design fires is an essential component in performance based FSE design. Design fire scenarios are often selected after the consideration of several fire scenarios.

A fire scenario is a set of conditions that defines the development of fire and the spread of combustion products throughout a building or part of a building [2]. On the other hand, the design fire scenario is set of conditions that describe the critical factors determining the outcomes of trial designs [2]. Bwalya [9] presented a comparison of definitions from ISO and SFPE, see Table 2-4. 
Table 2-4 Comparison of Definitions [8]

\begin{tabular}{|c|c|c|}
\hline \multirow{2}{*}{ Term } & \multicolumn{2}{|c|}{ Definition by source reference } \\
\hline & ISO/TS-16733 & SFPE engineering guide \\
\hline $\begin{array}{l}\text { Fire } \\
\text { scenario }\end{array}$ & $\begin{array}{l}\text { A qualitative description of the course } \\
\text { of a specific fire with time, identifying } \\
\text { key events that characterize the fire } \\
\text { and differentiate it from other possible } \\
\text { fires }\end{array}$ & $\begin{array}{l}\text { A set of conditions that defines } \\
\text { the development of fire and the } \\
\text { spread of combustion products } \\
\text { throughout a building or part of a } \\
\text { building }\end{array}$ \\
\hline $\begin{array}{l}\text { Design fire } \\
\text { scenario }\end{array}$ & $\begin{array}{l}\text { A specific fire scenario on which an } \\
\text { analysis will be conducted. It includes } \\
\text { a description of the impact on the fire } \\
\text { of building features, occupants, fire } \\
\text { safety systems and would typically } \\
\text { define the ignition source and process, } \\
\text { the growth of the fire on the first item } \\
\text { ignited, the spread of the fire, the } \\
\text { interaction of the fire with the } \\
\text { building occupants and the interaction } \\
\text { with the features and fire safety } \\
\text { systems within the building }\end{array}$ & $\begin{array}{l}\text { A set of conditions that defines or } \\
\text { describes the critical factors } \\
\text { determining the outcomes of trial } \\
\text { designs }\end{array}$ \\
\hline $\begin{array}{l}\text { Design fire } \\
\text { Design fire } \\
\text { curve }\end{array}$ & $\begin{array}{l}\text { Design fire: A quantitative temporal } \\
\text { description of assumed fire } \\
\text { characteristics based on appropriate } \\
\text { fire scenarios. Variables used in the } \\
\text { description include: HRR, fire size } \\
\text { (including flame length), quantity of } \\
\text { fire effluent, temperatures of hot } \\
\text { gases, and time to key events such as } \\
\text { flashover }\end{array}$ & $\begin{array}{l}\text { Design fire curve: An engineering } \\
\text { description of a fire in terms of } \\
\text { HRR versus time (or in other } \\
\text { terms elaborated in the stated } \\
\text { reference) for use in a design fire } \\
\text { scenario }\end{array}$ \\
\hline
\end{tabular}

Design fire scenarios represent an important input into any fire safety design [2]. A combination of hazard analysis and risk analysis may be used to develop design a fire scenario. The hazard analysis identifies potential ignition sources, fuels, and fire development. The risk analysis might include the indicated hazard analysis while also noting the likelihood of the occurrence, either quantitatively or qualitatively, and the severity of the outcomes. The SFPE engineering guide to performance-based fire protection concludes that 
the design fire scenario should present a conservative approach for analysis and determination of required fire safety measures. Design fire scenarios are often characterized by quantifying building characteristics, occupant characteristics and design fire curve. According to ISO/TS-16733 [8], a risk ranking process is recommended as the most appropriate basis for selection of design fire scenarios. This process takes into account the consequence and likelihood of the scenario. The key aspects of the risk ranking process include:

- identification of a comprehensive set of possible fire scenarios;

- estimation of the probability of occurrence of the scenario using available data and engineering judgment;

- estimation of the consequence of each scenario using engineering judgment;

- estimation of the relative risk of the scenarios (product of consequence and probability of occurrence); and

- ranking of the fire scenarios according to the relative risk.

The SFPE Engineering Guide to Performance-Based Fire Protection Analysis and Design of Buildings [2] provides detailed steps for identifying possible fire scenarios and developing them into design fire scenarios. These steps are as follows:

- Consider possible fire scenarios; this step considers the form of ignition source, type of fuel first ignited, location of fire, effects of compartment geometry, effects of openings (ventilation), fixed combustibles and available form of intervention (e.g., occupants, sprinklers, fire department).

- Defining the design fire: at this stage, a large number of possible fire scenarios are reduced to a manageable number of design fire scenarios for trial design purposes. 
According to the SFPE, probabilistic approaches (based on statistics and historical information) and deterministic approaches (based on analysis or calculations using correlations developed from tests) can be used.

- Quantifying the design fire scenario. At this stage, the significant aspect of the design fire scenario is quantified. If the design fire scenario is too conservative, it can lead to an uneconomical building. In order to quantify the design fire scenario, there is the need to establish a design fire curve. The stages of the fire development - ignition, growth, flashover, decay and burnout, describes the design fire (curve) for a particular design fire scenario selected. The establishment of an appropriate design fire curve should be based on building characteristics information such as: architectural features - area and geometry of compartment, construction materials and finishes, openings; structural components - properties of structural elements; fire loads; egress components and fire protection systems - fire detection and suppression systems. Other factors such as occupant characteristics (e.g., human behavior, response characteristics and evacuation time) should be considered.

\subsection{Design Fires}

Design fire(s) are usually determined based on fire scenarios. Design fire events are those fires that are expected to occur over the life of a building for which the building is expected to meet its design safety objectives [10]. This may be determined using historic data or by conducting a fire hazard analysis to determine the fires that are reasonably expected as the maximum possible threats that should be mitigated. The SFPE [2] defines design fire as design fire curve, an engineering description of a fire in terms of HRR versus time. 


\subsubsection{Selection of Design Fires}

According to Bukowski [10] "the selection of the design fire(s) directly impacts all aspects of fire safety performance, including the structural fire resistance, compartmentation against fire spread, egress systems, manual or automatic detection systems, suppression systems, and smoke control". Bwalya [9] reported that, the selection of design fire for use is a possible source of uncertainty in conducting any fire safety engineering assessment. According to the same report, the uncertainty is as a result of the difficulty in accurately calculating the combustion process (heat release rate, production of smoke and other gaseous species) based on the type, quantity, and arrangement of combustibles (fire load), as well as the point of ignition and subsequent fire spread to adjacent combustibles.

Another important parameter in determining the design fire is the fire load density, often expressed in $\mathrm{MJ} / \mathrm{m}^{2}$. Fire load density is an indication of the total heat energy that will be released through complete combustion of all combustibles within a compartment. Design fires are often expressed as the heat release with respect to time (HRR). The fire load density alone is insufficient to determine the exact behavior of the design fire curve during the initial stage of the fire development. There is currently no correlation between the fire load density of a particular compartment and the design fire curve [9]. Characterization of the behavior of the HRR is often based on experimental data or modelling and fire simulations [11].

\subsection{Compartment Fire Development}

Heat release rate within a compartment is often defined by the growth stages of the fire. These stages are ignition, growth, flashover, fully developed, and decay. It must be noted that 
not all fires follow all the stages of fire development. The characteristic of a particular fire depends on the availability of the fuel and suppression systems available. The stages of fire development are often simplified into two regimes: pre-flashover and post -flashover, Figure $2-2$.

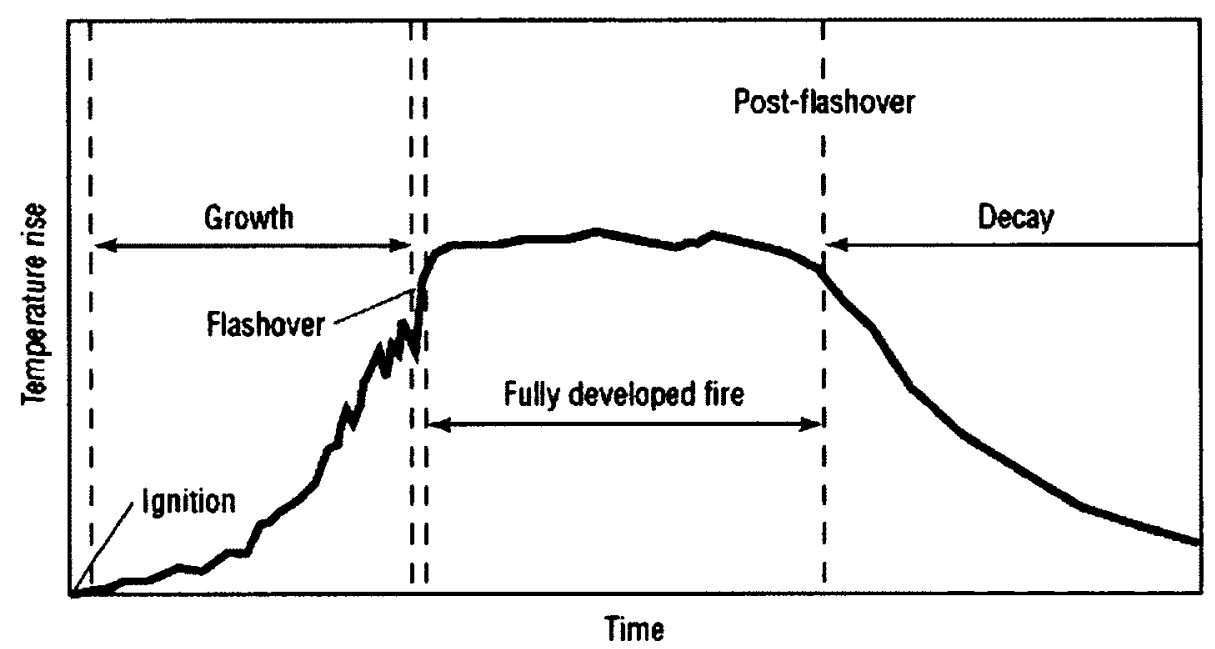

Figure 2-2 Fire Growth Curve (modified from [11])

\subsubsection{Pre-flashover Fires}

The pre-flashover regime includes all the stages of a fire from ignition (incipient stage), through the growth stage until flashover.

\section{Ignition and Incipient Stage}

This is when the fire begins. In order for ignition to occur there must be the presence of three items-fuel, oxygen, and an ignition source. Ignition will not occur unless there is sufficient contact time with the source for the fuel to be raised to its ignition temperature given the energy of the ignition source [2]. The duration of this stage usually depends on the source of ignition, availability of oxygen to sustain ignition, and the properties of the fuel package (thermal, surface area and orientation) [9]. 


\section{Growth}

After ignition, the fire continues through the growth period. This period may initially have little or no influence from the compartment of origin [12]. Combustion at this stage is often described as fuel controlled. The SFPE guide to performance based design [13] suggests that designs should consider the possibility of design fire scenarios with a relatively long smoldering. It further states that little data is available for smoldering fires; therefore, the engineer should choose carefully when developing any specific relationship for the design fire curve heat release rate. The growth stage is often approximated by

$\dot{Q}=\alpha\left(t-t_{i g n}\right)^{2}$

Equation 2.1

Where, $\dot{Q}$ HRR $(\mathrm{kW}) ; t=$ Time after effective ignition (s); $t_{i g n}=$ time to effective ignition; $\propto$ $=$ fire growth coefficient $\left(\mathrm{kW} / \mathrm{s}^{2}\right)$. The growth coefficient is often determined from experiments. However, the NFPA [2] expresses the fire growth coefficient $\propto$, as

$\propto=\frac{\dot{Q}_{o}}{t_{o}^{2}}$

Equation 2.2

Where, $\dot{Q}_{o}=$ reference $\mathrm{HRR}$, usually taken to be $1055 \mathrm{~kW}$, and the growth time, $t_{o}(\mathrm{~s}),=$ time to reach $\dot{Q}_{o}$. The NFPA classifies the fire growth as: ultra-fast, fast, medium, and slow. Figure 2-3 and Table 2-5 shows characteristics of these categories. The $t^{2}$ fire equation presented above is typically for a single burning object and hence, may not be a true representation of a compartment fire where several items with different peaks of HRR are involved. 


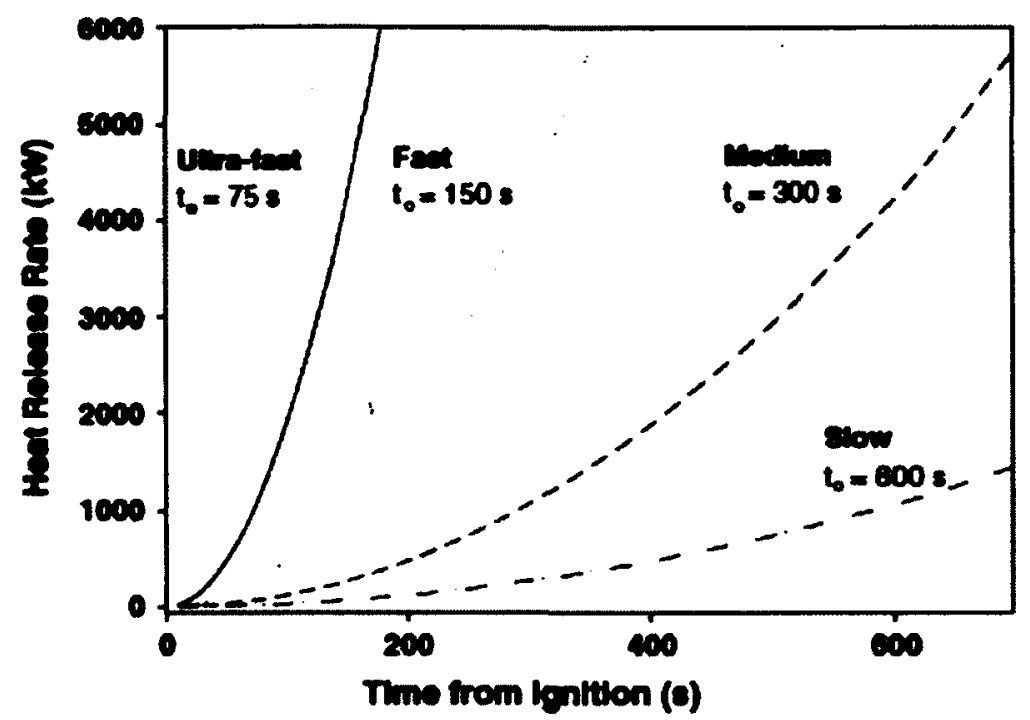

Figure 2-3 Fire Growth Constants [2]

Table 2-5 The Growth Constant with Typical Combustibles [2]

\begin{tabular}{llll}
\hline $\begin{array}{l}\text { Growth } \\
\text { Category }\end{array}$ & Typical Examples & $\begin{array}{l}\text { Fire Growth } \\
\text { Coefficient, } \\
\propto\left(\mathrm{kW} / \mathrm{s}^{2}\right)\end{array}$ & $\begin{array}{l}\text { Growth } \\
\text { time, } \mathrm{t}_{0}(\mathrm{~s})\end{array}$ \\
\hline Slow & Floor Coverings & 0.00293 & 600 \\
\hline Medium & Shop Counters, Office furniture & 0.0117 & 300 \\
\hline Fast & $\begin{array}{l}\text { Bedding, displays and padded work- } \\
\text { station partitions }\end{array}$ & 0.0466 & 150 \\
\hline Ultra-Fast & $\begin{array}{l}\text { Upholstered furniture and stacked } \\
\text { furniture near combustible linings, } \\
\text { lightweight furnishings, packing material } \\
\text { in rubbish pile, non-fire-retarded plastic } \\
\text { foam storage, cardboard of plastic boxes } \\
\text { in vertical storage arrangement }\end{array}$ & 0.1874 & 75 \\
\hline
\end{tabular}

\section{Tenability Criteria}

At the pre-flashover stage of the fire development, the major concern of fire protection engineering is life safety. Heat, combustion products and smoke from the fire can create conditions that are untenable for occupants [14]. According to Bwalya[9], the HRR and quantity of fire effluent produced are the most important attributes of pre-flashover fires. 
Potential exposure to toxic gases, heat and smoke obscuration (poor visibility) may affect the time available for safe evacuation of occupants.

\section{Exposure to Toxic Gases}

The primary fire effluents produced at the initial stages of the fire may be classified as being asphyxiants or irritants. Asphyxiants include: oxygen depletion $\left(\mathrm{O}_{2}\right)$, carbon monoxide $(\mathrm{CO})$, carbon dioxide $\left(\mathrm{CO}_{2}\right)$, and hydrogen cyanide $(\mathrm{HCN})$. Exposure to asphyxiant gases may cause incapacitation, a state when people lose their physical abilities and hence their inability to escape from a fire. Depletion or vitiation of $\mathrm{O}_{2}$ may also pose a threat to occupant safe evacuation. At normal conditions, oxygen constitutes about $21 \%$ of clean air. $\mathrm{O}_{2}$ depletion is not severe if the concentration is greater than $13 \%$. Concentrations below $15 \%$ by volume lead to hypoxia causing increased breathing, faulty judgment and rapid onset of fatigue. Table 2-6 shows effects of different oxygen concentration limits.

Table 2-6 Effects of Oxygen concentration limits [15]

\begin{tabular}{cl}
\hline$\%$ Oxygen in Air & Symptoms \\
\hline $21-20$ & Normal \\
\hline 18 & Night vision begins to be impaired \\
\hline 17 & $\begin{array}{l}\text { Respiration volume increases, muscular coordination diminishes, } \\
\text { attention and thinking clearly requires more effort }\end{array}$ \\
\hline $12-15$ & $\begin{array}{l}\text { Shortness of breath, headache, dizziness, quickened pulse, effort } \\
\text { fatigues quickly, muscular coordination for skilled movement lost }\end{array}$ \\
\hline $10-12$ & Nausea and Vomiting, exertion impossible, paralysis of motion \\
\hline $6-8$ & Collapse and unconsciousness \\
\hline 6 or below & Death in 6 to 8 minutes \\
\hline
\end{tabular}

The time to loss of consciousness $\left(t_{K}\right)$ for a victim exposed to a hypoxic fire environment is given by equation $[15]$ :

$\left(t_{\mathrm{OO}}\right) \min =\exp \left[8.13-0.54\left(20.9-\% \mathrm{O}_{2}\right)\right]$

Equation 2.3 
where, $\left(20.9-\% \mathrm{O}_{2}\right)=\% \mathrm{O}_{2} \mathrm{Vit}$ (percent oxygen vitiation). For a constant level of hypoxia, the time to incapacitation due to oxygen depletion is given by

$t_{T^{\circ}}=\exp \left[8.13-0.54\left(20.9-\% \mathrm{O}_{2}\right)\right]$

Equation 2.4

where, Dose to incapacitation $=\left(20.9-\% \mathrm{O}_{2}\right)\left(t_{\mathrm{O}}\right)$.

The toxic effect of $\mathrm{CO}$ is due to its affinity with the hemoglobin in human blood to form carboxyhemoglobin $(\mathrm{COHb})$, reducing the transport of oxygen in the blood to various parts of the body. On the other hand, $\mathrm{CO}_{2}$ causes hyperventilation (increase rate of breathing) in the concentration range of $2-6 \%$. This may increase the uptake rate of other toxic gases from the fire. $\mathrm{HCN}$ is about 25 times more toxic than CO. The Fire Engineering Design guide [16] in New Zealand uses the following tenability criteria of $\mathrm{CO} \leq 1400 \mathrm{ppm}$ and $\mathrm{CO}_{2} \leq$ $0.05 \mathrm{~mol} / \mathrm{mol}$.

Fractional effective dose (FED) approach is often used to determine the time after which incapacitation occurs. Equation 2.5 gives the FED as a result of short exposure to $\mathrm{CO}$ at high concentrations [61].

$\mathrm{FED}_{\mathrm{in}, \mathrm{CO}}=\sum_{\mathrm{t}_{0}}^{\mathrm{t}} \frac{[\mathrm{CO}] . \Delta \mathrm{t}}{3500} \exp \left(\frac{\% \mathrm{CO}_{2}}{5}\right)$

Equation 2.5

where, $[\mathrm{CO}]$ is the inhaled carbon monoxide concentration in parts per million; $\Delta t$ (minute) is the discrete increment of time; 35000 (ppm.min) is the incapacitation dose for the $\mathrm{CO}$ exposure, and $\exp \left(\% \mathrm{CO}_{2} / 5\right)$ is a $\mathrm{CO}_{2}$-induced hyperventilation factor for breathing $[17,15]$. $\mathrm{FED}_{\text {in, }} \mathrm{CO}=0.3$ represents incapacitation dose for some susceptible population such as children, whereas $\mathrm{FED}_{\mathrm{in}, \mathrm{CO}}=1$ represent incapacitation dose for healthy adults.

On the other hand, irritant gases stimulate receptors in eyes, nose, mouth, throat and respiratory track, causing discomfort and pain. Examples include: HCL and acrolein. The 
average human can endure an atmosphere with high levels of $\mathrm{HCl}$ provided the volume concentration is less than $1000 \mathrm{ppm}$.

\section{Exposure to Heat}

Occupants may be exposed heat through convective heat transfer from hot gases to the skin or by radiant heat from the fire and the hot smoke layer. According to the ISO 13571 [17], the rate of convective heat transfer from the hot gases to the skin depends on temperature, ventilation, humidity and clothing over the skin. The fractional effective dose for incapacitation due to convection is calculated using Equation 2.6 [15].

$\mathrm{FED}_{\text {in, heat }}=\sum_{t_{0}}^{t} \frac{\mathrm{T}^{3.4}}{5 \times 10^{7}} \Delta t$

Equation 2.6

Where, $\mathrm{T}\left({ }^{\circ} \mathrm{C}\right)$ is the temperature and $\Delta t$ (minute) is the time interval. Uncertainty in calculation is in the range of $25 \%$. Radiant heat from the smoke layer (when its temperature is over $200^{\circ} \mathrm{C}$ ) with a heat flux of $2.5 \mathrm{kWm}^{-2}$ will cause second degree burning to the skin.

\section{Visibility}

The visibility through smoke is proportional to the reciprocal of the OD for non-irritating smoke. The smoke obscuration can be expressed as the optical density per meter (OD in $\mathrm{m}^{-1}$ ) in the Equation 2.7 below:

$\mathrm{OD}=\frac{1}{L} \log _{10}\left(\frac{I_{0}}{I}\right)$

Equation 2.7

Where, $I_{0}$ is the intensity of the incident light; $I$ is the intensity of the light transmitted through the path length, $L(\mathrm{~m})$, of smoke. The OD can be expressed in terms of the extinction coefficient $k\left(\mathrm{~m}^{-1}\right)$ as $\mathrm{OD}=k / 2.303$. OD of $2 \mathrm{~m}^{-1}$ or lower is often used as the tenability limit for smoke obscuration. According to ISO 13571 [17], smoke obscurity limit is taken as the $O D$ at which occupants cannot see their hands within a distance of $0.5 \mathrm{~m}$ or less in front of 
their face. This will occur at an OD of $3.4 \mathrm{~m}^{-1}$, using Equation 2.7 above. The Fire Engineering Design guide [31] in New Zealand uses tenability criteria where visibility should not fall below $2 \mathrm{~m}$, corresponding to OD of $0.5 \mathrm{~m}^{-1}$.

$\mathrm{Su}$, et al. [14] conducted full-scale experimental program to study the impact of two basement fire scenario on tenability conditions. Visual obscuration by the optical density of the smoke was the first hazard to arise that could impede evacuation by occupants.

\subsubsection{Flashover}

This point follows the growth period. It is the stage between the growth period and a fully developed fire. A hot upper layer of fire gases is formed within a compartment usually during the growth phase of the fire. If the fire is allowed to continue without any intervention, the hot upper layer will begin to emit thermal radiation to all exposed surfaces within the compartment. Flashover is the point at which the heat release rate, temperature, smoke production, and smoke toxicity increase rapidly. This usually corresponds to a hot upper smoke layer of 500 and $600^{\circ} \mathrm{C}$, and heat flux levels of about $15-20 \mathrm{~kW} / \mathrm{m}^{2}$ at the floor level of the compartment. Following this, the fire may either be ventilation-controlled or fuel controlled. The factors that affect whether flashover occurs in an enclosure include the following: surface area of the enclosure $\left(A_{t}\right)$, the area of enclosure openings $\left(A_{v}\right)$, the effective height of enclosure openings $\left(h_{v}\right)$, heat release rate, and thermal properties of compartment boundaries [18]. According to SFPE [2], eliminating the chance of flashover analytically does not necessarily prevent fire extension or large-scale fire development. However, flashover does not always occur. Several mathematical models exist for the prediction of the HRR, whether flashover will occur and whether a fire will be ventilation or 
fuel controlled. Table 2-7 presents a comparison of different methods for predicting the minimum HRR at which flashover would occur from three different sources.

Table 2-7 Comparison of Different Methods for Predicting Heat Release Rate

\begin{tabular}{llll}
\hline & $\begin{array}{c}\text { McCaffrey, Quintiere and } \\
\text { Harkload }(\mathrm{MQH})[19]\end{array}$ & Babrauskas [20] & Thomas[21] \\
\hline & & By calculation & \\
\hline & & $\dot{Q}=600 A_{o} \sqrt{H_{o}}$ & $\dot{Q}=7.8 A_{T}+378 A_{o} \sqrt{H_{o}}$ \\
& & & \\
& & Modified by test & \\
\hline
\end{tabular}

Where, $A_{o}=$ area of opening $\left(\mathrm{m}^{2}\right), H_{o}=$ height of opening $(\mathrm{m}), h_{k}=$ effective heat transfer coefficient $(\mathrm{kW} / \mathrm{mK})$, and $A_{T}=$ total compartment surface area $\left(\mathrm{m}^{2}\right)$.

$\mathrm{MQH}$ equation suggests that an increase in the height of opening and total compartment surface area will increase the HRR needed for flashover to occur. Similar to MQH, Thomas' equation takes into account the total compartment surface area. Babrauskas' equation does not consider the effect of compartment surface area. The equation suggests that an increase in the area of opening will increase the HRR needed for flashover to occur. Therefore, Babrauskas' equation may not apply to larger compartments where the opening characteristics may have little or no effect on the HRR at the initial stage of the fire development. The methods presented above were based on the conservation of energy expression of the upper layer developed by McCaffrey, Quintiere and Harkload [19].

$\dot{Q}=\dot{m}_{g} c_{p}\left(T_{g}-T_{\infty}\right)+q_{\text {loss }}$ Equation 2.8

Where, $\dot{Q}=$ heat release rate of the fire $(\mathrm{kW}), \dot{m}_{g}=$ gas flow rate out the opening, $c_{p}=$ specific heat of gas $(\mathrm{kJ} / \mathrm{kgK}), T_{g}=$ temperature of the upper gas layer $(\mathrm{K}), T_{\infty}=$ ambient temperature $(\mathrm{K})$ and $q_{\text {loss }}=$ net radiative and convective heat transfer from the upper gas layer $(\mathrm{kW})$. 
This method was developed using a simple conservation of energy expression and a correlation with data to approximate the upper layer temperature in a compartment. According to McCaffrey et al, the limitations on the use of the conservation of energy expression of the upper layer for estimating temperatures are:

- The correlation holds for compartment upper layer gas temperatures up to approximately $600^{\circ} \mathrm{C}$,

- It applies to steady-state as well as time-dependent fires, provided the primary transient response is the wall conduction phenomenon,

- It is not applicable to rapidly developing fires in large enclosures in which significant fire growth has occurred before the combustion products have exited the compartment,

- The energy release rate of the fire must be determined from data or other correlations,

- The characteristic fire growth time and thermal penetration time of the room-lining materials must be determined in order to evaluate the effective heat transfer coefficient, and

- The correlation is based on data from a limited number of experiments and does not contain extensive data on ventilation-controlled fires nor data on combustible walls or ceilings. Most of the fuel in the test fires was near the center of the room.

\subsubsection{Post flashover}

This stage comprises of the fully developed fire stage and the decay phase.

\section{Fully Developed Fire}

This is the stage when there is full involvement of the compartment in the fire. The design fire in the fully developed stage will be either ventilation controlled or fuel controlled. 
However, according to Klote [12] fully developed fires are often ventilation controlled and depend on the amount of air that may be entrained by the fire. In a very large compartment a fire may not become ventilation controlled. Klote reported that fully developed fires are characterized by insufficient combustion and high production of carbon monoxide. The theoretical maximum of HRR is often approximated by the Equation 2.9 [20] below.

$\dot{Q}=1500 A_{v} \sqrt{H_{v}}$ Equation 2.9

Where, $\dot{Q}=$ Heat release rate $(\mathrm{KJ} / \mathrm{s}), A_{v}=$ Area of ventilation opening $\left(\mathrm{m}^{2}\right), H_{v}=$ Height of ventilation opening $(\mathrm{m})$.

Temperatures within the compartment are very high at this stage of the fire development. The concern for structural integrity makes temperature history prediction a very important parameter at this stage [9]. The most widely used equation for prediction of temperature within the compartment during the fully developed stage of the design fire is the Eurocode [22] parametric equation. The equation produces a time-temperature relationship for combinations of fire load, ventilation opening and wall lining material. The equation is based on the time-temperature curves provided by Magnusson and Thelandersson [22], Figure 2-4. 

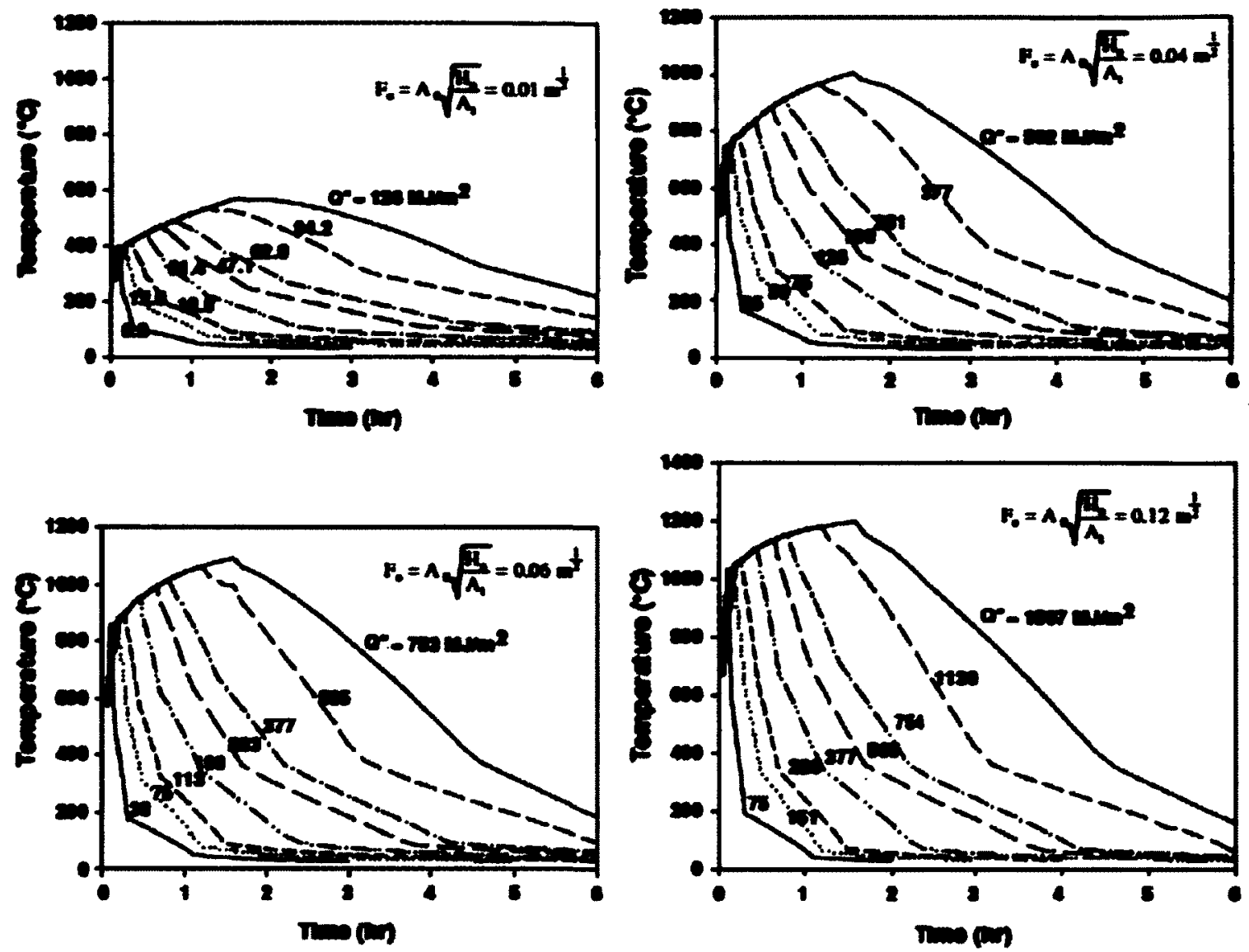

Figure 2-4 Time - Temperature Curves [22]

The Eurocode distinguishes between the burning phase and the decay phase. For the heating phase temperature is expressed as;

$T=1325\left(1-0.324 e^{-0.2 t^{*}}-0.204 e^{-0.7 t^{*}}-0.472 e^{-19 t^{*}}\right)$

Equation 2.10

Where, $T=$ temperature and $t^{*}=$ fictitious time (in hours) given by:

$$
\begin{aligned}
t^{*} & =t\left(\frac{\left(F_{d} / F_{\text {ref }}\right)}{\left(b / b_{\text {ref }}\right)}\right)^{2} \\
t & =\sqrt{k \rho c_{p}}\left(\mathrm{Ws}{ }^{0.5} / \mathrm{m}^{2} \mathrm{~K}\right)
\end{aligned}
$$


$F_{o}=\frac{F_{v}}{A_{t}}$

Equation 2.13

$F_{\text {ref }}$ is the reference value of the opening factor, taken to be $0.04, k \rho c_{p}$ is the thermal inertia, and $b_{\text {ref }}$ is the reference value of $\sqrt{k \rho c_{p}}$, given the value of 1160 .

$t^{*}$ can be rewritten as

$t^{*}=t\left(\frac{F_{o}}{\sqrt{k \rho c_{p}}}\right)^{2}\left(\frac{1160}{0.04}\right)^{2}$

Equation 2.14

Where, $t=$ time (in hours)

On the other hand, the Eurocode temperature-time curve in the cooling phase is given by:

$T_{g}=T_{g, \max }-625\left(t^{*}-t_{d}^{*}\right) \quad$ for $t \leq 0.5$

Equation 2.15

$T_{g}=T_{g, \max }-250\left(3-t_{d}^{*}\right)\left(t^{*}-t_{d}^{*}\right) \quad$ for $0.5 \leq t_{d}^{*} \leq 2.0$

Equation 2.16

$T_{g}=T_{g, \max }-250\left(t^{*}-t_{d}^{*}\right) \quad$ for $t_{d}^{*} \geq 2.0$

Equation 2.17

Where, $T_{g, \max }=$ maximum temperature in the heating phase for $t=t_{d}$ and:

$t_{d}^{*}=\frac{0.13 \times 10^{-3} Q_{t}^{\prime \prime}}{F_{o}}\left(\frac{F_{o}}{\sqrt{k \rho c_{p}}}\right)^{2}\left(\frac{1160}{0.04}\right)^{2}$

Equation 2.18

The duration of the heating phase, is given in terms of real time, by:

$t_{d}=\frac{0.13 \times 10^{-3} Q_{t}}{F_{o}}$

Equation 2.19

Therefore, the modified duration time can be written as:

$t_{d}^{*}=t_{d}\left(\frac{F_{o}}{\sqrt{k \rho c_{p}}}\right)^{2}\left(\frac{1160}{0.04}\right)^{2}$

Equation 2.20 
At the fully developed stage of the fire development the concerns of fire protection engineering shifts from life safety to structural integrity and safety of fire fighters [9]. For designs involving compartmentation or structural fire resistance, the expected duration of the fire needs to be considered. To determine this value, it is necessary to determine or estimate the fire load (fuel load). It must be noted that fire load is expressed as energy units per unit floor area $\left(\mathrm{MJ} / \mathrm{m}^{2}\right)$, whereas fuel load is generally expressed in terms of mass of fuel per unit $\operatorname{area}\left(\mathrm{kg} / \mathrm{m}^{2}\right)$.

\section{Decay and Extinction}

The final stage of the design fires is the decay phase. The decay phase is often attributed to the depletion of fuel load, lack of ventilation, or manual or automatic suppression systems extinguishing the fire. This stage is often represented by the $t$-squared equation.

\subsection{Heat Release Rate (HRR)}

The HRR of a fire is important for quantifying growth and spread of the fire within a compartment [23]. According to Linteris [24], previous studies have related flame size to the HRR indirectly by predicting the flame size as a function of the fuel flow rate. Historically, HRR was measured in experiments based on the temperature rise of ambient air as it passed over the burning item. This method has several errors because the radiant emission from the heat varies with the type of material being burned, and because not all the radiant energy contributes to temperature rise of the air. As a result of these measurement errors, the oxygen consumption calorimetry technique was developed. The technique is now used worldwide and forms the basis for several national and international standards [24]. The oxygen consumption principle is based on the observation that, generally, the net heat of combustion 
is directly related to the amount of oxygen required for combustion [24]. The heat release is determined by the measurement of the oxygen consumption, as determined by the oxygen concentration and the flow rate in the combustion product stream, in a full scale environment. Approximately $13.1 \mathrm{MJ}$ of heat are released per $1 \mathrm{~kg}$ of oxygen consumed.

A set of equations have been developed by Janssen [25] for the calculation of the HRR. Janssen's equations have been used in the Large Fire Research Facility at the National Institute of Standards and Technology (NIST) for heat release rate calculations [26]. Equation $2.21-2.23$ represent the third case of Janssen where $\mathrm{O}_{2}, \mathrm{CO}_{2}$ and $\mathrm{CO}$ are measured.

$$
\begin{aligned}
& \dot{q}=\left(E \emptyset\left(E_{C O}-E\right) \frac{1-\varnothing X_{C O}}{2 X_{0_{2}}}\right) \frac{m_{e} M_{r}\left(O_{2}\right)}{1+\varnothing(a-1) M_{r}(E)}\left(1-X_{H_{2} O}^{0}\right) X_{O_{2}}^{0} \\
& \varnothing=\frac{X_{O_{2}}^{0}\left(1-X_{C_{2}-}-X_{C O}\right)-X_{O_{2}}\left(1-X_{C O_{2}}^{0}\right)}{X_{O_{2}}\left(1-X_{O_{2}}-X_{C O_{2}}-X_{C O}\right)} \\
& X_{H_{2} O}^{0}=\frac{R H_{a m b}}{100} \frac{\left(0.6107+0.06052 T_{a m b}-0.0002088 T^{2}+0.00007376 T_{a m b}^{4}\right)}{P_{a m b}}
\end{aligned}
$$

Equation 2.22

where, $\dot{q}=$ heat release rate of the fire $(\mathrm{kW}), E=$ heat released per unit mass of oxygen consumed $\left(13.1 \mathrm{MJ} / \mathrm{kg}\right.$ of $\left.\mathrm{O}_{2}\right), \emptyset=$ oxygen depletion factor, $E_{C O}=$ heat released per unit mass of oxygen consumed for combustion of $\mathrm{CO}$ to $\mathrm{CO}_{2}\left(\approx 17.6 \mathrm{MJ} / \mathrm{kg}\right.$ of $\left.\mathrm{O}_{2}\right)$, $M_{r}\left(\mathrm{O}_{2}\right)=$ relative molecular mass of oxygen $(\approx 32 \mathrm{~kg} / \mathrm{kmol}), \alpha=$ combustion expansion factor $(1.105), M_{r}(\mathrm{E})=$ relative molecular mass of exhaust gas $(\approx 28.97 \mathrm{~kg} / \mathrm{kmol}), X_{\mathrm{H}_{2} \mathrm{O}}^{0}=$ mole fraction of $\mathrm{H}_{2} \mathrm{O}$ in the incoming air, $X_{\mathrm{O}_{2}}^{0}=$ measured mole fraction of $\mathrm{O}_{2}$ in the incoming air, $\mathrm{X}_{\mathrm{CO}_{2}}=$ measured mole fraction in the exhaust gases, $\mathrm{X}_{\mathrm{CO}}^{0}=$ measured mole fraction of $\mathrm{CO}$ in the incoming air , $X_{\mathrm{O}_{2}}=$ measured mole fraction in the exhaust gases, $X_{\mathrm{CO}}=$ measured mole fraction of $\mathrm{CO}$ in the exhaust gases, $\mathrm{X}_{\mathrm{CO}} \mathrm{O}_{2}=$ measured mole fraction of $\mathrm{CO}_{2}$ in the 
incoming air, $R H_{a m b}=$ relative humidity of ambient air, $T_{a m b}=$ temperature of ambient air (293.13K), and $P_{a m b}=$ pressure of ambient air.

\subsubsection{Development of Heat Release Rate}

According to Hietaniemi [11], there are basically two ways to determine the HRR in fires in a performance based design: i. analysis and synthesis of experimental data, and ii. computer modelling and fire simulations.

\subsubsection{Analysis and Synthesis of Experimental Data}

The first step in the analysis process is to compile all relevant data in the literature. Simplified model representations are then drawn for the available data. An example is shown

Figure 2-5.

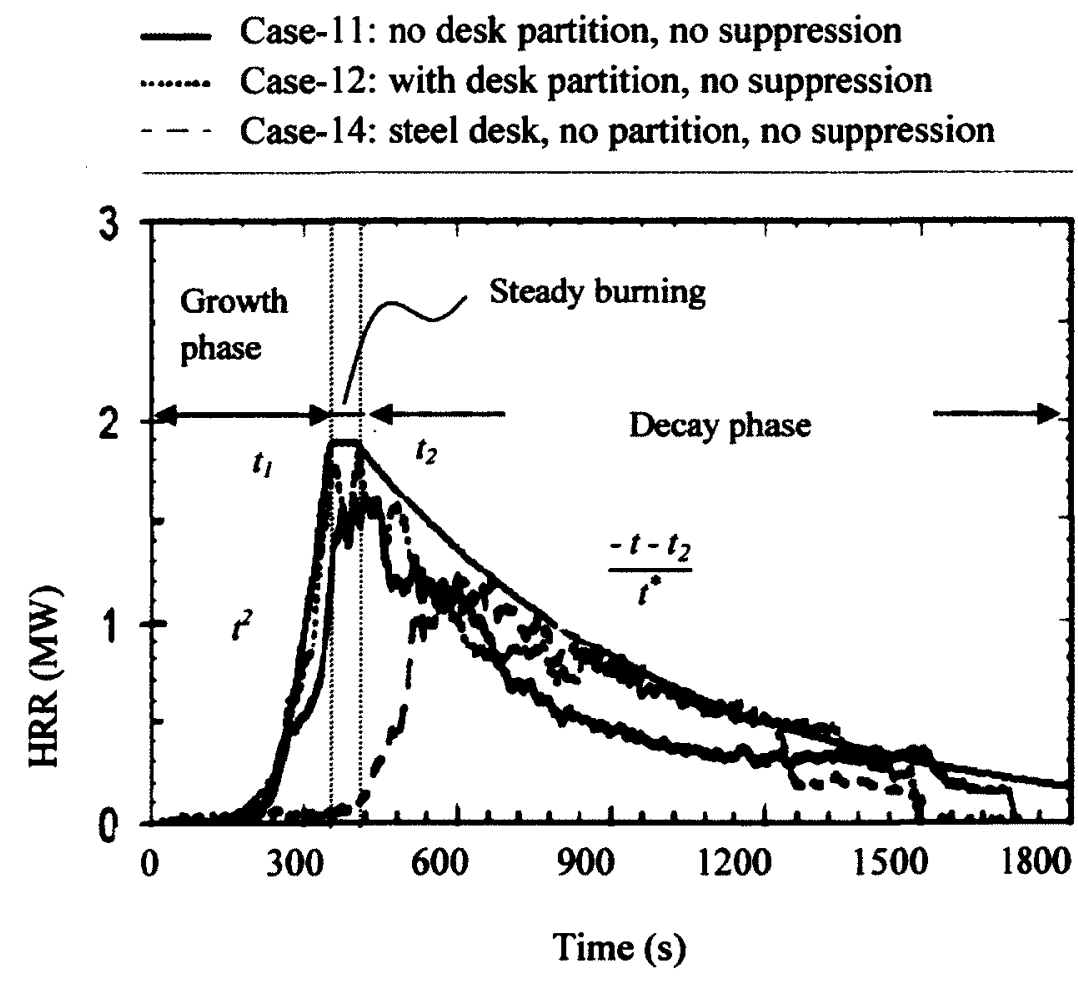

Figure 2-5 Design Fire Curves [11] 
The growth phase of the fire was modeled as a $t$-squared fire, $t^{p}$ (where $\left.p=2\right)$. After the growth phase the fire experiences steady burning from $t_{1}$ to $t_{2}$ and then it begins to decay. The decay phase was modeled with $\exp \left(-t-t_{2} / t^{*}\right)$, where $t^{*}$ is the parameter that characterize how fast the HRR decays. The compiled data is then analyzed to obtain parameters that allow generalization of the results. The next step is to tabulate the characteristic fire parameters and analysis using statistical methods. The final step is to develop suitable fractiles of the characteristic parameters to describe the fire load entities.

\subsubsection{Computer Modelling and Fire Simulation}

With the help of relevant test data, computer modelling and fire simulations can be used to determine the heat release rate. FDS version 5 fire simulation program uses a novel methodology which is able, to some extent, to predict the heat release rate [11]. The use of computer simulation to determine HRR requires careful analysis and validation with experimental results in most instances. The accuracy of HRR predictions obtained is sufficient for performance based Fire Safety Engineering (FSE) usage [11].

\subsection{Fire Loads}

An important parameter in determining the design fire is the fire load density. The HRR can be determined based on knowledge of the available combustibles within the compartment. The total fire load in a compartment is often calculated using the equation [27]:

$$
Q=\sum \boldsymbol{k}_{i} \boldsymbol{m}_{i} h_{c i}
$$


Where, $Q=$ total fire load in a compartment (MJ), $k_{i}=$ proportion of content or building component $i$ that can burn, $m_{i}=$ mass of items $(\mathrm{kg})$, and $h_{c i}=$ calorific value of item $(\mathrm{MJ} / \mathrm{kg})$.

The total fire load is commonly expressed as the total heat energy (MJ) that can be released through complete combustion. It is often expressed as energy density per unit floor area, Q" $\left(\mathrm{MJ} / \mathrm{m}^{2}\right)$, to enable extrapolation to compartments of different sizes. Fire Loads usually consist of fixed fire loads and contents (movable) fire load.

\subsubsection{Fire Load Survey}

The fire load is determined by surveying a representative sample of the buildings of interest and listing the compartment's dimensions, fixed and content combustibles and their pertinent characteristics. Fire load surveys in the past have used different survey methodologies [2843], including: the inventory, weighing, a combination of inventory and weighing, use of questionnaires and web based photographs of real estate sites. However, three basic methods are often used to estimate the combustible energy content of a particular compartment. These are:

- direct measurement of mass, with conversion based on the net heat of combustion;

- direct measurement of volume (with conversion based on a combination of density and net heat of combustion); and

- energy release measurement by calorimetry of an item sufficiently similar to the fuel package.

Several fire load survey methodologies (techniques) have been identified from the literature review[28-43]. Discussion of those methodologies is presented in the sections below. 


\subsubsection{Inventory Method}

The NFPA Standard 557[27], guidance on fuel load surveys (special facility and occupancy based) defines the inventory method as the determination of the mass of an item based on its measured volume and corresponding density. The method requires the physical entry of a building by an expert to list content and characteristics of all combustible items within the compartment. In the past, surveyors have used measured dimensions (physical characteristics of items) to obtain the mass of the item being surveyed. Mass of the items can therefore be calculated using known densities of the corresponding material or by estimations based on pre-weighed items data $[27,28]$. Combustible energy of the compartment contents is then calculated based on the net heat of combustion of the fuel package.

Culver [28] used an inventory survey method employing the collection of visual data, i.e., observable physical characteristics of the various content items, from which weights were obtained. The concept involved the assumption that a relationship existed between the visual characteristics (measured dimensions) of items and their weight. This relationship can be viewed as a transfer function or formula for weight expressed in terms of physical characteristics. Masses of items were developed based on transfer functions. Weights of items used to develop the transfer functions were from pre-weighed items and manufacturer's catalogues. Twenty three office buildings across the United States were surveyed. The following information was gathered for each item: type of item (desk, table and etc.), the construction material (wood, metal and etc.), and the measured dimension (length, width and height). For irregular shaped items and irregular pile of papers, approximate dimensions were recorded. Transfer functions were used for the survey but no direct weighing was done. The survey classified weights as movable contents (furniture, equipments and other 
combustible contents) and interior finish (combustible finish material for walls ceilings and floors). The fire loads presented were obtained by converting the weights of surveyed items to equivalent weights of combustible having a calorific value of $18.5 \mathrm{MJ} / \mathrm{kg}$.

Issen [29] conducted a fire load survey of a residential compartment using a method similar to Culver's. Both Issen and Culver used transfer functions which presume that items being surveyed are of standard materials and sizes. According to Issen [29], although no industrywide standards existed, the market place and available technology during the period of the survey produced furniture types that appeared to be consistent in their weight characteristics. Similar to Culver, combustibles stored in enclosed cabinets (combustibles and noncombustibles) or shelves were not reduced by any factors (derating factors) for fire resistance. Fire loads were calculated based on the heat of combustion of wood $(18.5 \mathrm{MJ} / \mathrm{kg})$.

Kumar [30] also conducted a fire load survey using the inventory method. The approach for the survey was similar to the method Culver used. The aim of the survey was to update existing fire load survey data to reflect conditions that prevailed at the time of the survey in 1993. The survey was conducted on 8 office buildings in Kanpur, India, and may not be comparable to fire loads in Canada because of differences in building occupancy characteristics. However, the purpose of this review is the type of methodology used and therefore the study is relevant. Similar to Culver [28] and Issen [29], no derating factors were used for enclosed combustibles such as combustibles in cabinets. Derating factors are usually used to reduce the weights of combustibles that are stored in cabinets. This is because the combustibles stored in the cabinets are expected not to burn as efficiently as items that are not. According to Kumar, the justification of not using derating factors is that cabinets may be left opened during the event of a fire. Kumar observed that fire load 
intensities reported may be reduced by approximately $10 \%$ when using the derating factors. Fire loads were computed by multiplying the masses of different items by their specific calorific values. The total energy content of the room was then divided by the floor area to get the fire load per unit area corresponding to that room.

Korpela et al [31] used a method of fire load survey similar to Culver's method. Korpela determined weights of items based on the physical characteristics (dimensions) of the item and pre-weighed item tables. The study surveyed 1,500 office rooms, open plan offices, archives, libraries and conference rooms. The method was based on the assumption that most office furniture is of standard size and form. First, an inventory list was created from accurately weighing different categories of combustible items from an initial visit to two buildings. The inventory consisted of 10 different tables each consisting of a single category of items such as tables, shelves, chairs, computers, displays, etc. Typical dimensions of each of these items were given. The second step was to determine the fire load of the items within a given compartment by taking some dimensions of items and matching them to the relevant inventory list. However, all non standard items had to be estimated by the surveyor. Items were matched by comparing physical characteristics of items within the compartment to preweighed items. It must be noted that Korpela did not use any transfer functions.

Drawbacks of the inventory method include the following. The use of derating factors has not been clearly defined. As a result of this, different surveyors may use different factors to reduce combustibles stored in enclosures. The current review shows that surveyors considered the fire load as the total combustible content without the use of derating factors for enclosed combustibles. The difference in survey results of the use of these factors has been found to be in the range of $10 \%$ [30]. In addition to the issue of use of derating factors, 
the use of incorrect approximations for miscellaneous and irregular shaped objects can significantly affect the survey results. Furthermore, the use of transfer functions which presume that items are standardized in terms of size and material may significantly affect survey results. These functions only represent mean values of furniture or items in that category. The lack of standardization in the industry especially for domestic furniture also has an impact on the use of these functions. Incorrect identification and matching of preweighed items to similar items in compartments being surveyed can also affect the quality of the survey results. Finally, in estimating fire load, Issen used the heat release rate of wood to convert masses of items into energy units. This simplification does not effectively account for the contribution of other items (plastics, liquid fuels and etc) to the total amount of energy released. In occupancies where plastics and liquids form a significant part of combustible contents, the use of the heat release rate of wood for all items will significantly affect the fire load. Culver also converted the weights of surveyed items to equivalent weights of combustibles having a calorific value of $18.5 \mathrm{MJ} / \mathrm{kg}$. This value was based on the heat of combustion of wood and may not be true for other materials, e.g. plastics and liquid fuels.

\subsubsection{Direct Weighing Method}

This method also requires physical entry into a building by a surveyor to document contents and characteristics of all items within the compartment. However, unlike the inventory method, the combustible masses of items within the compartment are obtained by direct weighing.

Ingberg [32] conducted an extensive fire load survey using the direct weighing method. The report presented fire loads for different occupancies including; apartments and residences, 
hospitals, schools, mercantile and manufacturing establishments. In commercial establishments, the survey was limited to selling areas and small storage areas frequented by clerks, and did not include workshops and offices associated with the selling areas. Combustible loads per floor area of the whole department were determined by weighing the combustible contents in a representative area of the department. However, little detail was given in the report as to how other occupancies were surveyed. Combustible contents in this report refer to movable, floor coverings and exposed wood work other than on the floor. Fuel load was presented per floor area of the compartment.

Baldwin et al [33] also conducted a fire load survey of two office buildings using the direct weighing method. The survey used detailed plans to describe the layout of the furniture and room, and provided a list of the types and weight of individual items of furniture. The reported fire load data did not include fixed combustibles on walls and partitions. Fuel load was presented as the total weights of combustibles per floor area $\left(\mathrm{kg} / \mathrm{m}^{2}\right)$.

Caro [34] surveyed six office buildings using the direct weighing method. Two different direct weighing methods were used. In the first method, all combustible contents within the compartment were taken from their operational location and weighed. In the second, the weights of office contents when packaged for remodeling purposes were determined. The fuel load was calculated for only the combustible contents and does not include all metal contents. Derating factors were used to decrease enclosed combustible items. The fuel load estimates for each office were separated into the following categories: paper/books, computer equipment, furniture, partitions and miscellaneous. This was done to group items of similar material composition. Fuel load was calculated as the ratio of the total equivalent weight of the fuel commodities to the floor area, (lb/sq.ft). 
The use of the direct weighing method may not be as common as the inventory method; however in most cases, it is used with the inventory method. The major drawback of the weighing method is the difficulty in accounting for fixed combustibles. Directly weighing fixed combustibles may be impractical. As a result of this difficulty, fixed combustibles are often not included in fire load calculations or assumed based on the surveyor's discretion. Another drawback of the direct weighing method is how to determine the weight of combustible materials in items having both combustible and non-combustible materials. Metals can form a significant portion of the mass of such items, e.g. padded metal chair, metal racks with wooden shelves etc. Measuring the mass of combustibles of such items becomes difficult. Also, the use of the direct weighing survey method is likely to disrupt business activities and invade privacy. This may be controlled by planning the survey during out of office hours and may not directly affect the quality of survey results. However, if certain areas are inaccessible to the survey team due to ongoing business activities or privacy concerns, the fire loads cannot be determined. As discussed above, the method used by Caro is not likely to disrupt business but the risk of error may be high since package contents may not accurately reveal the material characteristics of the item. This is because items within the compartment were packaged and concealed in boxes which do not permit a thorough investigation (material documentation) of the item being surveyed. The weighing method may also affect the survey time adversely. Directly weighing all items within a compartment may require significant amount of work. Lifting of items to weigh may require more than a single surveyor and heavy items may require more people. The method may require special weighing devices. 


\subsubsection{Combination of Direct Weighing and Inventory Method}

This method combines the use of the direct weighing method and the inventory method, the latter of which, may include inventory of pre-weighed items and calculation of mass based on direct measurement of volume and corresponding material densities.

One of the earliest fire load surveys that employed the use of both the inventory method and the direct weighing method is reported in BMS Report 92 by the National Bureau of Standards [35]. The survey covered different types of building occupancies, including residential, educational, offices, hospitals and warehouses. Weights were obtained by weighing furniture and other contents that could easily be weighed. Fire loads of combustible floors, as well as, fixed combustible and heavy furniture were determined from thickness and area. Doors, windows, frames and trims were included at half their total weight; however no explanation as to this consideration was given in the report. Contents of metal lockers, filing cabinets etc were also included as its total weight without any reduction in weight (no derating factors were used). Contents of closets in residential apartments were averaged with those of the adjoining room or hall. In schools, desks were assumed to be empty and surveys did not include weights of clothing (e.g. outdoor jackets or gym kit) stored by pupils. Fuel load was presented as weight (pounds) of all combustible items per floor area (square foot), which was assumed to be uniformly distributed. Similar to Culver, weights of items, other than wood, were modified to give the equivalent weight of a material having a calorific value of $18.5 \mathrm{MJ} / \mathrm{kg}$.

Green [36] also used a combination of the direct weighing and inventory methods to conduct a fire load survey of a hospital. The study described combustible contents by their nature, weight, thickness or surface area. For combustibles that could not be easily weighed, 
dimensions were measured, volumes were calculated and then weights of combustibles were calculated by using an assumed density of $600 \mathrm{~kg} / \mathrm{m}^{3}$. The study assumed that all combustibles had the same calorific value as wood. Fire loads were estimated based on the calorific value of wood.

Barnett [37] conducted a pilot fire load survey using a combined method of both inventoried data and direct weighing. This survey was not intended to give precise fire load results but was only intended to determine the order of magnitude of likely results for each type of building and to set a basic framework for future surveys. The survey was conducted in one building of each of the following building categories: hospitals, offices, shops and factories. The survey was divided into two main stages. First, combustibles were divided into fixed and movable fire loads. Fixed fire loads included combustibles in or on the walls, floors and ceiling including power and telephone cables, plastic light fittings, telephones, doors and frames. The second stage was to record weights of combustible contents and to compute volumes from measured dimensions of both fixed and combustible contents that cannot be weighed. In order to obtain fire load densities from inventoried data, a gross calorific value of wood of $20 \mathrm{MJ} / \mathrm{kg}$ (wood at oven dry conditions) was used.

Yii [38] conducted a fire load survey using both methods to investigate the effects of surface area and thickness on fire loads. The survey was conducted in six sample university rooms, four samples of postgraduate offices, one sample of motel (kitchen and bedroom) and from several bedrooms in flats. In order to facilitate the data collection a fire load data entry sheet was prepared. Fuel loads were classified into fixed fire loads and movable fire loads. Fixed items such as skirting boards and wall switches were ignored. This was due to the difficulty in assuming the exposed surface area to the fire. Fuel loads were also divided into different 
types of materials such as wood, plastic and etc. The mass and dimensions were the two most important parameters that were measured. For combustible objects that were too large, the volume was measured and mass obtained by multiplying the volume with the density. Another parameter that was considered in the study was the surface area of the fuel exposed to the fire.

Zalok [39] used the direct weighing method, inventory of pre-weighed common items and calculation of mass based on measured volume and corresponding density. 167 commercial stores were surveyed. Zalok noted that combinations of these methods facilitated the survey process. All questionnaires that were needed to be completed by the store owners or individuals were conducted in-person by the surveyor. This helped to ensure a high quality of survey data and consistencies in data. In order to collect data in a systematic and consistent order a survey form was developed and used for all buildings surveyed. The survey also followed a similar procedure for all compartments. Combustible contents were classified into three main groups: cellulosic, plastics and textiles. Masses of items that could easily be weighed were measured and their material composition noted. Percentages of each type of material were also determined for items composed of more than one material. Volumes of items that could not be weighed were determined and the mass was calculated from the product of the material density and the measured volume. Items such as carpets and lining material were determined in a similar manner. Masses of items surveyed were converted into energy units using the calorific value of the items. The total fire load of each compartment was then calculated.

Either the inventory or direct weighing method, if used alone, has several drawbacks that may impede the progress of the survey and also adversely affect survey results. This has 
resulted in the use of both methods for a number of surveys in the past. According to Culver [28], the inventory method (mass obtained from inventory of pre-weighed items) gives about $10 \%$ degree of error as compared to the direct weighing method and uncertainties between different surveyors can be in the range of $15-20 \%$. Culver attributed this to the fact that the inventory method requires some estimation by the surveyor (e.g. miscellaneous items and irregular piles of paper). The direct weighing method may reduce the degree of error associated with the inventory method. However, it is also not practical to use the direct weighing method for every item within the compartment. For instance, weights of built-in shelving or fixed furniture units may have to be determined by measuring their volume and using the density of the material to calculate their mass. In addition, for items that are made up of different material types, the percentage of each item have to be determined and quantified using the inventory method (mass based on measured volume and corresponding density). Thus, a survey method that combines the best features of the direct weighing and the inventory method should be advantageous. Items that can easily be weighed such as toys and books are directly weighed while inventorying is used for all items that cannot be easily weighed such as bulky furniture and fixed combustibles.

The use of the two methods in combination may still involve some amount of approximations. From the review of literature, the use of the combined method utilizes table of pre-weighed items in order to facilitate the survey process [31,39]. Identifying similar items within the compartment on the catalogue also involves some surveyor discretion. This is critical because no industrial standardization of furniture exists. Therefore, pre-weighed items can only be assumed to have similar characteristics to items within the compartment. Moreover; problems with privacy and disruption of business may impede the effectiveness of 
the method. The combination method which usually requires walk-down surveys may also involve an appreciable amount of time, especially when the extent of survey is large. Finally, the method of fire load calculation can affect the fire load data obtained from the survey. Barnett [37] used a gross calorific value of wood of $20 \mathrm{MJ} / \mathrm{kg}$ (wood at oven dry conditions). This may produce conservative fire load results as compared to surveys that used $18.5 \mathrm{MJ} / \mathrm{kg}$. Green [36] also assumed that all combustibles had the same calorific value as wood. This assumption may not hold for occupancies where the majority of the combustible are flammable liquids, plastics or upholstery. This is because these materials may have different burning characteristics than wood.

\subsubsection{The Questionnaire Method}

The Questionnaire method involves the distribution of questionnaires, usually with an explanatory sheet to occupants of a particular building use type. The method relies on indirect measurements through tabular look ups and furniture selection tables to compute fire loads. Fire loads are then estimated based on the calorific value of items sufficiently similar to the fuel package.

Kose et al [40] surveyed 216 single-family dwellings using the questionnaire approach. The questionnaires were sent to the occupants with a list of standard furniture and goods commonly found in dwellings. An explanatory sheet with figures of commonly used furniture was also added to the questionnaire. Additionally, occupants were required to do measurements of some items within the compartment not included in the figures shown on questionnaires. Clothing can be a significant source of fire load in dwellings. However, the 
survey did not sufficiently account for clothing stored within the compartments. Fire load was presented as the total weights of all combustibles per floor area, $\mathrm{kg} / \mathrm{m}^{2}$.

Bwayla [41] also conducted a survey of 74 single-family residences using the questionnaire approach. The survey utilized a web based questionnaire which was distributed through the internet, mainly to employees at the National Research Council of Canada. Similar to Kose et al.[40], questionnaires had a pre-determined list of household items which are commonly found in the living rooms. The web based questionnaire only allowed participants to choose quantity, size, materials and other pertinent attributes. The questionnaire did not make any provision for occupants to provide physical measurements of items within the compartment; nor were illustrations provided for the residents to identify furniture items easily. This means that configuration and size of items within the compartment were largely based on assumptions. The questionnaire also made provision for occupants to fill in type and size of the house, number of exits, number of windows in a specific room. Fire load was then calculated using highest values of weight and heat of combustion found for each grouping of furniture.

The use of the questionnaire method has several drawbacks that can significantly affect the fire load. A closer look at the Kose's questionnaire indicates that items such as bookshelves, wardrobes and drawers only had inputs for width, depth and height. This implies that gaps and cavities within those items were considered based on assumptions. It was not clearly stated how gaps and cavities were accounted for in the report. Fire load data obtained from questionnaires are usually qualitative. Information received from the questionnaires cannot be easily verified. Independent verification (i.e. verification of wrong measurements by residents in the case of Kose's method and inability to verify inaccurate furniture 
characteristics provided by residents) are some of the critical issues to be considered. Inability to verify data from questionnaires may have a greater degree of uncertainty as compared to the use of the inventory and the direct weighing method.

\subsubsection{Real Estate Website Review}

This method involves a review of real estate websites by an expert to determine fire loads based on architectural drawings and photographs. Weights of the combustible content of a particular compartment is developed using visible information from the photographs. Fire loads are estimated based on the calorific value of items sufficiently similar to the fuel package.

Bwayla et al. [43] conducted a fire load survey using information from a real estate web site. The scope of this study was limited to a local real estate website only. The survey used pictures and dimensions of spaces (likely from original floor plans). The method also used weights of furniture items through a survey of shops.

This method also has limitations to its effective use. Photographs provided only a limited view of the compartment which makes it very difficult to fully document the entire fire load within that compartment. Photographs also show tidy and ideal setting with no clutter conditions [43]. This therefore does not represent the real situation. In addition, the weight of all items within the compartment was based on estimates and assumptions. These assumptions may result in some degree of error. The advantage of this method is that it does not require the physical presence of the surveyor in the compartments being surveyed. The method is therefore not likely to disrupt business or invade privacy. 


\subsubsection{Evaluation of Fire Load Survey Methodologies}

The literature review presented in this thesis has identified several fire load survey methodologies: weighing, inventory, combination, questionnaires (directly distributed to occupants or web-based) and real estate websites review. The use of each survey methods has been found to have some degree of error and uncertainty that can significantly affect the effective use of that particular method and as a result affect quality of the fire load survey results. Table 2-8 provides a summary of these findings.

The inventory method is able to account for both fixed and content fire loads in a compartment. However, the literature review identified the following issues:

- The issue of whether to use derating factors has not been explicitly addressed in earlier fire load surveys.

- The use of the surveyor's discretion for approximating mass of miscellaneous and irregular shaped objects can have a significant impact on the quality of the survey results.

- The lack of standardization in the industry especially for domestic furniture, hence the use of transfer functions which presumes that items are standardized in terms of size and material may not be valid.

- Finally, incorrect identification and matching these functions (pre-weighed items) to similar items in compartments being surveyed can also affect the quality of survey results. 
Table 2-8 Summary Table

\begin{tabular}{ccccc}
\hline Method & Inventory & Direct Weighing & Questionnaire & $\begin{array}{c}\text { Website } \\
\text { Review }\end{array}$ \\
\hline $\begin{array}{c}\text { Derating factors } \\
\text { (combustibles in drawers and } \\
\text { cabinet) }\end{array}$ & $\begin{array}{c}\text { Not clearly } \\
\text { defined }\end{array}$ & Not clearly defined & NA & NA \\
\hline $\begin{array}{c}\text { Miscellaneous and irregular } \\
\text { shaped objects }\end{array}$ & $\begin{array}{c}\text { Based on } \\
\text { estimations and } \\
\text { assumptions }\end{array}$ & $\begin{array}{c}\text { Precise values } \\
\text { from weights of } \\
\text { items }\end{array}$ & NA & NA \\
\hline $\begin{array}{c}\text { Transfer functions } \\
\text { (relationship between the } \\
\text { weight and physical } \\
\text { characteristics of an object) }\end{array}$ & $\begin{array}{c}\text { Can be verified } \\
\text { by measuring } \\
\text { dimensions }\end{array}$ & $\begin{array}{c}\text { Based on } \\
\text { estimations and } \\
\text { assumptions }\end{array}$ & $\begin{array}{c}\text { Bastimations and } \\
\text { assumptions }\end{array}$ & $\begin{array}{c}\text { estimations } \\
\text { and } \\
\text { assumptions }\end{array}$ \\
\hline $\begin{array}{c}\text { Accounting for Fixed } \\
\text { Combustibles }\end{array}$ & $\begin{array}{c}\text { Precise values } \\
\text { from measured } \\
\text { dimensions }\end{array}$ & $\begin{array}{c}\text { Based on } \\
\text { estimations and } \\
\text { assumptions }\end{array}$ & NA & $\begin{array}{c}\text { Dependent on } \\
\text { design } \\
\text { drawings } \\
\text { availability }\end{array}$ \\
\hline Time needed for survey & Medium & Long & Relatively short & Short \\
\hline $\begin{array}{c}\text { Verification of survey results } \\
\text { by surveyor }\end{array}$ & Yes & Yes & No & No \\
\hline $\begin{array}{c}\text { Privacy concerns and } \\
\text { disruption of business }\end{array}$ & Yes & Yes & No & No \\
\hline
\end{tabular}

The ability to weigh every combustible item within a compartment would have resulted in the most accurate values for fire load. However, the weighing method has shortfalls that must be addressed.

- The use of this method cannot effectively account for fixed combustibles within a compartment because of the difficulty in weighing these items.

- It is difficult to determine the exact weight of combustibles by directly weighing items that are made up of non-combustibles and combustibles.

- Issues such as: number of people needed for the survey, use of special weighing apparatus, business disruption and privacy concerns must be carefully considered before using this method for any survey.

The 'questionnaire' and the 'web site review' methods are able to deal effectively with the issues of privacy concerns and disruption to business. In addition, both methods can be used 
for surveys that involve a very large sample size. However, these shortfalls have been identified:

- There are often difficulties in verifying information received from these methods (refer to Table 2-8).

- Fire loads are based on assumptions (website review).

- Information from the use of these methods is largely qualitative.

\subsubsection{Review of Fire Load Survey Results in Office Buildings}

Several data sets for fire/ fuel load have been reported in the past by different researchers. Table 2-9 presents survey results from different sources. In 1942, the National Bureau of Standards (NBS) [35] reported fire load results for several occupancies. Office occupancies had a mean fuel load of $2060 \mathrm{MJ} / \mathrm{m}^{2}$. Fifteen years after the NBS survey, Ingberg et al. [32] reported mean fuel load of $1270 \mathrm{MJ} / \mathrm{m}^{2}$. Ingberg et al.'s survey results were about $40 \%$ less than the NBS survey results. The reduction in fire loads may be attributed to a decline in combustible content in offices as a result of evolution in the furniture industry over the fifteen year period and the move from wooden to steel cabinets. The methodology used for the different surveys might have contributed to the differences in fire loads. However, the methodology for the surveys is not known.

In 1960, Baldwin et al. [33] reported results of fuel load survey for offices. The mean fuel load was $400 \mathrm{MJ} / \mathrm{m}^{2}$. The fire load values reported by Baldwin varied significantly from values reported by NBS in 1942 and Ingberg in 1957. It must be noted that Baldwin's survey was conducted in the United Kingdom whereas the NBS' survey was conducted in the United 
States. Differences in fire load values may be attributed to regional differences. Bryson and Gross [44] in 1967 reported mean fire load density value of $527 \mathrm{MJ} / \mathrm{m}^{2}$.

In 1975, Culver reported fire loads of offices from a survey that was conducted in the United States. The fire load density had a mean of $960 \mathrm{MJ} / \mathrm{m}^{2}$. This value was higher than Baldwin's values but close to Ingberg's values. Regional and cultural differences may account for the difference between Culver's values and Baldwin's values. In 1984, 9 years after Culver's survey, Barnett [37] conducted fire load surveys and reported mean fire load density in offices to be $440 \mathrm{MJ} / \mathrm{m}^{2}$. Regional, cultural, and survey methodology used may account for the variation in fire load densities of Barnett and Culver's values.

Kumar [30] in 1993 reported mean fire load density value of $348 \mathrm{MJ} / \mathrm{m}^{2}$ obtained from survey of offices in India. Cultural and regional differences were the major contributors to the differences in fire load values between Kumar and Culver's survey. The differences can also be attributed to technological advancement over the years. For example, the evolution of the furniture industry and the development of computer work stations for data storage had a major impact on fire loads within offices. The introduction of non-combustible material components (e.g. metal) in the furniture industry reduced the combustible components (e.g. wood) of most furniture. The use of electronic storage system replaced a large volume of paper documents. However, the introduction of computer work stations in most office increased plastic based combustible content.

Caro [34] in 1995 reported fire load density values with a mean of $1298 \mathrm{MJ} / \mathrm{m}^{2}$. In 1999 , Korpela [31] reported fire load density of $1000 \mathrm{MJ} / \mathrm{m}^{2}$ and in 2000, Yii [38] reported $950 \mathrm{MJ} / \mathrm{m}^{2}$. Fire load densities reported between 1995 and 2000 compares well to Ingberg 
and Culver's values reported in 1957 and 1975 respectively. The availability of electronic storage system has significantly reduced the use of paper format documents in recent times. This has contributed to a reduction in combustible paper contents in offices. However, there has been an increase in plastic contents. This is as a result of the increased use of plastic based items (e.g. computer work stations, printers, furniture, etc) in offices. Plastics are known to have high heat release (calorific value) which results in higher fire load densities. The high fire load density values reported by Korpela in 1999 and Yii in 2000 may be attributed to the increased plastic contents within offices.

Table 2-9 Fire Load Survey Results from Different Researchers

\begin{tabular}{|c|c|c|c|c|c|}
\hline Author & Method used & $\begin{array}{c}\text { Building } \\
\text { occupancy } \\
\text { type }\end{array}$ & $\begin{array}{l}\text { No of rooms } \\
\text { surveyed/area }\end{array}$ & Fire load values & References \\
\hline NBS (1942) & - & Offices & & $21.1 \mathrm{psf}\left(* 2060 \mathrm{MJ} / \mathrm{m}^{2}\right)-$ mean & 35 \\
\hline $\begin{array}{l}\text { Ingberg et al } \\
\text { (1957) }\end{array}$ & - & offices & & $13.0 \mathrm{psf}\left({ }^{*} 1270 \mathrm{MJ} / \mathrm{m}^{2}\right)-$ mean & 32 \\
\hline $\begin{array}{l}\text { Baldwin et al } \\
(1960)\end{array}$ & - & 93 offices & $\begin{array}{l}245 \mathrm{~m}^{2} \\
490 \mathrm{~m}^{2}\end{array}$ & $20 \mathrm{~kg} / \mathrm{m}^{2}\left(* 400 \mathrm{MJ} / \mathrm{m}^{2}\right)-$ mean & 33 \\
\hline $\begin{array}{l}\text { Bryson and } \\
\text { Gross (1967) }\end{array}$ & Combination & Office & $\begin{array}{c}6579 \mathrm{~m}^{2} \\
11701 \mathrm{~m}^{2}\end{array}$ & $\begin{array}{l}6.0 \mathrm{psf}\left(* 585 \mathrm{MJ} / \mathrm{m}^{2}\right)-\text { mean } \\
4.8 \mathrm{psf}\left(* 469 \mathrm{MJ} / \mathrm{m}^{2}\right) \text {-mean }\end{array}$ & 44 \\
\hline Culver (1975) & Inventory & Offices & 520 & $960 \mathrm{MJ} / \mathrm{m}^{2}$ & 28 \\
\hline $\begin{array}{l}\text { Barnett } \\
(1984)\end{array}$ & Combination & Offices & & $22 \mathrm{~kg} / \mathrm{m}^{2}\left({ }^{*} 440 \mathrm{MJ} / \mathrm{m}^{2}\right)$ & 37 \\
\hline Annon (1991) & - & Offices & - & $1120 \mathrm{MJ} / \mathrm{m}^{2}$ & 45 \\
\hline $\begin{array}{l}\text { Kumar and } \\
\text { Rao (1993) }\end{array}$ & Inventory & Offices & $\begin{array}{l}388 \text { Offices } \\
11720 \mathrm{~m}^{2}\end{array}$ & $\begin{array}{l}348 \mathrm{MJ} / \mathrm{m}^{2} \text { - average } \\
262 \mathrm{MJ} / \mathrm{m}^{2} \text { - S.D }\end{array}$ & 30 \\
\hline $\begin{array}{l}\text { Narayanan } \\
\text { (1995) }\end{array}$ & - & Offices & - & $680 \mathrm{MJ} / \mathrm{m}^{2}-$ mean & 46 \\
\hline \multirow[t]{2}{*}{ Caro (1995) } & $\begin{array}{c}\text { Direct } \\
\text { weighing }\end{array}$ & $\begin{array}{c}\text { Offices } \\
\text { (open plan) }\end{array}$ & & $\begin{array}{l}14.55 \text { psf } \quad\left(* 1420 \mathrm{MJ} / \mathrm{m}^{2}\right) \\
\text { mean } \\
3.98 p s f\left(* 388 \mathrm{MJ} / \mathrm{m}^{2}\right)-\text { S.D }\end{array}$ & 34 \\
\hline & & $\begin{array}{c}\text { Offices } \\
\text { (closed) }\end{array}$ & & $\begin{array}{l}13.29 \mathrm{psf}\left({ }^{*} 1298 \mathrm{MJ} / \mathrm{m}^{2}\right) \\
\text { mean } \\
1.43 \mathrm{psf}\left(* 140 \mathrm{MJ} / \mathrm{m}^{2}\right)-\mathrm{SD}\end{array}$ & 46 \\
\hline Yii (2000) & Combination & Offices & & $950 \mathrm{MJ} / \mathrm{m}^{2}$ - mean & 38 \\
\hline $\begin{array}{l}\text { Korpela } \\
(2000)\end{array}$ & Inventory & Offices & - & $1000 \mathrm{MJ} / \mathrm{m}^{2}-$ mean & 31 \\
\hline
\end{tabular}


From the discussion, fire load density values may vary due to various reasons. These include: survey methodology used, regional and cultural differences, economy, technological advancements, design and taste, construction, and evolution in the furniture industry.

\subsection{Fire Experiments}

Several fire tests have been conducted in the past to understand the dynamics of fire and the behavior of material as they are exposed to fire temperatures. The dynamics of a fire in the open is very different from a fire in a compartment. Important parameters often measured in fire experiments include: heat release rate, gas temperature, mass lose rate of the fuel, and rate of species generation (products of combustion). Those parameters can be used as inputs in characterizing the design fire of a particular fuel package within a compartment. Fire experiments provide input data for computer fire modelling and simulations which help fire

protection engineers to understand conditions in a fire compartment, egress of occupants in fire scenarios and response of detection, suppression systems, and expected impact on building elements.

\subsubsection{Fire Experiments in Office Buildings}

This section presents small scale cone calorimetry and full-scale tests conducted by different authors.

Madrzykowsk and Walton [47], conducted heat release rate experiments using two scales: bench scale experiments using the cone calorimeter and full-scale experiments in the Large fire facility at NIST. The methods utilize the same principles of oxygen depletion 
calorimetry to measure the heat release rate. The test protocol detailed in ASTM E 1354 was used for these Cone Calorimeter experiments. Two similar samples of each item were tested using the cone calorimeter, exposed to either an external heat flux of $35 \mathrm{~kW} / \mathrm{m}^{2}$ or $70 \mathrm{~kW} / \mathrm{m}^{2}$. A number of flammability properties were measured including heat release rate, specimen mass loss rate, smoke generation rate, combustion gas production, and ignitability. Table 210 gives values for HRR measured during the test.

Table 2-10 Heat Release Rate

\begin{tabular}{lcc}
\hline Exposure Heat flux & $35 \mathrm{~kW} / \mathrm{m}^{2}$ & $70 \mathrm{~kW} / \mathrm{m}^{2}$ \\
\hline Item & Avg. peak HRR $\left(\mathrm{kW} / \mathrm{m}^{2}\right)$ & Avg. Peak HRR $\left(\mathrm{kW} / \mathrm{m}^{2}\right)$ \\
\hline Carpeting & 260 & 380 \\
\hline Ceiling Tile (face-down) & 10 & 40 \\
\hline Ceiling Tile (face-up) & 70 & 90 \\
\hline Computer monitor case & 410 & 490 \\
\hline Letter tray & 1020 & 1170 \\
\hline Office Chair & 210 & 350 \\
\hline Paper (stacked flat) & 260 & 340 \\
\hline Paper (stacked on edge) & 210 & 250 \\
\hline Paper (staked flat - covered & 320 & 460 \\
with cardboard) & 1560 & 2970 \\
\hline Plastic Wastebasket & 110 & 160 \\
\hline Vinyl blinds & 340 & 460 \\
\hline Wall covering & 140 & 230 \\
\hline Workstation - side panel & 340 & 590 \\
\hline Workstation - work surface & &
\end{tabular}

In addition to the small scale experiments, two types of full-scale experiments were conducted. The first experiment was conducted with a single workstation. A small $50 \mathrm{~kW}$ natural gas fueled burner was used as an ignition source. The experiments were conducted under an exhaust hood. This test did not consider compartmentation effects.

The second type of experiment was conducted in a compartment that contained four workstations. In addition to the $50 \mathrm{~kW}$ natural gas burner in one of the workstations, the enclosure also had a $2 \mathrm{MW}$ heptane burner to simulate a fire exposure such as flames coming 
out of the doorway from a flashed-over room. Mass loss, heat flux and heat release rate were measured during the experiment.

\section{Single Work Station without Compartmentation Effect Experiment}

The work surface was a $32 \mathrm{~mm}$ thick composite made of a particleboard core with a face laminate on the top and a backer laminate on the bottom surface. The work surface provided a work area of $1.8 \mathrm{~m} 2$. The $50 \mathrm{~kW}$ natural gas fueled burner was used. Figure 2-6 shows a schematic description of the work station test.

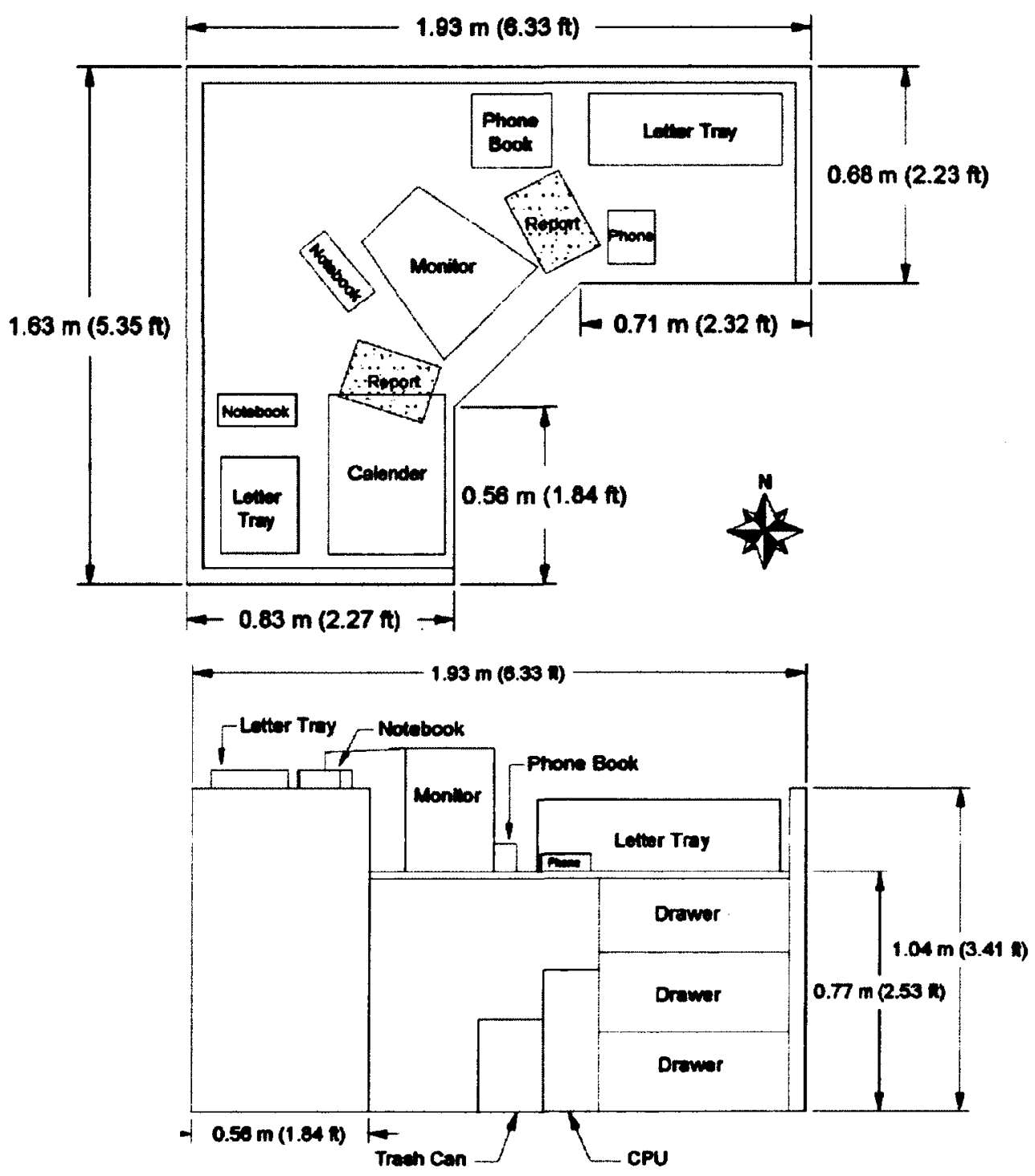

Figure 2-6 Schematic Plan and Elevation View of the Workstation [47] 
Figure 2-7 shows the HRR and Heat Flux measurements during the test. The heat release rate was observed to peak at $3.3 \mathrm{MW}$ at approximately $380 \mathrm{~s}$. Two distinct peaks of Heat Flux can be seen on the graph. The first small peak heat flux, $5.8 \mathrm{~kW} / \mathrm{m}^{2}$ was observed at approximately 160 seconds. The second peak, $28 \mathrm{~kW} / \mathrm{m}^{2}$, was at $380 \mathrm{~s}$, occurred when the office chair and most of the workstation were burning.
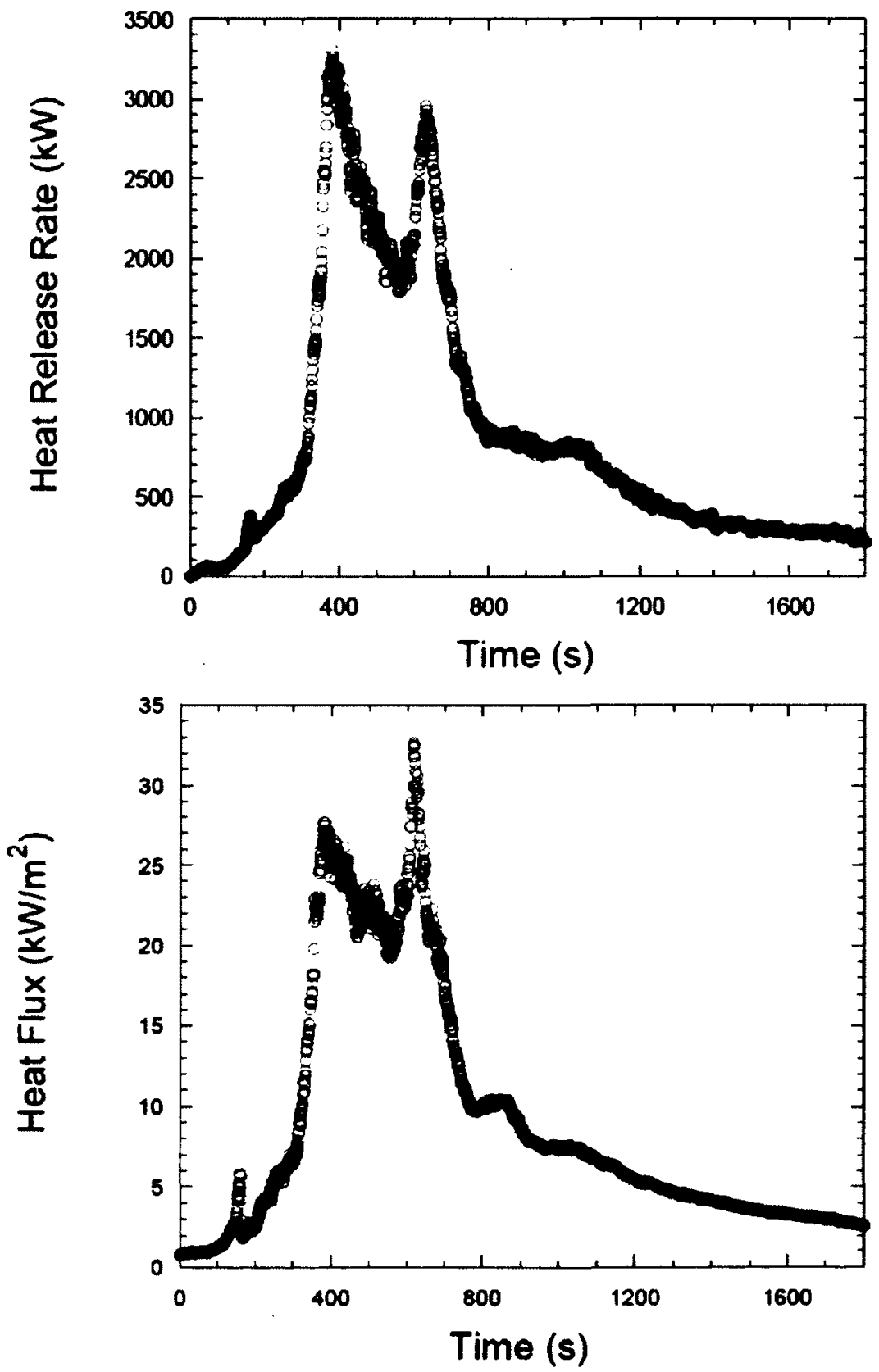

Figure 2-7 Heat Release Rate and Heat Flux Measurements [47] 
The mass loss (Figure 2-8) was observed to have some discontinuity. Madrzykowsk and Walton [47] reported that the discontinuity shown at approximately $650 \mathrm{~s}$ is the result of burning material and debris that fell off of the load cell.

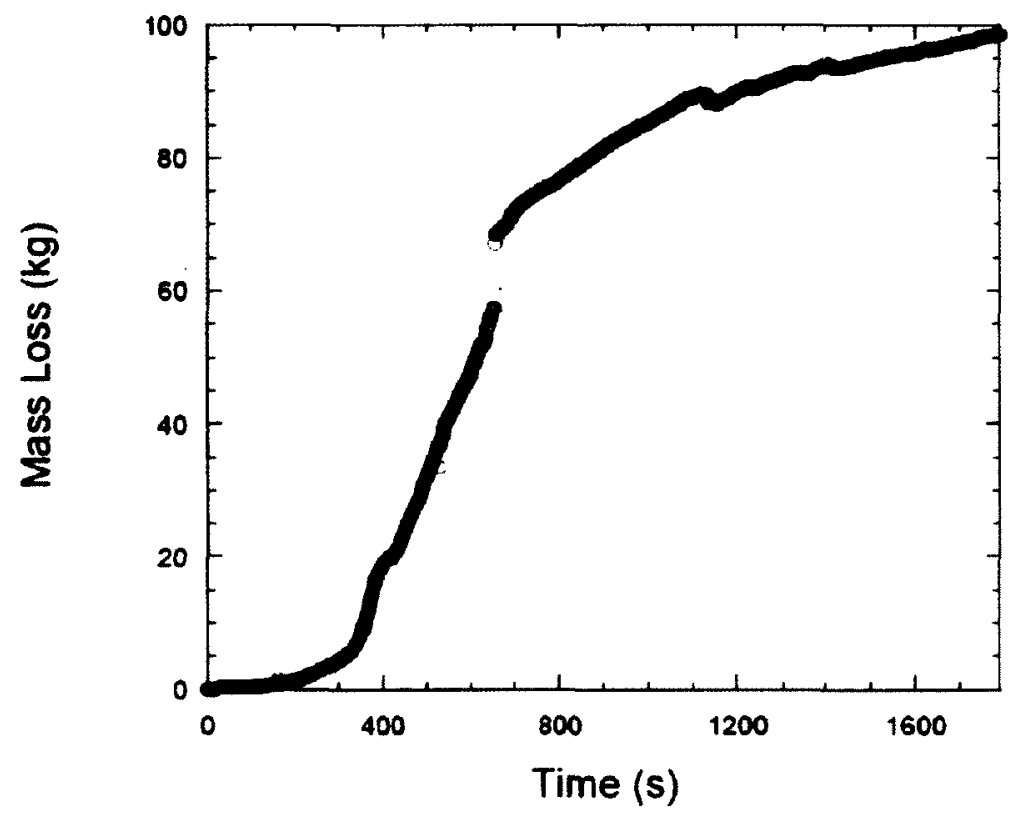

Figure 2-8 Mass Loss Rate Measurements [47]

\section{Enclosure Fire Experiment}

In this test, four workstations with fuel package similar to the single workstation were assembled in a compartment of $7.0 \mathrm{~m}$ wide $\mathrm{X} 7.3 \mathrm{~m}$ length $\mathrm{X}$ of $3.4 \mathrm{~m}$ height. A suspended ceiling assembly was installed at $2.7 \mathrm{~m}$ above the floor. The test area opened at one side as illustrated in the Figure 2-9. 

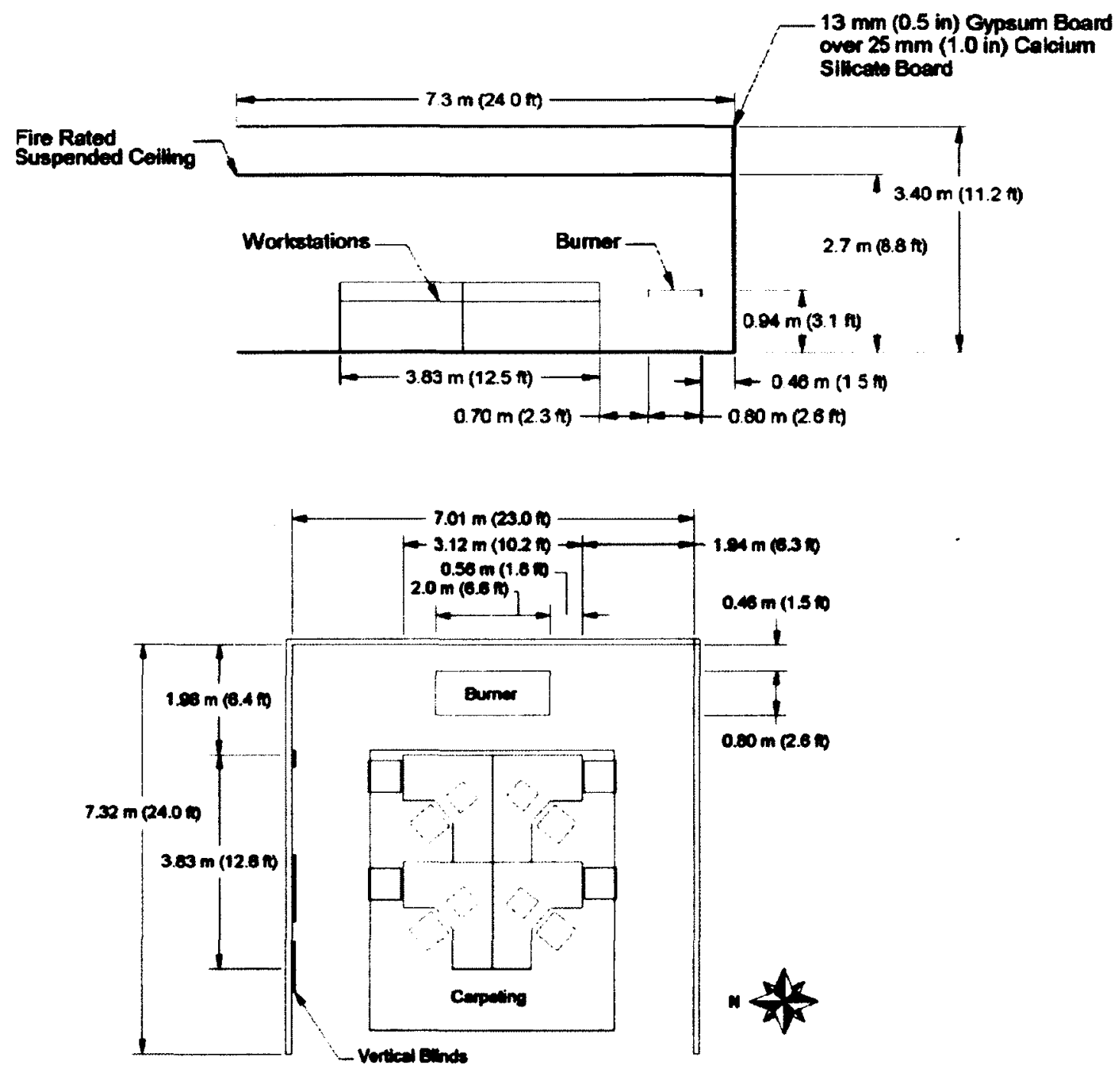

Figure 2-9 Schematic Layout of the Test Compartment, [47]

Figure 2-10 shows the rate of heat release in the compartment. For the first 60 seconds after ignition, the majority of the heat release was provided by the heptane burner. As the furnishings began to burn, the heat release rate increased and reached a peak of approximately $17 \mathrm{MW}$. The HRR finally peaks at approximately $19 \mathrm{MW}$. 


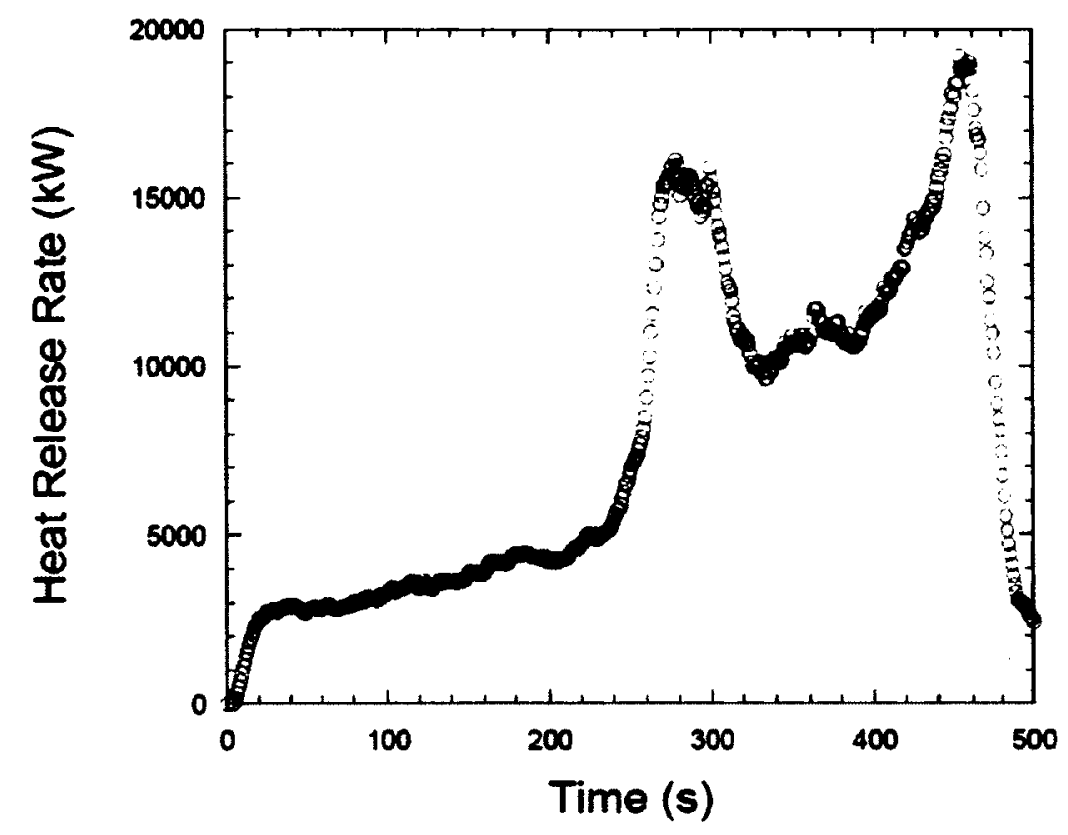

Figure 2-10 Heat Release Rate Measurements [47]

Figure 2-11 and Figure 2-12 show readings of temperature from thermocouples in different locations within the compartment. Similar to the HRR, several temperature peaks were recorded.
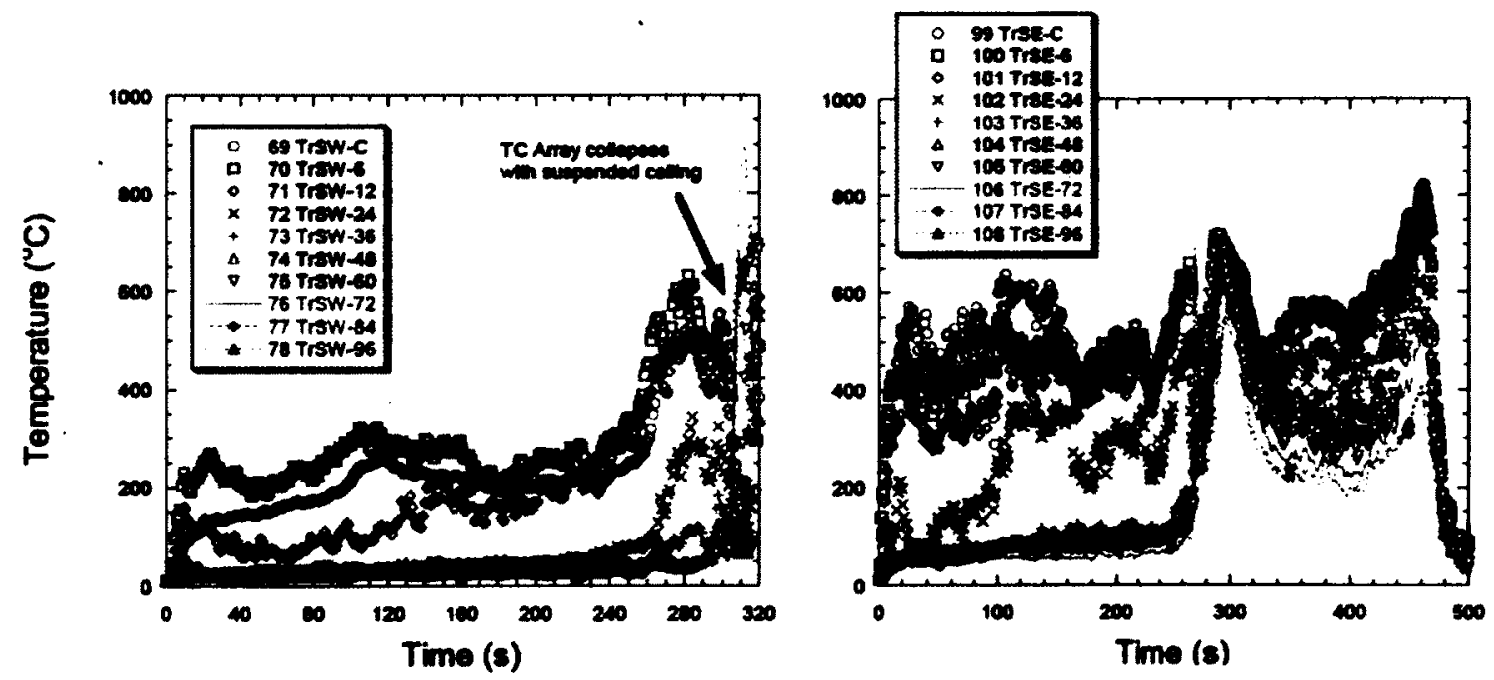

Figure 2-11 Gas Temperature Measurements within the Compartment (A), [47] 

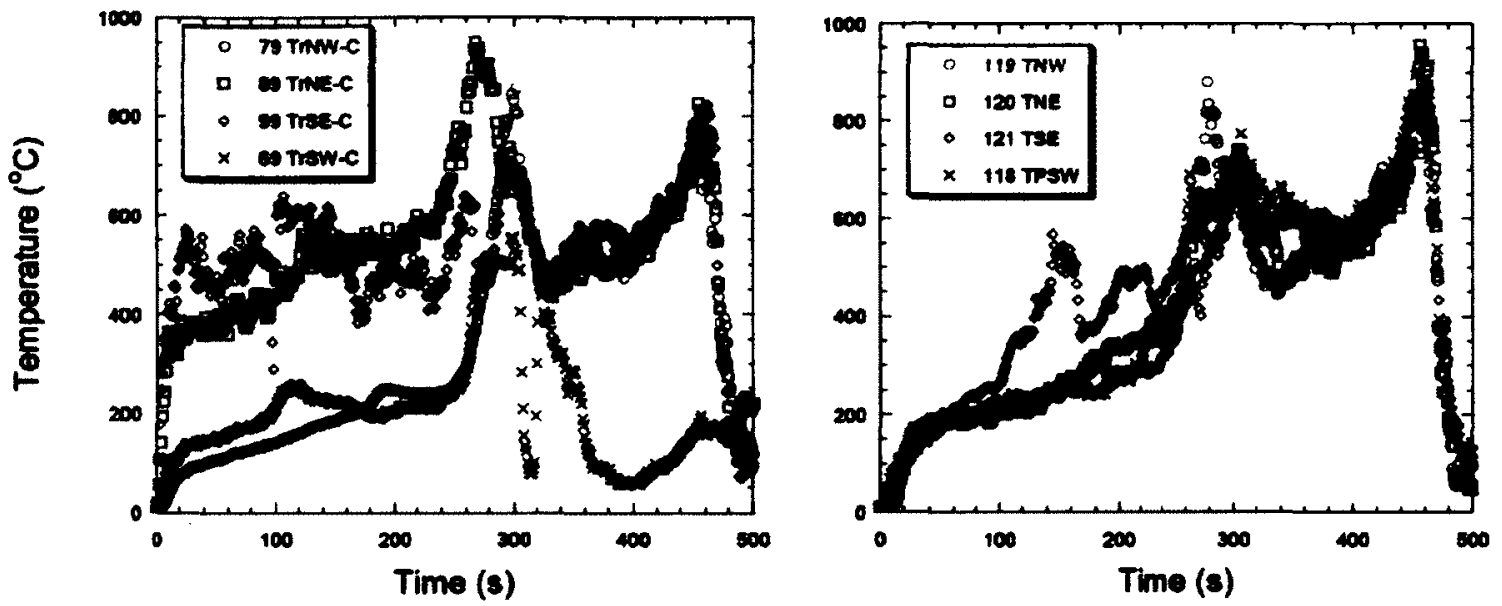

Figure 2-12 Gas Temperature Measurements within the Compartment (B), [47]

The maximum temperature did not go above $1000 \mathrm{C}$. Most of the thermocouples recorded highest temperature within $\approx 5$ minutes $(\approx 280$ seconds $)$ of the fire exposure. Higher temperatures, peaking at approximately $950^{\circ} \mathrm{C}$, were recorded in thermocouples closed to window openings, Figure 2-12. On the other hand, thermocouples located away from window openings recorded temperature peaks less than $800^{\circ} \mathrm{C}$, Figure 2-11.

Hamins et al [48] also conducted two large-scale test series plus various small-scale experiments to provide FDS with input data. The two large-scale test series involved fires in compartments and both series of experiments were conducted in the NIST Large Fire Laboratory. A liquid fuel spray burner was used to generate a fixed amount of energy in the compartments tested. The fire sizes tested were between $1.9 \mathrm{MW}$ and $3.4 \mathrm{MW}$ to assure that the structural components were immersed in flames and hot gases. Six fire experiments were conducted, and nearly 70 instruments were used to measure a number of important variables, including the heat release rate of the fire and the vertical profiles of gas phase temperatures. 
The results of the reduced-scale experiments were used as input for FDS, which was then used to simulate the fire spread and growth, heat release rate, and the thermal environment associated with the burning of multiple workstations in a compartment. A detail of the fuel package used for the work stations tested is shown in Table 2-11.

Table 2-11 Mass of Workstation Material by Type, [48]

\begin{tabular}{lccc}
\hline Material & $\begin{array}{c}\text { Mass } \\
(\mathbf{k g})\end{array}$ & $\begin{array}{c}\text { Function of } \\
\text { Total }\end{array}$ & $\begin{array}{c}\text { Effective Heat of Combustion } \\
(\mathrm{MJ} / \mathbf{k g})\end{array}$ \\
\hline Wood/laminate & 111.5 & 0.45 & 14 \\
\hline Paper & 63.7 & 0.25 & 14 \\
\hline Plastics & 39.3 & 0.16 & $16-38$ \\
\hline Carpet & 34.2 & 0.14 & 22 \\
\hline
\end{tabular}

The mass loss rates during two burning periods were recorded. Table 2-12 shows the mass loss of the three different work stations used in the test. Total mass loss and the mass loss rate are indicators of the fire intensity as materials burn and release heat.

Table 2-12 The Mass Loss Rate during the Rapid and Slow Burning Periods, [48]

\begin{tabular}{ccccccc}
\hline & \multicolumn{3}{c}{$\begin{array}{c}\text { Mass Loss Rate during the rapid burning } \\
\text { period, } \Delta \mathrm{t}_{\mathrm{r}}(\mathrm{kg} / \mathrm{s})^{\mathrm{a}}\end{array}$} & \multicolumn{3}{c}{ Mass Loss Rate during the slow burning } \\
period $\Delta \mathrm{t}_{\mathrm{s}}(\mathrm{kg} / \mathrm{s})^{\mathrm{a}}$
\end{tabular}

a. The standard relative uncertainty in the mass loss rate was estimated as 15 percent and 50 percent for the rapid and slow buming periods respectively b. Excludes test 5

The mass loss rate for workstations configured in which the combustibles were "shielded" from the fire was about 40 percent less than the mass loss rate for workstations burning in the standard configuration. 
The largest value of the heat release rate was almost $16 \mathrm{MW}$, Figure 2-13. The heat release rate measurements complemented the mass loss measurement results.

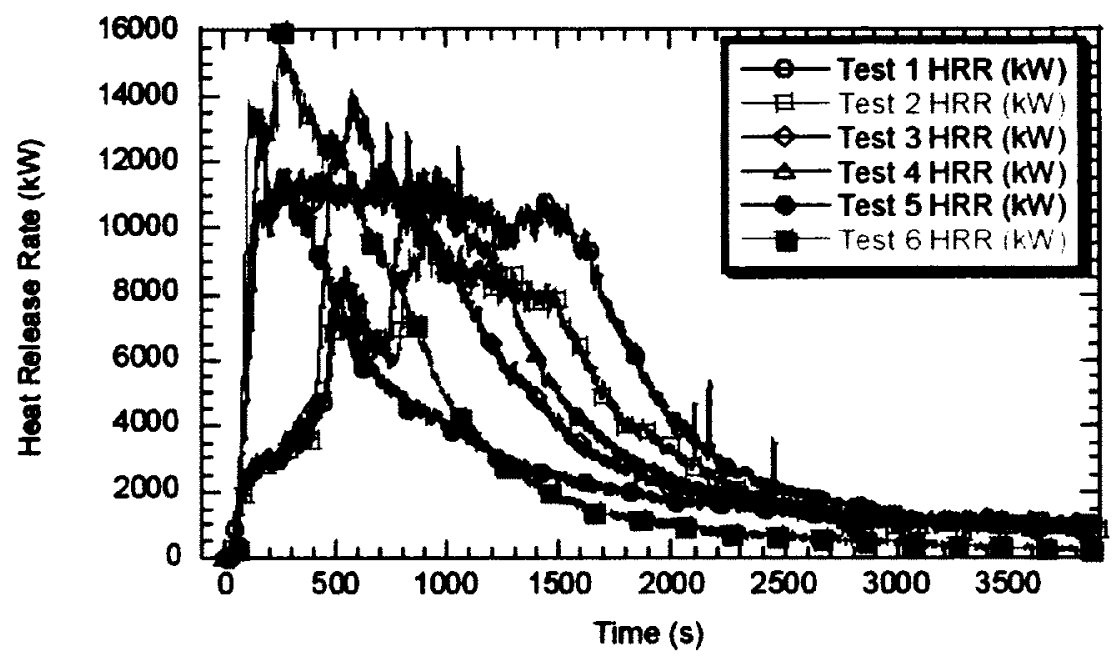

Figure 2-13 The Heat Release Rate as a Function of Time, [48]

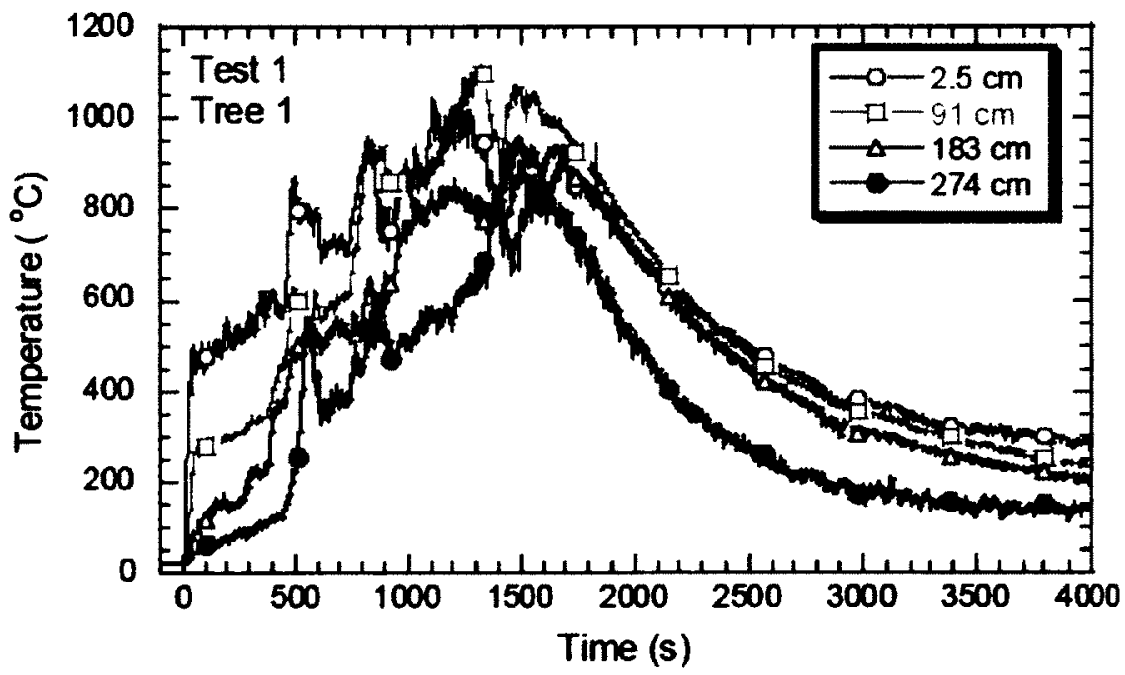

Figure 2-14 Bare Bead Thermocouple Measurements as a Function of Time at Different Locations

Temperature measurements were taken from thermocouples in different locations. The thermocouples closest to the ceiling obtained peak temperatures over $1000^{\circ} \mathrm{C}$ to $1100^{\circ} \mathrm{C}$, Figure 2-14. Hamins et al [48] observed that the compartment temperatures closer to the windows obtained the largest peak temperatures. 
The test also measured the upper layer concentration of $\mathrm{CO}_{2}, \mathrm{CO}$ and $\mathrm{O}_{2}$. Gas samples were extracted and analyzed to determine the volume fractions of $\mathrm{O}_{2}, \mathrm{CO}$, and $\mathrm{CO}_{2}$. The instrumentation required removing water from the samples, and the results are reported here on a dry basis. Figure 2-15 shows the volume fractions of $\mathrm{O}_{2}, \mathrm{CO}$, and $\mathrm{CO}_{2}$ on a dry basis as a function of time during Test 1 . The depletion in oxygen concentration saw a rise in carbon dioxide concentration.

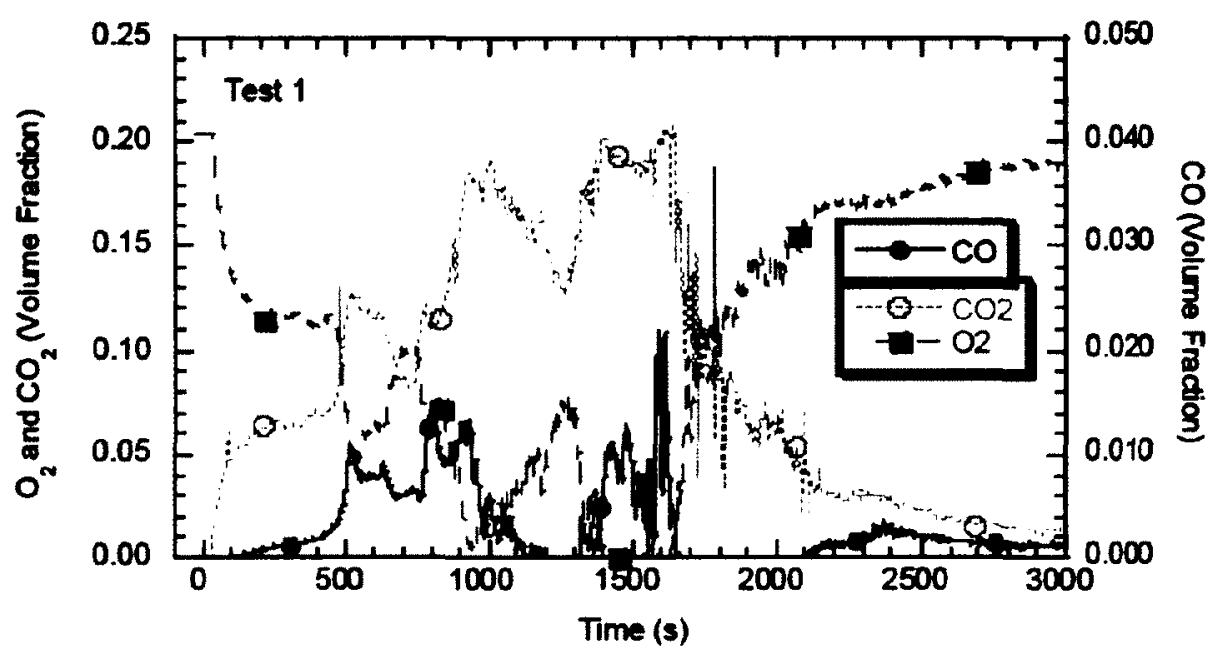

Figure 2-15 The Volume Fraction of $\mathrm{O}_{2}, \mathrm{CO}, \mathrm{CO}_{2}$ on a Dry Basis as a Function of Time, [48]

Lai et al [50] conducted full-scale office model experiments to explore the influence of ignition source location on fire spread. The office used for the experiment measured, $6 \mathrm{~m}$ length X $5 \mathrm{~m}$ width and $3.3 \mathrm{~m}$ high. The office had a door $(2.1 \mathrm{~m} \mathrm{X} 0.9 \mathrm{~m})$ and 2 fire resistant windows ( $2.4 \mathrm{~m} \mathrm{X} 1.2 \mathrm{~m}$ each). The total fire load used was approximately $15.4 \mathrm{~kg} / \mathrm{m}^{2}$ which comprised of fixed and content fire loads. Four different fire scenarios were investigated. Table 2-13 gives details of the 4 test conducted. 
Table 2-13 Fire Scenarios [50]

\begin{tabular}{|c|c|c|c|c|}
\hline Test & Opening & Movable Fire Load & Fixed Fire Load & Ignition Source \\
\hline 1 & $\begin{array}{l}\text { Single } \\
\text { Opening }\end{array}$ & $\begin{array}{l}200 \text { wood strips (a full- } \\
\text { sized crib) in the center }\end{array}$ & & $\begin{array}{l}\text { Central movable fire } \\
\text { load (a full-size crib) }\end{array}$ \\
\hline 2 & $\begin{array}{l}\text { Single } \\
\text { Opening }\end{array}$ & $\begin{array}{l}100 \text { wood strips (a half- } \\
\text { size crib) in the } \\
\text { northeastern and } \\
\text { southwestern corners }\end{array}$ & $\begin{array}{l}\text { North/South: tall cabinets } \\
\text { and upper hanging } \\
\text { cabinets }\end{array}$ & $\begin{array}{l}\text { Northeast and } \\
\text { Southwest movable fire } \\
\text { loads (two half-size } \\
\text { cribs) }\end{array}$ \\
\hline 3 & $\begin{array}{l}\text { Single } \\
\text { Opening }\end{array}$ & $\begin{array}{l}100 \text { wood strips (a half- } \\
\text { size crib) in the center } \\
\text { and in the southwestern } \\
\text { corner }\end{array}$ & $\begin{array}{l}\text { East/ West: lower } \\
\text { cabinets and plywood } \\
\text { walls }\end{array}$ & $\begin{array}{l}\text { Central movable fire } \\
\text { load (half-size crib) }\end{array}$ \\
\hline 4 & $\begin{array}{l}\text { Single } \\
\text { Opening }\end{array}$ & $\begin{array}{l}100 \text { wood strips (a half- } \\
\text { size crib) in the center } \\
\text { and in the northwestern } \\
\text { corner }\end{array}$ & & $\begin{array}{l}\text { Northwest movable fire } \\
\text { load (a half-sized crib) }\end{array}$ \\
\hline
\end{tabular}

Wood cribs were used as ignition sources. The experiments were carried out in a $10 \mathrm{MW}$ fire test facility. The facility consisted of a smoke collection bend, mixture tube, measurement section, exhaust bend and exhaust pipe. HRR was measured using the concept of oxygen consumption, which measures the consumption of $\mathrm{O}_{2}$ or generation of $\mathrm{CO} / \mathrm{CO}_{2}$ in combustion. The calculation is based on the observation that a constant amount of heat is released per mass unit of $\mathrm{O}_{2}$ consumed and $\mathrm{CO} / \mathrm{CO}_{2}$ generated.

Table 2-14 gives a summary of results from the 4 test conducted. Flashover occurred in the range of 450 seconds to 618 seconds with a HRR of $6.0 \mathrm{MW}$ to $7.3 \mathrm{MW}$.

Table 2-14 Experimental Results [50]

\begin{tabular}{lcccc}
\hline Test & $\begin{array}{c}\text { Sprinkler actuation } \\
\text { time } \\
(\mathrm{s})\end{array}$ & $\begin{array}{c}\text { Flashover } \\
\text { time } \\
(\mathrm{s})\end{array}$ & $\begin{array}{c}\text { Mass loss rate for } \\
\text { crib(s) near the time } \\
\text { of flashover }(\mathrm{kg} / \mathrm{s})\end{array}$ & $\begin{array}{c}\text { Max. } \dot{Q}_{o} \\
(\mathrm{MW})\end{array}$ \\
\hline 1 & 318 (S1 sprinkler) & 600 & 0.192 & 6.0 \\
\hline 2 & 139 (S2 sprinkler) & 618 & 0.192 & 6.0 \\
\hline 3 & 191 (S3 sprinkler) & Not occurred & n.a & 1.1 \\
\hline 4 & 99 (S1 sprinkler) & 450 & 0.165 & 7.3 \\
\hline
\end{tabular}


Figure 2-16 shows the distribution of HRR and time as measured in Test 1 and 2. Several different peaks of heat release at different times were observed. Both test recorded maximum heat release of approximately $6 \mathrm{MW}$.
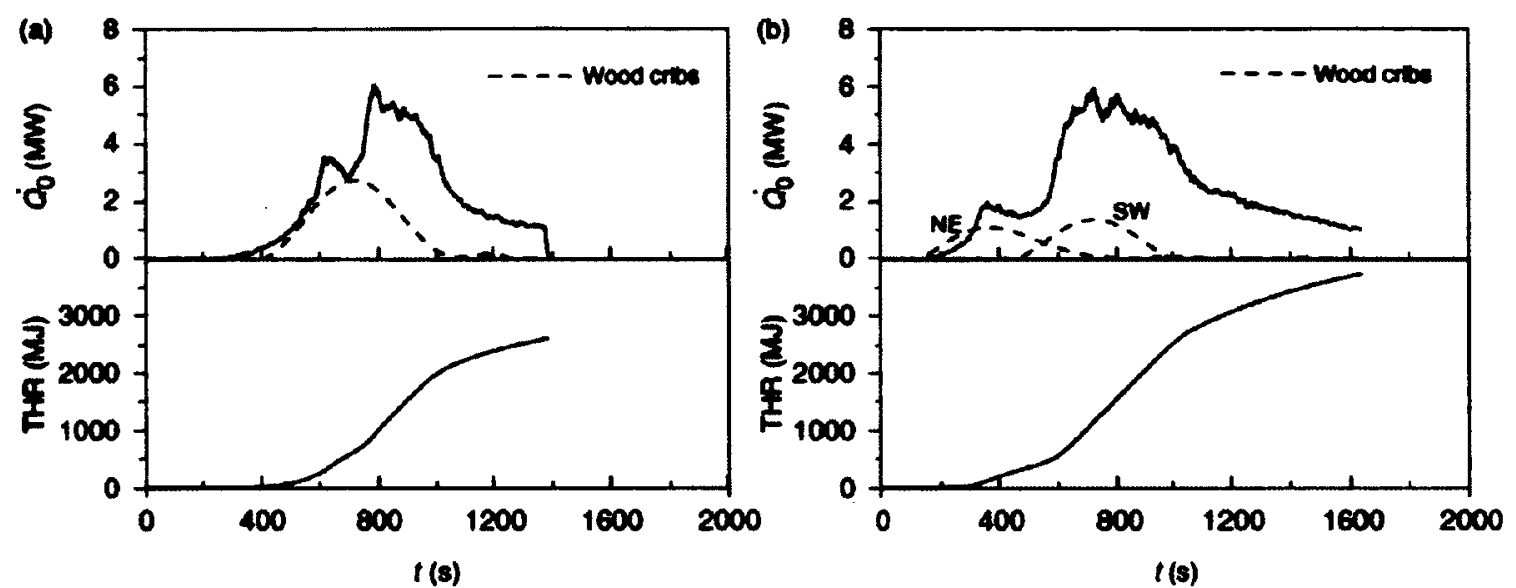

Figure 2-16 Heat Release Rate Profile [50]

Bennetts et al. [51] conducted small-scale and full-scale tests to study the ability of sprinklers to extinguish fires in closed and open offices. Offices were furnished as typical offices consisting of paper, wood and plastic furniture, nylon carpets, curtains and vinyl wall paper. The wood equivalent fire load in these tests was approximately $50 \mathrm{~kg} / \mathrm{m}^{2}$. It was observed from the tests that for fires within small offices sprinklers activated with a relatively small fire. This is because it takes a relatively longer time to heat the upper layer in a large room. The gas temperatures measured during the test were generally below $100^{\circ} \mathrm{C}$. This was because of the activation of sprinklers within the offices. 


\subsection{Computer Modelling}

As a result of the high cost of conducting fire experiments, several modelling programs have been developed for use in fire protection engineering. These include: Network models and Fire models (zone and field models).

\subsubsection{Network Models}

Network models calculate flow through buildings based on pressure differences between different sections of the building. Compartments are represented by nodes with specified characteristics and connected through links. A typical example of Network models is CONTAM, a multizone indoor air quality and ventilation analysis computer program. It is able to calculate building airflows and relative pressures between zones of the building [52]. CONTAM is useful for assessing the adequacy of ventilation rates in a building, for determining the variation in ventilation rates over time, for determining the distribution of ventilation air within a building, and for estimating the impact of envelope air-tightening efforts on infiltration rates. In fire protection engineering, CONTAM has been used extensively for the design and analysis of smoke management systems [52].

\subsubsection{Fire Models}

Fire models can be classified as being deterministic or probabilistic. There are two types of deterministic models: Zone and Field models.

\subsubsection{Zone Models}

The zone models divide each compartment into two spatially homogeneous volumes, a hot upper layer and a cooler lower layer. Conditions, such as temperature, pressure, and density 
in each zone, are assumed to be uniform across a particular zone. Each zone is modelled separately and then linked together through fluid dynamics and heat transfer equations. Typical examples of such phenomena include fire plumes, flows through doors, windows and other vents, radiative and convective heat transfer, and solid fuel pyrolysis [53]. CFAST (Consolidated Model of Fire and Smoke Transport) is a typical example of a zone model. The model can be used to predict the evolving distribution of smoke, fire gases and temperature within a fire compartment [54].

\subsubsection{Field Model (Computational Fluid Dynamics)}

Computational fluid dynamics (CFD) model have been developed and applied to fire research problems. CFD models have several advantages over zone models. The use of CFD models has allowed simulation in complex geometries, and the incorporation of a wide variety of physical phenomena. Unfortunately, the evolution of large eddy structures characteristic of most fire plumes is lost with such an approach, as is the prediction of local transient events.

Large Eddy Simulation (LES) techniques in fire applications is aimed at extracting greater temporal and spatial fidelity from simulations of fire performed on the more finely meshed grids allowed by ever faster computers. The phrase LES refers to the description of turbulent mixing of the gaseous fuel and combustion products with the local atmosphere surrounding the fire. According to the FDS manual [53], small-scale eddy motion can either be crudely accounted for or ignored.

Direct Numerical Simulation (DNS), solves the Navier-Stokes equations numerically without any turbulence model. The computational cost of DNS is very high, even at low Reynolds 
numbers. For the Reynolds numbers encountered in most industrial applications, the computational resources required by a DNS would exceed the capacity of the most powerful computers currently available [53].

\section{Fire Dynamics Simulator}

'Fire Dynamics Simulator (FDS), is a computational fluid dynamics (CFD) model of firedriven fluid flow. The model solves numerically a form of the Navier-Stokes equations appropriate for low-speed, thermally-driven flow with an emphasis on smoke and heat transport from fires. Lagrangian particles are used to simulate smoke movement, sprinkler discharge, and fuel sprays' [53]. FDS is able to compute Large Eddy Simulation (LES) and Direct Numerical Simulation (DNS). However, the default mode is LES [53].

The latest version of FDS, FDS 5 can be effectively used to model the following phenomena:

- Low speed transport of heat and combustion products from fire;

- Radiative and convective heat transfer between the gas and solid surfaces;

- Sprinkler, heat detector, and smoke detector activation.

FDS 5 includes the possibility for calculating the pyrolysis and burning rates on the basis of the reaction kinetics and material. According to Hietaniemi and Mikkola [11], this approach can produce good results regarding modelling of small scale experimental data.

\section{FDS Grid Size Optimization}

Bounagui, et al. [55], conducted numerical simulation using FDS to study fire performance of Canadian houses. The first part of the study was to investigate the effects of the grid sizes on the simulation results to determine an optimum resolution for future simulation. Three 
different fire sizes were used for the study with peaks ranging from 1500 to $3000 \mathrm{KW}$ following a t-square fire growth rate.

According to Bounagui, et al., CFD numerical simulations are computationally very expensive. The size of the computational grid has a significant impact on the computational time. It is therefore important to determine an appropriate grid size that will optimize the solution accuracy and time. The quality of the resolution depends on the size of the fire and size of the grid cell $[56,57]$. The resolution of the fire plume is often defined by equation [57],

$R^{*}=\frac{\max (\delta x, \delta y, \delta z)}{D^{*}}$

Equation 2.25

where,

$D^{*}=\left(\frac{Q}{\rho_{\infty C_{p} T_{\infty} \sqrt{8}}}\right)^{\frac{2}{5}}=\left(\frac{Q}{\rho_{\propto C_{p} T_{\infty} \sqrt{g D} D^{2}}}\right)^{\frac{2}{5}} D$

Equation 2.26

$D^{*}=$ characteristic plume length diameter, $\mathrm{m} ; Q=$ total heat release rate, $\mathrm{kW} ; \rho_{\infty}=$ density at ambient temperature, $\mathrm{kg} / \mathrm{m}^{3} ; C p=$ specific heat of gas, $\mathrm{kJ} / \mathrm{kg} \cdot \mathrm{K} ; T \infty=$ ambient temperature, $\mathrm{K} ; \mathrm{g}=$ acceleration of gravity, $\mathrm{m} / \mathrm{s}$, and $D=$ effective diameter, $\mathrm{m}$.

Previous research by Baum et al [58] have shown that the plume dynamics can only be accurately simulated if the resolution, $R^{*}=0.1$ or less. According to Bounagui, et al. [55], the ratio $D^{*} / \max (\delta x, \delta y, \delta z)$ is an indication of the number of cells in the fire region.

\subsection{Summary}

The selection of the design fire scenarios or design fires is an essential component in performance based Fire Safety Engineering (FSE) design. Design fire events are those fires 
that are expected to occur over the life of a building for which the building is expected to meet its design safety objectives.

\subsubsection{Fire Load Survey}

The literature review has found the fire load (often expressed in $\mathrm{MJ} / \mathrm{m}^{2}$ ) to be an important parameter in the determination of the design fire. Fire Load is often determined by conducting surveys. The following survey methodologies have been identified: weighing, inventory, combination, questionnaires (directly distributed to occupants or web-based) and real estate websites review. Each survey method has some degree of error and uncertainty that may affect survey results.

Fire load density values may vary as a result of different factors including: the fire load survey methodology, regional and cultural differences, economy, technological advancements, design and taste, construction, and evolution in the furniture industry. It must be noted that the focus of this thesis is on fire load survey methodology.

\subsubsection{Fire Experiments}

The literature review identified important fire protection parameters often measured in fire experiments to characterize a design fire. Those parameters include: Heat release rate, gas temperature, mass lose rate of the fuel, and rate of species generation (products of combustion). The fire experiments review in this thesis provided input data for the computer fire modelling.

Gas temperatures within compartments were found to have a similar profile as compared to the HRR profile. Gas temperature of the upper layer ranged between $400^{\circ} \mathrm{C}$ to $1100^{\circ} \mathrm{C}$. 
Higher temperatures were recorded close to window openings. In the sprinklered office fire experiments, it was observed that sprinklers activated earlier in small offices compared to larger offices. This is because it takes a relatively a longer time to heat the upper layer in a large room.

\subsubsection{Fire Modelling}

The high cost of conducting fire tests has necessitated the development and use of several computer fire modelling and simulation. The two types of deterministic fire models are zone and field (computational fluid dynamic) models. Computational Fluid Dynamic models (CFD) are the most widely used because it provides several advantages over zone models. For example, CFD models allow simulation in complex geometries, and the incorporation of a wide variety of physical phenomena. Fire Dynamics Simulator (FDS), an example of CFD model, can be effectively used to model several different phenomena: low speed transport of heat and combustion products from fire; radiative and convective heat transfer between the gas and solid surfaces; sprinkler, heat detector, and smoke detector activation. 


\section{3: Fire Load Survey}

\subsection{Introduction}

Fire loads and their pertinent characteristics represent an important input in the determination of the heat release rate (HRR) of design fires in a performance-based fire protection design. Knowledge of the type of materials that comprises the fire load within a compartment helps in the prediction of fire growth. The available fire load and its pertinent characteristics will help to calculate the HRR, and burning duration of a particular fuel package in a fire scenario. As discussed in previous sections, it is recognized that a fire load survey method has a significant impact on survey results, however, this impact has not been explicitly quantified. This section discusses a pilot fire load survey conducted for this research to explore the effects of using different survey methods on the survey results.

\subsection{Surveyed Buildings}

Fire load surveys were conducted in five different office buildings in the National Capital Region (Ottawa and Gatineau) of Canada between the years 2010 and 2011. The office buildings included private and federal government buildings. A total of 103 office rooms were surveyed (Table 3-1).

Table 3-1 Sample size of Rooms surveyed

\begin{tabular}{lc}
\hline Rooms & Number of Samples \\
\hline Enclosed offices & 27 \\
\hline Open offices (Cubicle) & 76 \\
\hline Total & 103 \\
\hline
\end{tabular}




\subsection{Survey Methodology}

Several survey methodologies have been identified in the literature [28-43]. Traditionally, surveys have been conducted by physically entering a building and listing the contents and their pertinent characteristics. Fire load surveys in a building may require measuring the mass of all combustibles and determining their corresponding calorific values. The mass of an item in a compartment may be determined by direct weighing (weighing method), or by determining the item's volume and identifying its density (inventory method). In most cases, a combination of the weighing and inventory method is used, in which some common items could be weighed, and the surveyor notes their inventory. The current study employs the use of weighing, inventory, combination, and questionnaire survey methodologies.

The data collection survey methods used in this study have been defined as follows:

- Weighing Method - mass obtained from direct weighing and estimations based on pre-weighed item table

- Inventory Method - mass obtained from direct measurement of volume with subsequent conversion based on corresponding density

- Combination Method - mass obtained from the use of the two methods described above.

- Questionnaire method - mass obtained from tabular look-ups based on hand delivered questionnaires

Fire Loads have been calculated based on conversion of mass into energy units (MJ) using the calorific value (heat release) of the corresponding material. To simplify the fire load estimations, the current survey made the following assumptions:

- combustible materials are uniformly distributed throughout the building 
- all combustible materials (with the exception of combustibles stored in enclosures) in the fire compartment would undergo total combustion.

\subsubsection{Survey Plan}

The survey was conducted in stages:

1. Preliminary visits were made to the buildings and a reconnaissance survey was conducted in selected rooms by random sampling of the compartments. This was done for the surveyors to become familiar with the fire loads expected and to update survey forms, questionnaires and furniture catalogue information. This helps the final survey to become more focused and less time consuming.

2. Survey questionnaires were prepared and sent to selected office occupants to document fire loads within their compartments without any direct supervision by a surveyor.

3. After the questionnaire method, a survey of fire loads was conducted using the weighing method. A table of pre-weighed furniture was used in situations where very large items of furniture could not be weighed. The catalogue was prepared from manufacturers' catalogues, visits to shops and direct contact with manufacturers through the internet. The necessary approximations were made in situations where office furniture did not directly match catalogue weights.

4. The fire load survey was conducted in the same compartments using the inventory method and finally a combination of the inventory and weighing methods was used. 


\subsubsection{Data Collection and Fire Load Calculations}

Survey forms were developed to facilitate the collection of data in an organized manner. Three different forms were developed, see Appendix F. To ensure consistency in data collection and comparison of results among methods, the three survey forms had similar sections. Each survey form had 6 sections as follows:

Section 1: office, building and survey information,

Section 2: type of office - closed or open plan,

Section 3: dimension and geometry of office space,

Section 4: number of openings and dimensions,

Section 5: fixed fire loads (floor, wall, and ceiling finish) and

Section 6: content fire loads.

The survey forms were designed to make the survey focused and less time consuming.

\subsubsection{Weighing Method}

The weighing method calculated the fire load based on measured weights of combustibles and the corresponding calorific value of the materials. A table of different furniture dimensions and weights was prepared and used in cases where very large items of furniture could not be weighed. The necessary approximations were made in situation where furniture items within the compartment did not match pre-weighed furniture items. Items (e.g. chairs and small tables) that could be weighed within the compartment were weighed. Other items such as computer monitors, keyboard, telephone, rubbish bins, paper binders and books of different dimensions were pre-weighed during the preliminary surveys. 
The fire load is calculated using the calorific value $\left(h_{c}\right)$ of different materials to convert measured weights into energy units (MJ). Fire load is presented in energy units per floor area $\left(\mathrm{MJ} / \mathrm{m}^{2}\right)$, commonly referred to as Fire load density. The calorific values (Heat of combustion) for different items and materials are presented in the Appendix C - Appendix E. For accurate results, materials were grouped under cellulosic (paper and wood), plastics and textiles. Table 3-2 shows the caloric values used in this research. Combustibles stored in enclosures were derated, see Table 3-3.

Table 3-2 Heat Release (MJ/kg) of Different Materials

\begin{tabular}{lccc}
\hline Material & $\begin{array}{c}\text { Minimum HR - } \\
\mathrm{MJ} / \mathrm{kg}\end{array}$ & $\begin{array}{c}\text { Average HR - } \\
\mathrm{MJ} / \mathrm{kg}\end{array}$ & $\begin{array}{c}\text { Maximum HR - } \\
\mathrm{MJ} / \mathrm{kg}\end{array}$ \\
\hline Paper & $13^{[48,59]}$ & $16.3^{[29]}$ & $21^{[48]}$ \\
\hline Wood & $17^{[35]}$ & $18.5^{[48]}$ & $20.0^{[48]}$ \\
\hline Plastic & $43^{[48]}$ & $\left.43.5^{[48}\right]$ & $44^{[48]}$ \\
\hline Textile & $17^{[48]}$ & $19^{[48]}$ & $21^{[48]}$ \\
\hline
\end{tabular}

Table 3-3 Derating Factors

\begin{tabular}{ccc}
\hline Container & Material & Derating Factors \\
\hline Desk, cabinet & Wood & 1.0 \\
& Metal & 0.1 \\
\cline { 2 - 3 } & Plastic & 1.0 \\
\cline { 2 - 3 } Shelve & Wood & 1.0 \\
& Metal & 0.75 \\
\cline { 2 - 3 } & Plastic & 1.0 \\
\cline { 2 - 3 } & Non-Combustible & 0.75 \\
\hline Misc-ltem &
\end{tabular}

Note: Derating factors were based on values used in Caro's report [34] 
The use of pre-weighed items data minimized the time used in surveying each compartment. In addition, the use of the pre-weighed items data reduced the amount of interruptions and disruption to business often associated with the direct weighing method. This is because weighing items such as office desks and other heavy items require special weighing equipments and a large team. The pre-weighed items data sheets had dimensions in addition to the weights. The dimensions were used to accurately match pre-weighed items to items within the compartment. These dimensions aided in approximation of weights where compartment items varied from that of the data sheets. This approach helps to reduce the level of uncertainty and degree of error that may have been associated with different surveyor's approximation bias.

It has been discussed in the literature review that the weighing method has several drawbacks. This includes how to account for the weights of items with more than one material composition, e.g. a chair with metallic legs and padded seats. To account for these items, pre-weighed similar items were split apart with each combustible component weighed. Additionally, the percentage of each combustible item to the total weight was noted and used during the survey.

\subsubsection{Inventory Method}

The inventory method calculated fire load based on the measured volume of items. Weights of items were obtained by multiplying the measured volume of combustibles by its density. This method did not use pre-weighed items and no direct measurement of mass was done. Similar to the direct weighing method, items were classified under cellulosic material (paper, cardboard and wood), plastics (includes foam based material), and textiles (includes carpets 
and clothing). Table 3-4 shows the density of different materials used in this research. Fire loads were calculated from the masses of the items and their corresponding calorific value, see Table 3-2. Similar to the weighing method, combustibles stored in enclosures were derated.

As discussed in the literature, accounting for irregular or complex shaped items are usually difficult with the use of the inventory method. Appropriate assumptions were made in cases where the volume of irregular shaped objects could not be easily measured. The volume of approximately $98 \%$ of all items within compartments could be measured. Therefore, inability to account for irregular shaped objects did not have a significant impact on the fire load densities calculated.

Table 3-4 Density of Different Materials

\begin{tabular}{llc}
\hline Material & \multicolumn{1}{c}{ Density } & Reference \\
\hline \multirow{2}{*}{ Paper } & $450 \mathrm{~kg} / \mathrm{m}^{3}$ or & Estimated \\
& $* 0.5 \mathrm{~kg} / \mathrm{m}^{2}$ & 31 \\
\hline \multirow{2}{*}{ Wood } & Minimum $-140 \mathrm{~kg} / \mathrm{m}^{3}$ & 60 \\
& Average $-450 \mathrm{~kg} / \mathrm{m}^{3}$ & 37 \\
& Maximum $-640 \mathrm{~kg} / \mathrm{m}^{3}$ & 60 \\
\hline \multirow{2}{*}{ Plastic } & Polystyrene $-1050 \mathrm{~kg} / \mathrm{m}^{3}$ & 61 \\
& Polypropylene $-905 \mathrm{~kg} / \mathrm{m}^{3}$ & 61 \\
\hline \multirow{2}{*}{ Textile } & Nylon carpet with synthetic backing - & 60 \\
& 2.4kg/m & 38 \\
\hline
\end{tabular}

* Paper with thickness not more than Imm

\subsubsection{Combination Method (Inventory and Weighing)}

This method used data from direct weighing method and inventory method. Weights of items were obtained from:

- directly weighing items, 
- pre-weighed item tables and

- measured dimensions with subsequent conversion into weights through the use of the item's material densities.

Fire load was calculated by the product of item weights and their corresponding calorific values. Similar to the two methods discussed above, items within the compartment were grouped into: Cellulosic, plastics and textile. Calorific values have been presented in Table 3-2. Items stored in enclosures (e.g. cabinets) were 'derated'.

\subsubsection{Questionnaire Method}

Fire load survey questionnaires were prepared and delivered by hand to occupants of selected offices. This method used tabular look-ups. Occupants of each office were supposed to select and identify the combustible items within their compartment using sets of items data sheets provided. The participants completed the questionnaires without direct supervision. Each questionnaire was accompanied by a description of how to complete the form, Appendix F. Unlike Kose's [40] method, this current method did not require participants to directly measure or weigh items. However, participants were required to estimate room dimensions and other combustible items that did not appear on the items data sheet. It must be noted that, other methods such as 'web-based questionnaires and 'web-reviews' may share similar approach ('piece count' and 'tabular look-ups') to the hand delivered questionnaire method used in this study. The scope of this study was limited to hand delivered questionnaires.

Weights of items within each compartment were determined by an experienced surveyor using filled questionnaire forms and pre-weighed items data sheets. Fire load density was 
calculated by converting calculated weights into energy units $\left(\mathrm{MJ} / \mathrm{m}^{2}\right)$ using the corresponding material calorific values.

Participation by building occupants in this method was poor. About $60 \%$ of the people contacted for participation in the questionnaire survey refused. Another $30 \%$ did not return the questionnaire that was sent to them. Furthermore, security concerns were a major problem during questionnaire distribution. Therefore, the survey was discontinued. As a result of this, the initial office building for the survey had to be changed. Another drawback to the questionnaire method was inaccurate and unreliable compartment dimensions estimated by the few participants who participated. 


\section{4: Fire Load Survey Data Analysis}

Data collected from the current survey was analyzed to determine the fire load, percentage contribution of different combustibles to the fire load, and the percentage differences between fire load values calculated based on various methods.

\subsection{Fire Load and Heat release rate}

Heat release rate (HRR) represents an important primary input in performance based fire safety engineering design. The rate of heat release can be evaluated using different fire test data and computer simulations [11]. Information on type, amount, arrangement, and characteristics of the combustibles (fire load) within a compartment is often needed as inputs for fire tests, and fire simulations. Therefore, uncertainties in fire load as a result of the type of survey methodology used may have a significant impact on the resulting HRR.

\subsection{Fire load Survey Methodologies}

Traditionally, fire load values using the direct weighing method would have been considered as the bench mark. This is because it gives direct measurements of combustible weights with least uncertainty in fire load predictions. However, it is very difficult in practice to use direct weighing method for every item within a compartment, especially with very large or fixed furniture items. As a result of this difficulty, the weighing method estimated the weights of heavy and fixed items based on knowledge of pre-weighed items. These approximations are likely to increase the degree of uncertainty associated with the traditional direct weighing method. As a result, the combination method which combines best practices from both the 
inventory and the weighing method has been considered as the bench mark. The combination method tends to reduce the amount of approximations associated with the singular use of either the weighing or inventory method.

\subsection{Floor Area}

Fire loads are often reported as energy density per unit floor area, $\dot{Q}\left(\mathrm{MJ} / \mathrm{m}^{2}\right)$, to enable extrapolation to compartments of different sizes. In this study, 103 office rooms, with a total floor area of $935 \mathrm{~m}^{2}$, in 5 different office buildings were surveyed. Enclosed offices had a total floor area of $406 \mathrm{~m}^{2}$. The 95th centile floor area per an enclosed office was $25.2 \mathrm{~m}^{2}$, with mean of $14.4 \mathrm{~m}^{2}$ and a standard deviation of $5.7 \mathrm{~m}^{2}$. On the other hand, cubicle offices had 95 th centile floor area of $11.1 \mathrm{~m}^{2}$, with a mean of $6.3 \mathrm{~m}^{2}$ and a standard deviation of $2 \mathrm{~m}^{2}$ per single office. Enclosed offices have larger floor areas as compared to open offices, Figure 4-1.

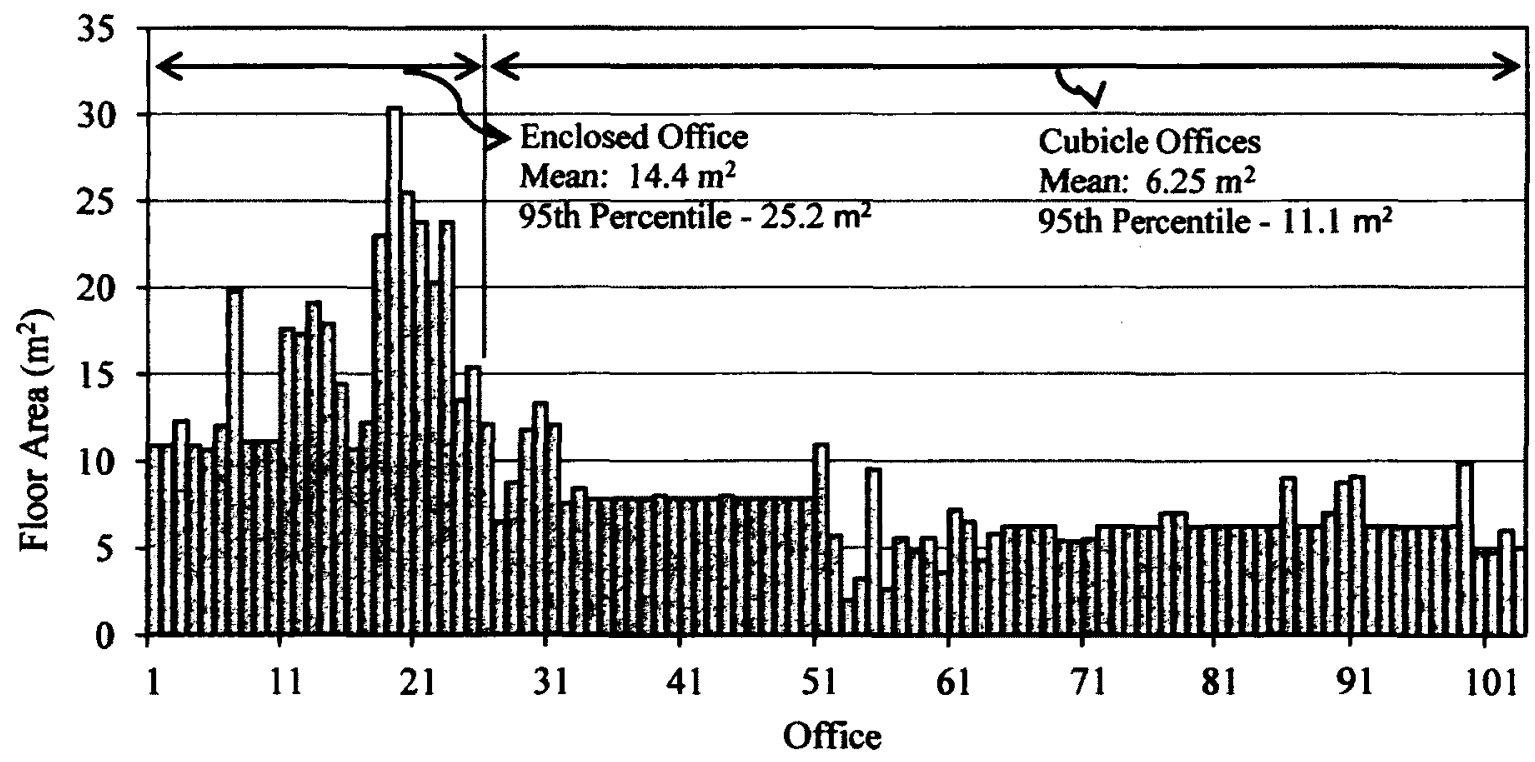

DFloor area

Figure 4-1 Floor Area of Enclosed and Cubicle Offices 


\subsection{Area of Opening}

Ventilation plays a significant role in fire development, as combustion cannot continue unless there is a supply of fresh air and exhaust of smoke gases. Theoretically, the size of the ventilation openings (ventilation factor, $F_{v}$ ) affects the HRR. It is known that the flow of air into a room is proportional to the ventilation factor [20]. In the current survey, enclosed offices had window openings with $95^{\text {th }}$ centile area of $4.4 \mathrm{~m}^{2}$, mean of $2.2 \mathrm{~m}^{2}$ and a standard deviation of $1.3 \mathrm{~m}^{2}$. Windows were made up of fixed glass with a metal frame.

\subsection{Statistical Analysis}

According to the literature $[31,59]$, fire load density is often considered to be lognormally distributed. This means that, the logarithm of the fire load density is expected to be normally distributed. The probability density function of lognormal distribution is given by Equation 4.1:

$f(q)=\frac{1}{q \sigma \sqrt{2 \pi}} e^{\frac{1}{2}\left(\frac{m q-\mu}{\sigma}\right)}$

Equation 4.1

where, the domain $0 \leq q<+\infty$, and $\sigma>0, \mu>0$.

Extreme value (General, Gumbel, and Weibull) distributions were also plotted (Figure 4-2). Previous studies [31] found extreme value (Gumbel and Weibull) to provide better fit as compared to the lognormal distribution. The Gumbel distribution is also known as type I extreme value distribution. The potential applicability of the Gumbel distribution to represent the distribution of maxima relates to extreme value theory which indicates that it is likely to be useful if the distribution of the underlying sample data is of the normal or exponential 
type. Some recent applications of Gumbel distribution have been for fire protection and insurance problems [62]. The probability density function of Gumbel is given by

$f(q)=\frac{1}{\beta} e^{-\frac{q-\mu}{\beta}} e^{e-\frac{q-\mu}{\beta}}$

Equation 4.2

Where, the domain $0<q<+\infty$

The Weibull distribution is the third extreme value distribution, also known as type III extreme value distribution. Korpela et al [31] found the Weibull distribution to fit well to the fire load data reported. The probability density function of 'Weibull distribution' is given by:

$f(q)=\frac{q}{\beta}\left(\frac{q}{\beta}\right)^{\alpha-1} \exp \left(-\left(\frac{q}{\beta}\right)^{\alpha}\right)$

Equation 4.3

Where, the domain $0 \leq q<+\infty$

The Kolmogorov-Smirnov test has been used as a goodness of fit test to estimate the plausibility of success using the Easy $\mathrm{Fit}^{\circ}$ statistical distribution software [73]. The Kolmogorov-Smirnov statistic quantifies a distance between the empirical distribution function of the sample and the cumulative distribution function of the reference distribution, or between the empirical distribution functions of two samples. The null distribution of this statistic is calculated under the null hypothesis that the samples are drawn from the same distribution (in the two-sample case) or that the sample is drawn from the reference distribution (in the one-sample case). The Kolmogorov-Smirnov test can also be modified to serve as a goodness of fit test as in the case of the current study [64].

Lognormal and Gumbel distribution fitted fairly well to fire load density values obtained from the inventory method, but the 'Weibull distribution' showed the best fit using the Kolmogorov Smirnov test. Unlike the inventory method, the Type I largest extreme value distribution (Gumbel) distribution presented the best fit for results obtained from the weighing method, followed by Weibulll distribution. Lognormal distribution also fitted quite 
well to the fire load density values. Similar to the weighing method, the Type I largest extreme value distribution (Gumbel) distribution presented the best fit for fire load density values obtained using the combination method, followed by Weibull distribution and the lognormal (see Figure 4-2).

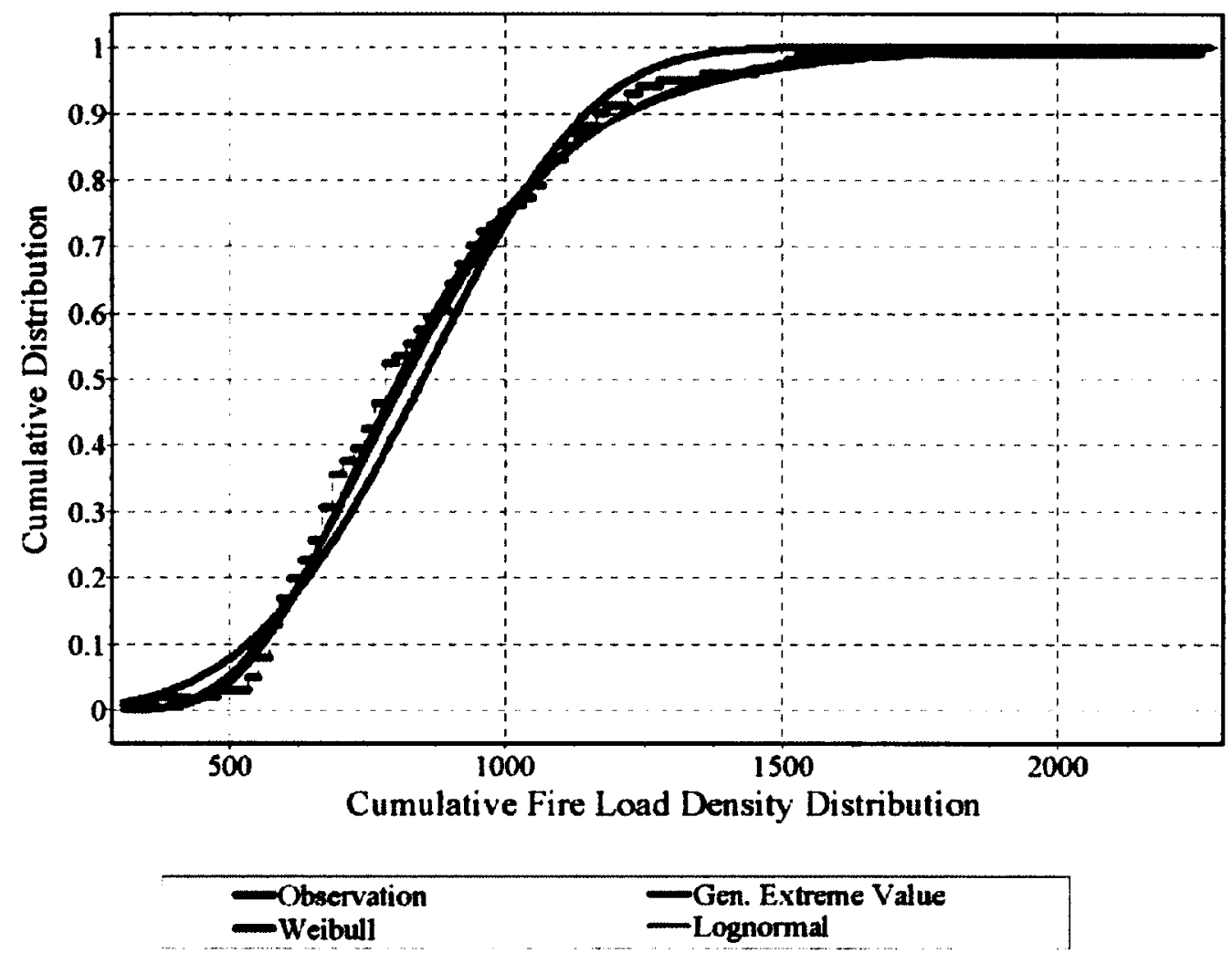

Figure 4-2 Cumulative Fire Load Density and Three Best Fit Curves

\subsection{Fire Load Data among Various Methodologies}

Fire load densities of all the 103 offices surveyed have been presented in Table 4-1. The $80^{\text {th }}$, $90^{\text {th }}$ and $95^{\text {th }}$ centile fire load density has been compared among different survey methodologies. The inventory method predicted higher fire load densities in most cases, followed by the combination method, while the weighing method predicted the lowest fire load density. This trend is shown in Figure 4-3. 
Table 4-1 Comparison of Fire Load Density

\begin{tabular}{lcccc}
\hline & $\begin{array}{c}\text { Sample } \\
\text { size }\end{array}$ & $\begin{array}{c}\text { Inventory } \\
\text { Method }\left(\mathrm{MJ} / \mathrm{m}^{2}\right)\end{array}$ & $\begin{array}{c}\text { Weighing } \\
\text { Method }\left(\mathrm{MJ} / \mathrm{m}^{2}\right)\end{array}$ & $\begin{array}{c}\text { Combination } \\
\text { Method }\left(\mathrm{MJ} / \mathrm{m}^{2}\right)\end{array}$ \\
\hline Mean & 103 & 852 & 530 & 557 \\
\hline $80^{\text {th }}$ centile & 103 & 1572 & 871 & 1077 \\
\hline $90^{\text {th }}$ centile & 103 & 1805 & 996 & 1182 \\
\hline $95^{\text {th }}$ centile & 103 & 2090 & 1188 & 1282 \\
\hline $\begin{array}{l}\text { Standard } \\
\text { Deviation }\end{array}$ & 103 & 484 & 257 & 286 \\
\hline
\end{tabular}

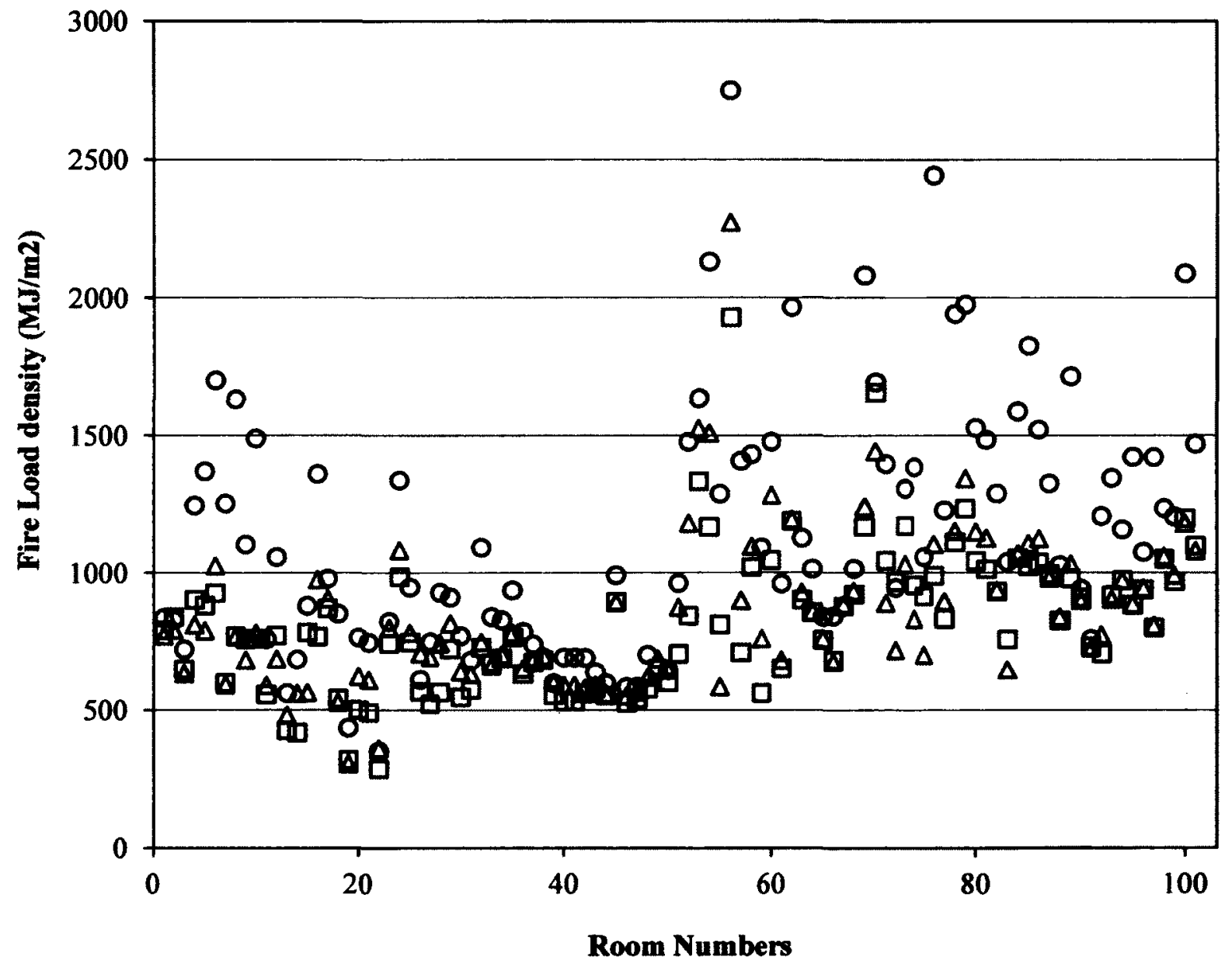

OInventory $\square$ Weighing $\Delta$ Combination (I. \& W.)

Figure 4-3 Correlation of Fire Load Density among Different Methods 


\subsection{Contribution of Different Materials to the Total Combustible Content}

This section presents a discussion on the contribution of different materials to the total combustible content. Fire load data are based on the combination method survey results.

The fire load within a particular compartment comprises several materials/products that each has a specific heat of combustion. Table 4-2 presents the contribution of different materials to the total combustible content.

Table 4-2 Contribution of Different Materials to the Total Fire Load

\begin{tabular}{|c|c|c|c|c|c|}
\hline \multirow{2}{*}{ Material } & \multirow{2}{*}{ Units } & \multicolumn{3}{|c|}{ Mean } & \multirow{2}{*}{$\%$ Contribution } \\
\hline & & $\mathrm{F}^{*}$ & $C^{*}$ & $T^{*}$ & \\
\hline \multirow[t]{3}{*}{ Paper } & $\mathbf{k g}$ & 5 & 68 & 73 & \multirow{3}{*}{24} \\
\hline & MJ & 86 & 1106 & 1192 & \\
\hline & $\mathrm{MJ} / \mathrm{m}^{2}$ & 12 & 89 & 101 & \\
\hline \multirow[t]{3}{*}{ Wood } & $\mathrm{kg}$ & 9 & 110 & 119 & \multirow{3}{*}{46} \\
\hline & MJ & 161 & 2048 & 2209 & \\
\hline & $\mathrm{MJ} / \mathrm{m}^{2}$ & 11 & 237 & 248 & \\
\hline \multirow[t]{3}{*}{ Plastic } & kg & 12 & 16 & 28 & \multirow{3}{*}{22} \\
\hline & MJ & 496 & 709 & 1205 & \\
\hline & $\mathrm{MJ} / \mathrm{m}^{2}$ & 68 & 95 & 163 & \\
\hline \multirow[t]{3}{*}{ Textile } & kg & 19 & 2 & 21 & \multirow{3}{*}{8} \\
\hline & MJ & 351 & 44 & 395 & \\
\hline & $\mathrm{MJ} / \mathrm{m}^{2}$ & 41 & 5 & 46 & \\
\hline \multirow{3}{*}{$\begin{array}{l}\text { Total Fire } \\
\text { Load }\end{array}$} & kg & 44 & 197 & 241 & \multirow{3}{*}{100} \\
\hline & MJ & 1095 & 3906 & 5001 & \\
\hline & $\mathrm{MJ} / \mathrm{m}^{2}$ & 131 & 426 & 557 & \\
\hline
\end{tabular}

Note: $\mathrm{F}^{*}=$ fixed fire load, $\mathrm{C}^{*}=$ content fire load, $\mathrm{T}^{*}=\mathrm{F}+\mathrm{C}$. Fire load values have been obtained using the combination method. Fixed combustibles represent all combustible materials on wall surfaces, floor, and ceiling, or part of the structure. Content combustibles refer to all other materials that can burn within the compartment. In the current survey, all fixed combustibles had single face exposure to the compartment.

\subsubsection{Percentage Contribution of Different Materials to the Fire Load Density}

Cellulosic materials (wood and paper based materials) had the highest contribution, $70 \%$, of the fire load density followed by plastics, $22 \%$. Textile materials (e.g floor tile, wall 
coverings, furniture cushion covers, jackets, and etc) contributed $8 \%$ to the total fire load density.

Previous surveys by Culver [28] in 1970 in the United States found wood and paper to contribute about $99.8 \%$ to the total fire load. Survey conducted by Kumar [30] in 1993, India, found paper and wood to contribute about $98.7 \%$. These values vary significantly from the current survey. This can be explained by the increase in the use of plastic materials (computers, printers and etc) within offices in recent times as compared to survey result conducted in the 70's. Kumar's survey results may also vary from the current survey as a result of regional differences. However, it must be noted that current office trends may vary significantly from offices during the 90 's.

\subsubsection{Percentage Contribution of Fixed and Content Combustibles}

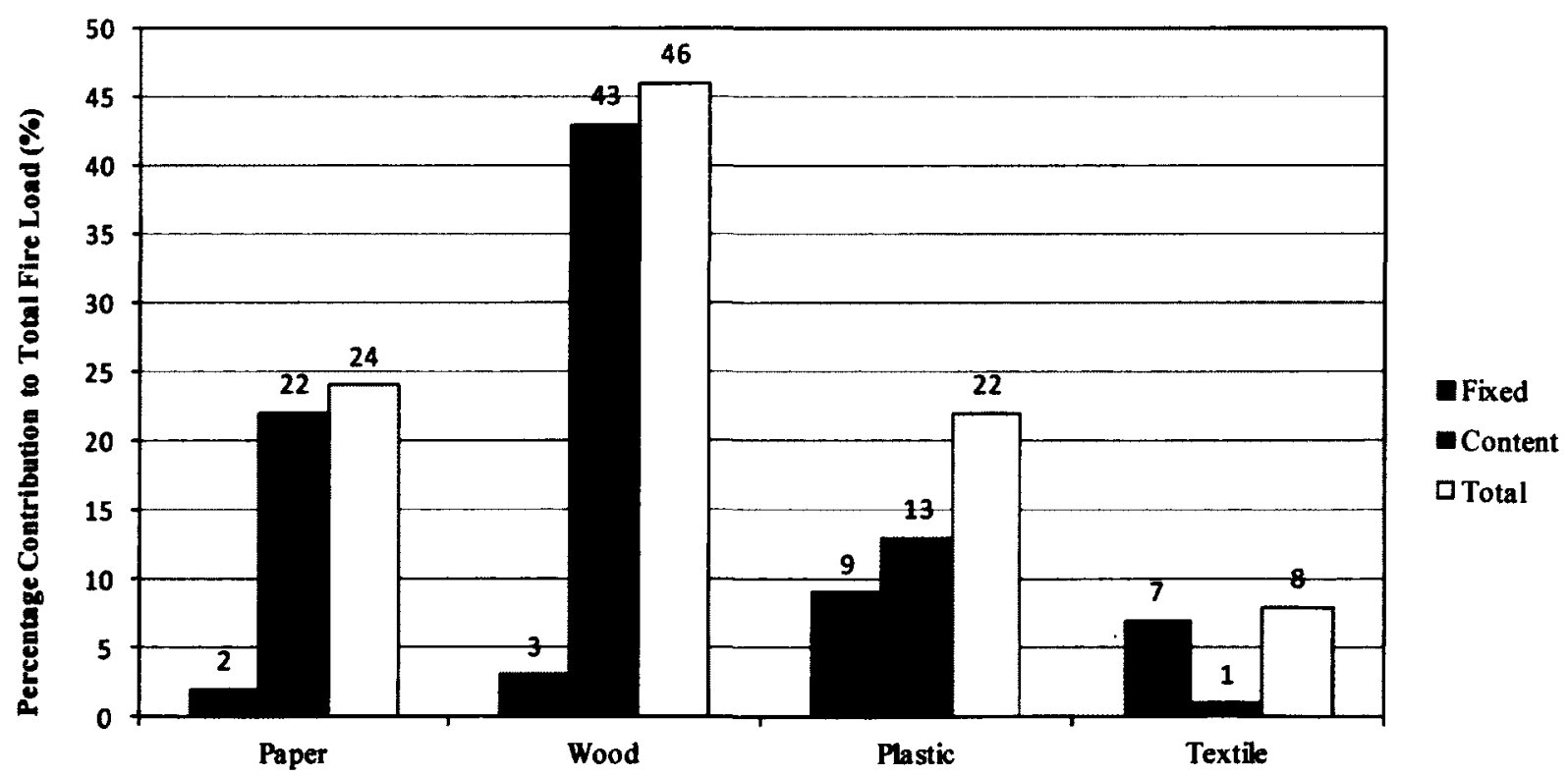

Combustible Material

Figure 4-4 Contribution of Fixed and Content Combustibles to the Total Fire Load 
Wood (content) contributed about $46 \%$ to the total fire load. None of the offices surveyed had wooden paneling as wall, ceiling or floor covering. Paper (Fixed and Content) contributed about $24 \%$ to the total fire load, Figure $4-4$.

Previous surveys [28] found paper and books to contribute about $40 \%$ to the total fire load. This varies significantly from the current survey. The survey was conducted in the 70's when very few electronic format data existed. The increase in the use of more electronic format files in offices today as compared to offices in the 70's confirms the current survey value of $24 \%$ paper contribution to the fire load.

In the current study, fixed combustibles contribute approximately $21 \%$ of the fire load density whereas content combustibles constituted $79 \%$. Culver made a similar observation. According to the report, fixed combustibles contribute $19.5 \%$ to the fire load whereas content (movable) combustibles contribute $80.5 \%$.

\subsection{Comparison of Fire Load Density Based on Inventory, Weighing and}

\section{Combination Method}

Data reduction was carried out to further analyze the fire load density distribution. This was done to understand the fire load distribution in specific room types. This section compares fire load densities based on room type: enclosed offices and cubicle offices.

\subsubsection{Mean, $95^{\text {th }}$ Percentile, and Standard Deviation}

Table 4-3 shows comparison of Mean and $95^{\text {th }}$ centile values for both inventory and weighing method. The inventory method predicted higher mean and $95^{\text {th }}$ centile values. The 
weighing method predicted the lowest values, whereas the combination method predicted values in-between the inventory and weighing method.

Table 4-3 Mean, $95^{\text {th }}$ centile and Standard Deviation Fire Load Densities $\left(\mathrm{MJ} / \mathrm{m}^{2}\right)$

\begin{tabular}{|c|c|c|c|c|c|c|c|c|c|c|}
\hline \multirow[b]{2}{*}{ Room } & \multirow[b]{2}{*}{ 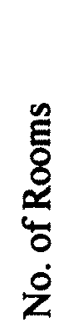 } & \multicolumn{3}{|c|}{ Mean $\left(\mathrm{MJ} / \mathrm{m}^{2}\right)$} & \multicolumn{3}{|c|}{$95^{\text {th }}$ centile $\left(\mathrm{MJ} / \mathrm{m}^{2}\right)$} & \multicolumn{3}{|c|}{$\begin{array}{c}\text { Standard } \\
\text { Deviation }\left(\mathrm{MJ} / \mathrm{m}^{2}\right)\end{array}$} \\
\hline & & 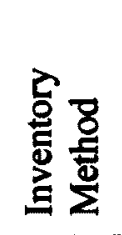 & 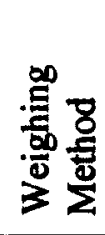 & 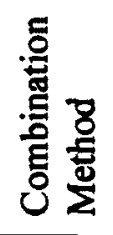 & 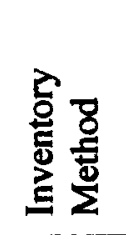 & 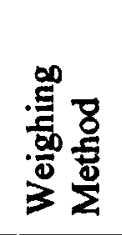 & 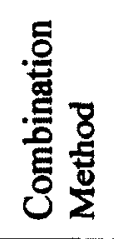 & 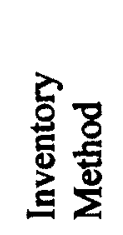 & 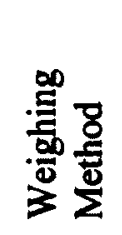 & 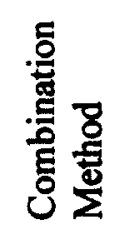 \\
\hline $\begin{array}{l}\text { Enclosed Offices } \\
\left(95^{\text {th }} \text { centile Floor }\right. \\
\left.\text { Area }=25 \mathrm{~m}^{2}\right)\end{array}$ & 27 & 905 & 758 & 685 & 1664 & 922 & 1016 & 368 & 193 & 189 \\
\hline $\begin{array}{l}\text { Cubicle offices } \\
\left(95^{\text {th }} \text { centile Floor }\right. \\
\left.\text { Area }=11 \mathrm{~m}^{2}\right)\end{array}$ & 76 & 1165 & 850 & 873 & 2202 & 1207 & 1385 & 505 & 261 & 290 \\
\hline $\begin{array}{l}\text { Percentage } \\
\text { Difference }\end{array}$ & - & 22 & 11 & 22 & 24 & 23 & 26 & - & - & - \\
\hline
\end{tabular}

Cubicle offices had higher fire loads densities $\left(\mathrm{MJ} / \mathrm{m}^{2}\right)$ as compared to enclosed offices. The percentage difference had an average of $25 \%$. The differences in fire load densities between cubicle offices and enclosed offices may be attributed to the total combustible content (MJ) and/ or the impact of the total floor area. It is worth noting that the total combustible content (MJ) of enclosed offices was higher than cubicle offices, Table 4-4. Therefore, higher fire load densities of the cubicle offices cannot be attributed to the total combustible content. On the other hand, enclosed offices had larger floor areas as compared to cubicle offices. The $95^{\text {th }}$ centile floor area of enclosed offices and cubicle offices was $25 \mathrm{~m}^{2}$ and $11 \mathrm{~m}^{2}$ respectively. Larger floor areas (enclosed offices) resulted in lower fire load densities whereas lower floor areas (cubicle offices) resulted in higher fire load densities. Similar observations have been reported in previous literature [42]. 
Table 4-4 Mean, $95^{\text {th }}$ centile and Standard Deviation Fire Load (MJ)

\begin{tabular}{|c|c|c|c|c|c|c|c|c|c|c|}
\hline \multirow[b]{2}{*}{ Room } & \multirow[b]{2}{*}{ 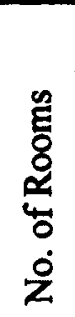 } & \multicolumn{3}{|c|}{ Mean (MJ) } & \multicolumn{3}{|c|}{$95^{\text {th }}$ centile (MJ) } & \multicolumn{3}{|c|}{ Standard Deviation(MJ) } \\
\hline & & 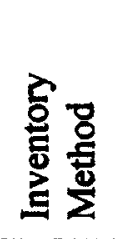 & 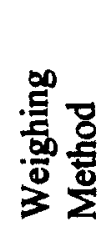 & 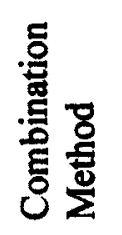 & 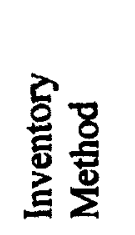 & 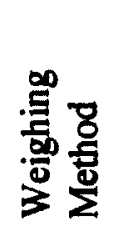 & 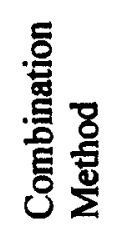 & 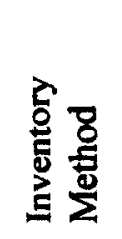 & 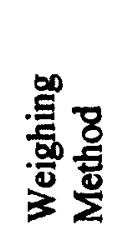 & 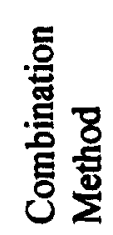 \\
\hline $\begin{array}{l}\text { Enclosed } \\
\text { Offices }\end{array}$ & 27 & 14972 & 9800 & 10044 & 20665 & 13355 & 15666 & 4395 & 2496 & 2912 \\
\hline $\begin{array}{l}\text { Cubicle } \\
\text { Offices }\end{array}$ & 76 & 7939 & 5577 & 5692 & 12519 & 8096 & 8822 & 2656 & 1430 & 1522 \\
\hline
\end{tabular}

\subsubsection{Percentage Difference between Inventory and Weighing Method}

The difference between the $95^{\text {th }}$ centile of the fire load density of the weighing and inventory method was found to be about $45 \%$. The differences between fire load density of the inventory method and the weighing method may be attributed to the use of material densities to convert measured volume to masses when using the inventory method and approximations associated with the use of each method, Table 4-5. The type of office (cubicle or enclosed office) had no significant impact on the percentage difference between the methods.

Table 4-5 $95^{\text {th }}$ centile Fire Load Density of Inventory and Weighing Method

\begin{tabular}{|c|c|c|c|c|c|}
\hline & Sample & $\begin{array}{c}\text { Inventory } \\
\text { Method }\end{array}$ & $\begin{array}{l}\text { Weighing } \\
\text { Method }\end{array}$ & & \\
\hline Room & size & $\begin{array}{c}95^{\text {th }} \text { centile } \\
\left(\mathrm{MJ} / \mathrm{m}^{2}\right)\end{array}$ & $\begin{array}{c}95^{\text {th }} \text { centile } \\
\left(\mathrm{MJ} / \mathrm{m}^{2}\right)\end{array}$ & $\begin{array}{c}\text { Difference } \\
\left(\mathrm{MJ} / \mathrm{m}^{2}\right)\end{array}$ & $\begin{array}{c}\text { Difference } \\
(\%)\end{array}$ \\
\hline $\begin{array}{l}\text { Enclosed } \\
\text { Offices }\end{array}$ & 27 & 1664 & 922 & 742 & 44 \\
\hline $\begin{array}{l}\text { Cubicle } \\
\text { Offices }\end{array}$ & 76 & 2202 & 1207 & 995 & 45 \\
\hline
\end{tabular}


Example 1 presents a correlation between fire load density values obtained using weighing method (WM) and the inventory method (IM). The correlation has been developed based on percentage differences presented in Table 4-5.

\section{Example 1}

$$
\begin{aligned}
& \mathrm{WM}=\mathrm{IM}-44.5 \% \mathrm{IM} \\
& \mathrm{WM}=\mathrm{IM}(1-44.5 \%) \\
& \mathrm{WM}=0.56 \mathrm{IM} \text { or } \mathrm{IM}=\mathrm{WM} / 0.56
\end{aligned}
$$

Culver [28] reported difference between mean room loads from the use of inventory (use of transfer functions based on pre-weighed items) and weighing method. The difference between the values of the two methods varied from about $0.1 \%-30 \%$ with an average of $10 \%$.

It must be noted that Culver compared mean values of total room loads (i.e. combustible and non-combustible) from 14 sample offices. The inventory method developed by Culver was also different from the method used in this study. The current study calculated weights based on density and physical characteristics (volume) of items whereas Culver calculated weights based on transfer functions and mean values of pre-weighed items.

\subsubsection{Percentage Difference between Inventory and Combination Method}

The difference between the fire load density of the combination method and inventory method was found to be about $38 \%$, see Table 4-6. 
Table 4-6 $95^{\text {th }}$ centile Fire Load Density of the Combination and Inventory Method

\begin{tabular}{lccccc}
\hline Room & No. of & $\begin{array}{c}\text { Inventory } \\
\text { Method }\end{array}$ & $\begin{array}{c}\text { Combination } \\
\text { Method }\end{array}$ & & \\
\cline { 3 - 6 } & Rooms & $\begin{array}{c}95^{\text {th }} \text { centile } \\
\left(\mathrm{MJ} / \mathrm{m}^{2}\right)\end{array}$ & $\begin{array}{c}95^{\text {th }} \text { centile } \\
\left(\mathrm{MJ} / \mathrm{m}^{2}\right)\end{array}$ & $\begin{array}{c}\text { Difference } \\
\left(\mathrm{MJ} / \mathrm{m}^{2}\right)\end{array}$ & Difference (\%) \\
\hline $\begin{array}{l}\text { Enclosed } \\
\text { Offices }\end{array}$ & 27 & 1664 & 1017 & 648 & 38 \\
\hline $\begin{array}{l}\text { Cubicle } \\
\text { Offices }\end{array}$ & 76 & 2202 & 1385 & 817 & 37 \\
\hline
\end{tabular}

Note: Percentage Difference $=((\mathrm{IM}-\mathrm{CM}) / \mathrm{IM}) \times 100$.

Example 2 presents a correlation between the fire load density values obtained using combination method (WM) and the inventory method (IM). The correlation has been developed based on percentage differences presented in Table 4-6.

Example 2

$$
\begin{aligned}
& \mathrm{CM}=\mathrm{IM}-38 \% \mathrm{IM} \\
& \mathrm{CM}=\mathrm{IM}(1-35 \%) \\
& \mathrm{CM}=0.62 \mathrm{IM} \text { or } \mathrm{IM}=\mathrm{CM} / 0.62
\end{aligned}
$$

Uncertainties in fire load density values of the inventory method may be attributed to: i) difficulties in accounting for irregular shaped objects and ii) the use of inaccurate combustible densities to convert measured volume into weights. High level of uncertainty may arise in occupancies where majority of the combustible content have irregular geometric configuration. In this study, irregular shaped items formed less than $5 \%$ of the total combustible content. Hence, uncertainties with the inventory method may not be attributed to that. It must be noted that, despite the small contribution of irregular shaped items, the combination method was effective by the use of weighing method for such items. On the other hand, inability to correctly identify and match material densities when using he inventory method may result in a significant uncertainty and increase the degree of error 
associated with the use of the survey method. The combination method also uses the inventory method, however, it must be noted that the inventory was used for fixed and heavy furniture items. Those items constitute less than $30 \%$ of the total combustibles. In addition, densities of combustible materials were grouped into cellulosic (paper and wood), plastics, and textiles. This therefore reduces the level of uncertainty associated with material densities of the combination method.

\subsubsection{Percentage Difference between Combination and Weighing Method}

Overall, the combination method predicted fire load densities very close to the weighing method. Despite this, the difference between the fire load density of the weighing and combination method was found to vary between $9 \%-13 \%$, with a mean percentage difference of $10 \%$, Table $4-7$.

Table 4-7 $95^{\text {th }}$ centile Fire Load Density of Combination and Weighing Method

\begin{tabular}{lccccc}
\hline Room & No. of & \multicolumn{2}{c}{$\begin{array}{c}\text { Weighing } \\
\text { Method }\end{array}$} & $\begin{array}{c}\text { Combination } \\
\text { Method }\end{array}$ & \\
\cline { 3 - 6 } & Rooms & $\begin{array}{c}95^{\text {th }} \text { centile } \\
\left(\mathrm{MJ}^{2} \mathrm{~m}^{2}\right)\end{array}$ & $\begin{array}{c}95^{\text {th }} \text { centile } \\
\left(\mathrm{MJ} / \mathrm{m}^{2}\right)\end{array}$ & $\begin{array}{c}\text { Difference } \\
\left(\mathrm{MJ} / \mathrm{m}^{2}\right)\end{array}$ & $\begin{array}{c}\text { Difference } \\
(\%)\end{array}$ \\
\hline $\begin{array}{l}\text { Enclosed } \\
\text { Offices }\end{array}$ & 14 & 922 & 1017 & -94 & -9.3 \\
\hline $\begin{array}{l}\text { Cubicle } \\
\text { Offices }\end{array}$ & 26 & 1207 & 1385 & -178 & -12.9 \\
\hline Note: Percentage Difference $=((\mathrm{WM}-\mathrm{CM}) / \mathrm{WM}) \times 100$ & & &
\end{tabular}

\section{Example 3}

$$
\begin{aligned}
& C M=W M+10 \% W M \\
& C M=W M(1+10 \%) \\
& C M=1.1 W M \text { or } W M=C M / 1.1
\end{aligned}
$$


Example 3 presents a correlation between the fire load density values obtained using combination method (WM) and the weighing method (IM). The correlation has been developed based on percentage differences presented in Table 4-7.

\subsection{Comparison of Fire Load Density Among Three Different Survey}

\section{Methodologies}

The discussions above provided percentage differences in fire load data sets among different survey methodologies. Example 1 to 3 provided conversion factors between different methodologies based on the percentage differences presented in Table 4-5 to Table 4-7.

Figure 4-5 provides a chart for the conversion of fire load density from one survey methodology to another. Sample calculations have been provided and illustrated on the chart. The chart has been developed based on the conversion factors provided in Example 1 to 3 and applies to fire load densities (obtained from combination Method) within the range of $250 \mathrm{MJ} / \mathrm{m}^{2}$ to $2300 \mathrm{MJ} / \mathrm{m}^{2}$. Interpolation may be used for values that fall outside the range. 


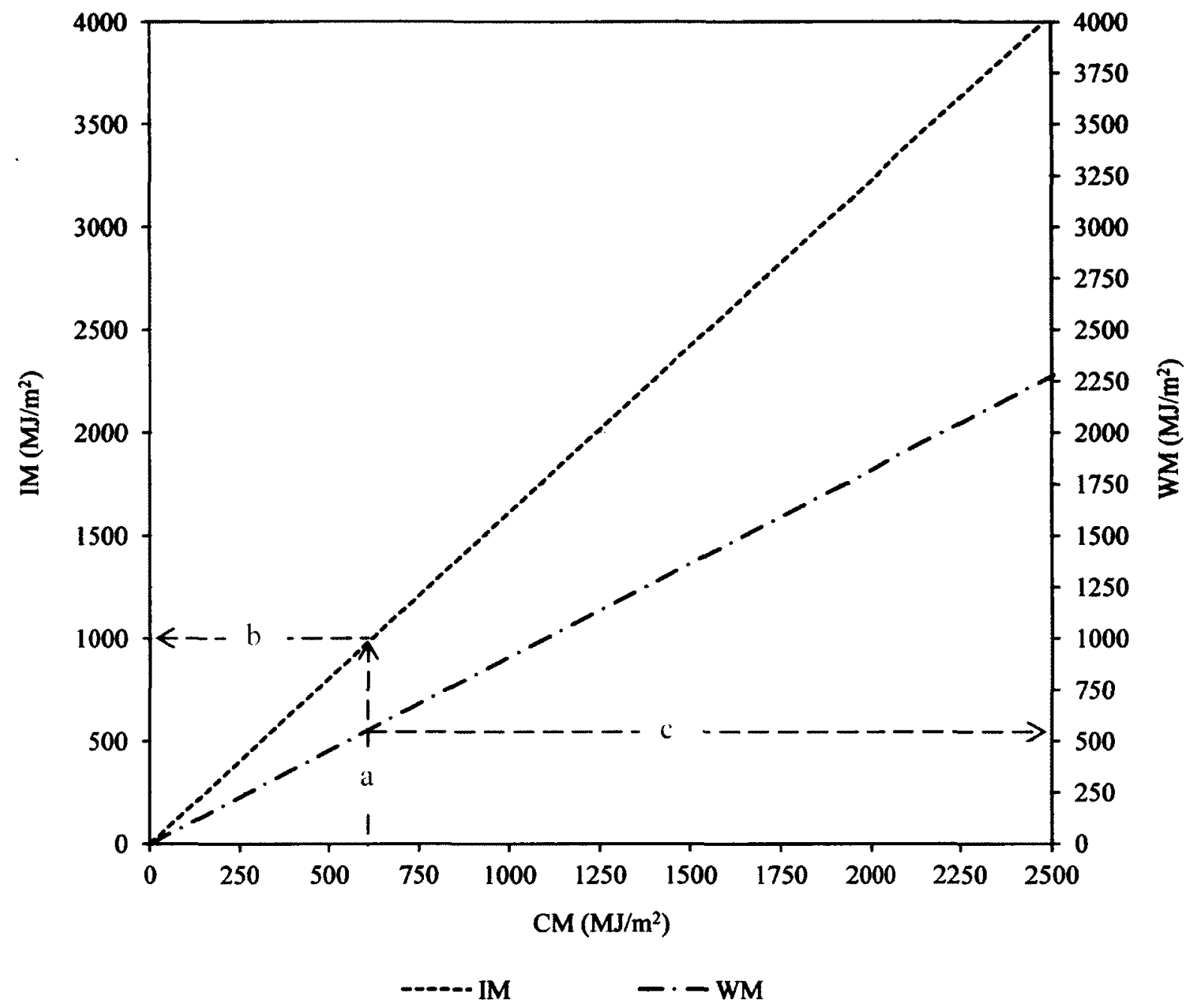

Note: To convert Fire load density from CM to IM, follow line $a-b$, to convert from CM to WM, follow $a-c$

Figure 4-5 Conversion of Fire Load Density among Three Different Survey Methodologies

Sample Calculations

(i) From Example 2, $C M=0.62 I M$

Given $C M=620 \mathrm{MJ} / \mathrm{m}^{2}$

$I M=\frac{620}{0.62}=1000 \mathrm{MJ} / \mathrm{m}^{2}$ (From chart, follow $a$ to $b$ ) 
(ii) From Example 3, $C M=1.1 W M$

Given $C M=620 \mathrm{MJ} / \mathrm{m}^{2}$

$W M=\frac{620}{1.1}=564 \mathrm{MJ} / \mathrm{m}^{2}$ (From chart, follow $a$ to $c$ )

(iii) From Example 1, $W M=0.56 I M$

Given $I M=1000 \mathrm{MJ} / \mathrm{m}^{2}$

$W M=0.56(1000)=560 \mathrm{MJ} / \mathrm{m}^{2}$ (From chart, follow $b$ to $a$ to $c$ )

Note: To ensure accuracy in results when converting values between IM and WM, always convert to $\mathrm{CM}$ before converting to either IM or WM. That is,

given $\mathrm{IM}=1000 \mathrm{MJ} / \mathrm{m}^{2}$,

$\mathrm{CM}=0.62(\mathrm{IM})=0.62(1000)=620 \mathrm{MJ} / \mathrm{m}^{2}$

Therefore, $\mathrm{WM}=620 / 1.1=564 \mathrm{MJ} / \mathrm{m}^{2}$.

\subsection{Questionnaire Method}

As a result of the small sample size, data from the questionnaire method has been analyzed differently. Fire load density of the five different offices has been presented and compared to values from other methods in Table 4-8.

Table 4-8 Fire Load Density (Questionnaire Method versus Other Methods)

\begin{tabular}{|c|c|c|c|c|}
\hline Office & $\begin{array}{l}\text { Questionnaire } \\
\text { Method } \\
\text { Fire Load } \\
\left(\mathrm{MJ} / \mathrm{m}^{2}\right)\end{array}$ & $\begin{array}{c}\text { Combination } \\
\text { Method } \\
\text { Fire Load } \\
\left(\mathrm{MJ} / \mathrm{m}^{2}\right)\end{array}$ & $\begin{array}{l}\text { Weighing } \\
\text { Method } \\
\text { Fire Load } \\
\left(\mathrm{MJ} / \mathrm{m}^{2}\right)\end{array}$ & $\begin{array}{c}\text { Inventory } \\
\text { Method } \\
\text { Fire Load } \\
\left(\mathrm{MJ} / \mathrm{m}^{2}\right)\end{array}$ \\
\hline 1 & 851 & 792 & 838 & 861 \\
\hline 2 & 867 & 867 & 648 & 748 \\
\hline 3 & 746 & 813 & 901 & 1305 \\
\hline 4 & 953 & 1025 & 926 & 1725 \\
\hline 5 & 1330 & 683 & 758 & 1133 \\
\hline
\end{tabular}


The questionnaire method predicted values quite close to the combination method. Table 4-9 provides the comparison between the fire loads obtained from the questionnaire method to values obtained from the use of the combination of weighing and inventory methods. The percentage difference varied from $-8 \%$ to $50 \%$, with an average of $20 \%$ and $95^{\text {th }}$ centile value of $48.6 \%$.

Table 4-10 provides comparison between the floor areas of the questionnaire method and the combination method. Floor areas of the questionnaire method were calculated from dimensions of room estimated by the occupants. The estimated floor area differed from the measured floor area in the range of $-33 \%$ to $28 \%$, with a mean of $15 \%$. It was observed that all the surveyed offices had simple geometric shapes (rectangular). The range of variability in the percentage difference may be wider in occupancies with complex geometric floor plans. As a result of this, fire load densities calculated using the questionnaire method may become misleading. Uncertainties may be reduced by verification based on: i) architectural drawings or ii) previous surveyed data of similar occupancies.

Table 4-9 Comparison of Fire Load Density Results Between the Questionnaire Method and the Combination of Weighing and Inventory Method.

\begin{tabular}{ccccc}
\hline Office & $\begin{array}{c}\text { Fire Load } \\
\left(\mathrm{MJ} / \mathrm{m}^{2}\right) \\
\text { Questionnaire } \\
\text { Method }\end{array}$ & $\begin{array}{c}\text { Fire Load } \\
\left(\mathrm{MJ} / \mathrm{m}^{2}\right) \\
\text { Combination Method }\end{array}$ & $\begin{array}{c}\text { Difference } \\
\left(\mathrm{MJ} / \mathrm{m}^{2}\right)\end{array}$ & $\begin{array}{c}\text { Percentage } \\
\text { Difference } \\
(\%)\end{array}$ \\
\hline 1 & 851 & 792 & 59 & 6.9 \\
\hline 2 & 867 & 867 & 0 & 0 \\
\hline 3 & 746 & 813 & -63 & -8.4 \\
\hline 4 & 953 & 1025 & -72 & -7.5 \\
\hline 5 & 1330 & 683 & 647 & 48.6 \\
\hline
\end{tabular}

Note: Values presented for the questionnaire method represent 5 sample offices, hence, must be use with caution 
Table 4-10 Comparison of Floor Area (Estimated by Occupant and Measured by Surveyor)

\begin{tabular}{ccccc}
\hline $\begin{array}{l}\text { Office } \\
\text { Number }\end{array}$ & $\begin{array}{c}\text { Floor Area }\left(\mathrm{m}^{2}\right) \\
\text { Questionnaire } \\
\text { Method }\end{array}$ & $\begin{array}{c}\text { Floor Area }\left(\mathrm{m}^{2}\right) \\
\text { Combination }(\mathrm{I} . \& \text { W. }) \\
\text { Method }\end{array}$ & $\begin{array}{c}\text { Difference } \\
\left(\mathrm{m}^{2}\right)\end{array}$ & Difference (\%) \\
\hline 1 & 14 & 10.9 & 3.1 & 28 \\
\hline 2 & 14 & 12.3 & 1.7 & 14 \\
\hline 3 & 13.9 & 10.9 & 3 & 28 \\
\hline 4 & 11.1 & 12 & -0.9 & -0.1 \\
\hline 5 & 7.4 & 11 & -3.6 & -33 \\
\hline
\end{tabular}

Note: Values presented for the questionnaire method represent 5 sample offices, hence, must be used with caution. I \& $\mathrm{W}$ refers to Inventory and Weighing method

\subsection{Summary and Recommendations}

The fire load survey was conducted in 103 office rooms in five different office buildings. The analysis explored the effects of the survey method on the survey results and found uncertainties associated with the use of each fire load survey method. The direct weighing method has uncertainties when estimating weights of heavy and fixed items. Estimations are often based on knowledge of pre-weighed items. Uncertainties in fire load density values of the inventory method may be attributed to difficulty in the measurement of irregular shaped objects, and also the use of inaccurate combustible densities to convert measured volume into weights. The questionnaire method may also have uncertainties in combustible content and floor areas estimated by occupants without direct supervision of an expert. As a result, the combination method which combines best practices from both the inventory and the weighing method has been considered as the most appropriate fire load survey method. The combination method reduces uncertainties associated with the singular use of either the weighing or inventory method. The combination method is considered to provide better fire load density values when compared to the other methods. The combination method resulted in fire load densities that are higher than weighing and lower than inventory methods. The use of the combination method should consider direct weighing for items that can be easily 
weighed, and use of inventory method for fixed combustibles and heavy furniture items. The inventory method could be done either by calculation of mass based on measured volume or through the use of catalogue (physical characteristics of items and their corresponding weights).

The study found wood and paper to be the major contributors to the fire load density. Wood and paper contributed approximately $64 \%$ to the total combustible content. In addition, the current survey shows an increase use of plastics in office spaces as compared to previous surveys done in the 70's and 90 's.

The study results show that cubicle offices have fire load densities greater than enclosed offices. However, combustible energy content (MJ) of cubicle offices was found to be less than that of enclosed offices. It was observed that fire load density decreased with increasing floor area. Larger floor areas (enclosed offices) resulted in lower fire load densities whereas lower floor areas (cubicle offices) resulted in higher fire load densities.

For accuracy, combustibles were classified into cellulosic (paper and wood), plastics and textiles. The surveyor must exercise caution with the choice of the appropriate calorific values. A list of different items and materials with their calorific value is provided in Appendix C - Appendix E. Additionally, for better results, a surveyor must be careful with the appropriate density to be used when converting measured volume into weights. The study used derating factors to reduce combustible items stored in enclosures (such as cabinets). During the survey, about $50 \%$ of metal cabinets in offices were opened. Based on this observation, the study recommends the consideration of combustibles stored within cabinets using derating factors, Table 3-3. 
Lack of participation was the major challenge encountered in the hand delivered questionnaire method. Future surveys should consider the use of several modes of questionnaire administration such as the use of the internet, phone interviews and by post. The focus should be to minimize threat to security and privacy as much as possible. The study results also showed that the floor area estimated by participants varied from $-33 \%$ to $28 \%$ as compared to the floor area calculated from actual measured dimensions. The mean difference was about $15 \%$. Therefore, the study suggests that one should be cautious when using the questionnaire method due to uncertainty caused by participants. To overcome this problem, it is recommended that an experienced surveyor should validate the questionnaire results before performing any analyses.

Fire load and fire load densities have been compared from different survey methods. The current study shows that fire load densities obtained from the inventory method is $45 \%$ greater than the weighing method and $38 \%$ greater than the combination method. Fire load densities obtained from the combination method is about $10 \%$ less than that of the weighing method. A chart for comparing fire load density values among different survey methodologies has been provided, Figure 4-7. 


\section{5: Fire Modelling}

\subsection{Introduction}

The purpose of the fire modelling is to suggest appropriate design fire characteristics that represent potential fires in a typical office floor based on analysis of the following parameters: $\mathrm{HRR}$, gas temperature, toxicity $\left(\mathrm{CO}, \mathrm{CO}_{2}\right.$, and $\mathrm{O}_{2}$ vitiation), and smoke and optical density.

Computational Fluid Dynamics (CFD) modeling has been used in this study. This is because CFD modeling has been found to have several advatages over zone models. According to the literature review, CFD models allow simulation in complex geometries and incorporate a wide variety of physical phenomena. The most widely used CFD model in fire modeling is the Fire Dynamics Simulator (FDS). FDS is a Computational Fluid Dynamics (CFD) model of fire-driven-fluid flow. The model solves numerically a form of Navier-Stokes equations appropriate for low-speed, thermally driven flow with emphasis on smoke and heat transport from fires. As outlined in the literature review, FDS version 5 is effective in modeling key phenomena such as the transport of heat and combustion products from fire; radiative and convective heat transfer between the gas and solid surfaces; and sprinkler, heat detector, and smoke detector activation. The focus of the fire modeling is on heat transport, toxicity, and effects of sprinklers on fire development in a typical office floor (based on fire load survey conducted) exposed to fire.

CFD models requires the compartment to be divided into small 3-dimentional rectangular control volumes (computational cell). The model computes the density, velocity, temperature, pressure and species concentration in each cell as a function of time. The model 
tracks the generation and movement of fire gases, based on the laws of conservation of mass, momentum, species and energy. Radiative heat transfer is also included in the model. All solid surfaces are assigned thermal boundary conditions, plus information about the burning behaviour of the material. It must be noted that, heat and mass transfer to and from solid surfaces is usually handled with emprical correlations. FDS uses material properties to compute fire growth and spread within the compartment.

\subsection{Inputs}

FDS requires the input of several parameters. These include geometry, computational grid size, vents (location and opening of vent to the outside), ignition sources (location and energy release rate), boundary conditions, and size and thermal properties of materials.

\subsubsection{Geometry}

The governing equations in FDS are approximated on a rectilinear grid. The 3-D grid represents the volume modeled by FDS. Smoke and heat generated by fire stays within the grid and air does not enter the grid depending on the boundary conditions specified by the user. However, vents that allow smoke and heat to leave and air to enter the grid may be specified by the user. FDS allows the use of more than one rectangular grid or mesh in calculation (multi-blocking).

All surveyed offices had drywall plaster construction. The drop ceiling was approximately $2.6 \mathrm{~m}$ from the floor. Enclosed offices had $95^{\text {th }}$ centile floor area of $25.2 \mathrm{~m}^{2}$ and a mean of $14.4 \mathrm{~m}^{2}$. On the other hand, cubicle offices had $95^{\text {th }}$ centile floor area of $11.1 \mathrm{~m}^{2}$ and mean of 
$6.3 \mathrm{~m}^{2}$. Based on the fire load survey conducted for this study, a medium sized typical office floor has been used for the simulation, see Figure 5-1.

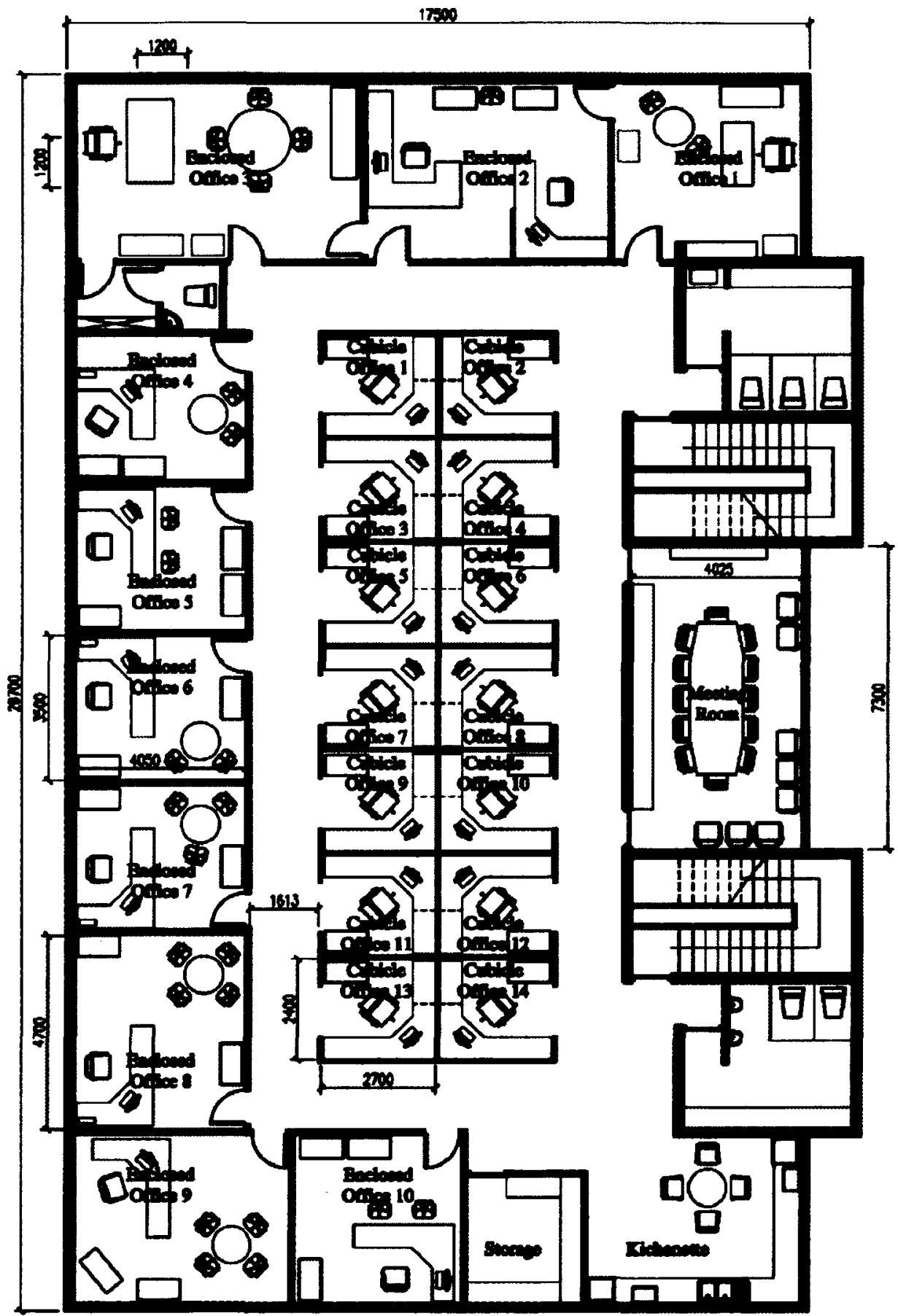

Note: Dimensions and arrangements of combustibles have been based data collected during the fire load surveys. All dimensions are in millimeter.

Figure 5-1 Floor Plan with Furniture Arrangements 


\subsubsection{Description of the Typical Office Floor Layout}

The typical office floor plan used for the simulation had a total floor area of $520 \mathrm{~m}^{2}$. Enclosed offices (including meeting rooms) had a total floor area of $180 \mathrm{~m}^{2}$ whereas cubicle offices had a total floor area of approximately $90 \mathrm{~m}^{2}$. Table 5-1 present floor areas and fire load values used. The floor plan layout has presented in Figure 5-1.

Table 5-1 Floor Areas and Fire Load

\begin{tabular}{lccc}
\hline Room & $\begin{array}{c}\text { Total floor } \\
\text { Area }\left(\mathrm{m}^{2}\right)\end{array}$ & $\begin{array}{c}\text { 95th centile Fire } \\
\text { Load }(\mathrm{MJ})\end{array}$ & $\begin{array}{l}\text { 95th centile Fire } \\
\text { Load Density } \\
\left(\mathrm{MJ} / \mathrm{m}^{2}\right)\end{array}$ \\
\hline Enclosed Office & 180 & 157000 & 870 \\
\hline Cubicle Office & 90 & 123500 & 1370 \\
\hline Totals & 270 & 280500 & 1040 \\
\hline
\end{tabular}

The office floor had a fire load of approximately $280500 \mathrm{MJ}$ and a density of $1040 \mathrm{MJ} / \mathrm{m}^{2}$.

\subsubsection{Computational Grid Size}

According to FDS (version 5) User's Manual [53], the basis of large eddy simulation is that accuracy increases as the numerical mesh is refined. The grid size specified affect the output and computational time required. Smaller cells will generaly capture more features of the flow. However, smaller cells increases the computational time. Therefore, it is important to use the smallest number of grid cells that still capture important features of the fire. A grid sensitivity analysis has been carried out to analyse the effect of grid size on HRR and temperature using a single enclosed office. Ma and Quintiere [57] reported that an indication of whether the fire is adequately resolved is given by $R^{*}$, the ratio of the characteristic fire diameter $\left(D^{*}\right)$ by the grid size $(\delta x)$. A grid size of $0.2 \mathrm{~m}$ within the fire region results in $R^{*}$ of 0.1 , which indicates that the fire plume is well resolved (see Sample Calculations 5.1). Based on the calculation of the fire resolution index and as a result of the computational 
requirements it was decided to use a grid size of $0.2 \mathrm{~m} \times 0.2 \mathrm{~m} \times 0.2 \mathrm{~m}$ grid size for the fire compartment and $0.4 \mathrm{~m} \times 0.4 \mathrm{~m} \times 0.4 \mathrm{~m}$ for the rest of the compartments in the typical office floor simulations discussed in this study.

\section{Sample Calculations 5.1: Calculation of Fire Resolution Index}

The resolution of the fire plume is often defined by the equation [57] below:

$R^{*}=\frac{\max (\delta x, \delta y, \delta z)}{D^{*}}=\frac{0.2}{1.72}=0.1$

where,

$D^{*}=\left(\frac{Q}{\rho_{\infty C_{p} T_{\infty 0} \sqrt{8 D} D^{2}}}\right)^{\frac{2}{5}} D=\left(\frac{3300}{1.204 \times 1.005 \times 293 \times \sqrt{9.81 \times 1.3} \times 1.3^{2}}\right)^{\frac{2}{5}} \times 1.3=1.72 \mathrm{~m}$

$D^{*}=$ characteristic plume length scale, $\mathrm{m}$;

$D=$ effective diameter, $1.3 \mathrm{~m}$;

$Q=$ Peak heat release rate, $3300 \mathrm{~kW}$;

$\rho_{\infty}=$ density at ambient temperature, $1.204 \mathrm{~kg} / \mathrm{m}^{3}$;

$C p=$ specific heat of gas, $1.005 \mathrm{~kJ} / \mathrm{kg} . \mathrm{K}$;

$T \infty=$ ambient temperature, $293 \mathrm{~K}$; and

$g=$ acceleration of gravity, $9.81 \mathrm{~m} / \mathrm{s}^{2}$.

$R^{*}$ value of 0.1 or less shows that the plume dynamics are accurately simulated. [55-58].

\subsubsection{Vents}

Vents are openings from the model to ambient conditions outside the computational domain. Vents allow smoke and heat to leave the grid area and air to enter.Vents may either have natural flow based on bouyancy of the hot gases or forced flow such as flow from a fan. The 
enclosed offices had window openings measuring $1.2 \mathrm{~m}$ wide by $1.8 \mathrm{~m}$ high. All the window openings had a $95^{\text {th }}$ centile area of $4.4 \mathrm{~m}^{2}$ and a mean of $2.2 \mathrm{~m}^{2}$. The window vent was specified as having natural flow (OPEN). OPEN denotes a passive opening on the exterior mesh boundary to the outside (ambient conditions).

From the fire load survey, it was observed that all windows were made up of fixed glass in metallic frames. To simulate window breakage, vents were made to open when their surface temperature reached $250^{\circ} \mathrm{C}$. It must be noted that, it is difficult to estimate a generalised time at which windows (glass) break when exposed to fire temperatures in a compartment. This is as a result of the wide variety of window (glass) products in the market. Research have shown that glass breaks as a result of temperature differences between the centre heated portion and the glass edge. [65]. Skelly, et al. reported the critical value to be approximately $90^{\circ} \mathrm{C}$. Observations from different fire tests show that compartment windows (glass) often break when the exposed surface temperatures range between $250^{\circ} \mathrm{C}-500^{\circ} \mathrm{C}$. Richardson and Oleszkiewicz [66] observed windows breakage when the exposed glass surface temperature was between $290^{\circ} \mathrm{C}$ and $380^{\circ} \mathrm{C}$. Shield, et al. [67] reported windows to break at an exposed surface temperature within the range of 278 to $615^{\circ} \mathrm{C}$ with an average of $447^{\circ} \mathrm{C}$ at failure. The Loss Prevention Council of UK [80] conducted fire tests using a fully-furnished office room arrangement, and concluded that double-glazed windows using $6 \mathrm{~mm}$ thick glass will fail at room gas temperature of $600^{\circ} \mathrm{C}$ and that, if the fuel load is significant, the failure may be expected to occur essentially at the instant that $600^{\circ} \mathrm{C}$ is first reached.

The study uses a window breakage temperature of $250^{\circ} \mathrm{C}$ for the simulation. This was chosen as a conservative lower bound value for the wide range of window breakage temperatures reported in literature [65 - 67]. 


\subsubsection{Boundary Conditions and Materials Properties}

When a material is defined in FDS, it is given a set of physical and thermal properties. These include thermal diffusivity, thermal conductivity, density, and thickness. These parameters impact the heat transfer in the material. To simulate a surface made of heat-conducting solids or a fuel you must specify certain thermal properties and pyrolysis behaviour. For combustible materials, additional parameters such as: ignition temperature, heat of combustion, heat of vapourization, and max burning rate are specified. The selection of materials can have a significant impact on FDS simulation [47]. To characterize material properties, small and large scale testing and model verification are used.

Different boundary conditions have been specified for floors, walls, and ceiling. The floor was simulated as a thermally-thin carpet having thermal properties similar to thermoplastics [48], see Table 5-2. The thermal properties are based on properties presented in NIST World Trade Centre experiments report [48] based on fire tests conducted at NIST. The compartment ceiling was modeled as an obstruction with properties of Marinite I, a product of BNZ Materials, Inc. The obstruction was used to represent a dropped ceiling (false ceiling). Gypsum was used as the boundary condition of all the compartment walls. Thermal properties are based on ATF NIST Multi-Floor validation test conducted at NIST [53], Table

\section{$5-2$.}

Combustible contents were classified into cellulosic, plastics, and textiles. The density of cellulosic materials (wood) was taken as $450 \mathrm{~kg} / \mathrm{m}^{3}$ with an ignition temperature of $360^{\circ} \mathrm{C}$. On the other hand, plastics and textiles were simulated using modified material properties based on literature, see Table 5-3 and Table 5-4. 
Table 5-2 Boundary Condition

\begin{tabular}{lcccc}
\hline Description & Floors & Ceiling & Walls & Units \\
\hline Density & 750 & 737 & 930 & $\mathrm{Kg} / \mathrm{m}^{3}$ \\
\hline Specific heat & 4.5 & $\begin{array}{r}1.2 @ 90^{\circ} \mathrm{C} \\
1.4 @ 425^{\circ} \mathrm{C}\end{array}$ & 1.09 & $\mathrm{~kJ} / \mathrm{kg} /$ \\
\hline Conductivity & 0.16 & 0.12 & 0.17 & $\mathrm{~W} / \mathrm{m} / \mathrm{K}$ \\
\hline Heat of vaporization & 2,000 & - & - & $\mathrm{kJ} / \mathrm{kg}$ \\
\hline Heat of combustion & $22,300 \pm 600$ & - & - & $\mathrm{kJ} / \mathrm{kg}$ \\
\hline Absorption coefficient & - & - & $5.0 \times 10^{4}$ & $1 / \mathrm{m}$ \\
\hline
\end{tabular}

Table 5-3 Material Properties [39]

\begin{tabular}{lccc}
\hline Description & Wood & Plastics & Units \\
\hline Density & 450 & 1050 & $\mathrm{Kg} / \mathrm{m}^{3}$ \\
\hline Specific heat & $1.2 @ 20^{\circ} \mathrm{C}$ & 1.7 & $\mathrm{~kJ} / \mathrm{kg} / \mathrm{K}$ \\
& $1.6 @ 900^{\circ} \mathrm{C}$ & & \\
\hline Conductivity & $0.13 @ 20^{\circ} \mathrm{C}$ & 0.16 & $\mathrm{~W} / \mathrm{m} / \mathrm{K}$ \\
& $0.16 @ 900^{\circ} \mathrm{C}$ & & $\mathrm{kJ} / \mathrm{kg}$ \\
\hline Heat of vaporization & - & 1134 & $\mathrm{~kJ} / \mathrm{kg}$ \\
\hline Heat of combustion & $14,000 \pm 800$ & 20,097 & ${ }^{\circ} \mathrm{C}$ \\
\hline Ignition temperature & 360 & 380 &
\end{tabular}

Table 5-4 Modified Material Properties [39]

\begin{tabular}{lccc}
\hline Material properties & Cellulosic* & $\begin{array}{c}\text { Plastics \& } \\
\text { Textiles }\end{array}$ & Units \\
\hline Density & 450 & 350 & $\mathrm{Kg} / \mathrm{m}^{3}$ \\
\hline Specific Heat & $1.2 @ 20$ & 1.7 & $\mathrm{~kJ} / \mathrm{kg} / \mathrm{K}$ \\
& $1.6 @ 900$ & & \\
\hline Conductivity & $0.13 @ 20$ & 0.16 & $\mathrm{~W} / \mathrm{m} / \mathrm{K}$ \\
& $0.16 @ 900$ & & \\
\hline Heat of Combustion & $1400 \pm 800$ & 20097 & $\mathrm{~kJ} / \mathrm{kg}$ \\
\hline Heat of Vaporization & 1620 & 1134 & $\mathrm{~kJ} / \mathrm{kg}$ \\
\hline Heat of Reaction & 1500 & 1500 & $\mathrm{~kJ} / \mathrm{kg}$ \\
\hline Temperature of Ignition & 260 & 380 & ${ }^{\circ} \mathrm{C}$ \\
\hline Thickness & 0.1 & 0.1 & $\mathrm{~m}$ \\
\hline Burn Away & Yes & Yes & - \\
\hline Backing & Insulated & Insulated & - \\
\hline
\end{tabular}

*Cellulosic refers to wood and wood products, including paper and cardboards 


\subsubsection{Ignition sources and Fire Size}

An ignition source is required to start a fire simulation in FDS. Surfaces are used to define ignition sources in FDS. Fuels are described as flat surfaces. Heat release rate or mass (fuel) loss rate may be specified. The heat release rate profile of a typical office desk test has been used as the source of fire in a cubicle office, see Figure 2-7. Trial runs in FDS were conducted to mimic the HRR profile of a typical office desk based on a test conducted at NIST [48]. The HRR profile was then placed within a cubicle office to replace a typical office desk having similar fire load. Fire therefore spread from the burning desk to other combustibles.

\subsection{Tenability Criteria}

Exposure to toxic gases, oxygen vitiation, rising compartment temperature, and smoke obscuration are the major concerns for occupant's safety at the initial stage of the fire development. The study uses the following tenability limits for $\mathrm{CO}, \mathrm{CO}_{2}$ exposure to assess life safety. These criteria are based on the Fire Engineering Design guide [16].

$$
\begin{aligned}
& >\mathrm{CO} \geq 1400 \mathrm{ppm} \mathrm{[16]} \\
& >\mathrm{CO}_{2} \geq 0.05 \mathrm{~mol} / \mathrm{mol} \mathrm{[16]}
\end{aligned}
$$

Tenability limit for $\mathrm{O}_{2}$ concentration was taken to be $15 \%$. According to Purser [15], $\mathrm{O}_{2}$ concentration below $15 \%$ by volume leads to hypoxia causing, faulty judgment and rapid onset of fatigue.

In addition to the tenability limits provided above, the study uses Fractional Effective Dose (FED) to determine tenability limits for occupants exposed to fire gases within the 
compartment. FED is often used to determine the time at which incapacitation occurs. FDS uses concentrations of $\mathrm{CO}, \mathrm{CO}_{2}$, and $\mathrm{O}_{2}$ to calculate $\mathrm{FED}$ using the following expression [53]:

$$
F E D_{\mathrm{TOT}}=F E D_{\mathrm{CO}} \times \mathrm{HV}_{\mathrm{CO}_{2}}+F E D_{\mathrm{O}_{2}}
$$

where, $F E D_{C O}$ is the fraction of incapacitation dose of $\mathrm{CO}, \mathrm{HV}_{\mathrm{CO}_{2}}$ is the hyperventilation factor induced by carbon dioxide, and $F E D_{O_{2}}$ is the faction of incapacitation dose of low $\mathrm{O}_{2}$ hypoxia.

$F E D_{C O}=4.607 \times 10^{-7}\left(C_{C O}\right)^{1.036} t$ Equation 5.2

$H V_{\mathrm{CO}_{2}}=\frac{\exp \left[0.1930 C_{c o_{2}}+2.0004\right]}{7.1}$ Equation 5.3

$F E D_{O_{2}}=\frac{t}{60 \exp \left[8.13-0.54\left(20.9-C_{o_{2}}\right)\right]}$ Equation 5.4

where, $t$ is time (s) and $C_{c o}$ is $\mathrm{CO}$ concentration (ppm), $C_{o_{2}}$ is the $O_{2}$ concentration (volume percent), $\mathrm{C}_{\mathrm{CO}_{2}}$ is the $\mathrm{CO}_{2}$ concentration (percent)

Table 5-5 shows the tenability limit for FED used in this study. FED of 1 was considered to be the tenability limit for a normal healthy adult.

Table 5-5 Tenability Criteria

\begin{tabular}{ccc}
\hline FED & Description & Reference \\
\hline 0.5 & $\begin{array}{c}\text { Susceptible population, e.g. } \\
\text { children }\end{array}$ & 61 \\
\hline 1 & Healthy Adults & 61 \\
\hline
\end{tabular}


Visual obscuration by the optical density of the smoke could impede the safe evacuation of occupants. As mentioned in the literature, Su et al [14], observed visibility to be the first hazard to arise that could affect the evacuation in the initial stage of the fire development. The current study uses tenability criteria where visibility should not fall below $2 \mathrm{~m}$. This corresponds to $O D$ of $0.5 \mathrm{~m}^{-1}[16]$.

Exposure to rising temperatures may affect the life safety of occupants through convective heat transfer to the skin or radiant heat from the fire and hot smoke layer. Radiant heat from the smoke layer (when its temperature is over $200^{\circ} \mathrm{C}$ ) with a heat flux of $2.5 \mathrm{kWm}^{-2}$ is used as the tenability criteria for exposure to heat. This stage of the fire development may cause second degree burns to skin.

\subsection{Flashover}

As mentioned in the literature, flashover is the point following the growth period at which the heat release rate, temperature, smoke production, and smoke toxicity increase rapidly. At this point all exposed combustibles within the compartment become involved in the fire. This is often characterized by a hot upper smoke layer of 500 and $600^{\circ} \mathrm{C}$, and heat flux levels of about $15-20 \mathrm{~kW} / \mathrm{m}^{2}$ at the floor level of the compartment.

Two separate criteria were used to determine whether flashover occurred during the simulation. First, the upper layer temperatures were averaged from five different locations at the central core (cubicle offices location) of the office floor. The upper layer temperatures of enclosed offices were also observed to determine whether flashover occurs within the enclosed office compartments. In addition, a temperature slice profile was taken across the entire office floor to verify the temperature rise within the upper layer. The second criteria to 
determine whether flashover occurred was through heat flux measurements at the floor level. The heat flux measurements were compared with the upper layer temperature to determine the level of heat flux that corresponds to an upper layer gas temperature of $500-600^{\circ} \mathrm{C}$.

\subsection{Fire Detection and Suppression System Activation}

In a fire scenario, the threat to a building and its occupants increases rapidly from the time of ignition. Safe evacuation from a building often depends on how early a fire is detected. Availability of fire detection systems provide an opportunity for safe evacuation of occupants, summons the fire department and ultimately helps to reduce the amount of damage. In addition, fire suppression systems such as sprinklers help to prevent fire growth and spread, as a result, reducing the impact of fire damage.

\subsubsection{Heat Detectors and Smoke Detectors}

The simulation uses heat detectors and smoke detectors to determine the time to activation of detectors in the event of a fire on a typical office floor. The response time index (RTI) defines the sensitivity of a heat detector. Heat detectors often have activation temperature within the range of $54^{\circ} \mathrm{C}$ to $74^{\circ} \mathrm{C}$. A room fire test conducted at NRC [70] indicates that smoke detectors often activate first followed by heat detectors. Smoke detectors were modeled with characteristics of an ionization smoke detector having an obscuration threshold of $3.28 \% / \mathrm{m}$. The heat detectors were modelled with an activation temperature of $57^{\circ} \mathrm{C}$ and RTI of $100 \mathrm{~m}^{1 / 2} \mathrm{~s}^{1 / 2}[70]$. 


\subsubsection{Sprinklers}

Sprinklers were modelled with an RTI of $100 \mathrm{~m}^{1 / 2} \mathrm{~s}^{1 / 2}$ and activation temperature of $74^{\circ} \mathrm{C}$. The locations of sprinklers were based on provisions of NFPA 13[71]. Office occupancy falls under the light hazard building classification. The minimum coverage area for each sprinkler is $20.1 \mathrm{~m}^{2}\left(225 \mathrm{ft}^{2}\right)$ or $15.6 \mathrm{~m}^{2}\left(168 \mathrm{ft}^{2}\right)$ for combustible construction.

\subsection{FDS Model Uncertainity}

Model output depends on a variety of input values. This includes: material properties, time lines, geometry, and ventilation openings. Accuracy in FDS in the prediction of temperature and velocity of gases has been previously evaluated in experiments and presented by several authors. According to McGrattan [69], for relatively simple fire driven flows, such as bouyant plumes and flow through doorways, FDS predictions are within the experimental uncertainity of values measured in experiments. On the other hand, in large scale fire tests, FDS temperature predictions were found to be within $15 \%$ of the measured temperatures and FDS HRR were predicted to within $20 \%$ of the measured values [69]. 


\section{Modelling Results and Discussion}

\subsection{Introduction}

This section presents a discussion on modelling results with a focus on fire development, and tenability limits of occupants.

\subsection{Grid Sensitivity Analysis}

According to the FDS (version 5) User's Manual [53], the basis of large eddy simulation is that accuracy increases as the numerical mesh is refined. It further states that it is not enough to describe the resolution of the calculation solely in terms of the grid cell size, but rather the grid cell size relative to the heat release rate. A grid sensitivity analysis was carried out to access the effects of varying grid size on HRR prediction, gas temperature and the computational time. A typical office floor, $3.5 \mathrm{~m} \times 4.0 \mathrm{~m}$ with an opening dimension of $1.2 \mathrm{~m} \times 1.8 \mathrm{~m}$, was used for the simulation.

Figure 6-1 compares the heat release rate profile of a single office scenario using different grid sizes $(0.1 \mathrm{~m}, 0.2 \mathrm{~m}$, and $0.4 \mathrm{~m})$. Gird size of $0.4 \mathrm{~m} \times 0.4 \mathrm{~m} \times 0.4 \mathrm{~m}$ produced the highest peak HRR. Refining the grid sizes reduced the HRR within the compartment. Halving the grid size to $0.2 \mathrm{~m} \times 0.2 \mathrm{~m} \times 0.2 \mathrm{~m}$ resulted in approximately $18 \%$ reduction in HRR and reduction in time to peak HRR. It must be noted that there was no significant difference in the time to peak HRR. A similar trend was observed in the temperature prediction of the upper layer gas temperature (see Figure 6-2). Refining the grid size reduced the gas temperature of the upper layer and time to first peak. This was as a result of the lower HRR observed by refining the grid size. However, unlike the HRR, the difference in gas 
temperature prediction by halving the grid size was not significant, less than $5 \%$. Table 6-1 compares the dimensionless fire resolution parameter $\left(R^{*}\right)$, the peak HRR, time to peak HRR, and the computational time required. Reduction in grid sizes has a significant impact on the computational time required for the simulation.

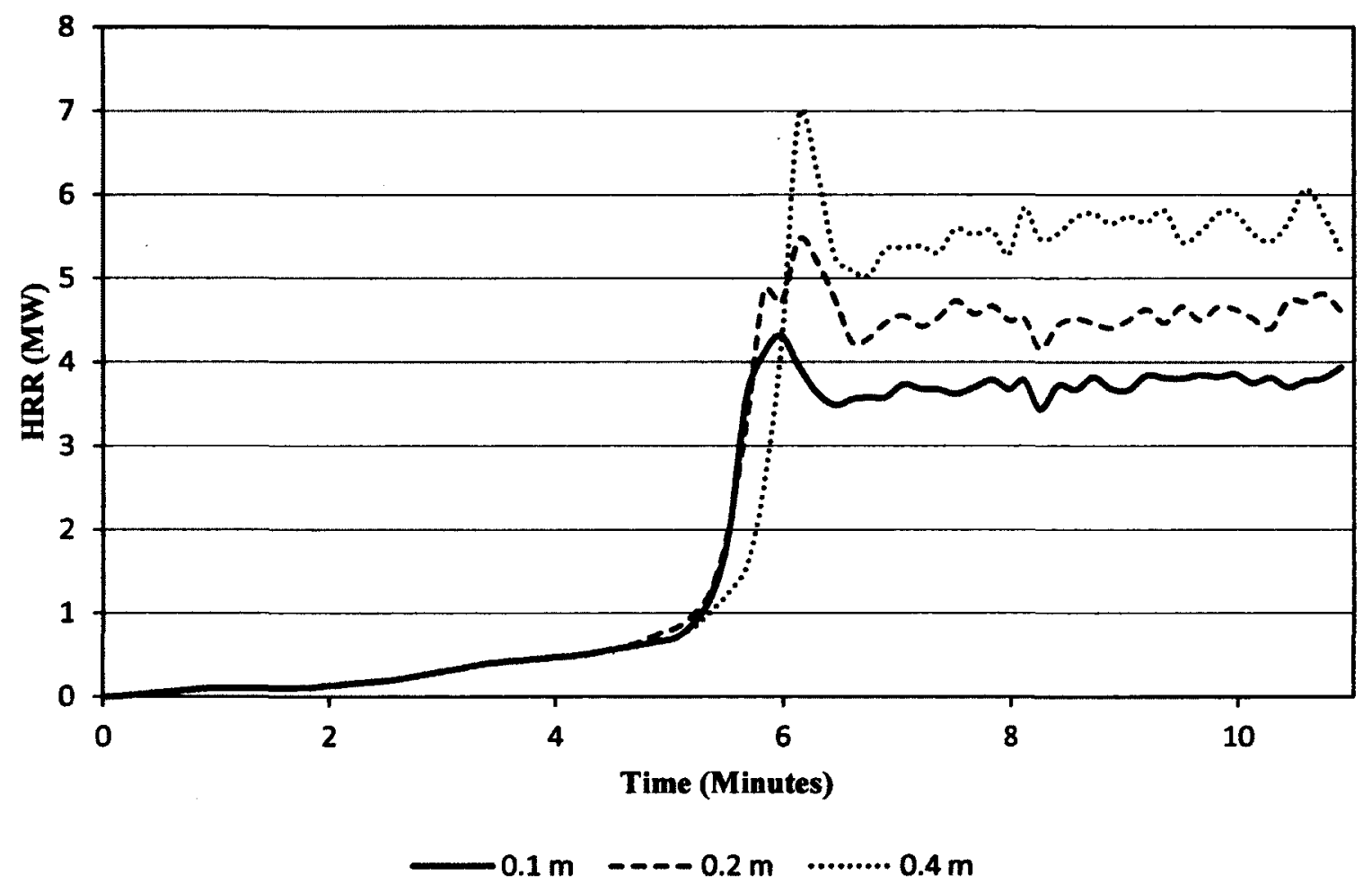

Figure 6-1 Grid Size Impact on HRR 


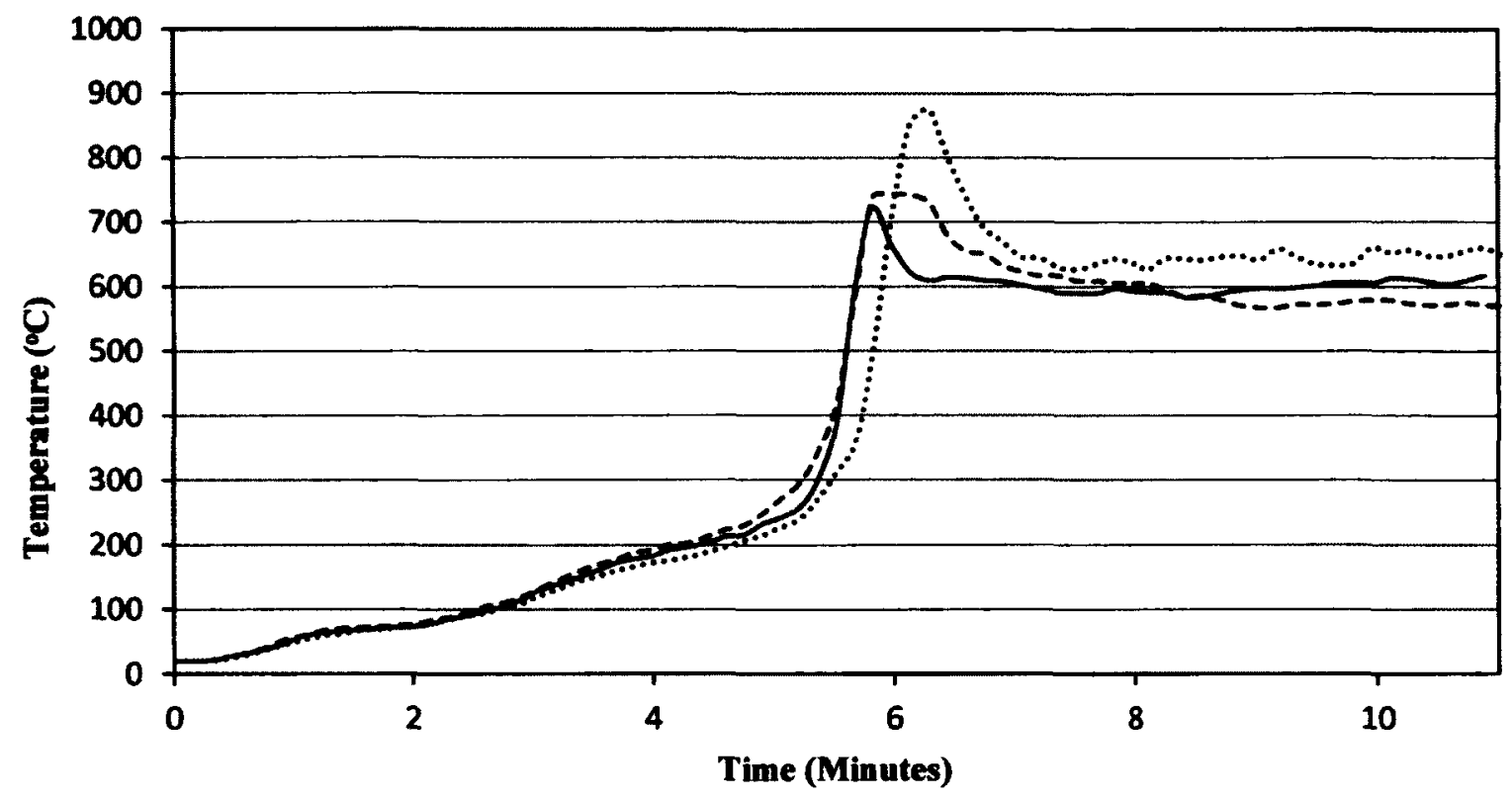

$0.4 \mathrm{~m}----0.2 \mathrm{~m} \longrightarrow 0.1 \mathrm{~m}$

Figure 6-2 Grid Sizes Impact on Gas Temperature

Table 6-1 Grid Sizes Impact on Peak HRR, Time to Peak and Computational Time Requirement

\begin{tabular}{lcccc}
\hline Grid Size & $\mathrm{R}^{*}$ & $\begin{array}{c}\text { Peak HRR } \\
\text { (MW) }\end{array}$ & $\begin{array}{c}\text { Time to Peak HRR } \\
\text { (Minutes) }\end{array}$ & $\begin{array}{c}\text { Computational } \\
\text { Time (Hours) }\end{array}$ \\
\hline 0.1 & 0.06 & 4.3 & 359 seconds (6 minutes) & 45 \\
\hline 0.2 & 0.12 & 5.5 & 368 seconds (6.1 minutes) & 6 \\
\hline 0.4 & 0.23 & 6.9 & 368 seconds (6.1 minutes) & 0.2 \\
\hline
\end{tabular}

\subsection{Simulation 1: Typical Enclosed Office}

This section presents HRR and temperature profiles of a typical enclosed office simulation. Similar to the sensitivity analysis simulations, a typical office floor, $3 \mathrm{~m} \times 4.0 \mathrm{~m}$ with an opening dimension of $1.2 \mathrm{~m} \times 1.8 \mathrm{~m}$, was used. The simulation considers a scenario where fire starts under a typical office work station. The fire was modeled using a $4 \mathrm{~m}^{2}$ burner with 
HRR profile based on a typical office work station fire test conducted at NIST, see Figure 27. The fire size was chosen based on a typical office work station configuration.

HRR had a peak of approximately $7 \mathrm{MW}$ in 6 minutes of fire exposure, Figure 6-3. The fire starts to decay after approximately 24 minutes of the fire exposure. First peak temperature occurs at the same time peak HRR is observed. Untenable conditions, using $200^{\circ} \mathrm{C}$ gas temperature for convective heat exposure of the skin, occurs within approximately 5 minutes of the fire (see Figure 6-4). Within 6 minute of the fire exposure, the entire compartment becomes fully engulfed in flames. At this stage the compartment is considered to have flashed over. Gas temperature of the entire compartment is observed to be above $800^{\circ} \mathrm{C}$. According to Klote [12], fires at this stage of the fire development are often ventilation controlled. In addition, the concern of fire protection shifts from life safety to structural safety. Untenable conditions are reached within approximately 5 minutes from the time of ignition.

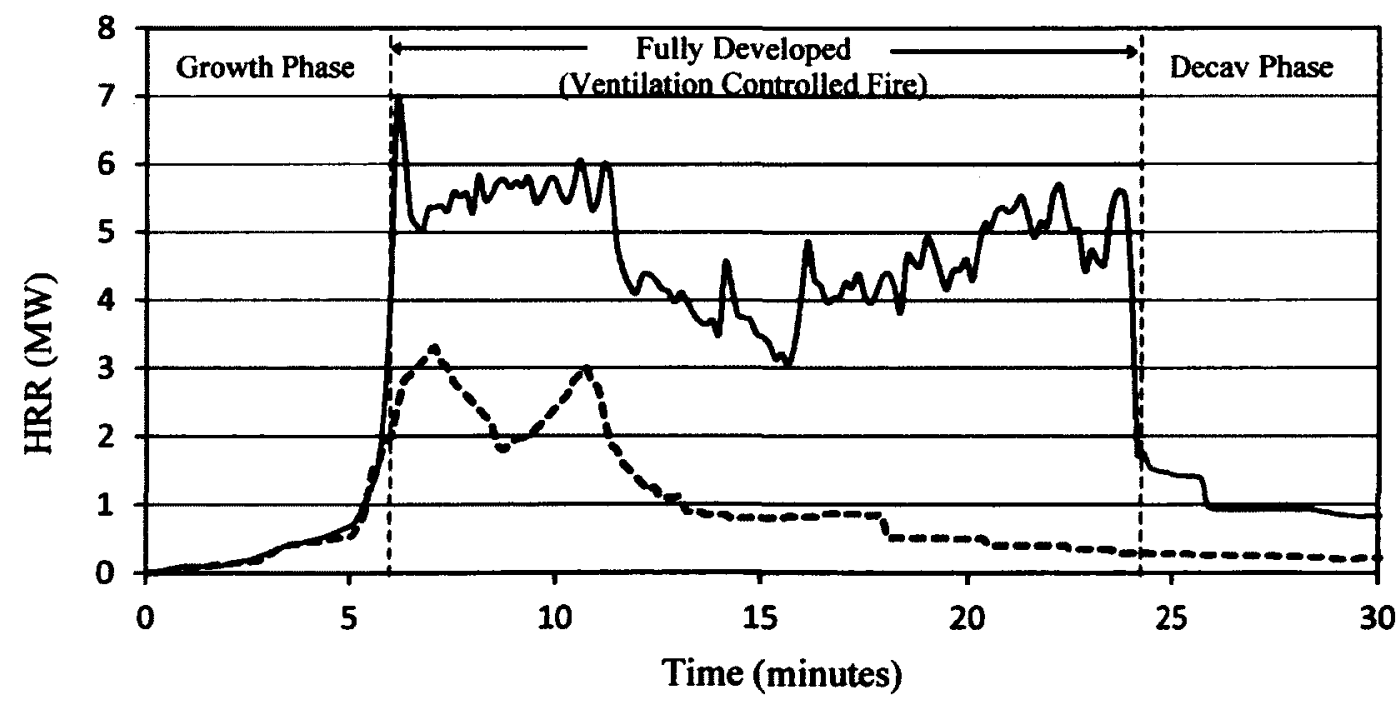

- Typical Office Room Simulation ----- NIST Typical Workstation Test

Figure 6-3 HRR of a Typical Enclosed Office 
The difference between the current simulation and the NIST typical workstation test can be attributed to the differences in fire load. The NIST test had a total fire load of approximately $3700 \mathrm{MJ}$ whereas the current simulation had a total fire load of approximately $10000 \mathrm{MJ}$.

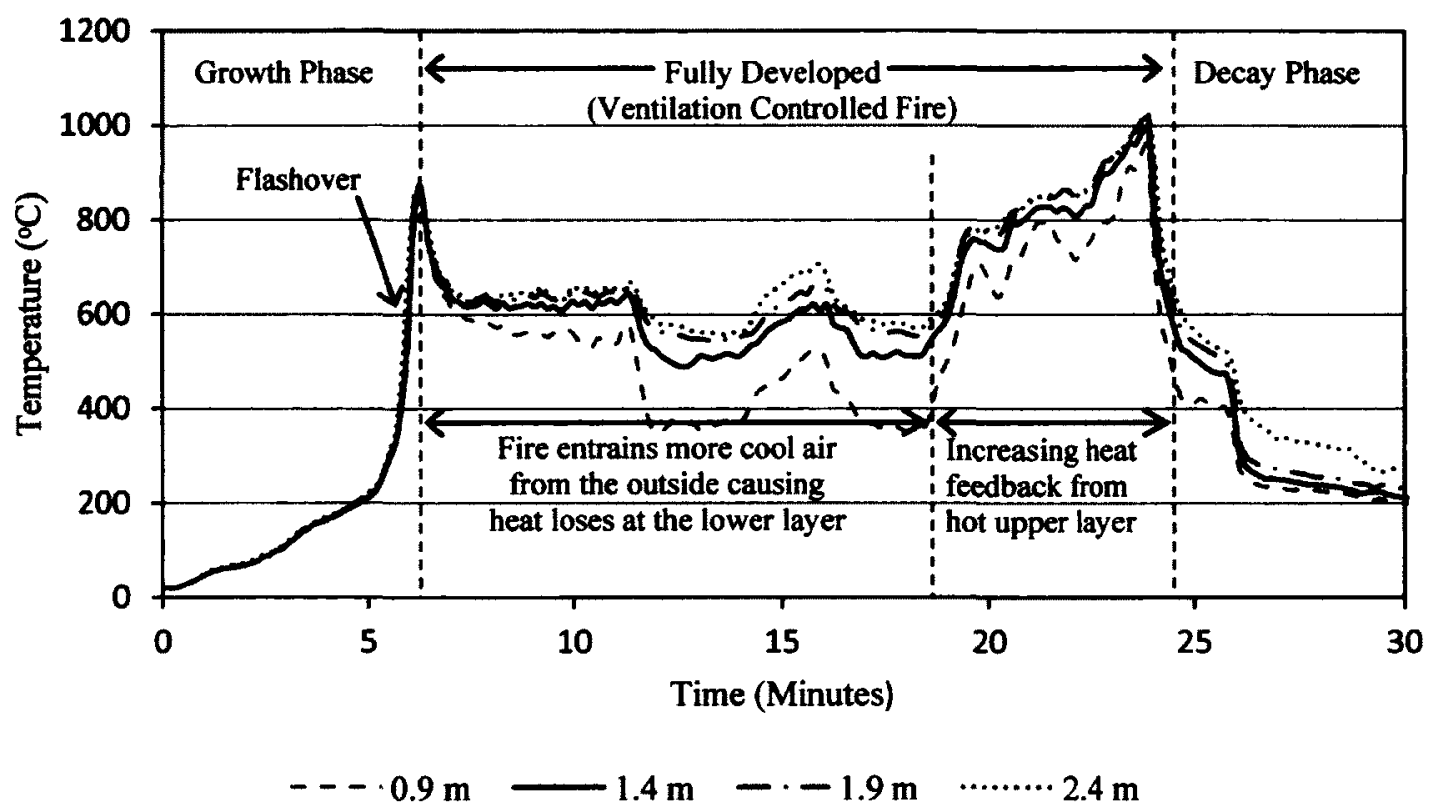

Figure 6-4 Gas Temperature Measurements of a Typical Enclosed Office

\subsection{Comparison of Model Results to Theoretical Equations}

Table 6-2 presents a comparison of theoretical maximum HRR and temperature versus model maximum HRR and temperature prediction. The maximum HRR has been calculated based on Equation 2.9. On the other hand, the theoretical maximum temperature has been calculated using the Eurocode parametric equations presented in the literature, Equation 2.10 to 2.20 . Grid size of $0.1 \mathrm{~m}(\delta \mathrm{x}, \delta \mathrm{y}, \delta \mathrm{z})$ produced maximum HRR that compares very well with the theoretical maximum. However, peak temperature prediction was poor. In addition, the simulation was computationally expensive compared to grid size of $0.2 \mathrm{~m}(\delta \mathrm{x}, \delta \mathrm{y}, \delta \mathrm{z})$ and $0.4 \mathrm{~m}(\delta \mathrm{x}, \delta \mathrm{y}, \delta \mathrm{z})$. A grid size of $0.4 \mathrm{~m}(\delta \mathrm{x}, \delta \mathrm{y}, \delta \mathrm{z})$ produced lower HRR peak, however, 
maximum temperature prediction compared well with the theoretical maximum. The $0.2 \mathrm{~m}$ $(\delta x, \delta y, \delta z)$ grid size produced fairly good HRR peak.

Table 6-2 Comparison of Model Results and Theoretical Calculations

\begin{tabular}{ccccc}
\hline Grid size & $\begin{array}{c}\text { Theoretical Max } \\
\text { HRR }(\mathrm{MW})\end{array}$ & $\begin{array}{c}\text { Model Max HRR } \\
(\mathrm{MW})\end{array}$ & $\begin{array}{c}\text { Theoretical Max } \\
\text { Temperature }\left({ }^{\circ} \mathrm{C}\right)\end{array}$ & $\begin{array}{c}\text { Model Max } \\
\text { Temperature }\left({ }^{\circ} \mathrm{C}\right)\end{array}$ \\
\hline 0.1 & 4.3 & 4.3 & 1085 & 844 \\
\hline 0.2 & 4.3 & 5.5 & 1085 & 870 \\
\hline 0.4 & 4.3 & 6.9 & 1085 & 1023 \\
\hline
\end{tabular}

\subsection{Effects of Window Configuration on HRR and Gas Temperature}

As mentioned in earlier sections, ventilation plays a significant role in the fire development.

The size of the ventilation factor is known to have an impact on the HRR. This section presents results of FDS simulation to analyze the effects of window configuration on HRR prediction. Three different opening (window) sizes, having varying height with the same area, were tested in the simulation, Table 6-3.

Table 6-3 Opening Characteristics

\begin{tabular}{cc}
\hline Area of Opening & Height of Opening \\
\hline 2.16 & 1.8 \\
\hline 2.16 & 1.2 \\
\hline 2.16 & 0.8 \\
\hline
\end{tabular}

\subsubsection{HRR}

Figure 6-5 presents the HRR profile of three different window sizes, $0.8 \mathrm{~m} \times 2.7 \mathrm{~m}$, $1.2 \mathrm{~m} \times 1.8 \mathrm{~m}, 1.8 \mathrm{~m} \times 1.2 \mathrm{~m}$. Reduction in opening height, $h_{v}$, reduced the initial HRR. However, it increased the peak HRR and delayed the time to peak, see Figure 6-5. Reduction 
in $h_{v}$ with a constant area implies an increase in opening width. Increasing the opening width within the upper layer resulted in an increased venting of the hot upper layer gases (ceiling jet). Heat buildup within the compartment reduced and resulted in the initial reduction in HRR. However, as the fire continues without any intervention, the rate of hot gases production from the fire may eventually exceed the rate at which the hot gases leave the compartment resulting in a later heat buildup within the compartment. As a result, the cases with reduced window heights observe higher peaks at approximately 26 minutes.

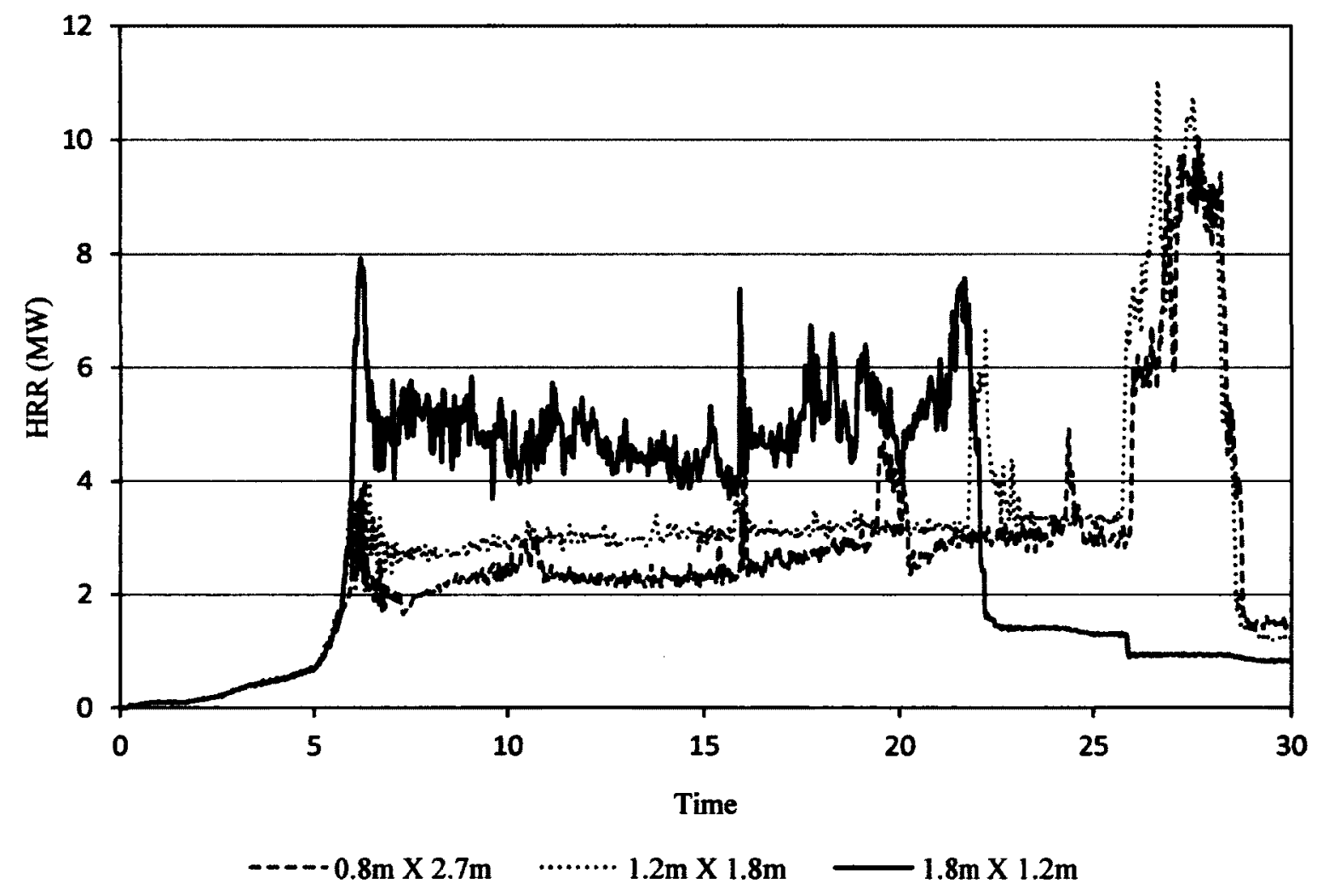

Figure 6-5 Impact of Opening Sizes on HRR

Theoretically, using Equation 2.9, peak HRR reduces with reduction in the ventilation factor $\left(f_{v}\right)$, see Table 6-4. Equation 2.9 uses area and height of the opening. This means that a reduction in the height of the opening with a constant area will cause a decrease in peak 
HRR, Table 6-4. Theoretically, higher ventilation factors will result in higher HRR peak. The current simulation demonstrated that the configuration (height to width ratio) of the opening have a significant effect on the fire development, peak HRR and the time to peak HRR. Equation 2.9 does not take into account the configuration/ position of the opening, hence, not applicable for scenarios similar to the ones tested in the simulation results discussed above.

Table 6-4 Height of Opening and Theoretical Peak HRR

\begin{tabular}{cccc} 
Area of Opening & Height of Opening & $F v=\frac{A_{v} \sqrt{H_{v}}}{A_{t}}$ & $\begin{array}{c}\text { Peak HRR } \\
Q=1500 A_{v} \sqrt{H_{v}}\end{array}$ \\
\hline 2.16 & 1.8 & 0.05 & 4.3 \\
\hline 2.16 & 1.2 & 0.04 & 3.5 \\
\hline 2.16 & 0.8 & 0.03 & 2.9 \\
\hline
\end{tabular}

\subsubsection{Gas Temperature}

Similar to the HRR profile, the initial gas temperature prediction dropped with reduction in opening height, see Figure 6-6 and Figure 6-7. However, there was an increase in the peak gas temperature prediction and a delay in the time to reach that peak. When window height was reduced from $1.8 \mathrm{~m}$ to $1.2 \mathrm{~m}$, the upper layer gas temperature was recorded around $400^{\circ} \mathrm{C}$ for most part of the simulation, see Figure 6-6. There was not much significant change in temperature when window size was reduced further to $0.8 \mathrm{~m}$. It must be noted that a reduction in opening height did not have a significant impact on the time to untenable conditions (when using tenability criteria of $200^{\circ} \mathrm{C}$ ) within the compartment. In all three cases, the time to untenable conditions was below 5 minutes. However, as a result of the delay in rising gas temperatures due to reduction in opening height, thermal insult on structural members may 
also be delayed. This may gives substantial time to extinguish the fire and as a result reducing damage to the structure due to rising gas temperatures within the compartment.

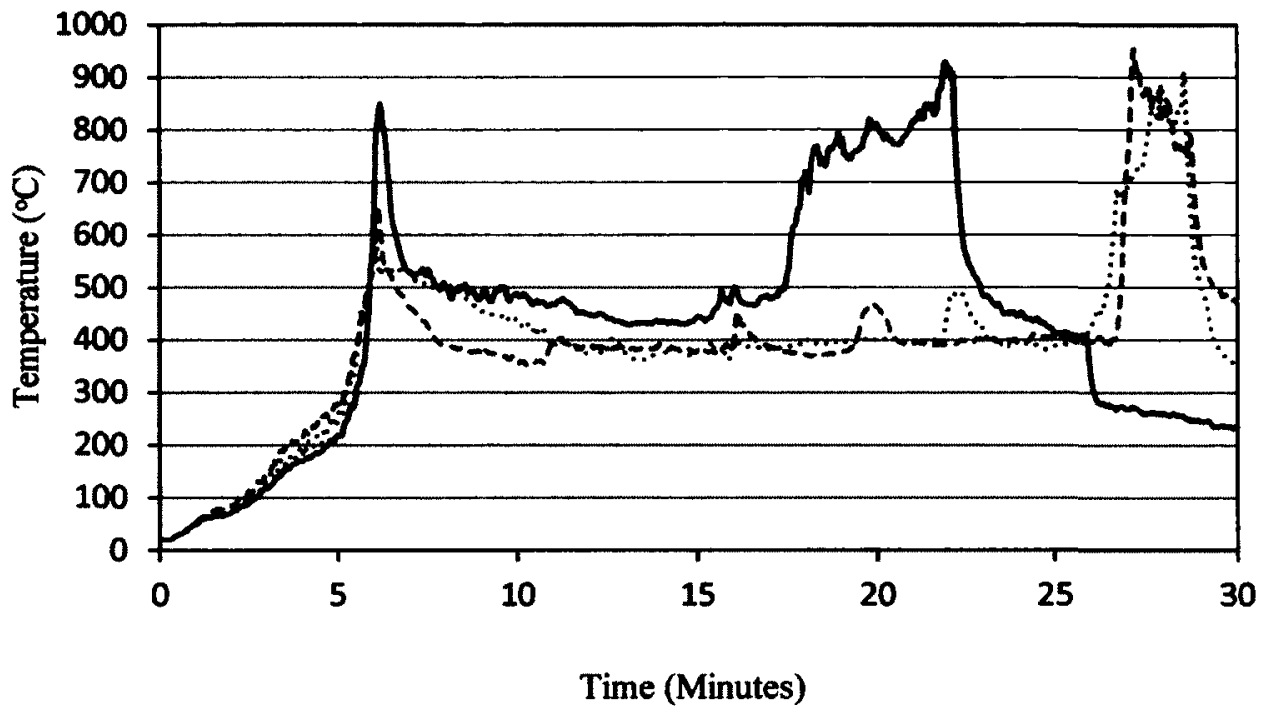

$-1.8 \mathrm{~m} \times 1.2 \mathrm{~m} \quad \cdots \cdots \cdot 1.2 \mathrm{~m} \times 1.8 \mathrm{~m} \quad-\cdots 0.8 \mathrm{~m} \times 2.7 \mathrm{~m}$

Figure 6-6 Upper Layer Gas Temperature among Three Different Opening Sizes

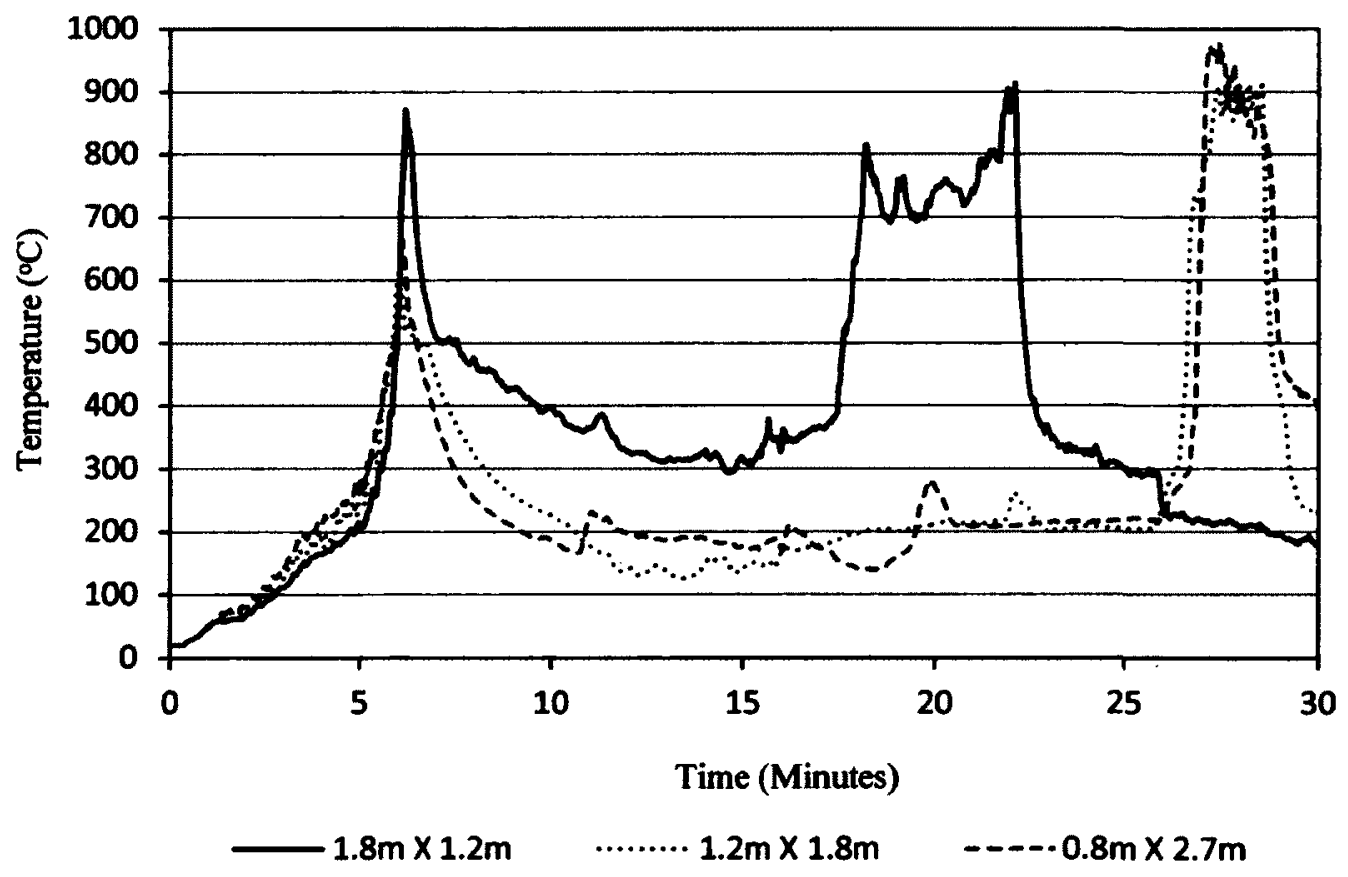

Figure 6-7 Lower Layer Gas Temperature among Three Different Opening Sizes 


\subsection{Simulation 2: Typical Office Floor (Non Sprinklered)}

The section discuses the simulation results of fire spread within an un-sprinklered office floor. Two different fire scenarios, fire starting within a cubicle office (Cubicle Office Fire Scenario) and fire starting within an enclosed office (Enclosed Office Fire Scenario), have been considered in this study. Preliminary runs were made with the fire in different locations (e.g cubicle offices: centre, north end, and south end; enclosed offices: east, west, north, and south) within the two scenarios considered. The worst case scenario in each category was selected and discussed under the heat release rate profile. However, for the purpose of this study, further discussions have been carried out based on the Cubicle Office Fire Scenario. This conclusion was based on the fact that fires starting within the cubicle office presented the worst case scenario in all the cases tested. It was observed that partitions within the cubicle areas contributed significantly to fire spread, making those scenarios the worst case as compared to fires starting in enclosed offices.

The fire was modeled using a $4 \mathrm{~m}^{2}$ burner representing the size of a typical work station. The HRR is ramped up following HRR of fire test conducted by NIST [47] on a typical office work station, see Figure 2-7.

\subsubsection{Heat Release Rate}

Figure 6-8 shows the HRR profiles of the two scenarios of the office floor. Similar HRR profile is observed in both scenarios. However, in the Cubicle Office Fire Scenario, rapid fire spread through the partition walls within the cubicle area causes the heat release to peak at a faster rate. The HRR profile for this scenario peaks at approximately 7 minutes of the fire exposure. On the other hand, there is a gradual heat build up in the enclosed office of fire 
origin (Enclosed Office Fire Scenario). Fire gradually spreads from the enclosed office to the entire floor resulting in HRR peaking at about 15 minutes from the time of ignition. The Cubicle Office Fire Scenario resulted in a more severe fire exposure at the initial part of the fire development. As mentioned above, further detailed discussions in this study have been based on the Cubicle Office Fire Scenario as a result of its initial fire severity.

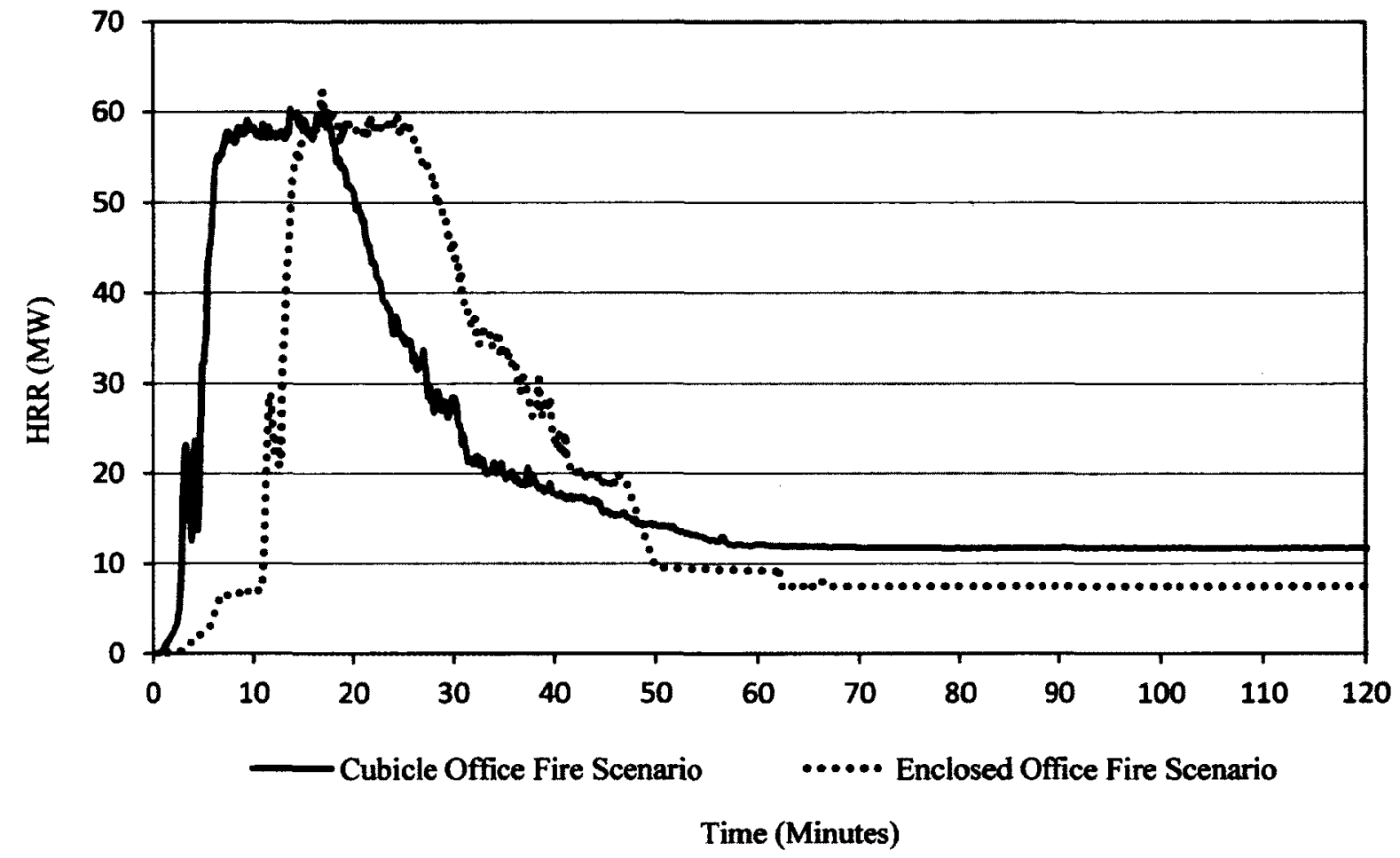

Figure 6-8 Heat Release Rate of the Entire Office Floor (Two Scenarios)

The available combustible content was approximately 280500 MJ. According to McGrattan et al [69], HRR predictions in FDS of a large scale test are expected to be within $\pm 20 \%$. This implies that the resulting area under the HRR curve (amount of combustibles consumed) for the available fire load of $280500 \mathrm{MJ}$ will be in the range of $220000-336600 \mathrm{MJ}$. In the current simulation, the area under the curve of the Cubicle Office Fire Scenario (120 minutes) is approximately $155000 \mathrm{MJ}$. This is equivalent to about $80 \%$ of the total fire load expected to be consumed considering the lower range. The fire continues at $10 \mathrm{MW}$ after 120 
minutes before finally experiencing a complete decay. This may accounts for the remaining $20 \%$.

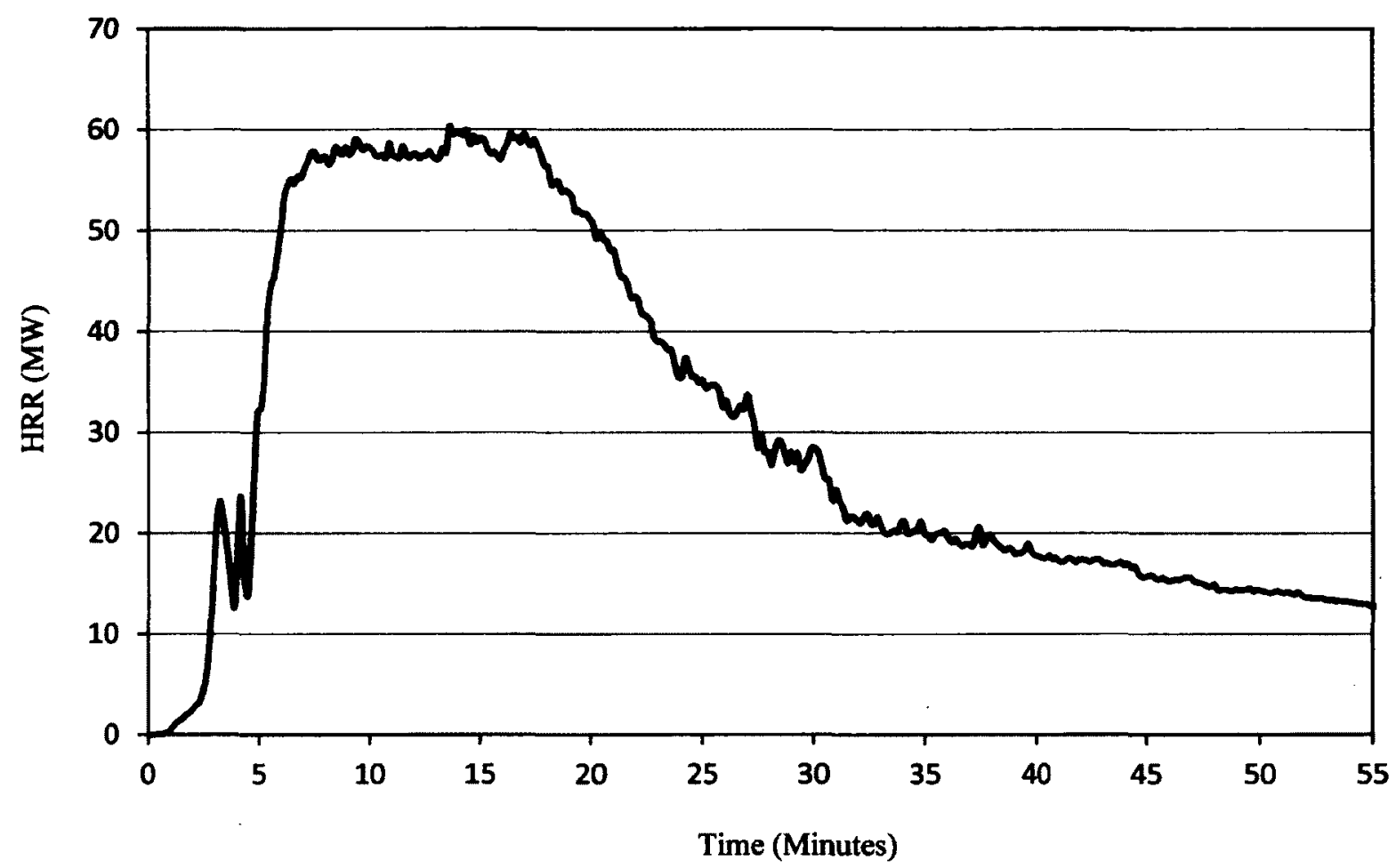

Figure 6-9 Heat Release Rate of the Entire Office Floor (Cubicle Fire Scenario)

Focusing only on the Cubicle Fire Scenario, Figure 6-9 shows details of the HRR profile. The HRR observes a peak, $25 \mathrm{MW}$, at approximately 5 minutes of the fire exposure. Rising temperature and window breakage results in rapid increase in the HRR reaching a peak of $60 \mathrm{MW}$ within 7 minutes from the time of ignition. Steady state conditions are observed for about 15 minutes. The decay phase starts at about 20 minutes. It was observed during the simulation that cubicle partitions contributed significantly to the fire spread. The partitions were made up of plastic and textile materials (easy to ignite and propagate the fire). 


\subsubsection{Fire Detection System Activation}

Fire detection and alarm systems play a major role in fire protection by alerting occupants within a building of a fire, hence, giving them time to safely evacuate the building before untenable conditions are reached. Table 6-5 shows the activation times of smoke and heat detectors. Smoke detectors were the first to activate, approximately 30 seconds of the fire. The radial distance of the detector to the fire may impact the time to device activation. The Ontario Building Code provides requirements for the provision of smoke detectors [7]. As mentioned in the literature, if a fire alarm system is required, smoke detectors shall be installed in: each room in a contained use area and corridors serving those rooms, each public corridor, and each exit stair shaft. In an office scenario, fire may start in different locations that may be very remote to the location of the smoke detector. This may impact the time to activation of the smoke detectors and as a result affect the time for safe evacuation of occupants. However, from the simulation, the effect of radial distance of smoke detector from the fire source had an impact on the activation time of the smoke detectors. The closest $(0.9 \mathrm{~m})$ and farthest $(8.1 \mathrm{~m})$ smoke detector activated within 30 seconds and 60 seconds respectively, see Table 6-5 below. Heat detectors were the last to activate. The closest and the farthest heat detectors activated in 200 seconds and 360 seconds respectively.

Table 6-5 Device Activation and Radial Distance

\begin{tabular}{ccl}
\hline Device & \multicolumn{1}{c}{$\begin{array}{c}\text { Radial Distance to Fire } \\
\text { Source }\end{array}$} & \multicolumn{1}{c}{ Time of Activation } \\
\hline \multirow{2}{*}{ Smoke Detector } & $0.9 \mathrm{~m}$ & 0.5 Minutes (30 Seconds) \\
\cline { 2 - 3 } & $8.1 \mathrm{~m}$ & 1 Minute (60 Seconds) \\
\hline \multirow{2}{*}{ Heat Detector } & $0.9 \mathrm{~m}$ & 3.3 Minutes (200 Seconds) \\
\cline { 2 - 3 } & $8.1 \mathrm{~m}$ & 6 minutes (360 Seconds) \\
\hline
\end{tabular}




\subsubsection{Temperature Profiles of the Cubicle Office Fire Scenario}

This section presents a discussion on gas temperature profiles. Gas temperatures were sampled from two distinctive measurement locations (cubicle area and enclosed office area). Thermocouple trees were virtually installed in all enclosed offices and evenly distributed across the cubicle office location. Each measurement location had 5 thermocouples at $0.4 \mathrm{~m}$, $0.9 \mathrm{~m}, 1.4 \mathrm{~m}, 1.9 \mathrm{~m}$, and $2.4 \mathrm{~m}$. The first four locations were chosen to correspond to height ranges for crawling and walking adults. The fifth thermocouple (close to ceiling) was chosen to correspond to detection devices installed at ceiling soffit. The ceiling had a height of 2.6 m. It was found during the initial trial runs that temperatures did not vary significantly beyond a height of $2.4 \mathrm{~m}$. As a result, using $2.4 \mathrm{~m}$ to represent the location of detection devices was a good approximation.

Figure 6-10 shows the average gas and peak gas temperatures across the entire office floor. At about 3 minutes from ignition, the average and peak gas temperature is approximately $400^{\circ} \mathrm{C}$ and $1100^{\circ} \mathrm{C}$ respectively. This corresponds to the first peak in the HRR profile, $25 \mathrm{MW}$. At 15 minutes, the peak gas temperature is approximately $1400^{\circ} \mathrm{C}$ with an average of $800^{\circ} \mathrm{C}$. This is the same time the highest peak HRR of $60 \mathrm{MW}$ was observed. At about 20 minutes, the peak gas temperature starts to decline and reaches a steady temperature of approximately $900^{\circ} \mathrm{C}$ at 35 minutes. The decay phase starts at approximately 1 hour from the time of ignition. On the other hand, the average gas temperature shows a gradual decline after approximately 20 minutes, similar to the HRR profile. As expected, it can be concluded based on the observations that the HRR profile had a direct impact on the average and peak gas temperature profile within the compartment. 


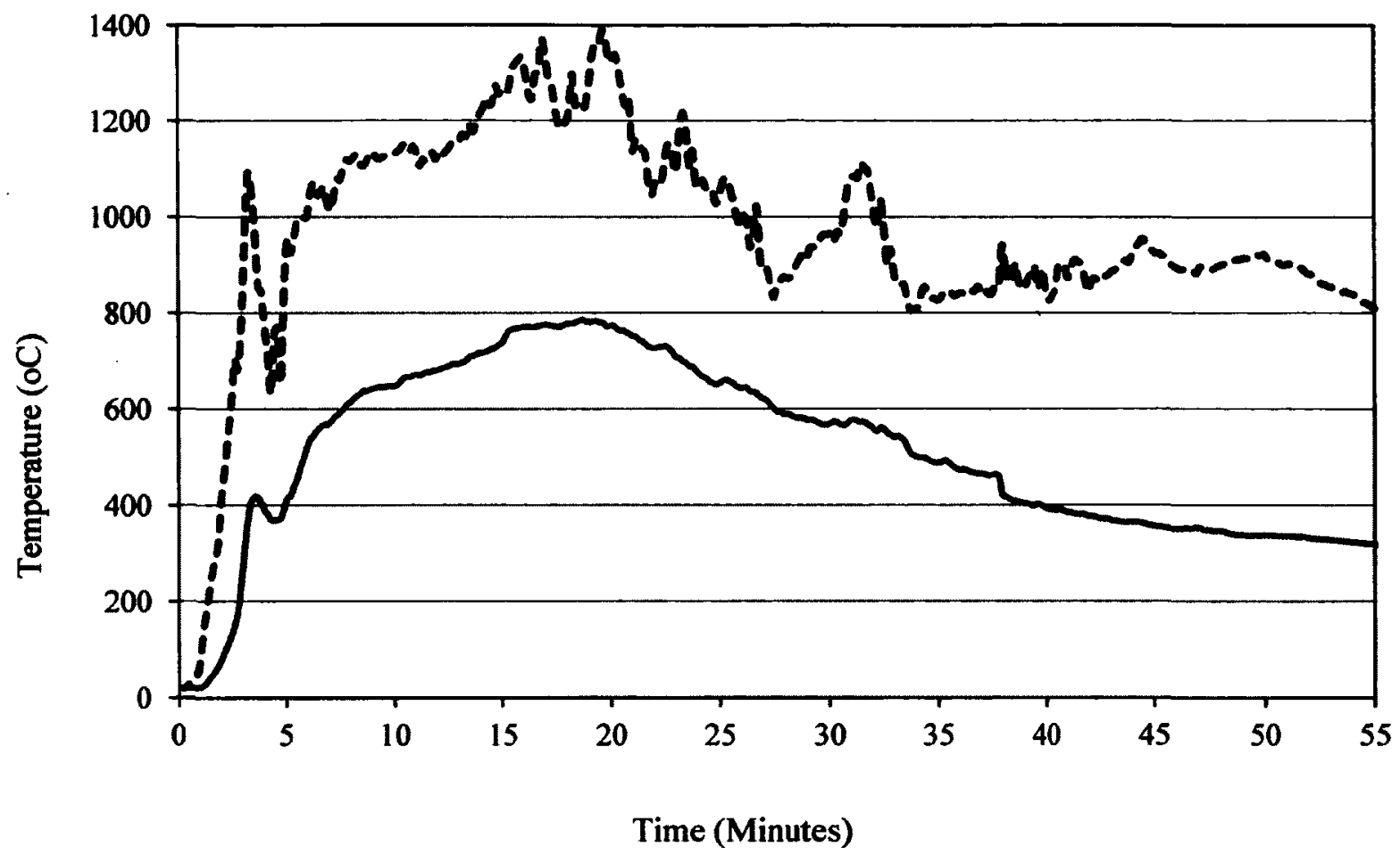

- - Peak Gas Temperature (Entire Floor)

Average Gas Temperature (Entire Floor)

Figure 6-10 Peak and Average Gas Temperature (Entire Floor)

\subsubsection{Gas Temperature Measurements at Cubicle \& Circulation Location}

In the previous section, peak and average temperatures of the entire office floor were discussed. This section provides further discussion on average temperatures at different heights across the cubicle and circulation areas.

Figure 6-11 shows average gas temperatures of thermocouple trees placed within cubicle offices. Average temperature did not rise above $900^{\circ} \mathrm{C}$. This is as a result of the large area the fire gases may have to fill before being able to raise the gas temperature of the compartment.

When using tenability criteria of $200^{\circ} \mathrm{C}$, temperature of the smoke layer at which occupants suffer from second degree burning to the skin, the time to untenable conditions will be 
reached at about 2 minutes, see Figure 6-11. In addition, it has been mentioned that the remote smoke and heat detectors activated between 60 seconds and 6 minutes from the start of ignition. Therefore, the time for safe evacuation of occupants may reduce depending on the type of fire detection system installed and the radial distance to the fire source. For example the available safe egress time (ASET) will be 1 minute and 0 minute when using smoke and heat detectors respectively, Table 6-5. It can be seen that, heat detectors activated after the time untenable conditions within the compartment was reached.

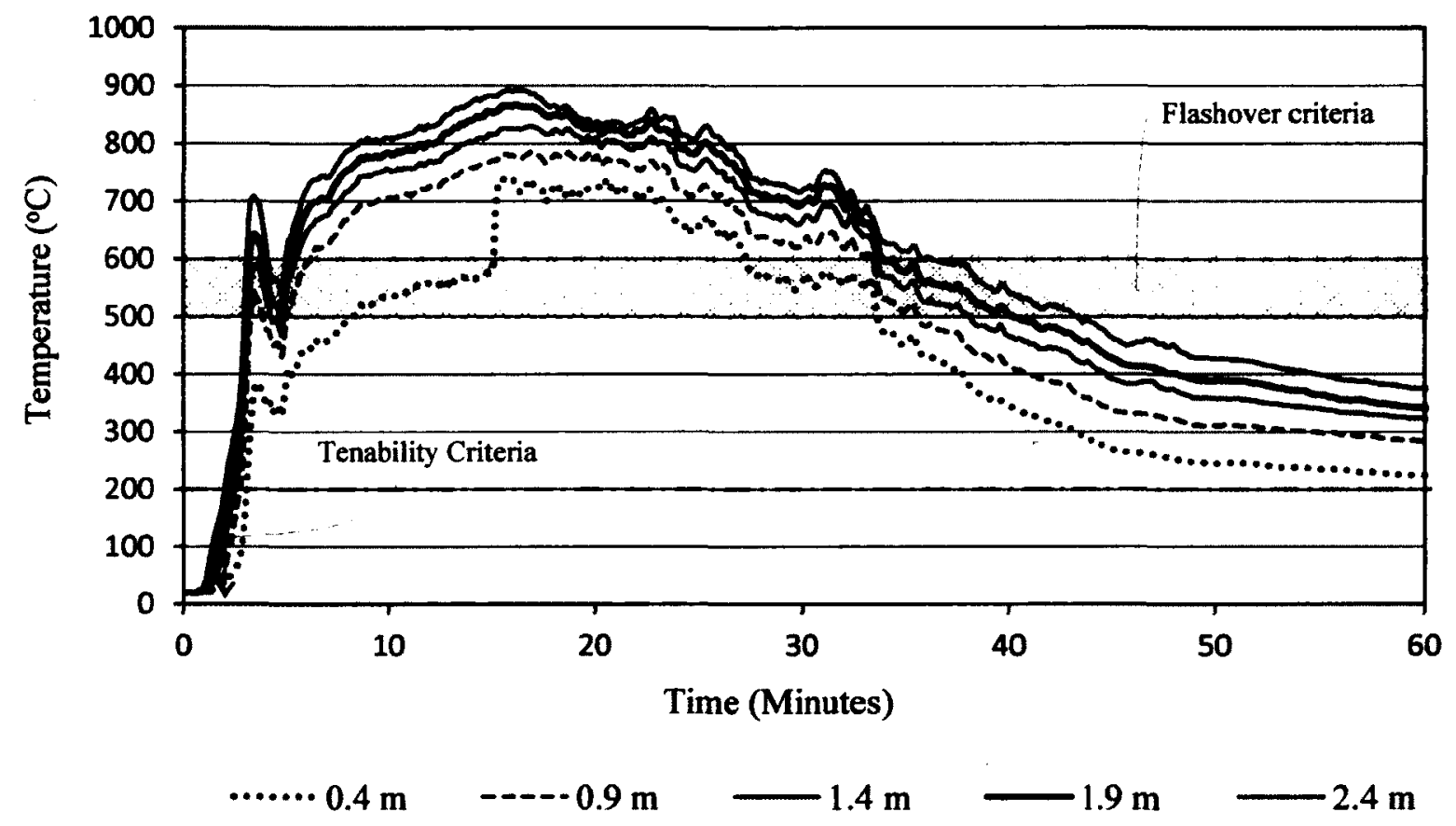

Figure 6-11 Average Gas Temperature Profile (Cubicle Offices)

\subsubsection{Gas Temperature Measurements within Enclosed Offices}

All enclosed office doors were considered to be opened. This assumption was made to depict a fire scenario which occurs during regular office hours when all offices are working with doors opened (open door policy). That was an observation made during the survey of offices. Gas temperatures recorded in the enclosed offices were lower than the cubicle offices 
location, Figure 6-12. The lower temperatures recorded within the enclosed offices may be attributed to the remote location of enclosed offices to the fire source. However, it must be noted that thermocouples located close to window openings recorded relatively higher gas temperatures as compared to those that were remotely located. Window breaking increased the oxygen concentration within those locations, hence, increasing the local temperature within locations closest to window openings. The increased temperature at window opening locations is as a result of the fire within those areas entraining more air due to window breakage. Similar observations were made by Hamins et al's [48] fire experiments. Therefore, the compartment openings have a significant impact on the gas temperature profile within the compartment.

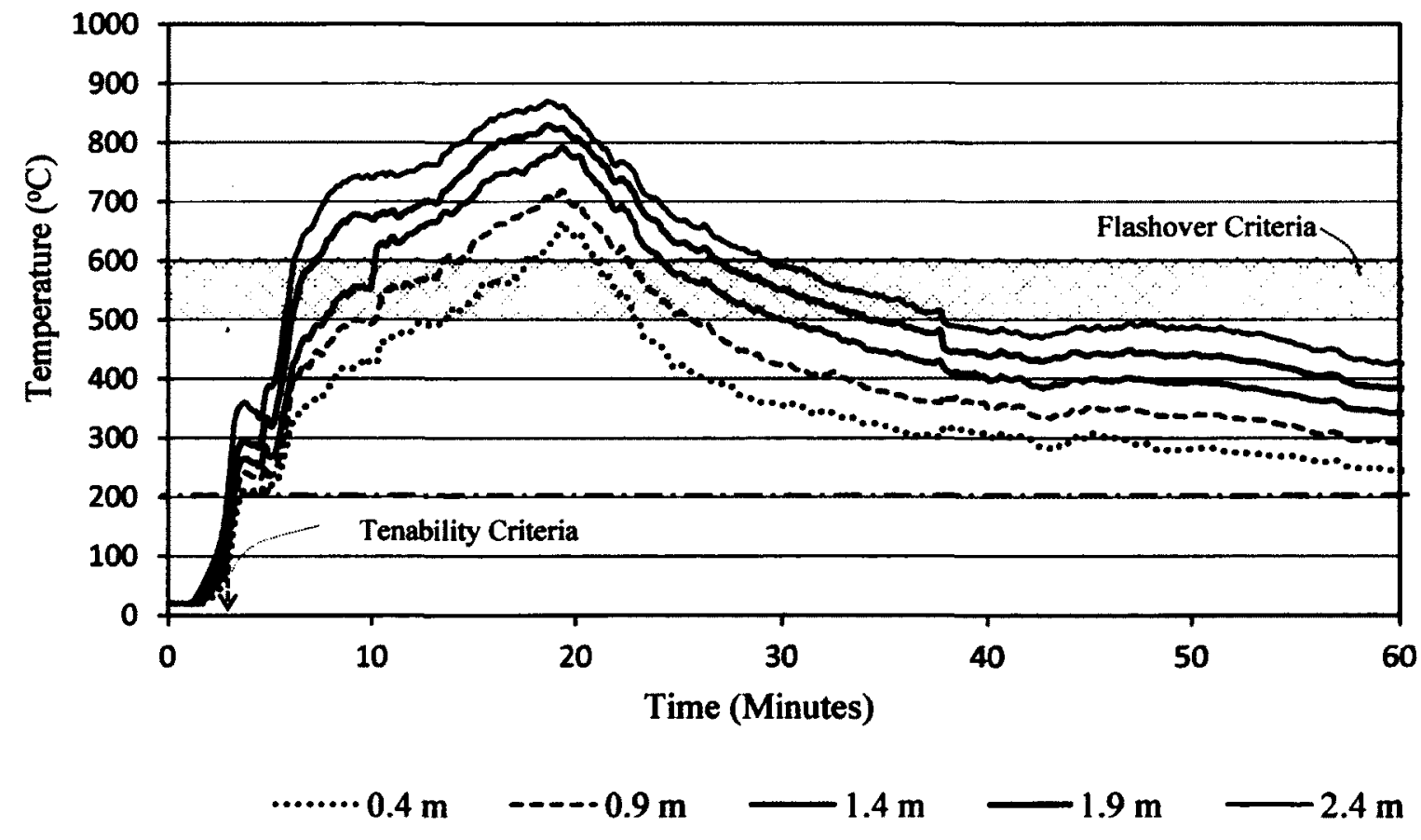

Figure 6-12 Average Gas Temperature Profile (Enclosed Offices)

When using $200^{\circ} \mathrm{C}$ as the tenability criteria of exposure to the hot gas temperature within the compartment, time to untenable conditions will be approximately 4 minutes (Figure 6-12). 


\subsubsection{Flashover}

The determination of flashover in rooms with very large floor area is often difficult. This is because hot gases may have to fill a larger area before raising the temperatures within the compartment to flashover. The situation becomes more complex with complex floor configuration, as in the case of the current simulation. Hot gases have to fill the central cubicle area which opens up to other enclosed office rooms. Temperature rise, to flashover temperatures, was observed to occur at different times within different locations of the entire office floor. This implies in complex floor configuration, flashover criteria can be reached in localized regions.

Upper layer gas temperature measurement from thermocouples placed within cubicle offices reached $500-600^{\circ} \mathrm{C}$ at approximately 4 minutes, see Figure 6-11. Using the upper layer gas temperature as the criteria, it can be said that flashover occurred. The enclosed office compartment temperatures reached $500-600^{\circ} \mathrm{C}$ at approximately 7 minutes, see Figure 6-12. It was observed from the simulation that higher gas temperatures within the compartment corresponded with the time when windows within the compartments started opening (breaking) to the outside. It can therefore be concluded that, within a complex floor layout where rooms are connected to each other, flashover may occur at different times. Temperature slice profile (isotherm) taken across the entire office confirmed the upper layer temperature variation at different times of the fire exposure. The occurrence of flashover was further confirmed by heat flux meters placed on the floor of the cubicle location and enclosed office location. Heat flux meters showed readings above $16 \mathrm{KW} / \mathrm{m}^{2}$ corresponding to the times the upper layer recorded temperatures within $500-600^{\circ} \mathrm{C}$. 


\subsubsection{Toxicity and Gas Concentration}

Exposure to toxic gases, oxygen vitiation, and smoke obscuration are some of the major concerns for occupant's safety at the initial stage of the fire development. This section discus effects of those parameters within the floor as the fire develops.

\subsubsection{CO and $\mathrm{CO}_{2}$ Concentration}

Figure 6-13 and Figure 6-14 presents $\mathrm{CO}(\mathrm{ppm})$ and $\mathrm{CO}_{2}(\%)$ respectively. $\mathrm{CO}$ concentration on the office floor starts to significantly rise after approximately 3 minutes. The tenability criteria are reached approximately at the same time when significant rise in $\mathrm{CO}$ concentration was observed. On the other hand, hazardous conditions as a result of $\mathrm{CO}_{2}$ exposure concentration occur at a faster time. Tenability limit for $\mathrm{CO}_{2}$ occurs before 3 minutes. It has been discussed in the literature that $\mathrm{CO}_{2}$ causes hyperventilation. It must be noted that, as a result of hyperventilation due to $\mathrm{CO}_{2}$, incapacitation of $\mathrm{CO}$ may occur within the compartment earlier than 3 minutes.

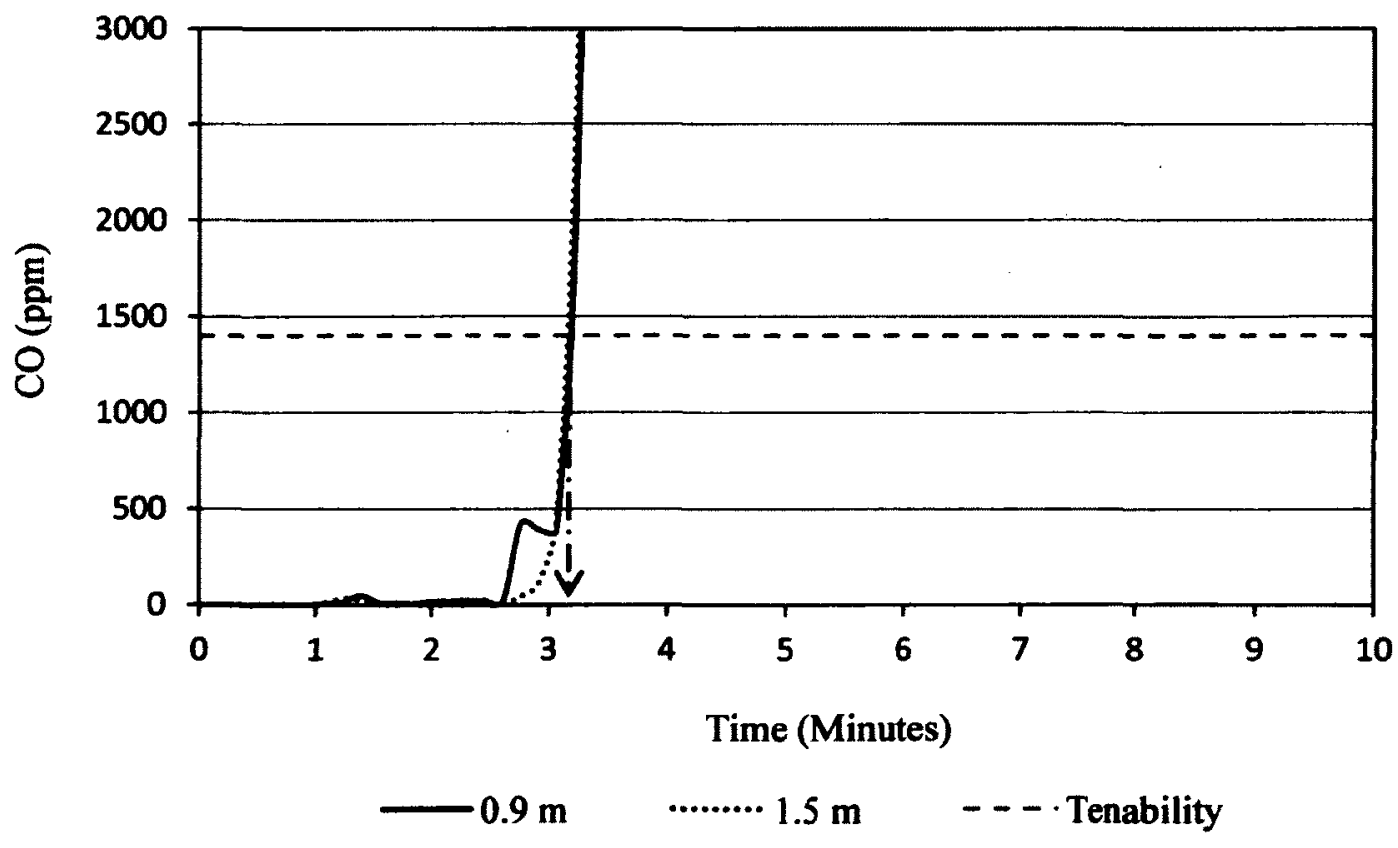

Figure 6-13 CO Concentration 


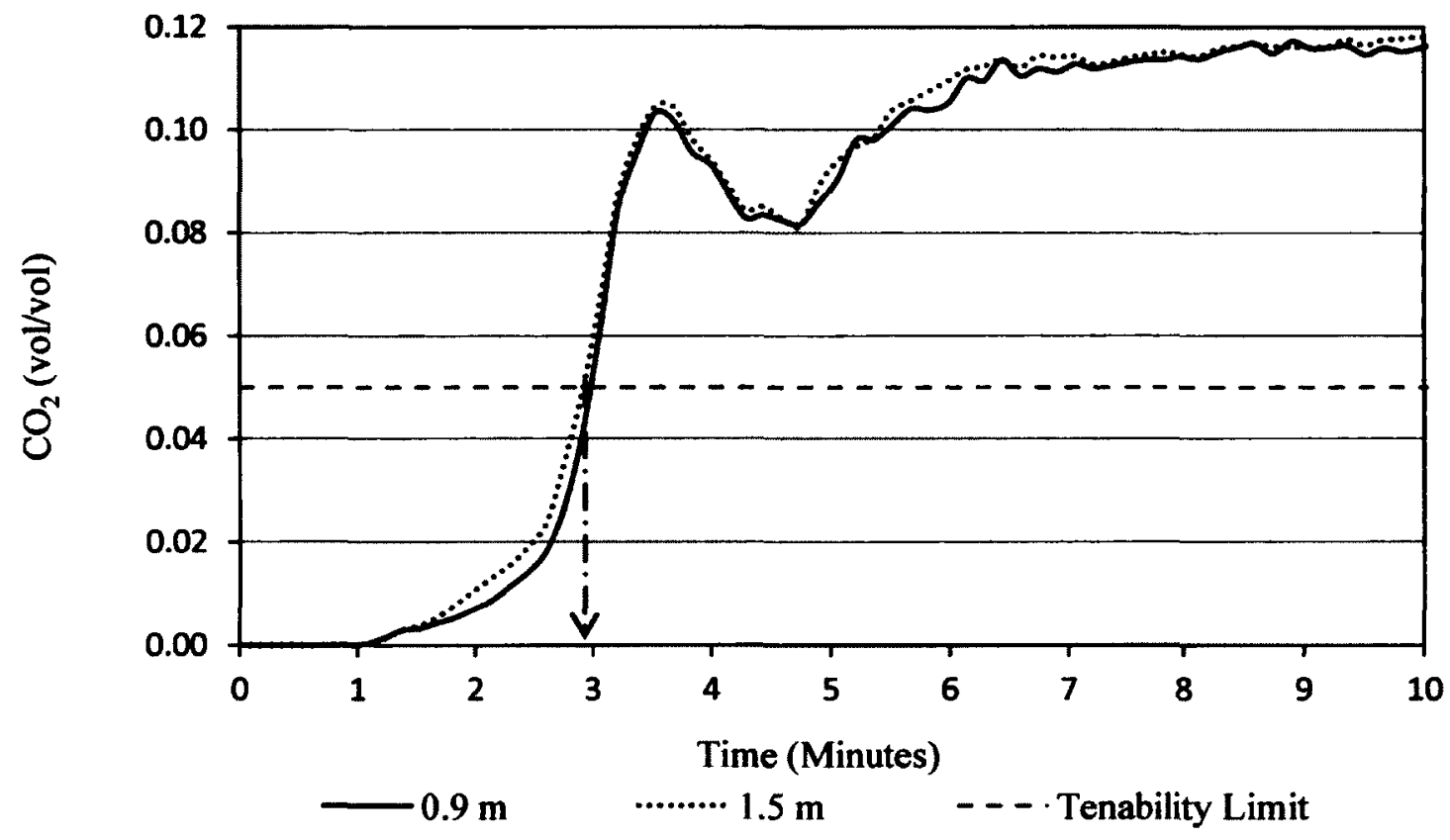

Figure 6-14 $\mathrm{CO}_{2}$ Concentration

\subsubsection{2 $\mathrm{O}_{2}$ Vitiation}

Oxygen concentration within the compartment starts to drop significantly after 2 minutes of the fire exposure within the compartment, Figure 6-15. At approximately 3 minutes $\mathrm{O}_{2}$ concentration falls below $15 \%$ by volume. Concentration of $\mathrm{O}_{2}$ below $15 \%$ leads to hypoxia causing faulty judgment and rapid onset of fatigue of occupants. Reduction in $\mathrm{O}_{2}$ concentrations corresponded to a rise in $\mathrm{CO}_{2}$ and $\mathrm{CO}$ concentrations within the compartment. 


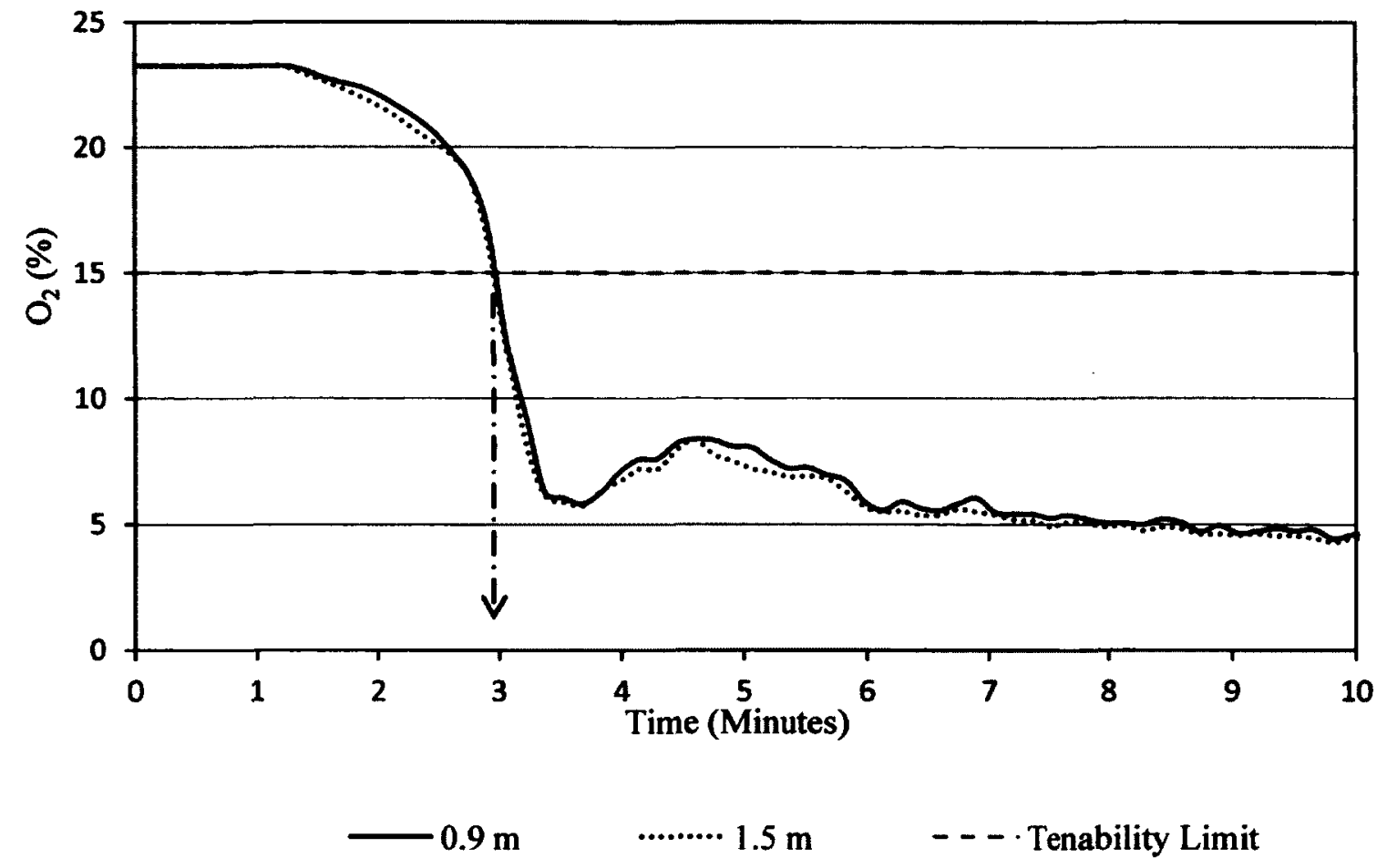

Figure 6-15 $\mathrm{O}_{2}$ Concentration

\subsubsection{Optical Density (OD)}

Visibility within the compartment drops at a faster rate compared to other hazards discussion above. Visibility affects the safe evacuation of occupants in the initial stage of the fire development. In about 1.5 minute visibility falls below $2 \mathrm{~m}$, this corresponds to an OD of $0.5 \mathrm{~m}^{-1}$, see Figure 6-16. It must be noted that, visibility drops at a very faster rate. The difference between optical densities measured at $1.4 \mathrm{~m}$ and $0.4 \mathrm{~m}$ was insignificant, Figure 616. 


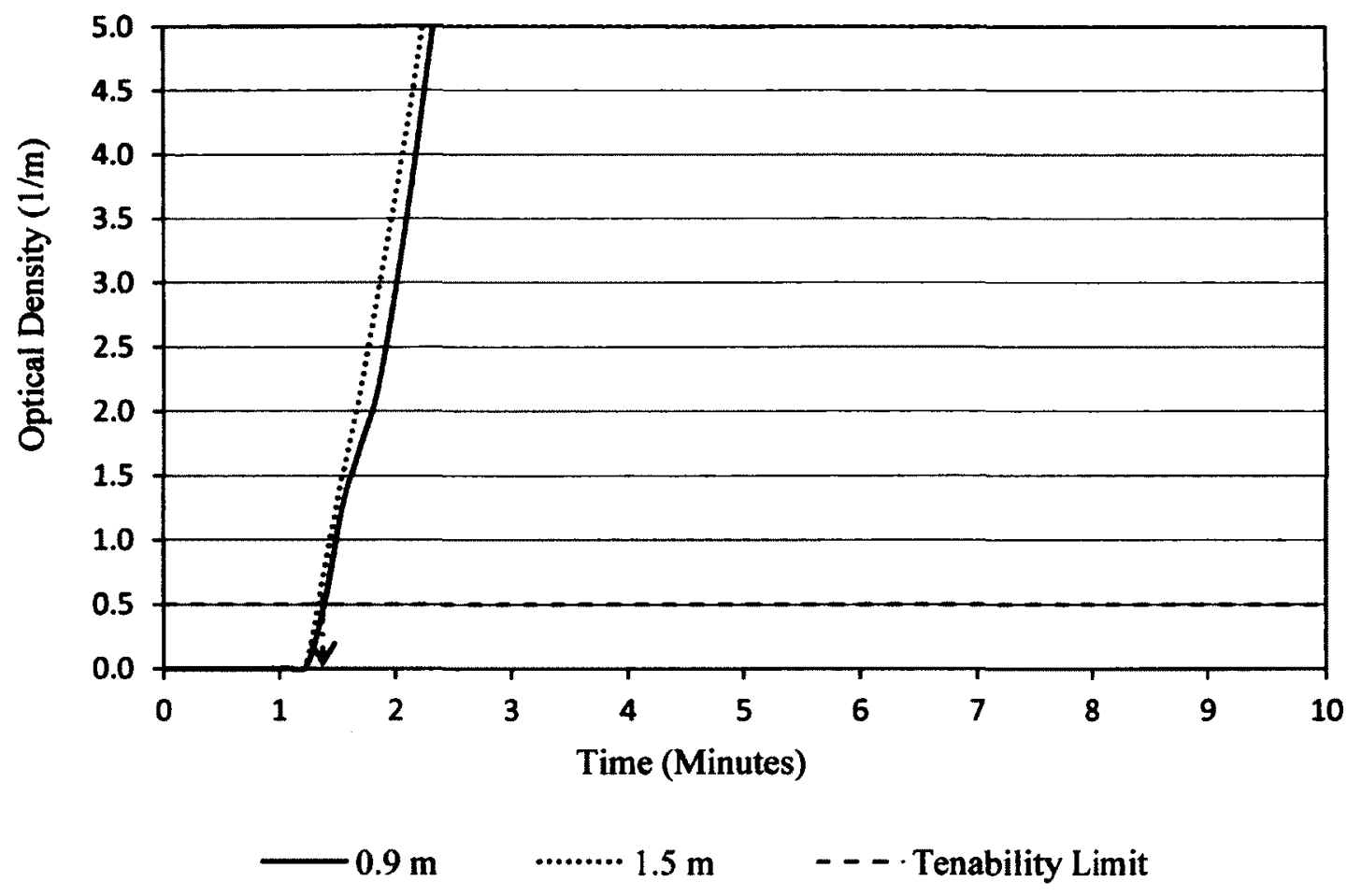

Figure 6-16 Tenability Limit of Optical Density

\subsubsection{Hazard and Time to Untenable Conditions}

Visibility is the first hazard to arise that could affect the evacuation in the initial stage of the fire development. Previous fire experiments conducted by Su et al [14] made similar observation. $\mathrm{CO}_{2}$ and $\mathrm{O}_{2}$ vitiation reached untenable limits at the same time, see Table 6-6.

Table 6-6 Hazard and Time to Reach Untenable Conditions

\begin{tabular}{lcc}
\hline Hazard & Tenability Criteria & Time to Reach Untenable conditions \\
\hline $\mathrm{CO}$ & $1400 \mathrm{ppm}$ & 192 seconds ( 3.2 minutes) \\
\hline $\mathrm{CO}_{2}$ & $0.05 \%$ & 174 seconds (2.9 minutes) \\
\hline $\mathrm{O}_{2}$ vitiation & $15 \%$ & 174 seconds (2.9 minutes) \\
\hline $\mathrm{OD}$ & $0.5 \mathrm{~m}^{-1}$ & 90 seconds (1.5 minutes) \\
\hline Heat Exposure & $200^{\circ} \mathrm{C}$ & 180 seconds (3 minutes) \\
\hline
\end{tabular}




\subsection{Simulation 3: Typical Office Floor (Sprinklered)}

The second simulation describes fire spread on a sprinklered office floor. Sprinklers were modeled with activation temperature of $74^{\circ} \mathrm{C}$. Fire starts with a burning office work station in a cubicle office similar to that of simulation 1 . The fire is modeled using a $4 \mathrm{~m}^{2}$ burner representing the size of a typical work station. This section discusses the effects of sprinkler on design fire (HRR, gas temperature and gas concentration) of a typical medium size office floor layout.

\subsubsection{HRR}

Sprinklers have a profound effect on the development of a fire within a compartment. Figure 6-17 shows the HRR of the office floor with sprinkler. HRR did not exceed $5 \mathrm{MW}$, it remained below $1 \mathrm{MW}$ for most part of the entire simulation.

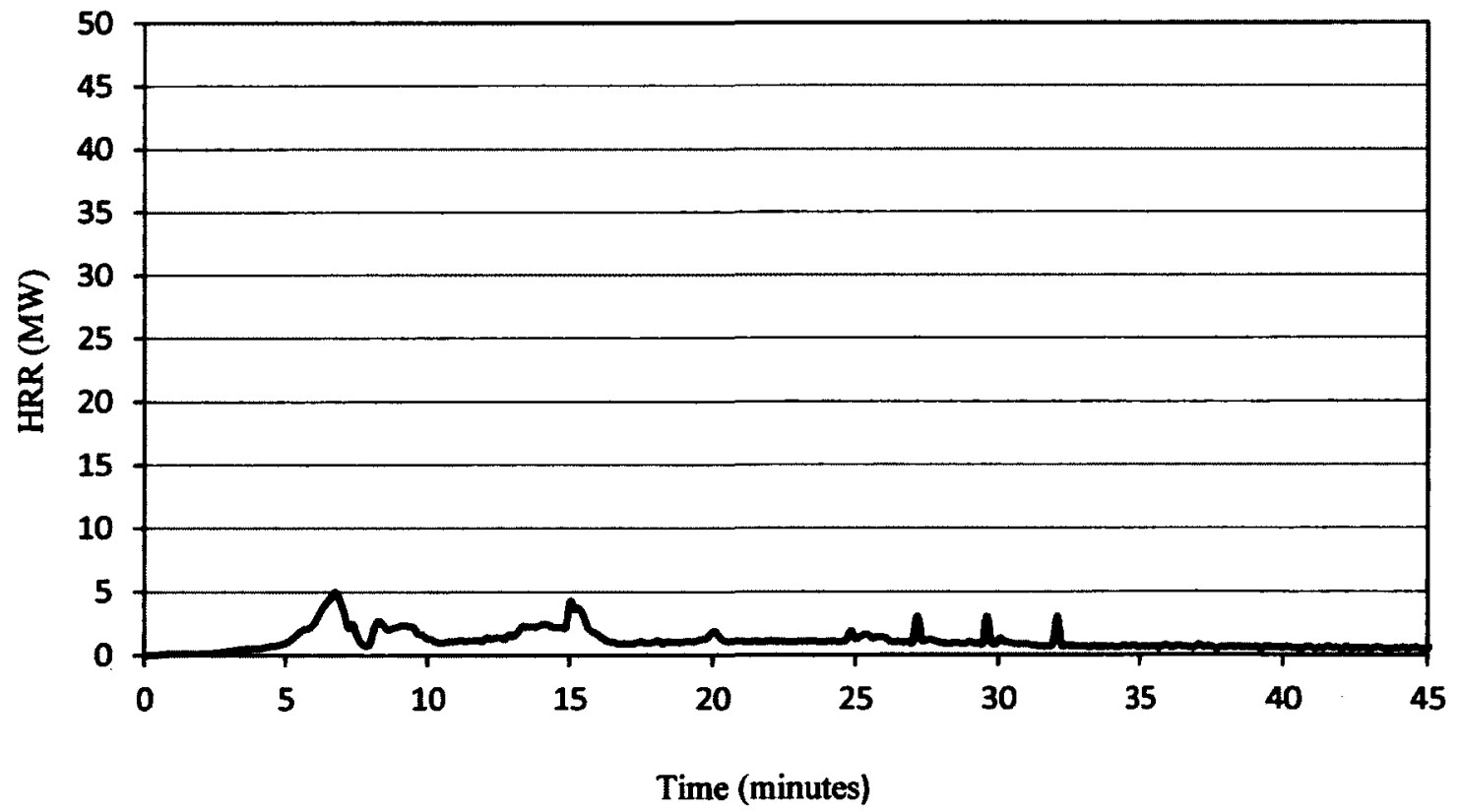

Figure 6-17 Heat Release Rate of Sprinklered Office Floor 


\subsubsection{Gas Temperature}

Figure 6-18 and Figure 6-19 represent average gas temperature measurements taken at the cubicle locations and enclosed office locations respectively. Gas temperature of the entire floor did not rise above $200^{\circ} \mathrm{C}$, tenability criteria used for heat exposure. The first temperature peak, approximately $180^{\circ} \mathrm{C}$, was recording before the first sprinkler activated. It was observed that gas temperature reduces dramatically when sprinklers activated, hence, keeping temperatures within the compartment below $80^{\circ} \mathrm{C}$ for most part of the fire exposure.

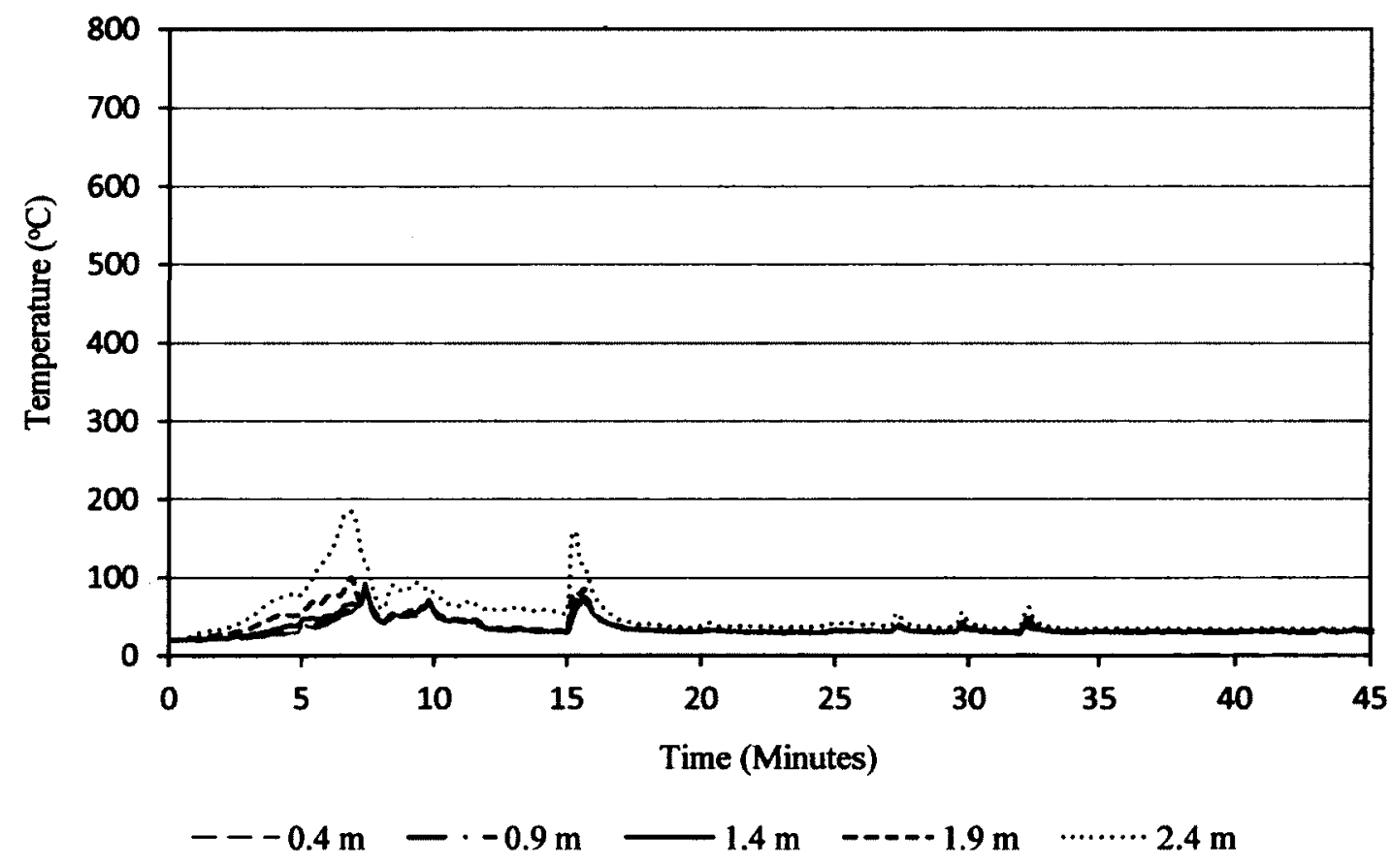

Figure 6-18 Gas Temperature of Sprinklered Office Floor (Cubicle Offices) 


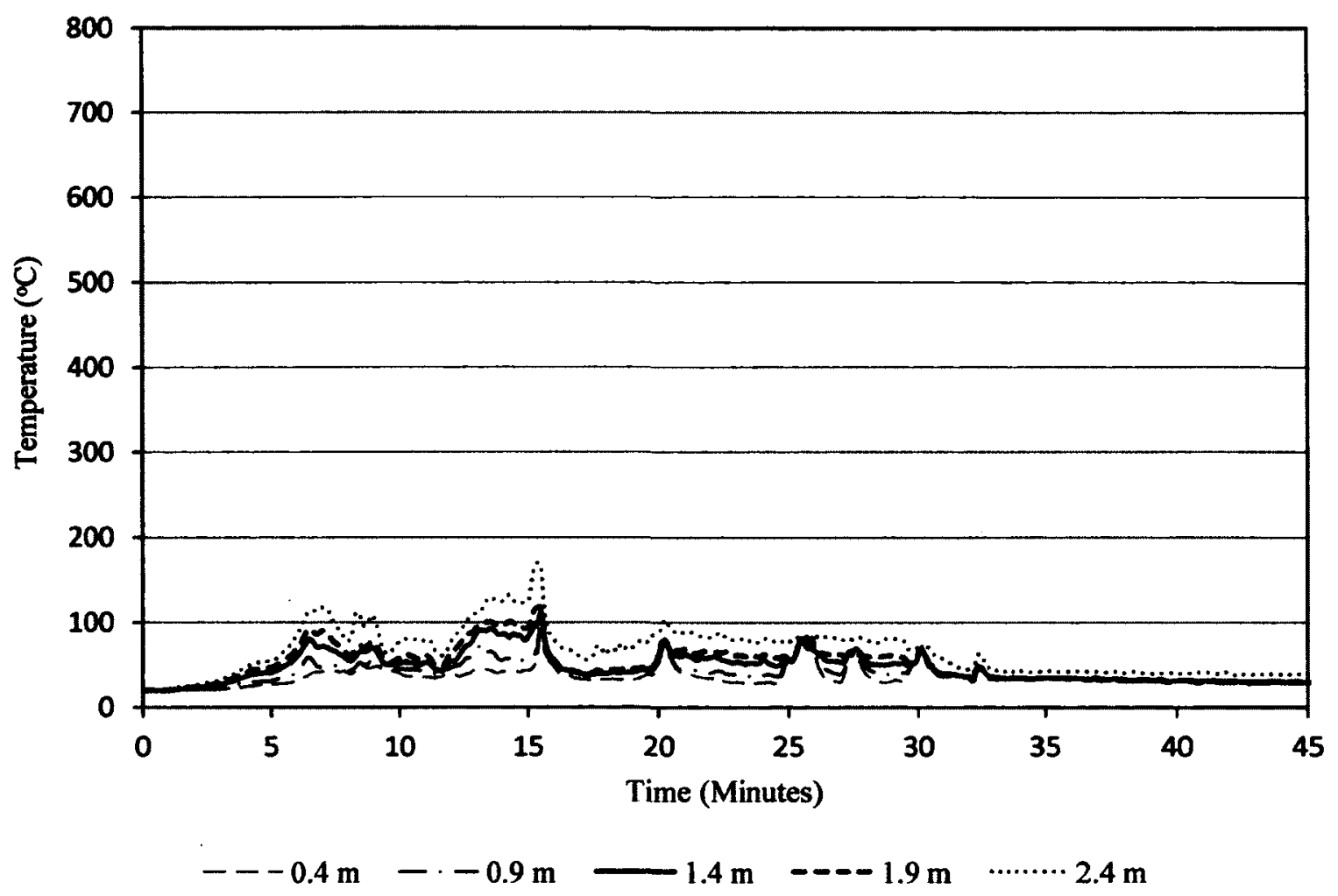

Figure 6-19 Gas Temperature of Sprinklered Office Floor (Enclosed Offices)

\subsubsection{Toxicity and gas concentration}

This section discusses the impact of sprinklers on fire gas concentrations within the compartment. The time to untenable conditions using criteria presented in earlier sections has been discussed.

\subsubsection{CO and $\mathrm{CO}_{2}$ Concentration}

Sprinklers have a profound effect on both the HRR and the temperature within a compartment exposed to fire. In addition, it was observed from the simulation that tenability limit for $\mathrm{CO}_{2}$ was never reached, Figure 6-20. This can be explained due to inefficiency in combustion as a result of the sprinkler action. As a result of the inefficiencies in combustion 
and reduced combustion, limited amount of combustion products are produced. On the other hand, inefficiency in combustion process causes more $\mathrm{CO}$ to be produced compared to the un-sprinklered scenario, Figure 6-21. It must be noted that tenability limit for $\mathrm{CO}$ occurred approximately the same time the un-sprinklered office floor occurs.

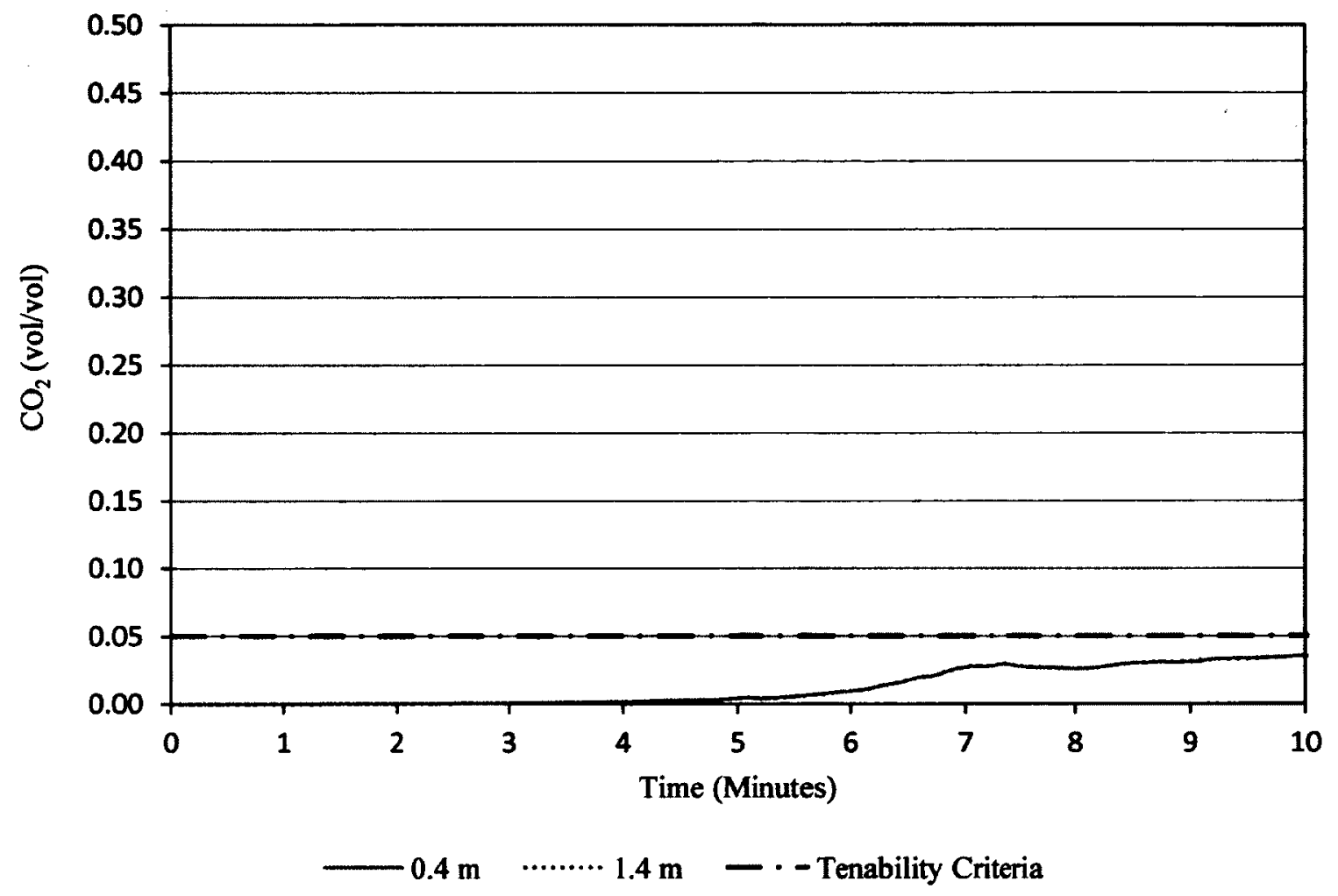

Figure 6-20 $\mathrm{CO}_{2}$ Concentration 


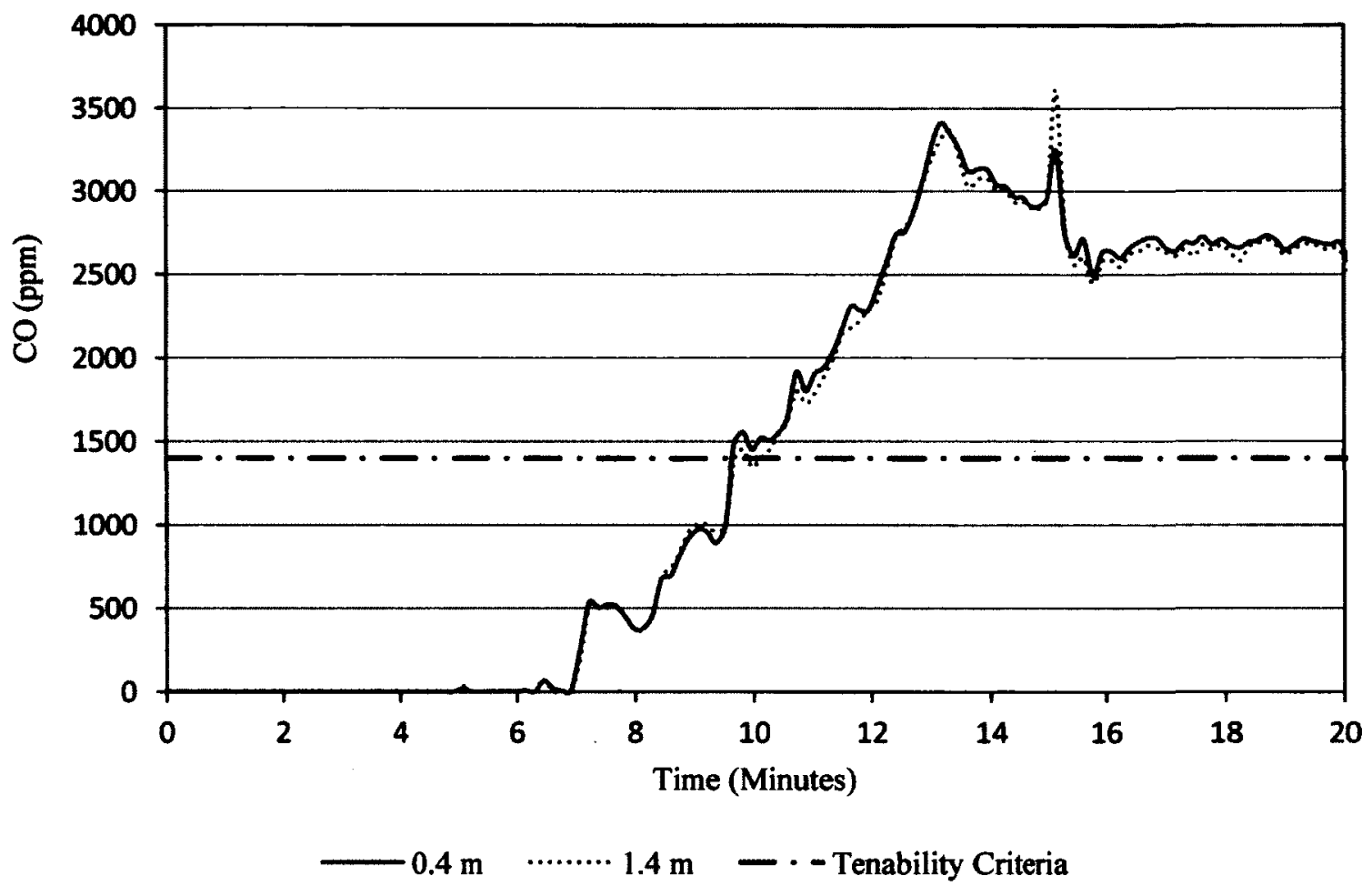

Figure 6-21 CO Concentration

\subsubsection{2 $\mathrm{O}_{2}$ Vitiation}

Similar to the non-sprinklered office scenario, $\mathrm{O}_{2}$ volume concentration begins to drop after 5 minutes of the fire exposure. However, it takes much longer, approximately 12 minutes, to reach the tenability criteria of $15 \%$, Figure 6-22. It must be noted that, $\mathrm{O}_{2}$ volume concentration does not drop below $13 \%$. It has been mentioned in the literature that collapse and incapacitation occurs in $\mathrm{O}_{2}$ concentration between 6 and 8\% (see Table 2-6). Death occurs in concentrations below $6 \%$. Though the tenability limit used for the current study was reached with approximately 12 minutes of the fire exposure, $\mathrm{O}_{2}$ concentration within the office floor is not likely to cause incapacitation or death. 


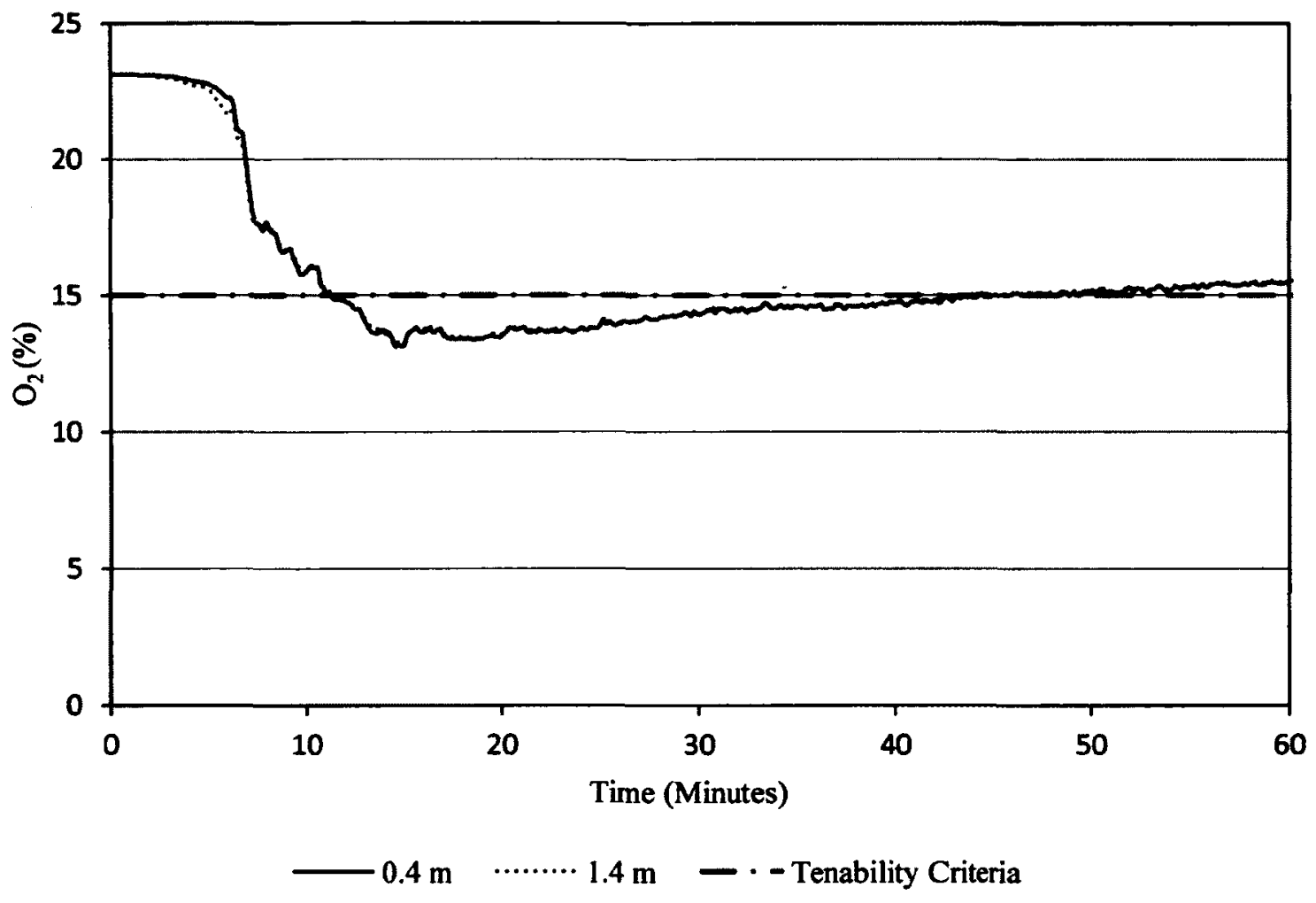

Figure 6-22 $\mathrm{O}_{2}$ Concentration

\subsubsection{Optical Density (OD)}

Similar to the un-sprinklered office floor, visibility within the sprinklered floor drops at a very fast rate to reach its tenability limit within approximately 3 minutes of the fire exposure, see Figure 6-23. 


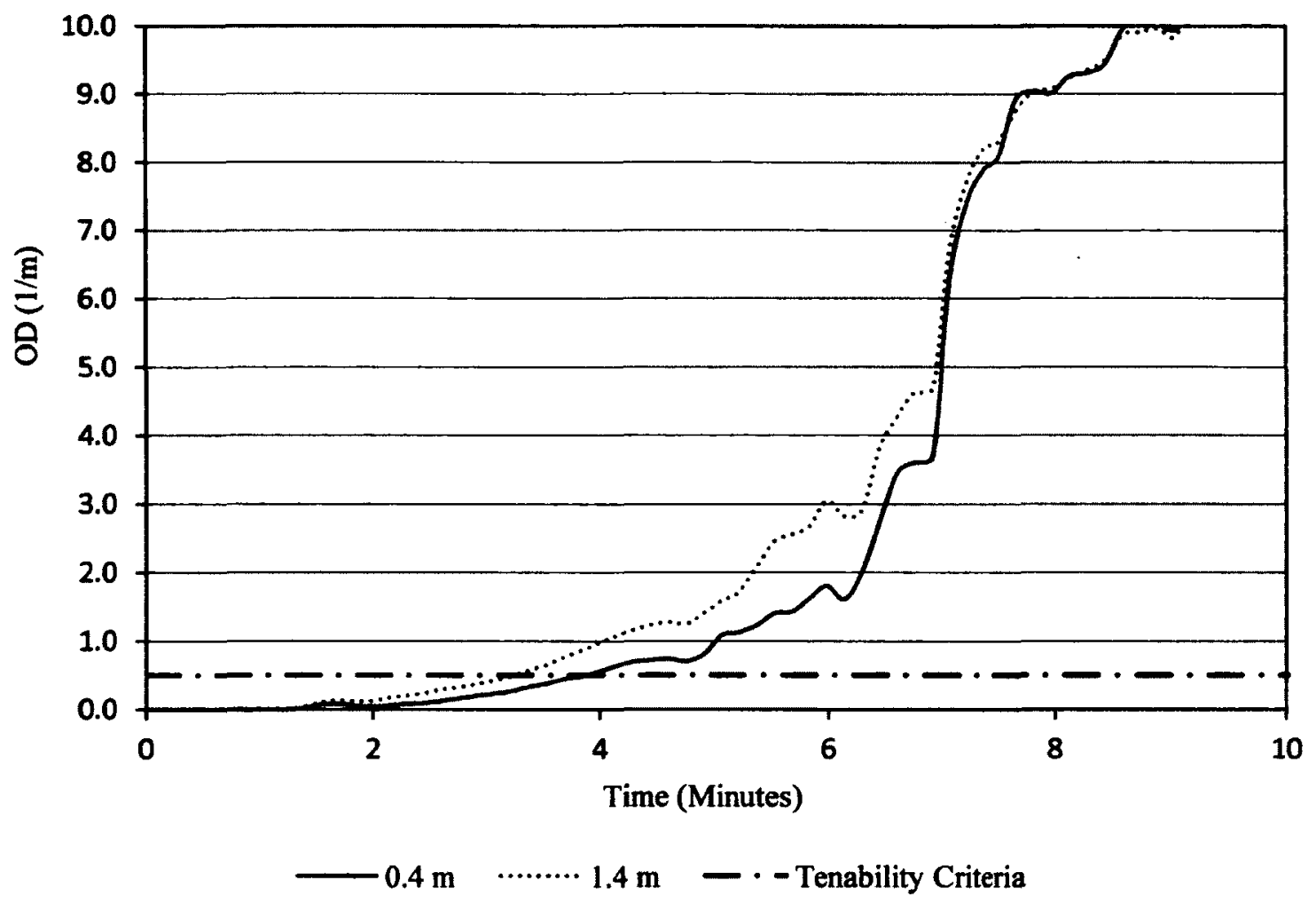

Figure 6-23 Tenability Limit of Optical Density

\subsection{Summary}

The purpose of the CFD modelling was to define appropriate design fire profiles that represent potential fires in office occupancies: Design fire has been discussed under the following headings: $\mathrm{HRR}$, gas temperature, toxicity $\left(\mathrm{CO}, \mathrm{CO}_{2}\right.$, and $\mathrm{O}_{2}$ vitiation), and smoke and optical density.

\subsubsection{HRR}

HRR was found to be very sensitive to underlying grid size. HRR predictions reduced when the grid size is refined. Halving the grid size resulted in approximately $18 \%$ reduction in HRR and reduction in time to peak HRR. Grid size of $0.1 \mathrm{~m}$ produced maximum HRR that 
compares very well with the theoretical maximum. The $0.2 \mathrm{~m}$ maximum grid size produced fairly good HRR peak comparison to the theoretical max.

For a typical single enclosed office, HRR had a maximum peak of about $7 \mathrm{MW}$ in approximately 6 minutes based on the fire scenario considered in this study. The fire had a steady state HRR of about 5MW and begun to decay after approximately 25 minutes of the fire exposure.

For the typical non-sprinklered office floor where fire started within the cubicle area, the HRR had first minor peak of $23 \mathrm{MW}$. The HRR observes a major peak of approximately $60 \mathrm{MW}$ with a steady burning period of about 15 minutes. The peak HRR was observed to be associated with time for major window breakage.

For the sprinklered typical office floor, HRR did not exceed $5 \mathrm{MW}$, it remained below $1 \mathrm{MW}$ for most part of the entire simulation, Figure 6-24.

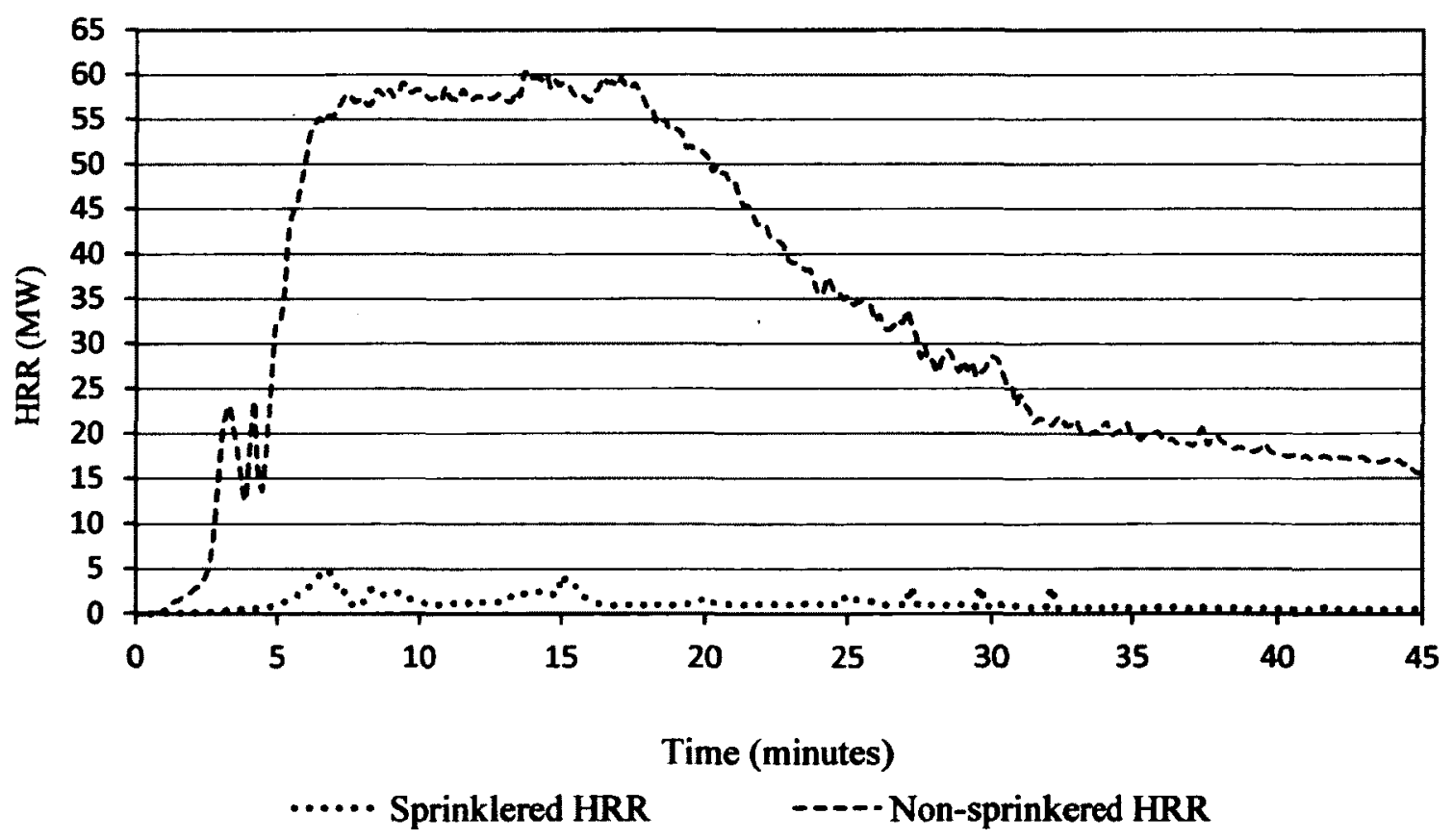

Figure 6-24 HRR of Sprinklered and Non-sprinklered Office Floor 


\subsubsection{Gas Temperature}

Similar to the HRR trend, refining the underlying grid size resulted in lower gas temperature predictions. However, the grid size did not have a significantly impact on the gas temperature predictions as compared to the HRR predictions.

For the non-sprinklered typical office floor, the gas temperature had a peak of approximately $1400^{\circ} \mathrm{C}$. On the other hand, the gas temperature of sprinklered typical office floor did not rise above $200^{\circ} \mathrm{C}$, see Figure $6-25$. The average gas temperature was significantly reduced when sprinklers activated. Gas temperature within the compartment was recorded below $80^{\circ} \mathrm{C}$ after the activation of sprinklers.

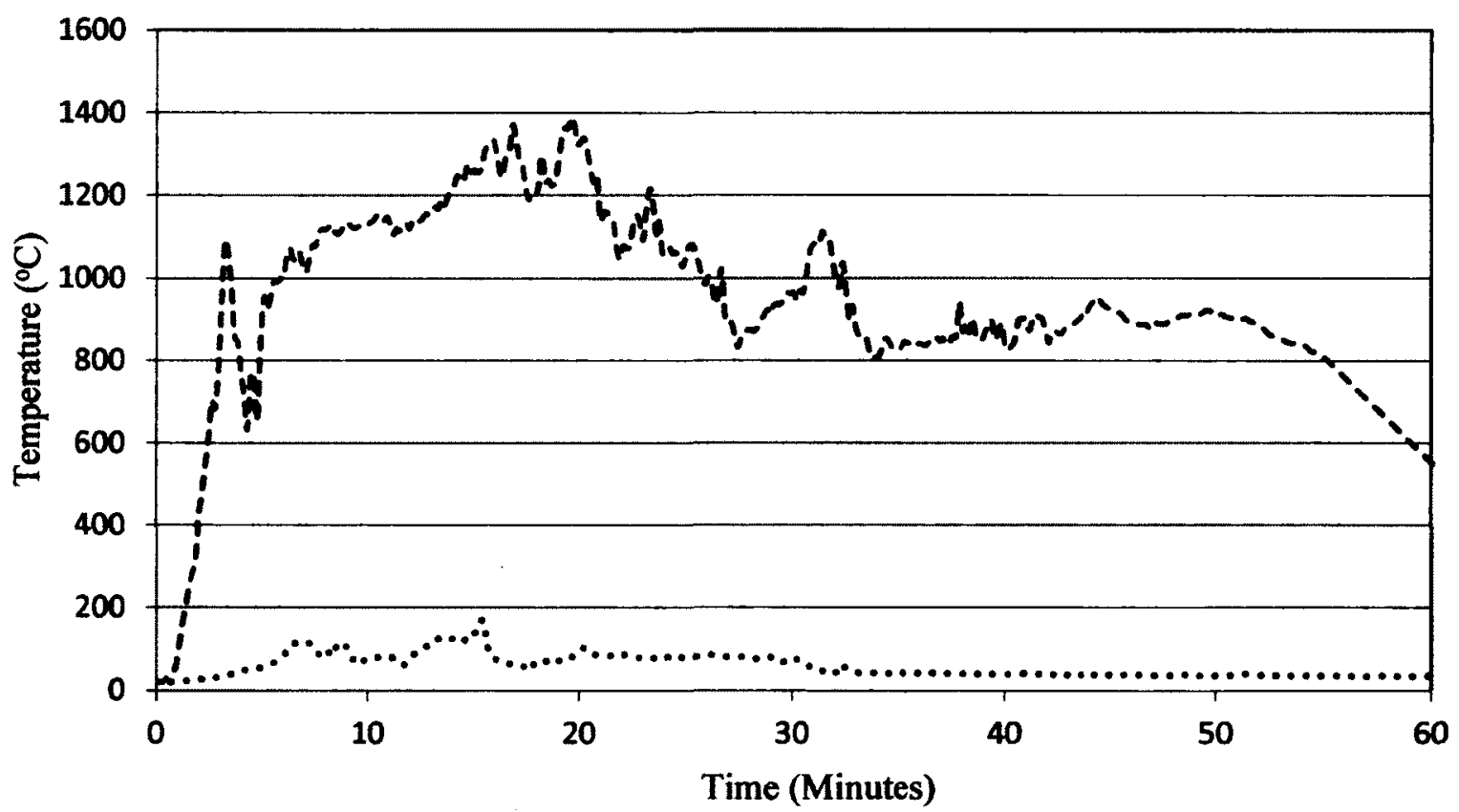

Peak Gas Temperature (Sprinklered) Peak Gas temperature (Non-sprinklered)

Figure 6-25 Peak Gas Temperature of Sprinklered and Non-sprinklered Floor 


\subsubsection{Tenability}

In the non-sprinklered office floor, visibility was the first hazard to arise at 1.5 minutes. Tenability limits for $\mathrm{CO}_{2}$ and $\mathrm{O}_{2}$ vitiation was the next hazard to arise at approximately 2.9 minutes. Tenability limits for a combined effect of $\mathrm{CO}_{2}, \mathrm{CO}$ and $\mathrm{O}_{2}$ vitiation (i.e FED) has been presented in Appendix H. CO concentration and convective heat exposure of the skin to hot gases within the compartment were the last hazards to arise at approximately 3 minutes. The presence of sprinklers reduced the overall fire gases produces within the compartment. Sprinkler action significantly reduced the time to reach untenable conditions, see Figure 6-26 to Figure 6-29.

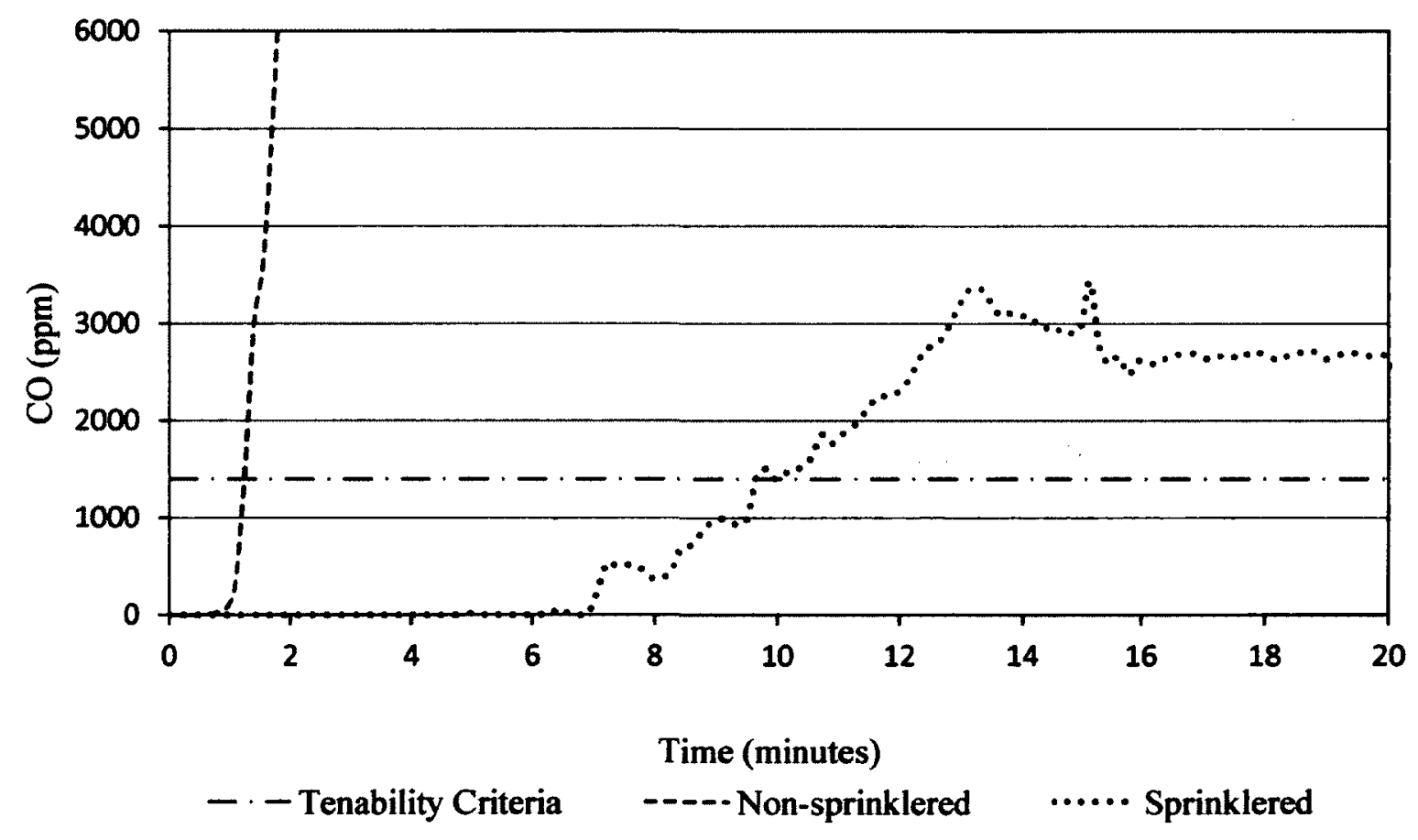

Figure 6-26 CO Concentration of Sprinklered and Non-sprinklered Floor 


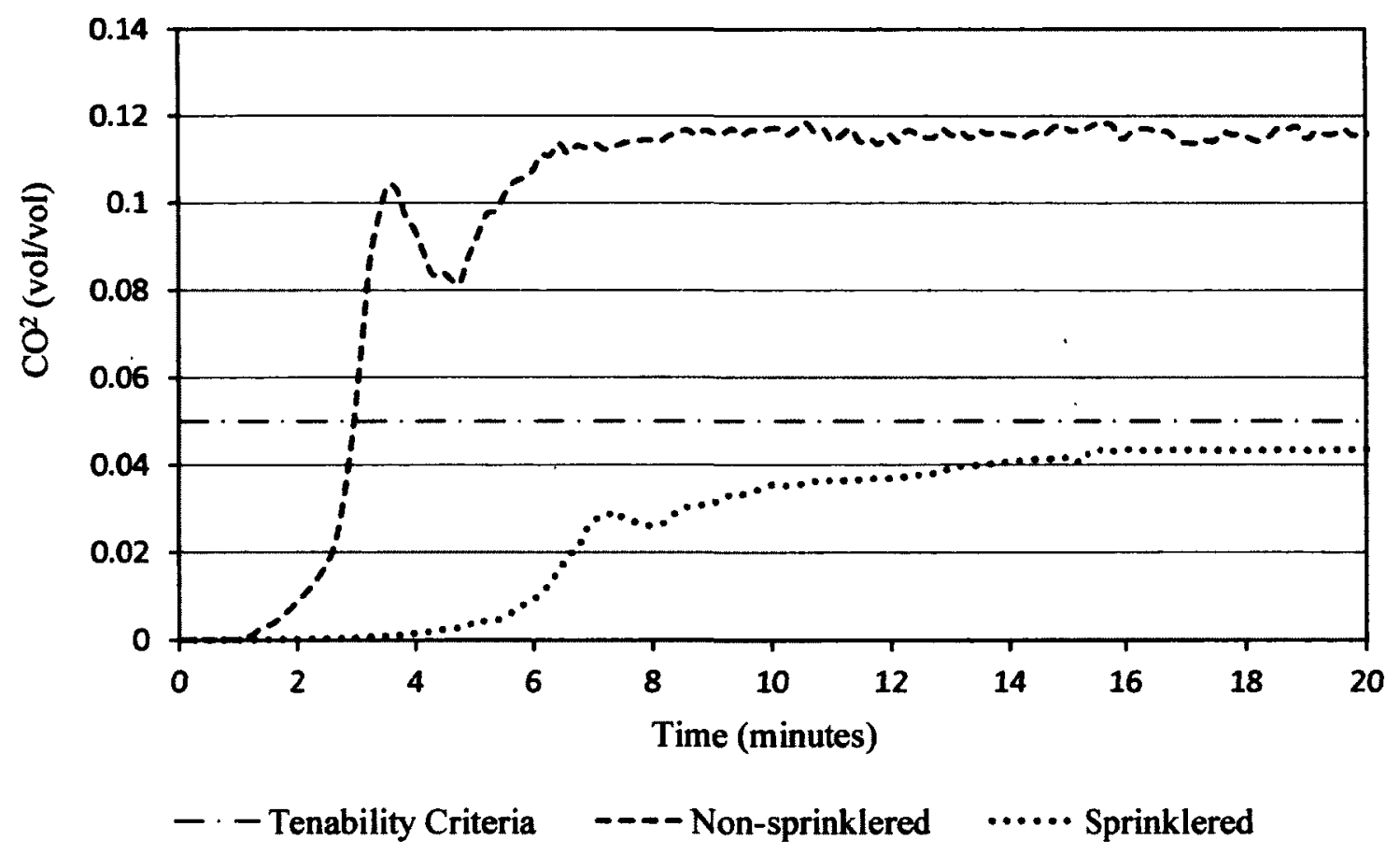

Figure 6-27 $\mathrm{CO}_{2}$ Concentration of Sprinklered and Non-sprinklered Floor

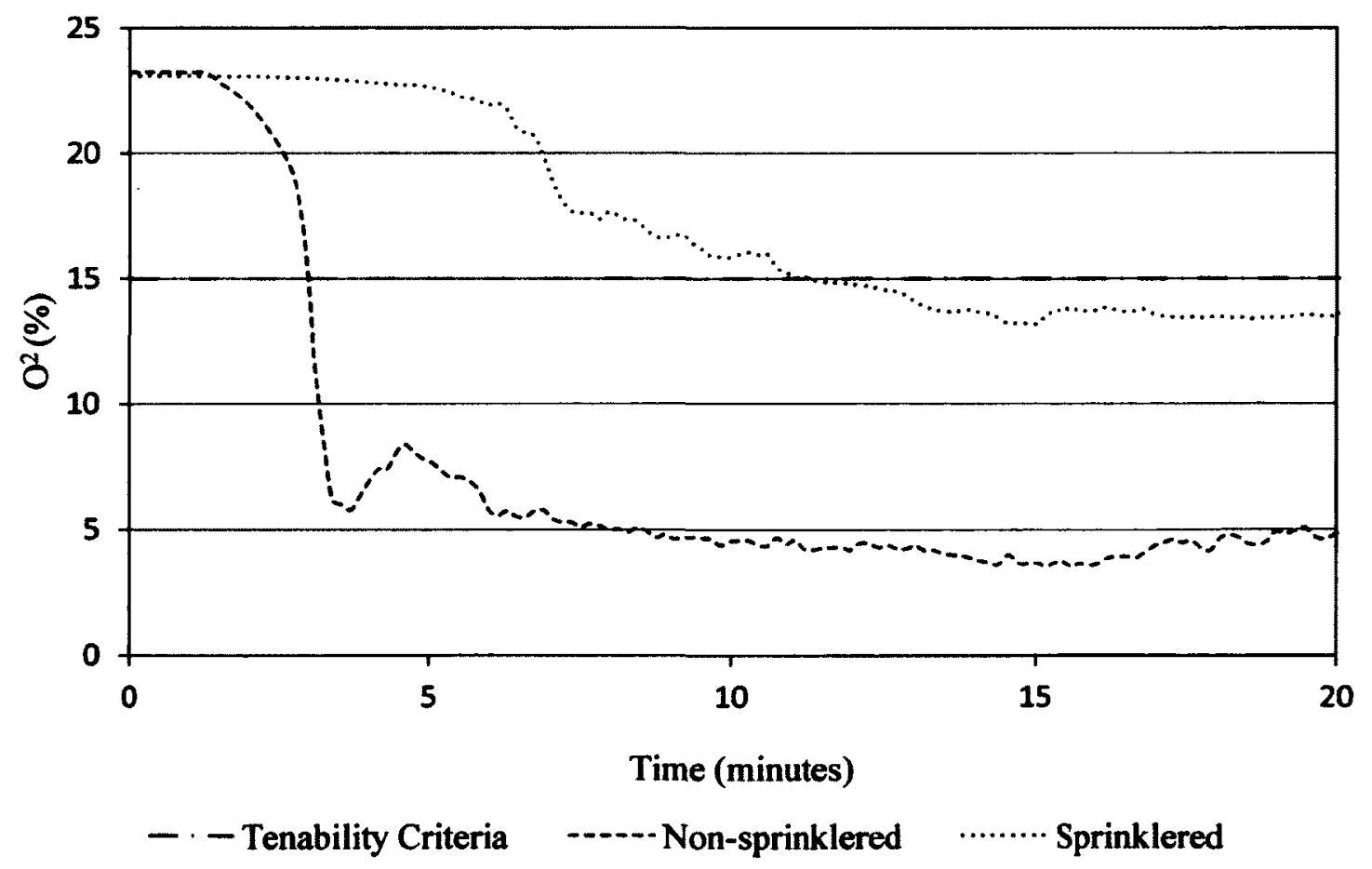

Figure 6-28 $\mathrm{O}_{2}$ Concentration of Sprinklered and Non-sprinklered Floor 


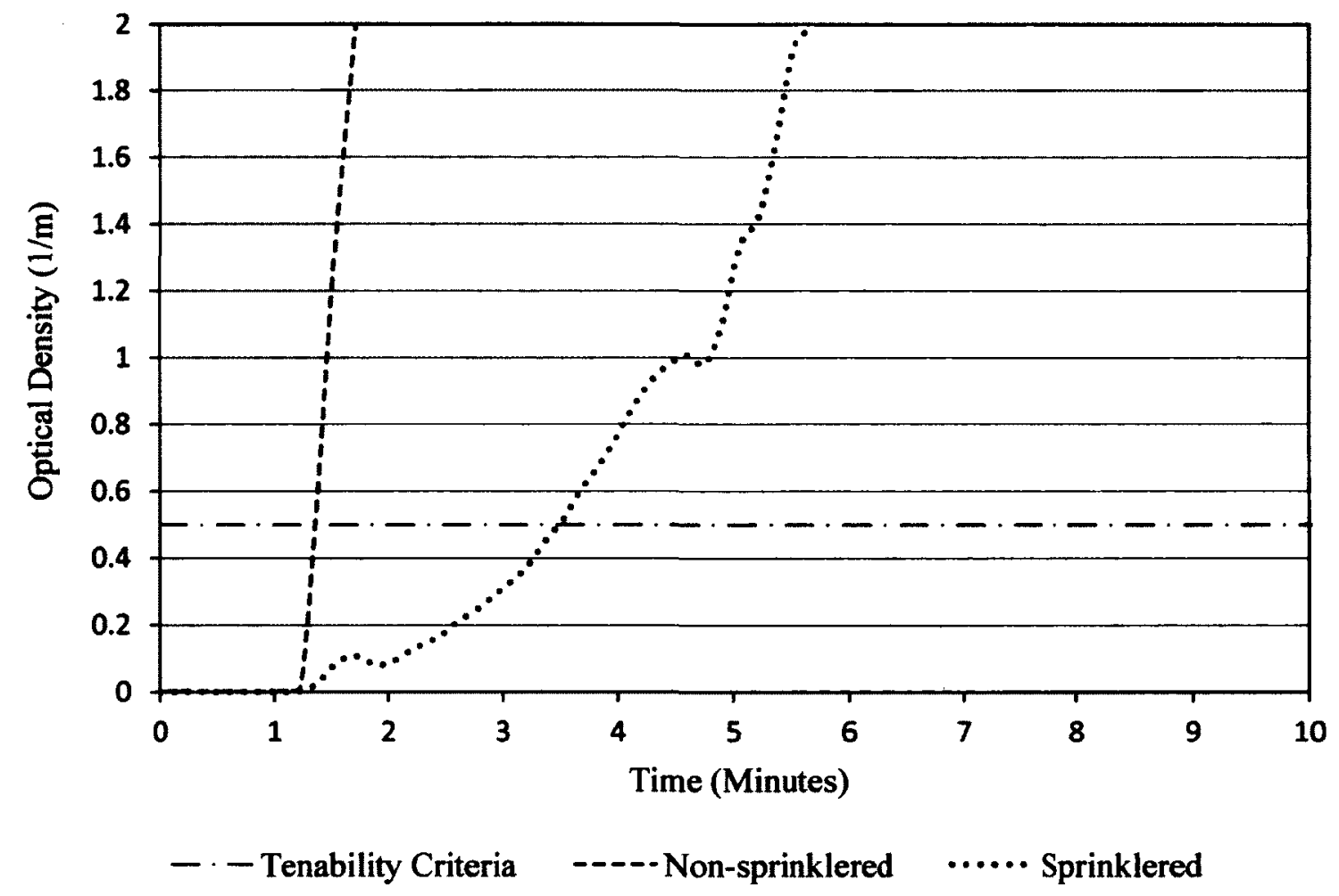

Figure 6-29 Optical Density of Sprinklered and Non-sprinklered Floor

\subsubsection{Fire Detection and Suppression System Activation}

Smoke detectors were the first fire detection system to activate, 30 seconds after ignition. Heat detectors activated at approximately 3.3 minutes (200 seconds). The first sprinkler head opened at approximately 1.7 minutes (100 seconds). 


\section{7: Conclusions and Recommendations}

\subsection{Introduction}

The approach used to achieve the set objectives of the study included:

- Fire load survey

The fire load survey was conducted in 103 offices in five different office buildings within Canada's National Capital Region, Ottawa and Gatineau, between November 2010 and April 2011. The following survey methodologies were used: weighing, inventory, combination and questionnaire method. The study collected and presented data on fire load density $\left(\mathrm{MJ} / \mathrm{m}^{2}\right)$, fire load (MJ), compartment size and geometry, characteristics of ventilation opening, types of combustibles and arrangements, and contribution of different materials to the total fire load.

- Correlation of fire load density among different survey methodologies

To determine the impact of varying methodologies on the survey results fire load data was compared among different survey methodologies (weighing, inventory, combination, and questionnaire). The ștudy presented percentage differences (Table 4-5 to Table 4-7) and fire load density conversion factors (Example 1 to 3 and Figure 4-5).

- Fire modeling

A computational fluid dynamics model (CFD) model, fire dynamic simulator (FDS) was used to simulate expected fire scenarios of a typical office floor. The simulation was based on fire load data from the survey results and input data from a series of tests conducted at NIST[48]. 
- Design fire recommendations

Appropriate design fire characteristics that represent potential fires in a typical office floor have been defined. Design fires presented in this study reflect modelling results and has been defined under the following: $\mathrm{HRR}$, gas temperature, toxicity $\left(\mathrm{CO}, \mathrm{CO}_{2}, \mathrm{O}_{2}\right.$ vitiation), and visibility (optical density).

\subsection{Conclusions}

The major findings and conclusions of this study include:

\subsubsection{Fire Load Survey}

- There are uncertainties associated with the use of each fire load survey method. The direct weighing method has uncertainties when estimating weights of heavy and fixed items. Uncertainties in fire load density values of the inventory method may be attributed to measurements of irregular shaped objects, and also the use of combustible densities to convert measured volume into weights. The questionnaire method may also have uncertainties in combustible content and floor areas estimated by occupants without direct supervision of an expert.

- The combination method reduces uncertainties associated with the singular use of either the weighing or inventory method hence provide better fire load density values as compared to all the other methods.

- The study found wood and paper to be the major contributor to the fire load density. Wood and paper contributed about $64 \%$ to the total combustible content. In addition, the current survey shows an increase use of plastics in office spaces as compared to previous survey done in the 70 's and $90^{\prime}$ s. 
- The survey results indicate that fire load density obtained from the inventory method is $45 \%$ greater than the weighing method and $38 \%$ greater than the combination method. Fire load density obtained from the combination method is about $10 \%$ less than that of the weighing method.

- Fire load density decreased with increasing floor area. Larger floor areas (enclosed offices) resulted in lower fire load densities whereas lower floor areas (cubicle offices) resulted in higher fire load densities.

- For accuracy, combustibles were classified into cellulosic (paper and wood), plastics and textiles. The surveyor must exercise caution with the choice of the appropriate calorific values and densities of various materials.

- During the survey, about $50 \%$ of metal cabinets in offices were opened. Based on this observation, the study considered combustibles stored within cabinets using 'derating' factors listed in Table 3-3.

- Security concerns and lack of participation were some of the major challenge encountered in the hand delivered questionnaire method. Future surveys should consider other modes of questionnaire administration (internet, phone interviews and by post).

- The study suggests that one should be cautious when using the questionnaire method due to uncertainty that may be caused by participants. To overcome this problem, it is recommended that an experienced surveyor should validate the questionnaire results before performing any analyses. 


\subsubsection{FDS Modelling}

- Larger grid sizes resulted in higher HRR peaks. Refining the grid sizes reduced the HRR within the compartment. From the simulation results, halving the grid sizes resulted in approximately $18 \%$ reduction in HRR and reduction in time to peak HRR.

- In addition, refining the grid size reduced the gas temperature of the upper layer and time to first peak. However, unlike the HRR, the difference in gas temperature prediction by halving the grid size was not significant, less than $5 \%$.

- Maximum HRR prediction, using grid size of $0.1 \mathrm{~m}$, compares very well with the theoretical maximum. However, peak temperature prediction was poor.

- Reduction in opening height, $h_{v}$, reduced the initial HRR, increased peak HRR and delayed the time to peak

- Similar to the HRR profile, reduction in opening height resulted in a reduction in the initial gas temperature prediction. However, there was an increase in the overall peak gas temperature prediction and a delay in the time to reach that peak.

- Visibility is the first hazard to arise that could affect the evacuation in the initial stage of the fire development.

- Sprinklers have a profound effect on the development of a fire within a compartment. According to the simulation results discussed in this study, sprinklers reduced the HRR by about $90 \%$.

\subsection{Contribution}

This thesis provided data on fire load and contribution of different combustibles in office occupancies. Those are often required as inputs to determine HRR in fire test and fire 
modelling in a performance based design. The study correlated fire load survey methodologies and analyzed the impact of the survey methodology on the fire load. A better understanding of this impact will help to reduce uncertainties that may potentially arise in the determination of design fires as a result of the fire load input. To better understand the relationship between fire load obtain from different survey methodologies, conversion factors and chart have been provided. The fire load density correlation chart developed will help compare/ convert fire load densities obtained using different methodologies. In addition, this thesis provided HRR, temperature profiles, and gas concentrations of typical office floor (sprinklered and non-sprinklered) fire scenario. Discussions based on suggested design fire curves in this study offers valuable considerations in the determination of design fires for office occupancies in a performance based fire protection engineering design.

\subsection{Recommendation for Future Research}

The study had identified through review of literature that several factors may account for variations in fire load data sets. Those factors include: the survey methodology, regional and cultural differences, time, taste, etc. The current study focused on the impact of survey methodology on fire load, it will be interesting for future research to consider the impact of other factors such as time, regional and cultural differences, and taste.

Additionally, it would be interesting to consider if the type of office ownership (private or government) has an effect on fire load results.

There is limited information on full scale fire tests of office occupancies. To help validate model results and increase confidence in the use of CFD modelling in performance based fire 
protection engineering, both small scale and large scale office fire experiments are recommended.

Several parameters in FDS may affect the HRR and the gas temperature prediction in FDS. The scope of the current study was limited to grid sensitivity analysis. It is recommended that future research considers the impact of other parameter such as, gas phase reaction, material characteristics, etc. on the HRR, gas temperature, and fire gases prediction.

It will be interesting for future research to study the impact of different parameters such as window breakage temperatures, ignition sources and location, boundary conditions, etc on the resulting design fire.

It will also be interesting for future research to analyze the impact of using different CFD models on the resulting design fire. 


\section{References}

1. Meacham, B. J., \& Custer, R. L. P. (1995). Performance-Based Fire Safety Engineering: An Introduction of Basic Concepts. Journal of Fire Protection Engineering, Vol. 7 (2), pp 35-54.

2. SFPE (2000). SFPE Engineering Guide to Performance-Based Fire Protection Analysis and Design of Buildings, Society of Fire Protection Engineers and National Fire Protection Association, Quincy, Massachusetts.

3. Hadjsophocleous, G. V., Benichou, N., \& Tamim, A. S. (1998). Literature Review of Performance-Based Codes and Design Environment. Journal of Fire Protection Engineering, Vol. 9 (1), pp 12-40.

4. Bukowski, R. W., \& Tanaka, T. (1991). Toward the goal of a performance fire code. Fire Material Journal, Vol. 15(4), pp 175-180.

5. Johnson, P. F. (1993). International Implications of Performance Based Fire Engineering Design Codes. Journal of Fire Protection Engineering, Vol. 5 (4), pp 141-146.

6. National Research Council (2010). 2010 National Building Code. Institute for Research in Construction, National Research Council of Canada, Ottawa

7. Ministry of Municipal Affairs and Housing (2006). 2006 Ontario Building Code. Building and Development Branch, Ontario Ministry of Municipal Affairs and Housing, Toronto, Canada

8. ISO/TS 16733 (2006) Fire Safety Engineering - Design Fire Scenarios and Deign Fires. Technical Report, International Organization for Standards, Geneva, Switzerland.

9. Bwalya, A., (2008). An Overview of Design Fires for Building Compartments. Fire Technology Journal, Vol. 44 (2), pp 167-184

10. Bukowski, R. W. (2006). Determining Design Fires for Design-level and Extreme Events. Paper presented at SFPE 6th International Conference on Performance-Based Codes and Fire Safety Design Methods, Tokyo. 
11. Hietaniemi, J., Mikkola, E. (2010). Design Fires for Fire Safety Engineering. VTT Working Papers 139, VTT Technical Research Centre of Finland, Vuorimiehentie, Finland.

12. Klote, J. H. (2002). Design Fires: What You Need to Know. HPAC Engineering, USA

13. SFPE (2000). SFPE Engineering Guide to Performance-based Fire Protection Analysis and Design of Buildings. Society of Fire Protection Engineers, Quincy, Mass. : National Fire Protection Association.

14. Su J. Z., Benichou, N., Bwalya A., Lougheed, G., Taber, B., \& Leroux, P. (2011). Unprotected Floor Assemblies and Tenability Conditions in a Test House Under Two Basement Fire Scenarios. Fire Technology, vol. 47(3), pp 631-664.

15. Purser, D. A. (2008). Assement of Hazards to Occupants from Smoke, Toxic Gases, and Heat. In: DiNenno, P. J., Drysdale, D., Beyler, C. L., Walton, W. D., Custer, R. L. P., Hall, J. R., \& Watts, J. M. (eds). The SFPE Handbook of Fire Protection Engineering, 4th edn. Society of Fire Protection Engineers, National Fire Protection Association, Quincy, MA, Section 2, Chapter 6

16. Buchanan, A.H. (1994). Fire Engineering Design Guide. Centre for Advanced Engineering, University of Canterbury, New Zealand

17. ISO 13571 (2007). Life-threatening components of fire - guidelines for the estimation of time available for escape using fire data. International Organisation for Standardization, Geneva, Switzerland.

18. Babrauskas, V. (1981). A Closed-form Approximation for Post-flashover Compartment Fire Temperatures. Fire Safety Journal, Vol. 4(1), pp.63-73

19. McCaffrey, B. J. , Quintiere, J. G., \& Harkleroad, M. F. (1981). Estimating Room Temperatures and the Likelihood of Flashover Using Fire Test Data Correlations. Fire Technology, Vol. 17(2), pp.98-119

20. Babrauskas, V. (1980). Estimating Room Flashover Potential. Fire Technology, Vol.16(2), pp.94-103.

21. Thomas, P. H. (1981). Testing Products and Materials for Their Contribution to Flashover in Rooms, Fire and Materials, Vol.5(3), pp.103-111. 
22. Eurocode 1: Actions on Structures - Part 1-2: General actions - Actions on Structures Exposed to Fire - European Standard 2002, Final Draft, Ref No. prEN 1991-12:2002E, Brussels.

23. Babrauskas, V., \& Peacock, R. D. (1992). Heat release rate-the single most important variable in fire hazard. Fire Safety Journal, Vol. 18, pp. 255-272.

24. Linteris, G. T., \& Rafferty, I. P. (2008). Flame size, Heat release, and Smoke Points in Material Flamability. Fire Safety Journal, Vol 43, pp 442-450.

25. Janssens, M. L. (1991). Measuring Rate of Heat Release by Oxygen Consumption. Fire Technology, Vol.27, pp.234-249.

26. Stroup, D. W., DeLauter, L., Lee, J., \& Roadarmel, G., (2000). Exhaust Hood Heat Release Rate Measurement System. NISTIR 6509, Large Fire Research Facility (Building 205), NIST, Gaithersburg, MD

27. NFPA (2010). Proposed Draft of NFPA 557, Standard for Determination of Fire Load for Use in Structural Fire Protection Design 2012 Edition, National Fire Protection Association, Quincy MA

28. Culver, C. \& Kushner, J. (1975). A Program for Survey or Fire Loads and Live Loads in Office Buildings. NBS Technical Note 858, National Bureau of Standards, Gaithersburg, MD.

29. Issen, L. A. (1980). Single-Family Residential Fire and Live Loads Survey. NBSIR Report 80-2155, National Bureau Standards, Gaithersburg, MD 20899.

30. Kumar, S. \& Rao, C. V. S. K., (1997). Fire Loads in office Buildings, Journal of Structural Engineering, Vol. 123(3), pp. $365-368$.

31. Korpela, K \& Kushner J., (2000). Fire Loads in Office Buildings. Proceedings $-3^{\text {rd }}$ International conference on Performance-Based Codes and Fire Safety Design Methods, Society of Fire Protection Engineers, Bethesda, MD.

32. Ingberg, S. H., Dunham, J. W., \& Thompson, J. P. (1957). Combustible Contents in Buildings. Building Materials and Structures Report 149, National Bureau of Standards, Washington, DC. 
33. Baldwin, R., Law, M., Allen, G., \& Griffiths, L. G. (1970). Survey of Fire-Loads in Modern Office Buildings - Some Preliminary Results, JFRO, Fire Research Note No. 808

34. Caro, T. \& Milke, J. (1996). A Survey of Fire Loads in Contemporary Office Building. NIST Report GCR-96-697, NIST, Gaithersburg, MD

35. NBS (1942). Building Materials and Science structures - Fire Resistance Classification of Building Construction. Report of Subcommittee on Fire Resistance Classification of Central Housing Committee on Research, Design and Construction, Report BMS92, National Bureau of Standards, Washington.

36. Green, M. (1977). A Survey of Fire Loads in Modern Office Building - Some Preliminary Results. Fire Technology, Vol. 13(1), pp $42-52$.

37. Barnett, C. R. (1984). Pilot Fire Load Survey. Project Report No 3580, New Zealand Fire Protection Association. MacDonald Barnett Partners, Auckland

38. Yii, H. W. (2000). Effects of Surface Area and Thickness on Fire Loads. Fire Engineering Research report, No. 2000/13 University of Canterbury, Christchurch, New Zealand

39. Zalok, E. (2006). Design Fires for Commercial Premises. PhD thesis, Carleton University, Canada, 258 pp.

40. Kose, S., Kawagoe, K., \& Hagiwara, I. (1988). Survey of movable fire load in Japanese dwellings. Fire Safety Science-Proceedings of the Second International Symposium, Hemisphere Pub., pp. 403-412.

41. Bwalya, A. C. (2004). An Extended survey of combustible content in Canadian residential Living Rooms. Research Report: Institute for Research in Construction, national Research Council Canada, Ottawa. No. 176.

42. Bwalya, A. C., Lougheed, G. \& Kashef, A., (2010). Survey results of combustible contents and floor areas in Canadian multi-family dwellings. Fire Technology Journal, Vol. 46(1), pp. 1-20.

43. Bwayla, A. C., Sultan, M. \& Benichou, N., (2004). A Pilot Survey of Fire loads in Canadian homes. Research Report: Institute for Research in Construction, national Research Council Canada, Ottawa. No. 159 
44. Bryson, J. O., \& GROSS, D. (1967). Techniques for the survey and evaluation of live floor loads and fire loads in modem office buildings. National Bureau of Standards, Building Science. Ser. 16, Washington, D.C.

45. Anon. (1998). Appendix C: Fire Load, Fire Resistance and Non-combustibility, Draft Part 2A. Fire code Reform Center, Sydney. NAW Australia, pp C1-C35.

46. Narayanan, P. (1995). Fire Severity for Structural Fire Engineering Design. Study Report No. 67. Judge Ford: Building Research Association of New Zealand. 23 p. ISSN:0113-3675.

47. Madrzykowski, D., \& Walton, W. D., (2004). Cook County Administration Building Fire, 69 Washington, Chicago, Illinois, October 17, 2003: Heat Release Rate Experiments \& FDS Simulation. NIST Special Publication SP-1021, Building and Fire Science Research Laboratory, NIST, Washington, US

48. Hamins A., Maranghides, A., McGrattan, B. K., Ohlemiller, J. T., \& Anleitner, R. L. (2005). Federal Building and Fire Safety Investigation of the WTC Disaster: Experiments and modelling of Multiple Workstations Burning in a Compartment (Draft). NIST NCSTAR I-SE (Draft), Special Publication, Building and Fire Research Laboratory, National Institute of Standards and Technology, Washington, U.S.A.

49. Bryant, R., Ohlemiller, T., Johnsson, E., Hamins, A., Grove, B., Guthrie, W. F., Maranghides, A., \& Mulholland, G. (2003). The NIST 3 Megawatt Quantitative Heat Release Rate Facility - Procedures and Guidance. NIST Special Report 1007, National Institute of Standards and Technology, Gaithersburg, MD.

50. Lai, C., Tsai, M., \& Lin, T., (2010), Experimental Investigations of Fire Spread for Movable to Fixed Fire Loads in Office Fires. Journal of Fire Sciences, Vol. 28(1), pp 539-559.

51. Bennetts, I. D., Moinuddin, K. A. M., Thomas, I. R., \& Oroe, D. J. (2008). Sprinklered Office Fire Tests, Fire and Material Journal, Vol. 32 (1), pp 159-198.

52. Walton G. N., \& Stuart, D. W. (2008). Contam 2.4 User Guide and Program. NISTIR 7251. National Institute of Standards and Technology, Gaithersburg, MD, USA 
53. McGrattan, K., Klein, B., Hostikka, K., \& Floyd, J. (2008). Fire Dynamics Simulator (Version 5) User's Guide. NIST Special Publication 1019-5.

54. Jones, W. W., Peacock, R. D., Forney, G. P., \& Reneke, P. A. (2005). CFASTConsolidated Model of Fire Growth and Smoke Transport (Version 6). Technical Reference Guide, NIST Special Publication 1026

55. Bounagui, A., Benichou, N., McCartney, C., and Kashef, A. (2003). Optimizing the Grid Size Used in CFD Simulations to Evaluate Fire Safety in Houses. Paper presented at the 3rd NRC Symposium on Computational Fluid Dynamics, High Performance Computing and Virtual Reality, Ottawa. National Research Council, Canada.

56. McGrattan, K. \& Forrey, G. (2005). Fire Dynamic Simulator (Version 4). User's Guide 2005. US Government Publishing Office. Washington DC USA 20402 202512-1800. NIST Special Publication

57. Ma, T. G., \& Quintiere, J. G. (2003). Numerical Simulation of Axi-Symetric Fire Plumes: Accuracy and Limitations. Fire Safety Journal, Vol 38, pp 467 - 492.

58. Baum, H. et al., (1997). Three Dimensional Simulation of Fire Dynamics. In: Proceedings of the 5th International IAFSS Symposium, Fire Safety Science, pp 511522.

59. Thomas P. H., (1986). Design Guide: Structure Fire Safety, CIB W14 workshop report. Fire Safety Journal, Vol. 10 (2), pp 77-137

60. SFPE (1995). The SFPE Handbook of Fire Protection Engineering. Society of Fire Protection Engineers, Second Edition. National Fire Protection Assn, Quincy MA

61. Joshi R. M. (1970). Encyclopaedia of Polymer Science and Technology, Vol. 13. Interscience, NY, USA

62. Ramachandran, G.,(1982). Properties of Extreme Order Statistics and Application in Fire Protection and Insurance Problems, Fire Safety Journal. Vol. 5(1): pp 59-76.

63. EasyFit (2011), Mathwave Technology, Distribution Fitting program. Retrieved: May 20, 2011. Website: http://www.mathwave.com 
64. Wikipedia Encyclopedia Online (2011). Kolmogorov-Smirnov test. Retrieved: May 28, 2011.

Website: http://en.wikipedia.org/wiki/Kolmogorov\%E2\%80\%93Smirnov test

65. Skelly, M. J., Roby, R. J. \& Beyler, L. (1991). An Experimental Investigation of Glass Breakage in Compartment fires. Journal of fire Protection Engineering, vol. 3 (1), pp 25 - 34.

66. Richardon J. K., \& Oleszkiewicz, I. (1987). Fire Tests on Window Assemblies Protected by Automatic Sprinklers. Fire technology, Vol. 23 (1), pp 115 - 132.

67. Shield T. J., Silcock, G. W. H., \& Flood, M. F. (2002). Performance of a Single Glazing Assembly Exposed to fire in the Centre of an Enclosure. Fire and Materials, vol. 26(1), pp 51 - 75.

68. Loss Prevention Council (1999). Fire Spread in Multi-Storey Buildings with Glazed Curtain Wall Facades (LPR 11: 1999). Loss Prevention Council, Borehamwood, England

69. McGrattan, K. B.; Hamins, A.; \& Stroup, D. W. (1998). Sprinkler, Smoke and Heat Vent, Draft Curtain Interaction: Large Scale Experiments and Model Development. International Fire Sprinkler-Smoke and Heat Vent-Draft Curtain Fire Test Project. NISTIR 6196-1, NIST, Gaithersburg, MD, USA

70. Crampton, G. P., Carpenter, D. W., McCartney, C., Leroux, P., \& Su, J. Z. (2002). Kamano Fire Studies - Part 2: Response of Residential Sprinkler System. Report: IRC-RR-109. National Research of Canada, Ottawa

71. NFPA 13 (2010). Installation of Sprinkler Systems. National Fire Protection Association, Quincy MA.

72. Thauvoye, C., Zhao, B., Klein, J., \& Fontana, M. (2009), Fire Load Survey and Statistical Analysis, Fire Safety Science, Vol. 9, pp 991-1002.

73. SFPE (2002). The SFPE Handbook of Fire Protection Engineering. Society of Fire Protection Engineers, 3rd Edition, Hazard Calculations, 3-107-3-108. National Fire Protection Assn, Quincy MA.

74. Krasny, J.F., Parker, W.J., \& Babrauskas, V. (2001). Fire Behavior of Upholstered Furniture. Noyes Publishers, NJ, USA 
75. Babrauskas, V. (2008). Heat Release Rates. In The SFPE Handbook of Fire Protection Engineering, 4th ed., p3-1-3-32, National Fire Protection Association, Quincy MA

76. Domalski, E. S., W.H. Evans, \& T.S. Jobe, J. (1978). Thermodynamic Data for Waste Incineration. NBSIR 78-1479. National Bureau of Standards, Washington, D.C.

77. Butcher, E. G., and Parnell, A. C., (1983). Design for Fire Safety, John Wiley and Sons

78. Babrauskas, V., \& Grayson, S. J. (1992). Heat Release in Fires. Elsevier Science, London, UK

79. Huggett, C. (1980). Estimation of Rate of Heat Release by Means of Oxygen Consumption Calorimetry. Fire and Materials, vol. 4(2), pp 61-65.

80. Armstrong, G. T., \& Domalski, E. S. (1974). Combustion Fundamentals for Waste Incineration. ASME, NY, pp 143-182.

81. Babrauskas, V. (1988). Fire Hazard Comparison of FR and NFR Products. NBS Special Publication 749, National Bureau of Standards, Washington, D.C.

82. Fire Code Reform Centre (1996). Flashover Fires An Experimental Program. FCRC Project 3, Technical Report FCRC-TR 96-07, FCRC, Canberra, Australia

83. Chamberlain, D.L. (1983). Heat Release Rates of Lumber and Wood Products. In Behavior of Polymeric Materials in Fires, Ed. E.L. Schaffer, ASTM STP 816, pp2141

84. Krasny, J.F., Parker, W.J., Babrauskas, V., (2001). 'Fire Behavior of Upholstered Furniture', Noyes Publ., NJ, pp208

85. Benisek, L., (1974). 'Improvement of the Natural Flame Retardants of Wool. Part I. Metal-Complex Applications', Journal of. Textile Institute, vol. 65, pp. 102-108

86. McGrattan, K., Klein, B., Hostikka, K., Floyd, J., Baum, H., Rehm, H., Mell, W., \& McDermott, R. (2008). Fire Dynamics Simulator Technical Reference Guide, Volume 1: Mathematical Model, NIST Special Publication 1018-5, pp.1-92

87. Mutala, A. (2008). Estimation of solid phase combustion parameters for fire simulation. Unpublished Master's Thesis, Helsinki University 
88. Drysdale, D. (1998). An Introduction to Fire Dynamics, 2nd Edition. John Wiley and Sons, Chichester, U.K.

89. McGrattan, Kevin B.; Baum, Howard R.; Rehm, \& Ronald G. (1998). Large Eddy Simulations of Smoke Movement. Fire Safety Journal, Vol 30, pp 161-178.

90. ASTM Standard E2067. (2008). Standard Practice for Full-Scale Oxygen Consumption Calorimetry Fire Tests. ASTM International, West Coshohocken, PA 


\section{Appendices}

\section{Appendix A: Review of Fire Load Survey Results in Residential Buildings}

\begin{tabular}{|c|c|c|c|c|}
\hline Author & Method used & $\begin{array}{c}\text { Building } \\
\text { occupancy type }\end{array}$ & $\begin{array}{l}\text { No of rooms } \\
\text { surveyedarea }\end{array}$ & Reported fire load values \\
\hline NBS (1942) & - & residential & & $\begin{array}{l}\text { 8.8psf } \\
\text { mean }\end{array} \quad\left({ }^{*} 860 \mathrm{MJ} / \mathrm{m}^{2}\right)-$ \\
\hline $\begin{array}{l}\text { Ingberg et al } \\
\text { (1957) }\end{array}$ & - & Residential & 113 rooms & $8.8 \mathrm{psf}\left({ }^{\left.* 859 \mathrm{MJ} / \mathrm{m}^{2}\right)}\right.$ \\
\hline $\begin{array}{l}\text { Kose et al (1965- } \\
1984)\end{array}$ & Questionnaire & residential & & $\begin{array}{l}34 \mathrm{~kg} / \mathrm{m}^{2}\left({ }^{*} 680 \mathrm{MJ} / \mathrm{m}^{2}\right)- \\
\text { mean } \\
11.7 \mathrm{~kg} / \mathrm{m}^{2}\left(* 234 \mathrm{MJ} / \mathrm{m}^{2}\right)- \\
\mathrm{SD}\end{array}$ \\
\hline Issen (1980) & Inventory & Residential & & $\begin{array}{l}12.2 \mathrm{psf} \\
\text { mean }\end{array}\left({ }^{*} 1192 \mathrm{MJ} / \mathrm{m}^{2}\right)-$ \\
\hline Bush et al (1991) & & residential & & $\begin{array}{l}134 \mathrm{~kg} / \mathrm{m}^{2} \quad\left(* 2680 \mathrm{MJ} / \mathrm{m}^{2}\right)- \\
\text { mean }\end{array}$ \\
\hline $\begin{array}{l}\text { Kumar and Rao } \\
\text { (1992) }\end{array}$ & Inventory & Residential & $\begin{array}{l}413 \text { Rooms } \\
4256.6 \mathrm{~m}^{2}\end{array}$ & $\begin{array}{l}487.0 \mathrm{MJ} / \mathrm{m}^{2}-\text { mean } \\
255.0 \mathrm{MJ} / \mathrm{m}^{2}-\text { S.D }\end{array}$ \\
\hline NRCC (2004) & Questionnaire & Residential & & $\begin{array}{l}600 \mathrm{MJ} / \mathrm{m}^{2}-\text { mean } \\
500 \mathrm{MJ} / \mathrm{m}^{2}\end{array}$ \\
\hline
\end{tabular}




\section{Appendix B: Review of Fire Load Survey Results in Other Occupancies}

\begin{tabular}{|c|c|c|c|c|}
\hline Author & Method used & $\begin{array}{c}\text { Building } \\
\text { occupancy type }\end{array}$ & $\begin{array}{l}\text { No of rooms } \\
\text { surveyed/area }\end{array}$ & Reported fire load values \\
\hline NBS (1942) & & warehouse & & $\begin{array}{l}70 \mathrm{psf} \\
\text { mean }\end{array} \quad\left({ }^{*} 6836 \mathrm{MJ} / \mathrm{m}^{2}\right)-$ \\
\hline \multirow[t]{4}{*}{$\begin{array}{l}\text { Ingberg et al } \\
\text { (1957) }\end{array}$} & - & school & & $15.0 \mathrm{psf}\left({ }^{*} 1465 \mathrm{MJ} / \mathrm{m}^{2}\right)$ \\
\hline & - & Hospital & 282 rooms & $10.0 \mathrm{psf}\left({ }^{*} 976 \mathrm{MJ} / \mathrm{m}^{2}\right)$ \\
\hline & - & Commercial & 18 floors & $20.0 \mathrm{psf}\left({ }^{*} 1953 \mathrm{MJ} / \mathrm{m}^{2}\right)$ \\
\hline & - & Warehouse & 35 floors & $50.0 \mathrm{psf}\left(* 4883 \mathrm{MJ} / \mathrm{m}^{2}\right)$ \\
\hline \multirow[t]{2}{*}{ Green (1977) } & Combination & Hospital Ward & & $\begin{array}{l}10.6 \mathrm{~kg} / \mathrm{m}^{2}\left(* 212 \mathrm{MJ} / \mathrm{m}^{2}\right)- \\
\text { mean } \\
2.1 \mathrm{~kg} / \mathrm{m}^{2}\left(* 42 \mathrm{MJ} / \mathrm{m}^{2}\right)-\mathrm{SD}\end{array}$ \\
\hline & & Hospital Storage & & $\begin{array}{l}162 \mathrm{~kg} / \mathrm{m}^{2}\left({ }^{*} 3240 \mathrm{MJ} / \mathrm{m}^{2}\right)- \\
\text { mean } \\
127 \mathrm{~kg} / \mathrm{m}^{2}\left({ }^{*} 2540 \mathrm{MJ} / \mathrm{m}^{2}\right)- \\
\mathrm{SD}\end{array}$ \\
\hline \multirow[t]{2}{*}{ Barnett (1984) } & Combination & Offices & & $22 \mathrm{~kg} / \mathrm{m}^{2}\left(* 440 \mathrm{MJ} / \mathrm{m}^{2}\right)$ \\
\hline & & Hospital ward & & $54 \mathrm{~kg} / \mathrm{m}^{2}\left(* 1080 \mathrm{MJ} / \mathrm{m}^{2}\right)$ \\
\hline \multirow[t]{2}{*}{ Yii (2000) } & Combination & motel & & $552 \mathrm{MJ} / \mathrm{m}^{2}$ - mean \\
\hline & & bedrooms & & $724 \mathrm{MJ} / \mathrm{m}^{2}$ - mean \\
\hline Zalok (2006) & Combination & Commercial & (168 shops) & $\begin{array}{l}750 \mathrm{MJ} / \mathrm{m}^{2}-\text { mean } \\
832 \mathrm{MJ} / \mathrm{m}^{2}-\mathrm{SD}\end{array}$ \\
\hline
\end{tabular}




\section{Appendix C: Calorific value of Wood/ Cellulosic Material}

\begin{tabular}{|c|c|c|}
\hline WOOD/CELLULOSICS & $\mathrm{MJ} / \mathbf{k g}$ & REF \\
\hline Beech & 18.7 & 77 \\
\hline Birch & 18.7 & 77 \\
\hline Celluloid & $17-20$ & 17 \\
\hline Cellulose & 15-18 & 17 \\
\hline Cellulose triacetate & 17.6 & 17,78 \\
\hline Corrugated Box & 16.0 & 60,81 \\
\hline Cotton & $15.6-20$ & 78 \\
\hline Douglas Fir & $16.4-19.6$ & $78,17,88$ \\
\hline Leaves, hardwood & 19.3 & 77,86 \\
\hline Lignite & 24.8 & 78 \\
\hline Maple & 17.8 & 78 \\
\hline Newsprint & 18.4 & 77 \\
\hline Paper (average) & 16.3 & 78 \\
\hline Paper, Cardboard & $13-21$ & 32 \\
\hline Particle Board (chipboard and hardboard) & $17-18$ & 17 \\
\hline Pine Wood & 19.1 & 17 \\
\hline Red Oak & $17.1-18.7$ & 85 \\
\hline Spruce & 20.4 & 77,86 \\
\hline Straw & $15-16$ & 77 \\
\hline White pine & 17.8 & 17 \\
\hline Wood & $17-20$ & 77 \\
\hline Wool & $20.5-26$ & $32,78,17$ \\
\hline
\end{tabular}




\section{Appendix D: Calorific Value of Different Products and Composites}

\begin{tabular}{lcc}
\hline \multicolumn{1}{c}{ PRODUCTS/COMPOSITES } & MJ/kg & REF \\
\hline 3 Seater Couch (41.8 kg) & 18.6 & 84 \\
\hline Chair T (NFR-PU Foam) & 27 & 83 \\
\hline Clothes & $17-21$ & 32,17 \\
\hline Candle & 46.2 & 80 \\
\hline Kitchen Refuse & 8 to 21 & 17 \\
\hline Leather & $18.6-20$ & 32 \\
\hline Linoleum & $19-21$ & 17 \\
\hline Cloth soaked with IPA & 30.4 & 80 \\
\hline Rubber tire & $31-33$ & 17 \\
\hline Silk & $17-21$ & 17 \\
\hline Single Chair (21.4kg) & 21.4 & 84 \\
\hline TV Cabinet G (FR-HIPS) & 20 & 83 \\
\hline TV Cabinet H (NFR-HIPS) & 23 & 83 \\
\hline Wardrobes & $14.2-18.8$ & 77 \\
\hline
\end{tabular}




\section{Appendix E Calorific Values of Different Plastics}

\begin{tabular}{|c|c|c|c|}
\hline PLASTIC & $\mathrm{MJ} / \mathrm{kg}$ & TYPICAL PRODUCTS (36) & REF \\
\hline $\begin{array}{c}\text { Acrylonitrile- } \\
\text { Butadiene-Styrene } \\
\text { (ABS) }\end{array}$ & $34-40$ & $\begin{array}{l}\text { Appliances, business machines, } \\
\text { containers and lids, fishing tackle } \\
\text { boxes, luggage, pipe, power tool } \\
\text { housing, sanitary ware, shoes, } \\
\text { telephones, toys, }\end{array}$ & 17 \\
\hline Acrilan Fiber & 31.8 & & 88,86 \\
\hline Acrylic & $25.9,27-29$ & $\begin{array}{l}\text { Carpet fibres, glazing, lighting panels, } \\
\text { sanitary ware, wall panels, }\end{array}$ & 79,17 \\
\hline Epoxy & $28.8,33-34$ & & 17,86 \\
\hline Isobutene & 20.1 & & 60,81 \\
\hline Melamine resin & $16-19$ & & 17 \\
\hline Nylon & $23.2-33.1$ & $\begin{array}{l}\text { Carpet fibres, clothing, upholstery, wire } \\
\text { insulation }\end{array}$ & $\begin{array}{l}79,81 \\
88,86\end{array}$ \\
\hline Polycarbonate & $28-30$ & $\begin{array}{l}\text { Glazing, lighting panels, milk bottles, } \\
\text { power tool housing, }\end{array}$ & 81,17 \\
\hline Polyethylene (PE) & $43.3-51.1$ & $\begin{array}{l}\text { Containers and lids, conduit, grocery } \\
\text { bags, house wares, milk bottles, pails, } \\
\text { pipe, toys, trash bags, tumblers, } \\
\text { wastebaskets, wire insulation }\end{array}$ & $\begin{array}{l}79,78 \\
-17 \\
85,86\end{array}$ \\
\hline $\begin{array}{c}\text { Polyethylene } \\
\text { terephthalate (PET) }\end{array}$ & 22.0 & & $\begin{array}{c}81,60, \\
86\end{array}$ \\
\hline Phenolformaldehyde & $27-30$ & & 17 \\
\hline $\begin{array}{c}\text { Pure Hydrocarbon } \\
\text { Plastics (PE, PP, PS) }\end{array}$ & 40 & & 85 \\
\hline Plastic (average) & 22.1 & & 32 \\
\hline $\begin{array}{l}\text { Polymethylmethacrylate } \\
\text { (PMMA) }\end{array}$ & 25.0 & & $\begin{array}{c}60,81, \\
86\end{array}$ \\
\hline Polyacrylonitrile & 30.8 & & $\begin{array}{c}60,81, \\
86\end{array}$ \\
\hline Polybutadiene & 42.8 & & $\begin{array}{c}60,81, \\
86\end{array}$ \\
\hline Polyester & $23.2-32.5$ & $\begin{array}{l}\text { Clothing, power tool housing, soft drink } \\
\text { bottles, }\end{array}$ & $\begin{array}{l}79,17 \\
88,86\end{array}$ \\
\hline Polyisobutylene & 43.7 & Pipes & $\begin{array}{c}81,60, \\
86\end{array}$ \\
\hline Polyisocyanurate foam & $22-26$ & & 17 \\
\hline Polyoxymethylene & 15.4 & & $\begin{array}{c}81,60, \\
86\end{array}$ \\
\hline Polypropylene & $42-51.1$ & $\begin{array}{l}\text { carpet fibres, containers and lids, } \\
\text { conduit, house wares, luggage, pails, } \\
\text { upholstery }\end{array}$ & $\begin{array}{l}79,81 \\
17,86\end{array}$ \\
\hline
\end{tabular}




\section{Calorific Values of Different Plastics continued}

\begin{tabular}{|c|c|c|c|}
\hline PLASTIC & $\mathrm{MJ} / \mathrm{kg}$ & TYPICAL PRODUCTS & REF \\
\hline Polystyrene & $39.2-44.1$ & $\begin{array}{l}\text { Appliances, ceiling tile, containers and } \\
\text { lids, lighting panels, house wares, }\end{array}$ & $\begin{array}{c}79,17 \\
86\end{array}$ \\
\hline Polyurethane & $22-37.2$ & & 79,17 \\
\hline Polyurethane foam & $23-28$ & Shoes, seat cushions & 17 \\
\hline Polyvinylidene chloride & 9.0 & & 81,60 \\
\hline Polyvinylidene fluoride & 13.3 & & 81,60 \\
\hline $\begin{array}{l}\text { Polytetrafluoroethylene } \\
\text { (PTFE) }\end{array}$ & $5-6.2$ & Non stick coating & 17,86 \\
\hline $\begin{array}{l}\text { Polyvinylchloride } \\
\text { (PVC) }\end{array}$ & $16.4-22.1$ & $\begin{array}{l}\text { Clothing, containers and lids, conduit, } \\
\text { floor tile, garden hose, gutters, house } \\
\text { siding, house wares, lighting panels, } \\
\text { phonograph records, pipe, sanitary } \\
\text { ware, shoes, shower curtain, toys, } \\
\text { upholstery, wall covering, wastebaskets, } \\
\text { weather stripping, windows, wire } \\
\text { insulation } \\
\end{array}$ & $\begin{array}{c}79,81 \\
17,88, \\
86\end{array}$ \\
\hline $\mathrm{PVC}$ w/ 25\%Cl & 31.6 & & 86 \\
\hline $\mathrm{PVC}$ w/ 36\% Cl & 26.3 & & 86 \\
\hline $\mathrm{PVC}$ w/ $48 \% \mathrm{Cl}$ & 20.6 & & 86 \\
\hline Polychloroprene & 25.3 & & $\overline{86}$ \\
\hline Rayon & $16.3-17$ & & 44,43 \\
\hline Rubber & 39.5 & & 32 \\
\hline Rubber foam & $34-40$ & & 17 \\
\hline Rubber isoprene & $44-45$ & & 17 \\
\hline Tedlar (PVF) & 13.3 & & 86 \\
\hline Teflon (PFA) & 5 & & 86 \\
\hline Ureaformaldehyde & $14-15$ & & 17 \\
\hline $\begin{array}{l}\text { Ureaformaldehyde } \\
\text { foam }\end{array}$ & 12 to 15 & & 17 \\
\hline
\end{tabular}




\section{Appendix F: Fire Load Survey Forms}


Fire Load Survey Forms (Inventory \& Weighing Method)

Building Name

..Building Age:

Address: Survey Date:

No of Floors: Surveyor:

1.1 Occupancy type

Closed: ........... Cubicle:

Storage Area

\subsection{Office Dimension}

\begin{tabular}{|l|l|l|l|}
\hline Shape & \multicolumn{2}{|l|}{ Dimension } & Total Area \\
\hline \multirow{5}{*}{} & L1: & W1: & \\
\cline { 2 - 3 } & L2: & W2: \\
\cline { 2 - 3 } & L3: & W3: & \\
\cline { 2 - 3 } & L4: & W4: & \\
\hline
\end{tabular}

\subsection{Opening Dimension}

\begin{tabular}{|l|l|l|l|l|}
\hline window & Width & Height & Sill Height & Area \\
\hline W1 & & & & \\
\hline W2 & & & & \\
\hline W3 & & & & \\
\hline
\end{tabular}

\begin{tabular}{|l|l|l|l|}
\hline Door & Width & Height & Area \\
\hline D1 & & & \\
\hline D2 & & & \\
\hline D3 & & & \\
\hline
\end{tabular}

\subsection{Fixed Fire Load}

\begin{tabular}{|l|l|l|l|l|l|l|l|}
\hline item & Quantity & Length & Width & Thickness & Material & Mass & comment \\
\hline Walls & & & & & & & \\
\hline Ceiling & & & & & & & \\
\hline Floors & & & & & & & \\
\hline Doors & & & & & & & \\
\hline Door (frames) & & & & & & & \\
\hline Windows & & & & & & & \\
\hline Window(frames) & & & & & & & \\
\hline $\begin{array}{l}\text { Book } \\
\text { Shelves }\end{array}$ & & & & & & & \\
\hline cabinet & & & & & & & \\
\hline Others & & & & & & & \\
\hline
\end{tabular}


1.5 Movable Fire Load

\begin{tabular}{|c|c|c|c|c|c|c|c|}
\hline Item & Quantity & Length & Width & Thickness & Material & Mass & comment \\
\hline & & & & & & & \\
\hline & & & & & & & \\
\hline & & & & & & & \\
\hline & & & & & & & \\
\hline & & & & & & & \\
\hline & & & & & & & \\
\hline & & & & & & & \\
\hline & & & & & & & \\
\hline & & & & & & & \\
\hline & & & & & & & \\
\hline
\end{tabular}

\subsection{Other items}

\begin{tabular}{|l|l|l|l|l|l|l|}
\hline Item & Yes/No & Qty & Type & material & Mass & Comments \\
\hline $\begin{array}{l}\text { Computer } \\
\text { (Display \& } \\
\text { CPU) }\end{array}$ & & & & & & \\
\hline Printer & & & & & & \\
\hline Refrigerators & & & & & & \\
\hline Coffee Makers & & & & & & \\
\hline & & & & & & \\
\hline
\end{tabular}


Fire Load Survey (Questionnaire Method)

\section{How to complete the Questionnaire}

The questionnaire is divided into six sections. Please read carefully and follow each step as required. If you need further assistance in filling the Questionnaire, you can contact James on jeduful@connect.carleton.ca (Phone: (613)252-6781)

\section{Section 1}

Provide the basic information that pertain to your office

\section{Section 2}

Select the type of your office

\section{Section 3}

Provide a schematic sketch of the shape of the office. Give the dimensions of your office space. (Can be estimated)

\section{Section 4}

Part A: Fill this part only if you have a window in your office. If applicable fill in the window dimensions (Can be estimated)

Parts B: Fill in the number of doors to your office. If it is a standard door size (3' $\mathrm{X} 6^{6}-8^{\prime}$ '), simply indicate in the space provided without written the estimated dimensions.

\section{$\underline{\text { Section } 5}$}

Indicate the floor, wall, and ceiling finish (e.g. floor - wood, woollen carpet, linoleum, Wall Gypsum plaster, wood paneling, plastics etc; Ceiling - wood, gypsum plaster, plastic) 


\section{Section 6}

Part A: from the furniture catalogue attached, indicate the type and number of item unit in your office. If similar but different, indicate and write comment on how it varies.

Part B: From the furniture catalogue attached, indicate the type of desk in your office. Write comments where applicable. If it is made up of a material that does not burn (noncombustible) indicate in your comment.

Part C: Follow the same procedure as above. Indicate a percentage of fill for combustible items (e.g. papers, books, plastic etc.) stored in shelve, from ' $100 \%$ representing shelve filled to capacity with no loose gaps' to ' $0 \%$ representing an empty shelve'.

Part D: Follow the same procedure as indicated in Part $\mathrm{C}$ above

Part E: Indicate in the options and spaces provided all other combustibles that have not been covered above. Example include, paper bins, stacks of papers and files that are not stored on shelves or cabinets, combustible television stands and etc. 
Fire Load Survey (Questionnaire Method)

Section 1

Building Name (XXX) Survey Date:

Office Number

Section 2

Occupancy type: Enclosed:

Section 3

Cubicle:

\section{Office Dimension (Can be estimated)}

In the spaces provided below provide a schematic sketch of the office outline (shape) and give estimated dimensions of the space or the floor area.

\begin{tabular}{|l|l|l|l|}
\hline Shape & \multicolumn{2}{|c|}{ Dimension } & \multirow{2}{*}{ Comment } \\
\hline \multirow{4}{*}{} & Length & & \\
\cline { 2 - 3 } & Width & & \\
\cline { 2 - 3 } & Height & & \\
\hline
\end{tabular}

\section{Section 4}

Opening Dimension (Can be estimated)

A. Number of windows.................(0 means No windows)

\begin{tabular}{|c|c|c|c|}
\hline window & Width & Height & Comments \\
\hline W1 & & & \\
\hline W2 & & & \\
\hline
\end{tabular}

B. Number of Doors.

Standard door.

.Material.

\begin{tabular}{|c|c|c|c|}
\hline Door & Width & Height & Comments \\
\hline D1 & & & \\
\hline D2 & & & \\
\hline
\end{tabular}

\section{Section 5}

\section{Fixed Fire Load}

Floor Finish................................ (e.g. - woollen carpet, wood, linoleum, plastic)

Wall Finish.........................................(e.g. - gypsum plaster, wood, plastic)

Ceiling Finish...................................(e.g. - gypsum plaster, wood, plastic)

Comments (Additional description) 


\section{Section 6}

\section{Movable Fire Load}

A. Seats

In the spaces below select which seats falls within your category (Refer to attached Furniture Catalogue)

A. Main Chair Number of Chair Comment

B. Visitors Chair

Number of Chair

Comments

C. Sofa Number of Sofa. Comments.

\section{B. Desks}

Select and indicate below from the attached catalogue the desk type in the office

Catalogue Desk No. Material

(e.g. wood, plastic etc)

Contents of drawers: Materials... (e.g. paper, folders, books etc) Percentage of fill. (e.g. 100\%-completely full, $0 \%$-empty)

Comment

C. Book Shelve

Select and indicate below from the attached catalogue the book shelve type in the office Catalogue Book Shelve No Material. (e.g. wood, plastic) Content of Shelve: Materials (items)

\section{File Cabinets}

Select and indicate below from the attached catalogue the File cabinet type in the office (Select only if combustible, if not fill in details for content only

Catalogue Book Shelve No Material (e.g. wood, plastic)

Contents of Cabinets: Materials (e.g. paper, folders, books etc)

Percentage of fill. (e.g. 100\%-completely full, $0 \%$-empty)

Comment

E. Other Items

\begin{tabular}{|l|l|l|l|l|l|}
\hline Item & Yes/No & Qty & Type & material & Comments \\
\hline $\begin{array}{l}\text { Computer } \\
\text { (Display \& } \\
\text { CPU) }\end{array}$ & & & & & \\
\hline Printer & & & & & \\
\hline Refrigerators & & & & & \\
\hline Coffee Makers & & & & & \\
\hline & & & & & \\
\hline & & & & & \\
\hline & & & & & \\
\hline & & & & & \\
\hline & & & & & \\
\hline
\end{tabular}




\section{Appendix G: Sample FDS Input File (Single Enclosed Office)}

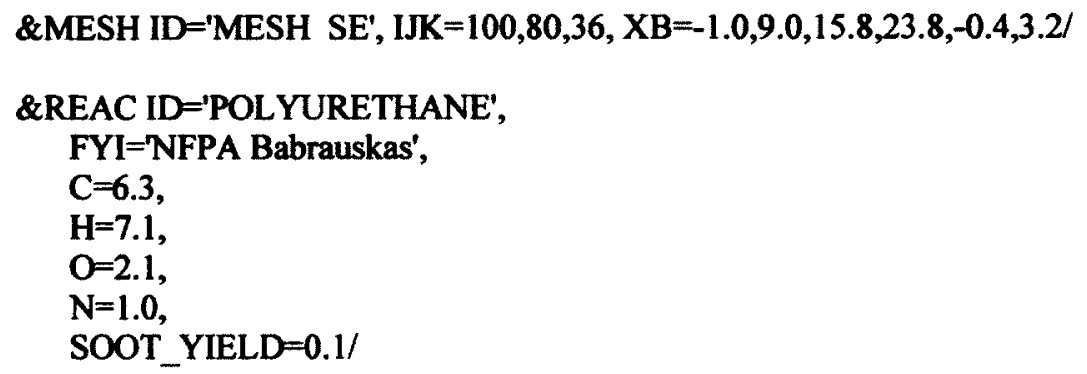

\&PROP ID='Default', QUANTITY='LINK TEMPERATURE', ACTIVATION_TEMPERATURE=250.0/ \&DEVC ID='TC @ 1.9 inside room', QUANTITY=THERMOCOUPLE', XYZ=3.8,19.0,1.9/ \&DEVC ID='TC @ 0.9 inside room', QUANTITY='THERMOCOUPLE', XYZ=3.8,19.0,0.9/ \&DEVC ID='TC @ 2.4 inside room', QUANTITY='THERMOCOUPLE', XYZ=3.8, 19.0,2.4/ \&DEVC ID='TC @ 2.55 inside room02', QUANTITY='THERMOCOUPLE', XYZ=3.8,19.0,2.55/ \&DEVC ID=TC @ 1.9 adjacent room', QUANTITY='THERMOCOUPLE', XYZ=3.8,21.7,1.9/ \&DEVC ID='TC @ 0.4 inside room', QUANTITY='THERMOCOUPLE', XYZ=3.8,19.0,0.4/ \&DEVC ID='TC @ 0.4 adjacent room', QUANTITY='THERMOCOUPLE', XYZ=3.8,21.7,0.4/ \&DEVC ID='TC @ 0.9 adjacent room', QUANTITY='THERMOCOUPLE', XYZ=3.8,21.7,0.9/ \&DEVC ID='TC @ 2.55 adjacent room', QUANTITY='THERMOCOUPLE', XYZ=3.8,21.7,2.55/ \&DEVC ID='TC @ 1.4 adjacent room', QUANTITY='THERMOCOUPLE', XYZ=3.8,21.7,1.4/ \&DEVC ID='HD 1', PROP_ID='Default', XYZ=0.2,20.2,1.6/

\&DEVC ID=TC @ 1.4 inside room', QUANTITY='THERMOCOUPLE', XYZ=3.8,19.0,1.4/ \&DEVC ID='TC @ 2.4 adjacent room', QUANTITY='THERMOCOUPLE', XYZ=3.8,21.7,2.4/

\&MATL ID='GYPSUM', FYI=NBSIR 88-3752 - ATF NIST Multi-Floor Validation', SPECIFIC_HEAT $=1.09$, CONDUCTIVITY $=0.17$, DENSITY $=930.0 /$

\&MATL ID='MARINITE 2', FYI='BNZ Materials Marinite I - NIST NRC Validation', SPECIFIC_HEAT_RAMP='MARINITE 2_SPECIFIC_HEAT_RAMP', CONDUCTIVITY_RAMP='MARINITE 2_CONDUCTIVITY_RAMP', DENSITY $=737.0$, EMISSIVITY $=0.8$ /

\&RAMP ID='MARINITE 2 CONDUCTIVITY_RAMP', $T=24.0, \mathrm{~F}=0.13$ / \&RAMP ID='MARINITE 2_CONDUCTIVITY_RAMP', $\mathrm{T}=149.0, \mathrm{~F}=0.12 /$ \&RAMP ID $=$ 'MARINITE 2_CONDUCTIVITY_RAMP', $\mathrm{T}=538.0, \mathrm{~F}=0.12 /$ \&RAMP ID='MARINITE 2_SPECIFIC_HEAT_RAMP', T=93.0, F=1.17/ \&RAMP ID $=$ 'MARINITE 2_SPECIFIC_HEAT_RAMP', $\mathrm{T}=205.0, \mathrm{~F}=1.26 /$ \&RAMP ID='MARINITE 2_SPECIFIC_HEAT_RAMP', T=316.0, $\mathrm{F}=1.34 /$ \&RAMP ID='MARINITE 2_SPECIFIC_HEAT_RAMP', T=425.0, $\mathrm{F}=1.42 /$ \&MATL ID $=$ 'Cellulosic 1', SPECIFIC HEAT RAMP='Cellulosic 1_SPECIFIC_HEAT_RAMP', CONDUCTIVITY_RAMP='Cellulosic 1_CONDUCTIVITY_RAMP', DENSITY $=450.0$, HEAT_OF_COMBUSTION $=2.0 \mathrm{E} 4 /$

\&RAMP ID $=$ 'Cellulosic 1 CONDUCTIVITY RAMP', $\mathrm{T}=20.0, \mathrm{~F}=0.13$ /

\&RAMP ID $=$ 'Cellulosic 1_CONDUCTIVITY_RAMP', $T=900.0, \mathrm{~F}=0.16 /$

\&RAMP ID $=$ 'Cellulosic 1_SPECIFIC_HEAT_RAMP', $\mathrm{T}=20.0, \mathrm{~F}=1.2 /$

\&RAMP ID $=$ 'Cellulosic 1_SPECIFIC_HEAT_RAMP', $T=900.0, \mathrm{~F}=1.6$

\&MATL ID $=$ 'Carpet - Thermoplastic', 


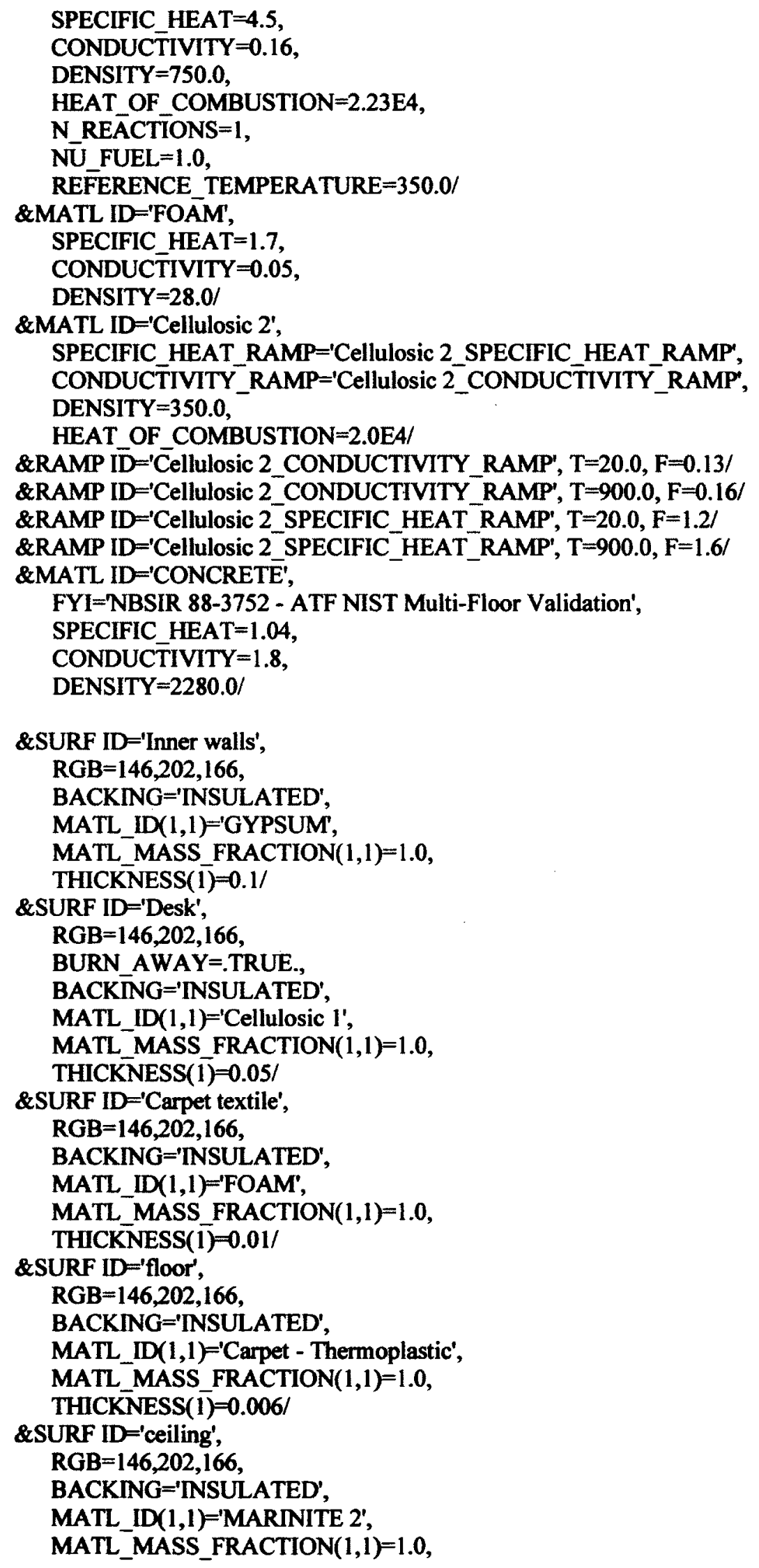


THICKNESS $(1)=0.1 /$

\&SURF ID $=$ 'Books n Cardboard',

$R G B=146,202,166$,

BURN_AWAY=.TRUE.,

BACKINNG='INSULATED',

MATL_ID $(1,1)=$ 'Cellulosic 2',

MATL_MASS_FRACTION $(1,1)=1.0$,

THICKNESS $(\overline{1})=0.02 /$

\&SURF ID $=$ 'Cubicle walls',

$\mathrm{RGB}=146,202,166$,

BURN AWAY $=$.TRUE.,

BACKĪNG $=$ 'INSULATED',

MATL_ID(1,1) $=$ 'FOAM FDS',

MATL_MASS_FRACTION $(1,1)=1.0$,

THICKNESS $(\bar{l})=0.05$ /

\&SURF ID $=$ 'concrete',

$R G B=146,202,166$,

BACKING $=$ 'INSULATED',

MATL_ID $(1,1)={ }^{\prime}$ CONCRETE',

MATL_MASS_FRACTION $(1,1)=1.0$,

THICKNESS $(\bar{l})=0.21$

\&SURF ID='burner 2',

COLOR='GRAY 80',

HRRPUA $=25.0$,

RAMP_Q='burner 2_RAMP_Q'

\&RAMP ID $=$ 'burner 2_RAMP_ $\overline{\mathrm{Q}}$ ', $\mathrm{T}=0.0, \mathrm{~F}=0.0$ /

\&RAMP ID='burner 2_RAMP_Q', $T=50.0, \mathrm{~F}=1.0$ /

\&RAMP ID ='burner 2_RAMP_Q', T $=100.0, \mathrm{~F}=1.0 /$

\&RAMP ID='burner 2_RAMP_Q', T $=150.0, F=2.0$ /

\&RAMP ID $=$ 'burner 2_RAMP_Q', $T=200.0, F=4.0 /$

\&RAMP ID='burner 2_RAMP_Q', $\mathrm{T}=250.0, \mathrm{~F}=5.0$ /

\&RAMP ID='burner 2_RAMP_Q', T=300.0, $\mathrm{F}=7.0 /$

\&RAMP ID='burner 2_RAMP_Q', $T=350.0, F=15.0 /$

\&RAMP ID='burner 2_RAMP_Q', $T=400.0, F=33.5 /$

\&RAMP ID='burner 2 RAMP $Q$ ', $T=450.0, F=33.5 /$

\&RAMP ID='burner 2_RAMP_Q', $T=500.0, F=33.5 /$

\&RAMP ID='burner 2_RAMP_Q', T=550.0, $F=33.5 /$

\&RAMP ID='burner 2_RAMP_Q', T=600.0, $F=33.5 /$

\&RAMP ID='burner 2_RAMP_Q', $T=650.0, F=30.0 /$

\&RAMP ID='burner 2_RAMP_Q', T=700.0, $\mathrm{F}=18.0$ /

\&RAMP ID='burner 2_RAMP_Q', $T=750.0, F=11.0 /$

\&RAMP ID='burner 2_RAMP_Q', T=800.0, $\mathrm{F}=\mathbf{9 . 0}$ /

\&RAMP ID='burner 2_RAMP_Q', T=850.0, $\mathrm{F}=9.0$ /

\&RAMP ID='burner 2_RAMP_Q', T=900.0, $F=9.0 /$

\&RAMP ID='burner 2_RAMP_Q', T=950.0, $F=9.0 /$

\&RAMP ID='burner 2_RAMP_Q', $T=1000.0, F=8.0 /$

\&RAMP ID='burner 2 RAMPQ $Q$ ', $T=1050.0, F=8.0 /$

\&RAMP ID='burner 2_RAMP_Q', $T=1100.0, F=7.0 /$

\&RAMP ID='burner 2_RAMP_Q', T=1150.0, $F=7.0 /$

\&RAMP ID='burner 2_RAMP_Q', $T=1200.0, F=6.0 /$

\&RAMP ID='burner 2_RAMP_Q', $T=1250.0, F=5.0 /$

\&RAMP ID='burner 2 RAMPQ', T=1300.0, $F=4.0 /$

\&RAMP ID='burner 2 RAMP $Q$ ', $T=1350.0, F=4.0 /$

\&RAMP ID='burner 2_RAMP_Q', $T=1400.0, F=4.0 /$

\&RAMP ID='burner 2_RAMP_Q', $T=1450.0, F=4.0 /$

\&RAMP ID='burner 2_RAMP_Q', $\mathrm{T}=1500.0, \mathrm{~F}=3.0 /$ 


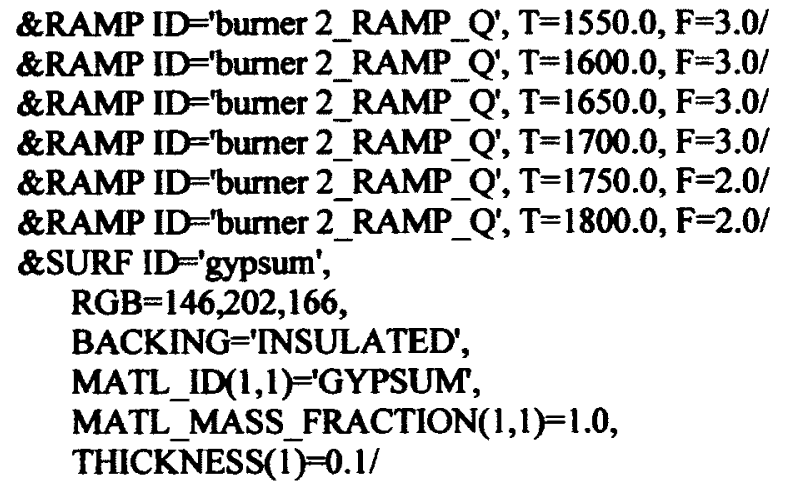

\&OBST XB $=0.2,4.2,22.018,22.118,0.0,3.4, \mathrm{RGB}=166,145,83, \mathrm{SURF}$ ID='Inner walls'/ AcDbLine \&OBST XB=0.2,4.2, 18.5, 18.6,0.0,3.4, RGB=166,145,83, SURF_ID='Inner walls'/ AcDbLine \&OBST XB=-5.55112E-17,4.3,17.0,23.0,2.6,2.605, COLOR='TNVISIBLE', SURF_ID='ceiling'/ ceiling \&OBST XB=0.0,0.2, 17.4,22.6,0.0,3.4, COLOR='GRAY 60', SURF_ID='gypsum'/ AcDbLine \&OBST XB=-1.38778E-16,4.3,17.0,23.0,0.0,0.006, COLOR='GRAY 80', PERMIT_HOLE=.FALSE., SURF ID='floor'/ Obstruction \&OBST XB=-5.55112E-17,4.3,17.0,23.0,-0.4,-0.2, SURF_ID='concrete'/ Obstruction[1] \&OBST XB=4.2,4.3,17.0,23.0,0.0,3.4, RGB=166,145,83, SURF_ID='Inner walls'/AcDbLine \&OBST XB=-5.55112E-17,4.3,17.0,23.0,-0.2,8.65974E-15, SURF ID='concrete'/Obstruction \&OBST XB=-5.55112E-17,4.3,17.0,23.0,2.8,3.0, COLOR='INVISIBBLE', SURF_ID='concrete'/ ceiling[1] \&OBST XB=1.4,1.5,19.1,19.1,0.2,0.4, RGB=255,191,0, SURF_ID='Books n Cardboard'/ AcDbFace

\&HOLE $X B=-0.147188,0.233368,20.0,20.8,0.0,2.6 /$ window[1][1][2]

\&VENT SURF_ID='OPEN', $X B=-0.9,8.9,15.8,15.8,-0.4,3.2 / V e n t[1]$

\&VENT SURF_ID $=$ 'burner 2 ', XB $=0.6,2.6,19.8,21.8,0.001,0.001 /$ burner vent

\&VENT SURF ID='OPEN', XB=9.0,9.0,15.9,23.7,0.0,3.2/ window[1][1][1][1][1]

\&VENT SURF_ID ='OPEN', $X B=-1.0,-1.0,15.9,23.7,-0.4,3.2 /$ window[1][1][1][1]

\&VENT SURF_ID='OPEN', XB=-0.9,8.9,23.8,23.8,-0.4,3.2/ Vent

\&BNDF QUANTITY='GAS TEMPERATURE'/

$\&$ SLCF QUANTITY='TEMPERATURE', PBY $=15.4 /$ 


\section{Appendix H: Tenability Criteria for FED}

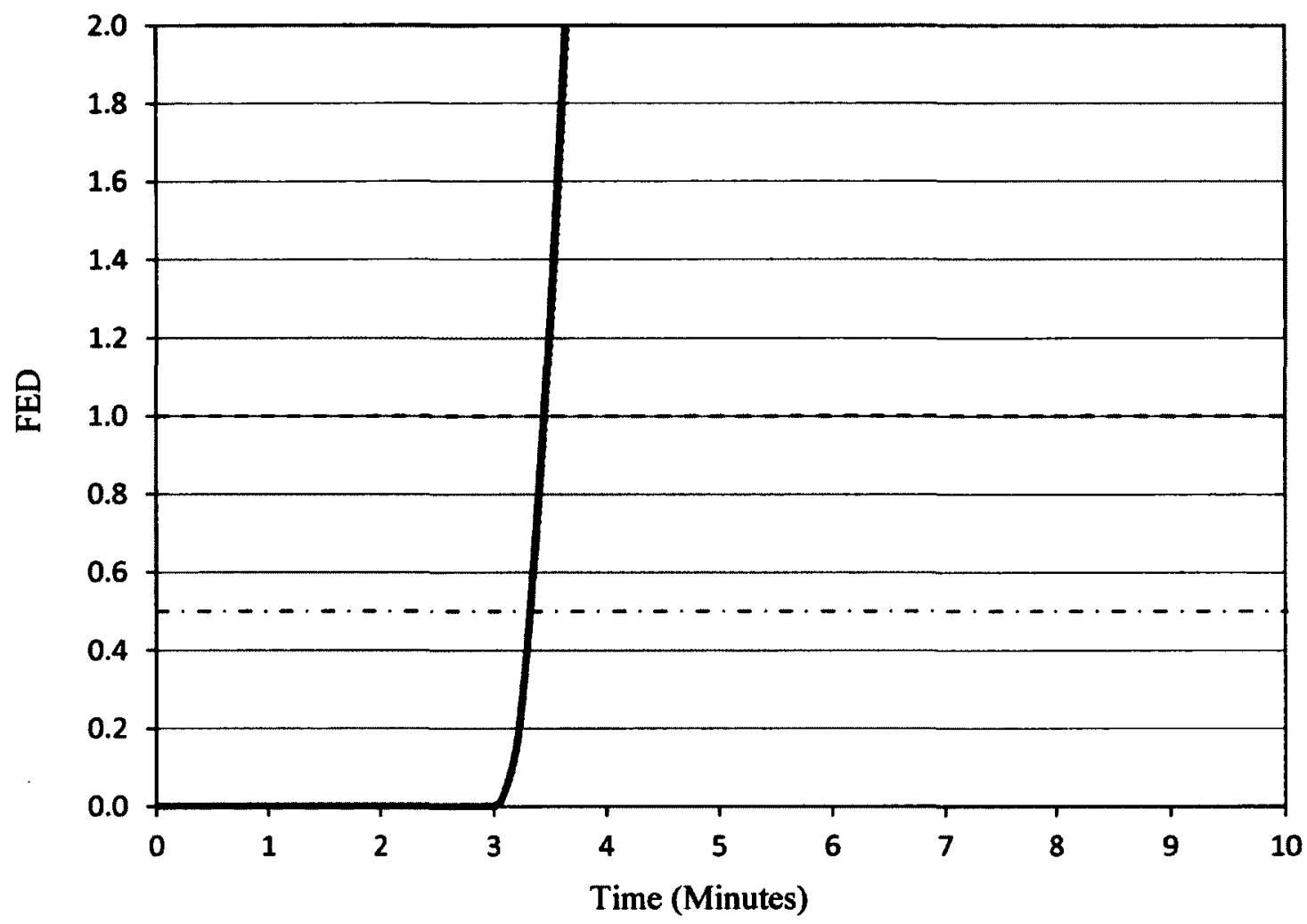

$\begin{array}{ll}-0.9 \mathrm{~m} & \cdots \cdots \cdot 1.5 \mathrm{~m} \\ \ldots-\cdot \text { Tenability (Suceptible Population) } & -\cdots \cdot \text { Tenability (Healthy Adult) }\end{array}$ 